
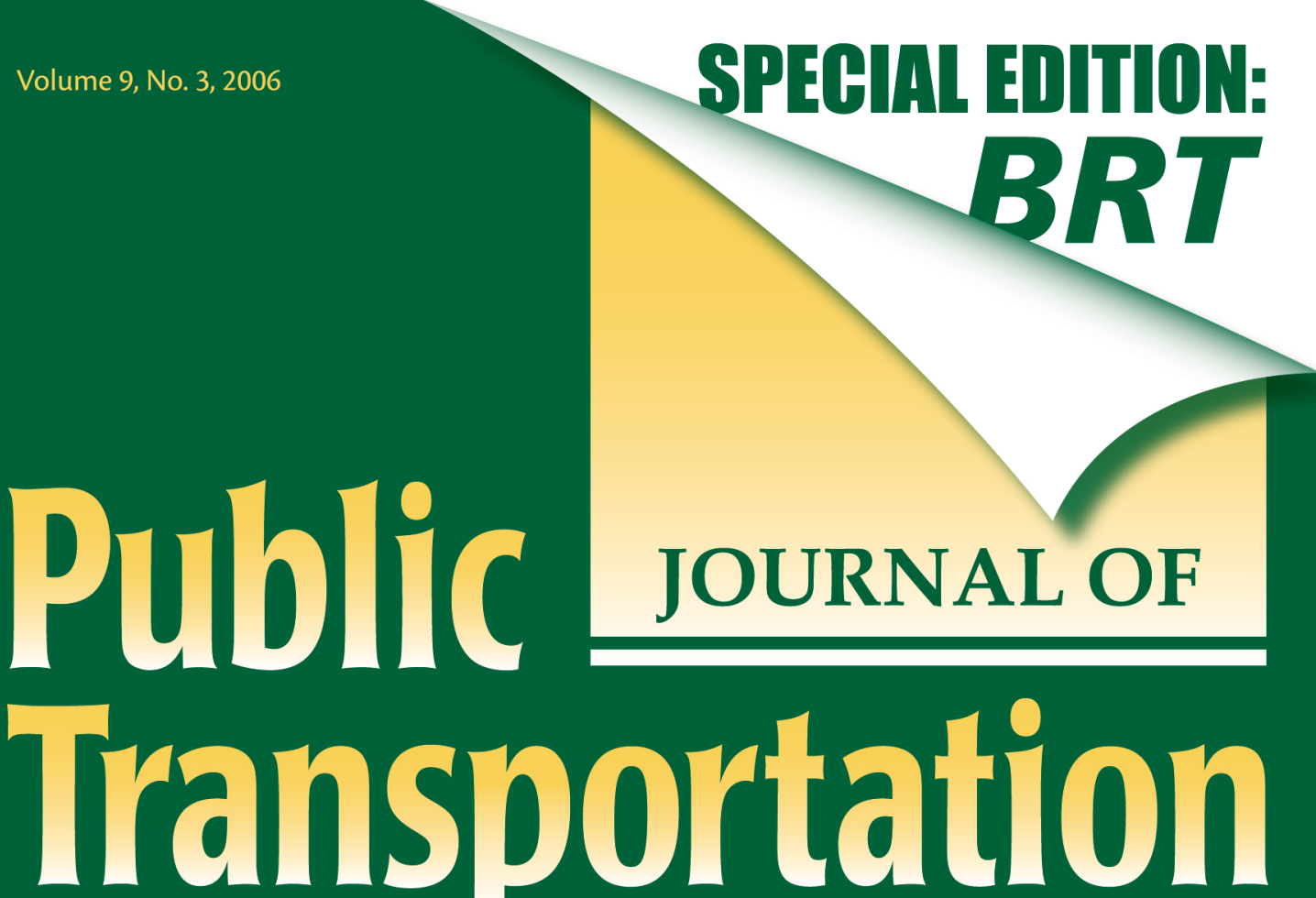

Bus Rapid Transit in Australasia: Performance, Lessons Learned and Futures—G. Currie

Bus Rapid Transit Plans in New York's Capital District-S. Falbel, H. Levinson, K. Younger, S. Misiewicz

Analyzing the Impacts of Vehicle Assist and Automation Systems on BRT-M. Hardy, S. Proper

The Issues and Realities of BRT Planning Initiatives in Developing Asian Cities-M. Hossain

Issues and Technologies in Level Boarding Strategies for BRT-D. Kantor, G. Moscoe, C. Henke

An Evaluation of Comprehensive Transit Improvements-TriMet's Streamline Program -P. Koonce, P. Ryus, D. Zagel, Y. Park, J. Parks

- Simulation of Transit Signal Priority Using the NTCIP Architecture-H. Liu, A. Skabardonis, M. Li

I Impact of Bus Priority Attributes on Catchment Area Residents in Dublin, Ireland -S. McDonnell, S. Ferreira, F. Convery

An Update on Curb Guided Bus Technology and Deployment Trends - D. Phillips

Microscopic Simulation Approach to Capacity Analysis of Bus Rapid Transit Corridors -A. J. Siddique, A. M. Khan

Ex-Ante Evaluation of Exclusive Bus Lanes Implementation-D. Tsamboulas

The Potential for Bus Rapid Transit to Reduce Transportation-Related $\mathrm{CO}_{2}$ Emissions -W. Vincent, L. Jerram

Calibration of Vissim for Bus Rapid Transit Systems in Beijing Using GPS Data

- L. Yu, L. Yu, X. Chen, T. Wan, J. Guo 


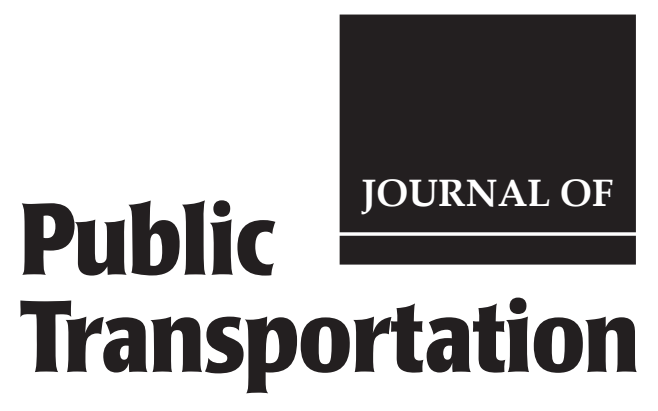

Volume 9, No. 3, 2006

ISSN 1077-291X

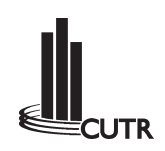

The Journal of Public Transportation is published quarterly by

National Center for Transit Research

Center for Urban Transportation Research

University of South Florida • College of Engineering

4202 East Fowler Avenue, CUT100

Tampa, Florida 33620-5375

Phone: $813 \cdot 974 \cdot 3120$

Fax: $813 \cdot 974 \cdot 5168$

Email: jpt@cutr.usf.edu

Website: www.nctr.usf.edu/journal.htm

(c) 2006 Center for Urban Transportation Research 
CONTENTS

Bus Rapid Transit in Australasia: Performance, Lessons Learned and Futures Professor Graham Currie

Bus Rapid Transit Plans in New York's Capital District

Stephen Falbel, Herbert Levinson, Kristina Younger, Sandy Misiewicz

Analyzing the Impacts of Vehicle Assist and Automation Systems on BRT

Matthew Hardy, Susannah Proper

The Issues and Realities of BRT Planning Initiatives in Developing Asian Cities Moazzem Hossain

Issues and Technologies in Level Boarding Strategies for BRT

David Kantor, Gregg Moscoe, Cliff Henke.

An Evaluation of Comprehensive Transit Improvements-

TriMet's Streamline Program

Peter Koonce, Paul Ryus, David Zagel, Young Park, Jamie Parks.

Simulation of Transit Signal Priority Using the NTCIP Architecture Hongchao Liu, Alexander Skabardonis, Meng Li

Impact of Bus Priority Attributes on Catchment Area Residents in Dublin, Ireland

Simon McDonnell, Susana Ferreira, Frank Convery.

An Update on Curb Guided Bus Technology and Deployment Trends

David Phillips.

Microscopic Simulation Approach to Capacity Analysis of Bus Rapid Transit Corridors

Abdul Jabbar Siddique, Ata M. Khan 183 
Ex-Ante Evaluation of Exclusive Bus Lanes Implementation

D. Tsamboulas.

The Potential for Bus Rapid Transit to Reduce Transportation-Related $\mathrm{CO}_{2}$ Emissions

William Vincent, Lisa Callaghan Jerram

Calibration of Vissim for Bus Rapid Transit Systems in Beijing Using GPS Data

Liu Yu, Lei Yu, Xumei Chen, Tao Wan, Jifu Guo 238

Our troubled planet can no longer afford the luxury of pursuits confined to an ivory tower. Scholarship has to prove its worth, not on its own terms, but by service to the nation and the world.

-Oscar Handlin 


\title{
Bus Rapid Transit in Australasia: Performance, Lessons Learned and Futures
}

\author{
Professor Graham Currie \\ Institute of Transport Studies, Monash University
}

\begin{abstract}
This paper presents a review of Bus Rapid Transit (BRT) systems in Australasia. It describes the major systems operating in Adelaide, Brisbane and Sydney, outlining their infrastructure, operations and development characteristics. The performance of these systems in terms of patronage, markets, operations and overall urban development impacts is described. Lessons learned in their implementation and operation are also reviewed. The paper concludes with an outline of future prospects for BRT development in Australasia and a discussion of the major findings of this review.
\end{abstract}

\section{Introduction}

Bus Rapid Transit (BRT) has been seen as a "creative, emerging public transit solution" (Levinson et al. 2003) which can be cost-effective in addressing urban congestion (U.S. General Accounting Office 2001). The development of new BRT systems in Australasian cities has been promoted as a cost-effective means of providing quality service for cities of low density (Fleming et al., 2001). Australasia has one of the oldest BRT systems-the Adelaide North East Busway (opened in 1986). It also has some of the world's newest systems: the Brisbane South East Busway, the Brisbane Inner Northern Busway, and the Sydney Liverpool-Parramatta Transitway (opened in 2001, 2004 and 2003). 
This paper reviews the experiences of Australasian BRT systems by describing each system, measuring performance, and identifying lessons learned in implementation. The paper also describes future BRT development in Australasia.

\section{Systems}

There are four Australasian bus-based transit systems that qualify for BRT status:

- Adelaide North East Busway (ANEB)

- Brisbane South East Busway (BSEB)

- Brisbane Inner Northern Busway (BINB)

- Sydney Liverpool-Parramatta Transitway (SLPT)

Table 1 shows a summary of the key design features of each of these systems. Each system has unique and distinctive features and functions; even the two Brisbane systems have different functions. The Adelaide busway is a guided bus system using guide wheels on the side of buses to enable a smoother and faster ride along the busway. The other systems are unguided and operate as effective bus-only roads with different strategic functions:

- SLPT is a cross-corridor service linking two major sub-regional centres in Western Sydney. An interesting part of this arrangement is that the transitway termini, Liverpool and Parramatta, are already linked by a direct rail service. The transitway loops to the west of the direct rail service, linking suburbs to the west with both centres.

- BSEB performs a central CBD radial function from southeastern suburbs. It is a major radial corridor service stretching from the CBD to the edge of Brisbane's sprawling suburban development.

- BINB is also radial but is short in length. Its major design rationale was to provide a traffic-free, fast, high-quality link to the CBD for the large number of northern corridor bus services. These services (like the South Eastern corridor routes) used to share congested inner city roads with traffic. Road bridges accessing the CBD were particularly difficult bottlenecks and had a significant impact on bus operating speeds and reliability. The busways considerably improve on this performance.

ANEB operates at a very high average speed ( $80 \mathrm{kph}$, including stopping time) and is potentially one of the fastest urban transit systems in the world. This is partly explained by the guided bus technology used in Adelaide, which results in high 
and safe operating speeds (with reasonable ride comfort) with maximum running speeds of up to $100 \mathrm{kph}$. ANEB has few stations reducing stop dwell time. With $5 \mathrm{kms}$ between stations, it is also possible for buses to reach a higher speed.

SLPT does not have the same quality of right-of-way separation that is exhibited in the other BRT system designs. This is partly explained by the nature of the development environment for each of these systems. SLPT was "built into" or "retro-fitted" into an area with much existing urban development using the alignment and reserve of the Sydney Water Pipeline corridor and also includes much on-street bus lane operation. This right-of-way had its limitations (Warrell, 2004), including the need for site access for the pipeline and adjoining properties, which required protection from noise. The other BRT systems have a very different development environment. The ANEB and Brisbane systems were built into a largely undeveloped right-of-way (parkland, a river valley, and a freeway reserve).

The nature of these development environments was part of the rationale for using BRT technology. BRT was seen as a "low impact mode" in Adelaide; low noise and narrower track profile were key reasons for using BRT (Bray and Scrafton 2000). However, this system, like SLPT, was designed with the potential for future conversion to light rail (Warrell 2004).

The bus operating strategies of the Adelaide and Brisbane systems are similar:

- A trunk bus route operates along the full length of the busway (terminating in the city and at the suburban end of the busway).

- Services from a wider suburban catchment operate on-street and feed into the busway at its suburban terminus and also at selected stations as the busway nears the CBD. These services enter and operate on the busway for part of their length.

- Some services on the busway operate express, i.e., they do not call at each station.

SLPT has a different pattern; only a trunk service is operated. Regional bus services feed busway stations where passengers transfer between trunk services. An integrated network plan including through running of routes on the transitway was originally planned for (Levinson et al. 2003) but has not been implemented at this stage. This was due to problems with reorganising contracts with private bus companies in the region. These issues are now being addressed, and the full network concept is expected to be offered by 2007. 
Journal of Public Transportation, 2006 BRT Special Edition

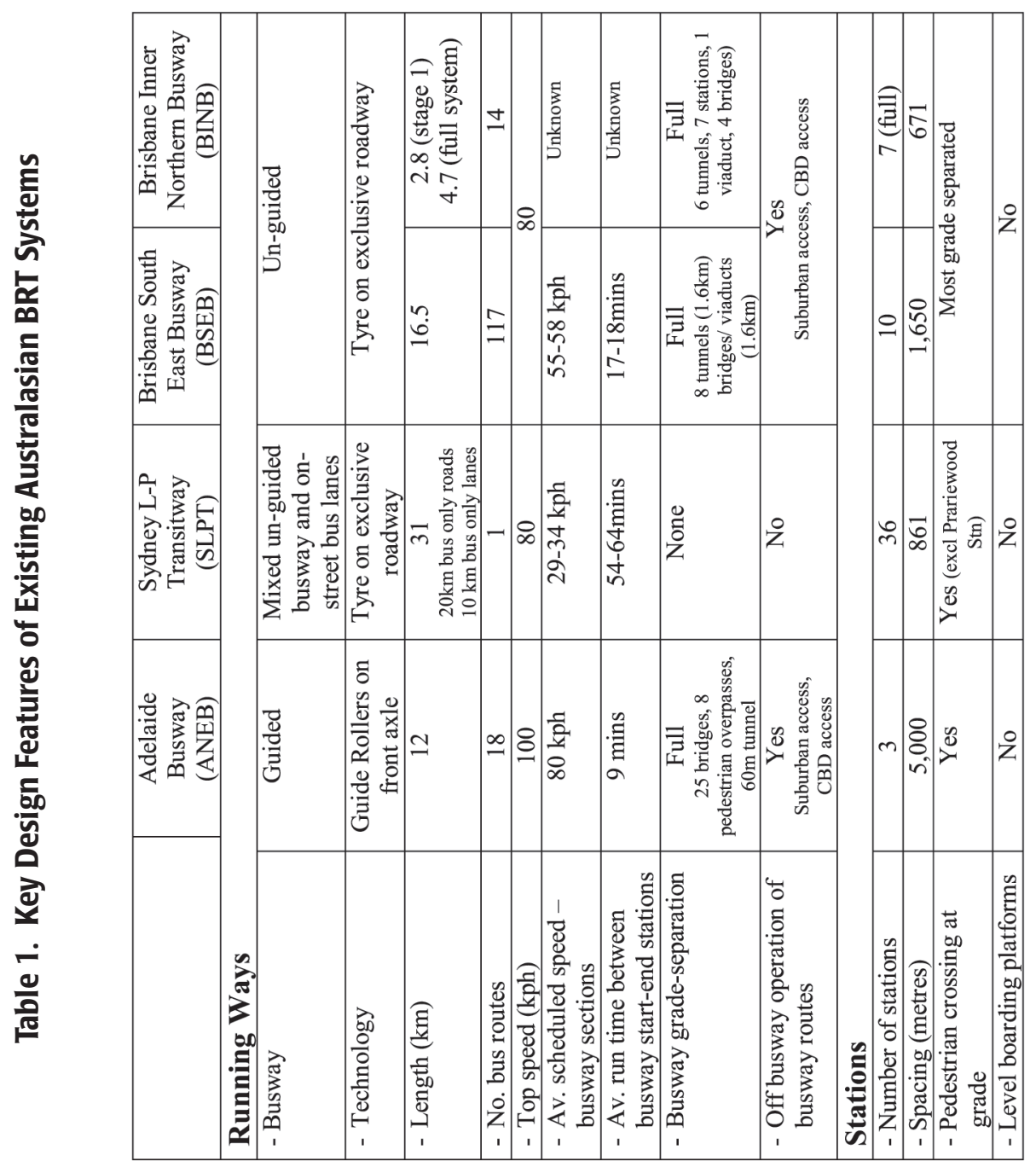




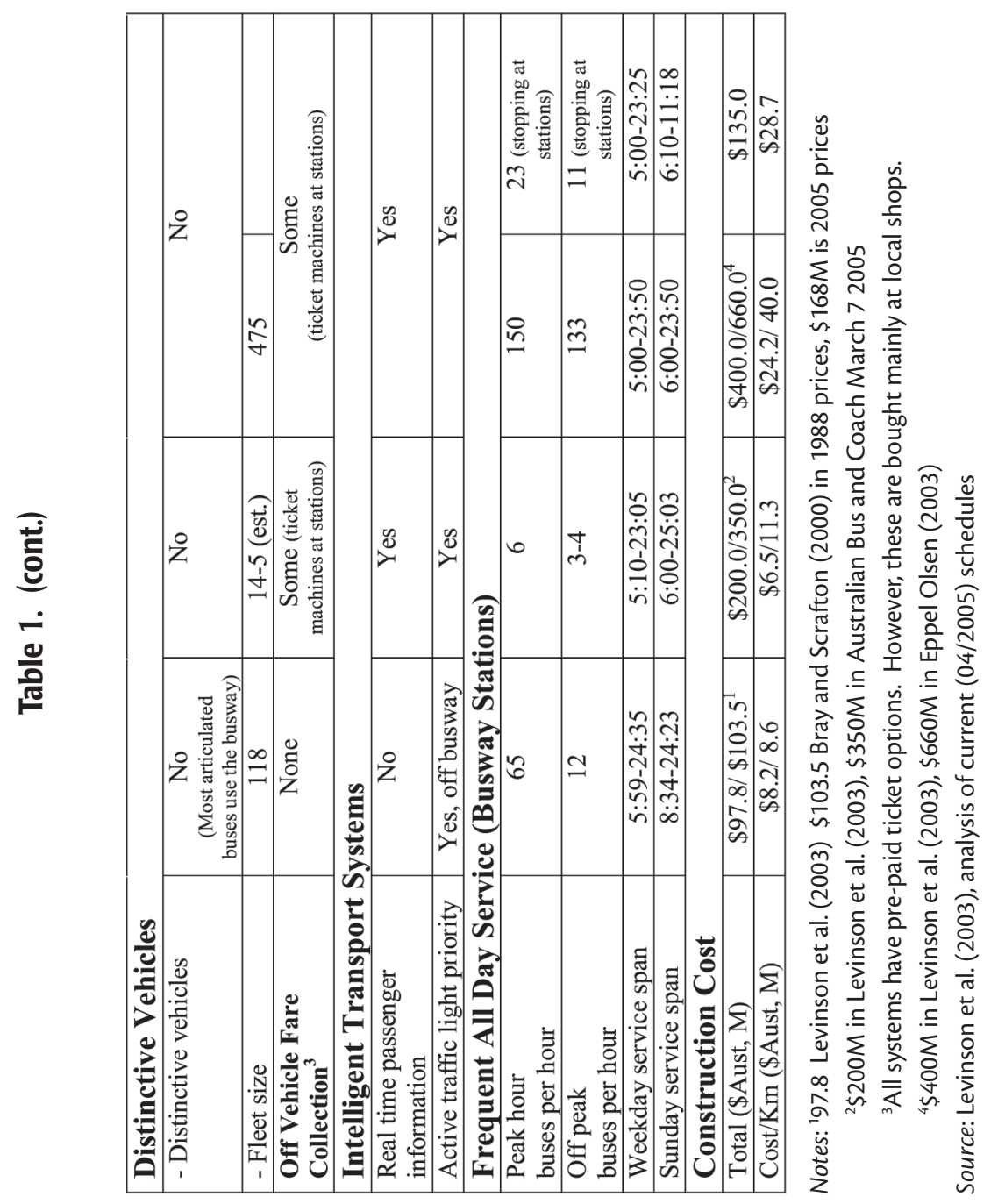


An impressive feature of most of the Brisbane systems is high-quality station design. Almost all Brisbane busway stations have grade-separated pedestrian access between platforms using covered overpasses with lifts (Figure 1). The Adelaide and Sydney systems have less substantial stations (Prariewood Station on the SLPT is an exception).

The Brisbane and Sydney systems use low-floor, wheelchair-accessible buses for trunk services. This is not the case in Adelaide. Although platforms are provided in each system, none achieve level boarding entry onto buses. A boarding ramp is required in each case.

\section{Figure 1. Typical Stations on the Australian Busways}

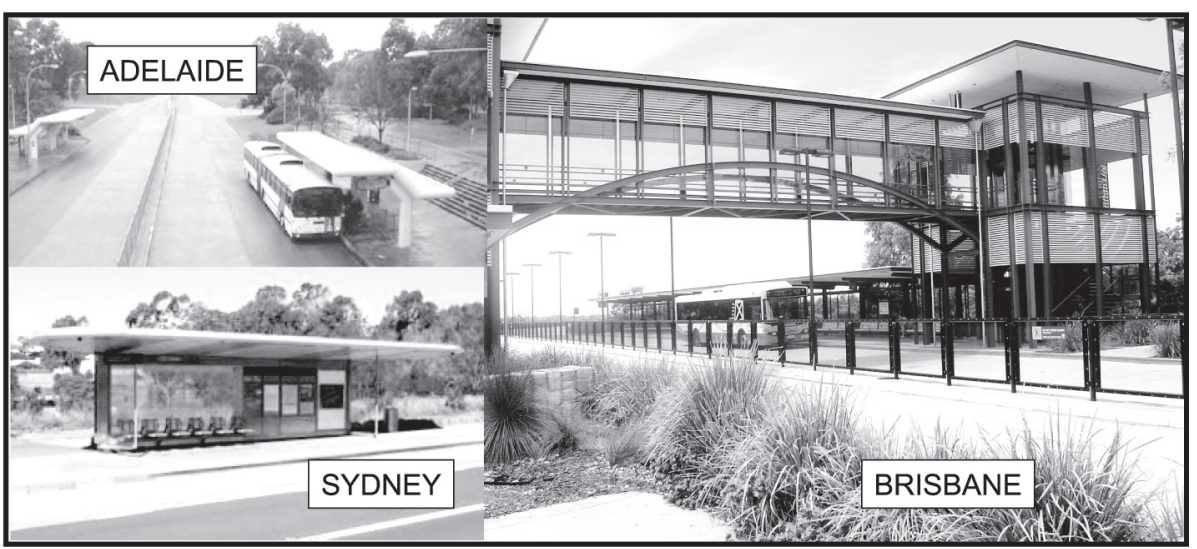

Distinctive bus vehicle design is a common feature of American BRTs (Levinson et al. 2003). None of the Australasian BRT systems use distinctive vehicles (although Adelaide does deploy its articulated buses on the ANEB).

All Australasian BRT systems have some off-vehicle ticket sales but also allow some on-vehicle sales. Intelligent Transport Systems are an important part of all systems; however, the newer systems use real-time information displays at stations (Adelaide does not have these). Active traffic light priority systems are a major feature of all systems, as is remote security monitoring.

All Australians BRT systems have high service levels including service spans and headways. BSEB is the largest system, with peak headways of 24 seconds. The scale of peak operations in Adelaide is broadly 40 percent of this volume, although a 
high volume of articulated buses are deployed (which will balance relative capacities). SLPT has relatively modest service levels (10-15-20 $\mathrm{min}$ ) because only the trunk element of the service plan is provided.

BSEB has the highest construction costs of the systems $(\$ 24-\$ 40 \mathrm{M} / \mathrm{km})$. ANEB appears to be the cheapest $(\$ 14 \mathrm{M} / \mathrm{km})$. BSEB costs are high due to quality station design. BINB also has much tunnelling, which has substantially increased costs.

Table 2 shows usage data for three of the systems (it is too close to the opening of the Inner Northern Busway for comparable data to be provided). BSEB, at 26M passengers per annum carries substantially more passengers than the Adelaide

\section{Table 2. Market Data-Australasian BRT Systems}

\begin{tabular}{|c|c|c|c|}
\hline & $\begin{array}{c}\text { Adelaide Busway } \\
\text { (ANEB) }\end{array}$ & $\begin{array}{c}\text { Sydney Transitway } \\
\text { (SLPT) }\end{array}$ & $\begin{array}{c}\text { Brisbane SE } \\
\text { Busway (BSEB) }\end{array}$ \\
\hline \multicolumn{4}{|l|}{ Ridership } \\
\hline - Usage per annum & $7.0 \mathrm{M}^{1}$ & $1.9 \mathrm{M}^{2}$ & $26.0 \mathrm{M}^{7}$ \\
\hline - Weekday average ${ }^{3}$ & 25,000 & 6,800 & 93,000 \\
\hline - Peak hour & $4,500^{4}$ & $\mathrm{~d} / \mathrm{k}$ & $15,000^{5}$ \\
\hline \multicolumn{4}{|c|}{ Immediate Travel Impacts } \\
\hline $\begin{array}{l}\text { Direct corridor } \\
\text { Ridership growth }\end{array}$ & $24 \% \%^{5}$ & $\begin{array}{c}56 \%{ }^{6} \\
(47 \% \text { new journeys) }\end{array}$ & $\begin{array}{c}56 \%^{8} \\
(17 \% \text { new journeys) }\end{array}$ \\
\hline $\begin{array}{l}\text { \% new pax who } \\
\text { previously drove }\end{array}$ & $40 \%^{5}$ & $9 \%{ }^{6}$ & $26 \%^{8}$ \\
\hline \multicolumn{4}{|l|}{ Station Usage } \\
\hline Board at stations & $20 \%{ }^{4}$ & $100 \%$ & $66 \%{ }^{9}$ \\
\hline Board off system & $80 \%{ }^{4}$ & $0 \%$ & $39 \%{ }^{9}$ \\
\hline
\end{tabular}

Notes: $\quad$ 'Based on 2003-4 financial year. Data courtesy of Office of Public Transport, Adelaide

${ }^{2}$ Jan-Dec 2005 data courtesy of Sydney RTA TransitWays

${ }^{3}$ Estimates using a year to weekday factor of 280 - a typical ratio in Australian cities

${ }^{4}$ Source: Passenger Transport Board (1999)

${ }^{5}$ Source: Peak hour peak direction estimate for 2004 made by Brisbane Transport (from a personal communication). Levinson et al. (2003) quoted 9,000/ hour

${ }^{6}$ Source: Parsons Brinckerhoff (2003)

${ }^{7}$ Source: Queensland Transport (2004)

${ }^{8}$ Source: McCormick Rankin Cagney (2002)

${ }^{9}$ Source: Queensland Transport (2003) 
and Sydney systems put together. BSEB usage data probably exaggerates performance because many busway services follow the busway only for a short proportion of its length. The "core" South East Busway services carry $4 \mathrm{M}$ trips per annum (Queensland Transport 2004). The Adelaide Busway carried 7M passenger trips per annum (2003/4), and most of these trips would be travelling its full length. Hence, BSEB and ANEB are of comparable scale, depending on the measures used. BSEB has a much higher peak maximum load than ANEB. It is also clear that SLPT has usage substantially below the other busways.

Table 2 also shows contrasts in busway station behaviour; ANEB is mainly accessed "off system" (20\% of passengers board at stations). In contrast, the Sydney Transitway is accessed entirely at station (because there are no "off system" services). BSEB lies somewhat between these two extremes, with well over half of boardings occurring at stations.

\section{Performance}

\section{Travel and Market Impacts}

All systems generated high corridor ridership growth (Table 2). The newer systems have increased usage by over 50 percent. The nature of growth has been different in each case. A high share of the ANEB ridership growth (40\%) came from car drivers (Levinson et al. 2003). In Sydney most growth in transit ridership came from new journeys. A smaller share of car drivers took to using the transitway (9 percent) (Parsons Brinckerhoff 2003). SLPT caters for cross-corridor demand, which is low in volume and highly dispersed. This is a difficult market to compete with the car. In Brisbane, growth of 56 percent included 26 percent who previously drove (McCormick Rankin Cagney 2002). Both the Brisbane and Adelaide systems perform a CBD radial function and compete with congested road markets. Their high car usage impact is due to the competitiveness of the busways in terms of travel time/ cost and the associated parking issues within associated CBD's.

SLPT is operating considerably below patronage forecasts. A prediction of 18,000 per weekday was identified in Levinson et al. (2003); however, actual is 5,100 (Table 2). The difference is explained by the difference between the service levels planned and those actually operated. Only the trunk service is being operated, while a far more comprehensive multi-operator network was envisaged in forecasts. In addition, integrated ticketing and redevelopment of Parramatta interchange is yet to occur, but both assumptions also were included in the original forecasts. Forecasts 
based on the current (less developed) system were around 1,700 per weekday, and current usage is well above this expectation.

ANEB has an impressive long-term market performance (Figure 2). The busway has demonstrated consistent patronage trends above the norm for other bus, tram and rail services. Current ridership is 16 percent larger than in 1990/91. For other corridors, patronage is more than 21 percent lower than in 1990/91.

\section{Figure 2. Relative Patronage Change of Busway Compared to Other City Public Transport-Adelaide Busway}

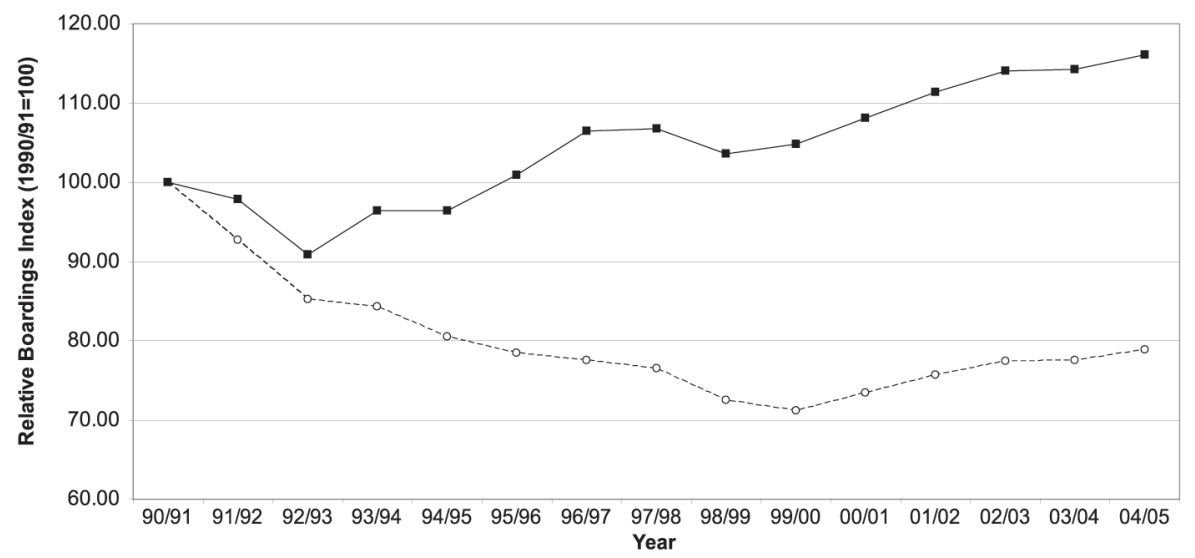

Note: $1990 / 91$ patronage $=100$, annual patronage is indexed relative to the 1990/91 value. 1990/91 is a year after the final extension of the busway and, hence, allows for "ramp up" market growth associated with new system introduction.

Since 2002-3 (a year after completion) ridership on the core BSEB routes had increased by 8 percent to 2003-4 (Queensland Transport 2004), while patronage for most of the remaining Brisbane bus services has increased by only 2 percent (Brisbane Transport 2003, 2004). This suggests that growth is four times higher for busway-related services.

There is also evidence that the type of people using busways is different from traditional on-street bus service markets. ANEB displays a lower share of ridership who have no car available for their trip than on-street bus services (Currie 2005). It also has a considerably higher share of "choice" passengers, i.e., those who have a car available but choose to use transit, and also those on high incomes compared 
to other corridors. Overall, the busway displays income and user "choice" characteristics, which are more similar to rail markets than traditional on-street bus markets (Currie 2005).

These characteristics are consistent with the high patronage growth impacts identified earlier, particularly those associated with reduced auto use. There is also consistency in BRT market characteristics for all Australasian systems (Parsons Brinckerhoff 2003; McCormick Rankin Cagney 2002).

All Australasian BRT systems have had a positive impact on customer satisfaction (as may be expected after a significant investment in service). In Adelaide this impact has been sustained in the long term. Figure 3 shows the results of a 2001 customer satisfaction survey of the Adelaide busway corridor compared to onstreet bus and rail/tram corridors. The busway shows consistently higher satisfaction than on-street bus and rail corridors and lower dissatisfaction rates. The share of very satisfied customers on the busway corridor is over 5 percent larger than those in the on-street bus corridors some 12 years after it was fully opened.

\section{Figure 3. Public Transport Customer Satisfaction- Adelaide BRT, On-Street Bus and Rail Corridors}

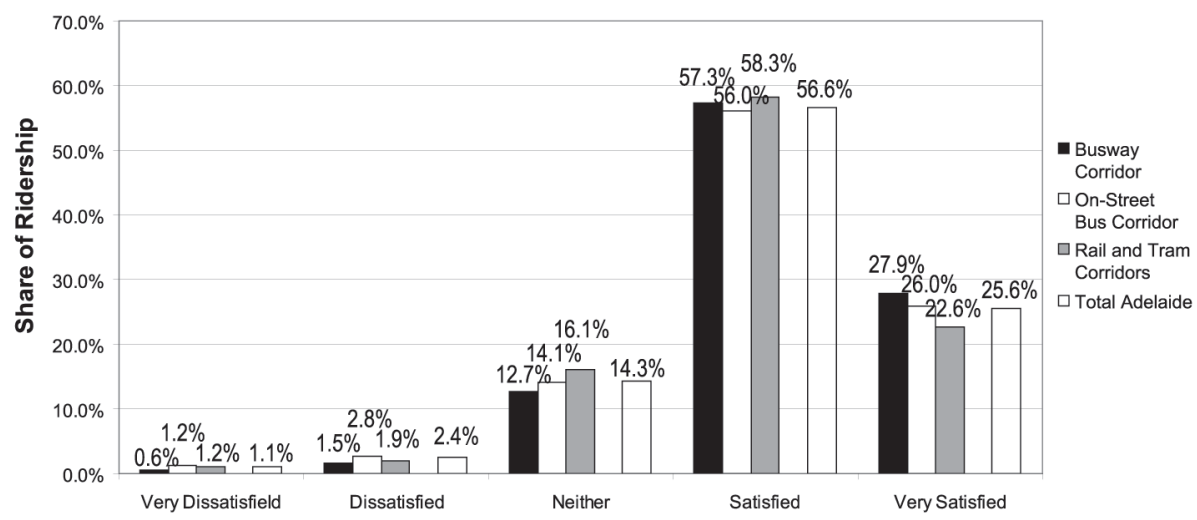

Source: Market Equity (2001) 
Figure 4 shows user-perceived busway advantages for the BSEB. Faster travel times, reduced traffic congestion, convenient stops, and frequent service were the main benefits identified.

\section{Figure 4. User Perceived Advantages of the Brisbane South East Busway}

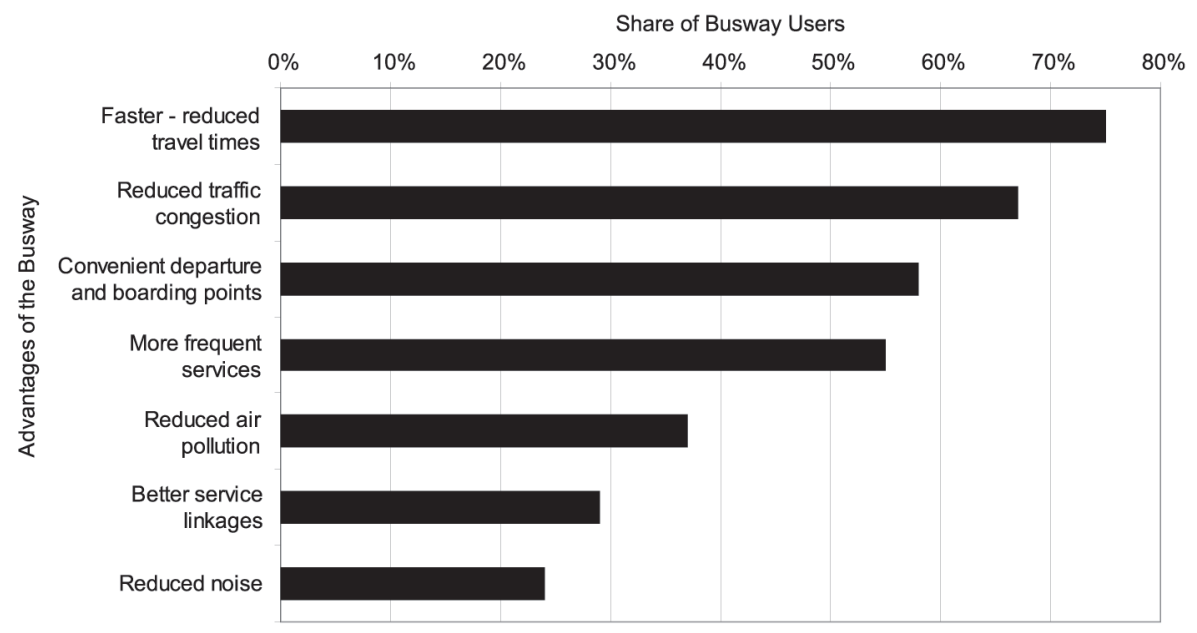

Source: McCormick Rankin Cagney (2002)

\section{Urban Development Impacts}

Urban development impacts for ANEB and BSEB were identified by Levinson et al. (2003) (see Table 3). Property value growth of up to 20 percent was identified in the region of BSEB, a higher growth than in other Brisbane corridors. Although urban development associated with Tea Tree Plaza has been associated with ANEB, in practice little development has occurred around the remaining stations. As a senior planner in Adelaide put it, there is "no evidence of the busway having encouraged additional urban development" (Currie 2005). The same source notes the very high park and ride access behaviour to most Adelaide busway stations (over $50 \%$ of boardings are via car access). Park-and-ride and urban development at stations are not well matched due to the extensive parking area required and the poor environmental quality associated with car access (Dittmar and Ohland 2004). This problem is exacerbated by BRT since the very high frequencies provided are very attractive boarding points for park-and-ride travellers. 
Table 3. Land Use Benefits of Selected Australian BRT Systems

\begin{tabular}{|l|l|}
\hline \multicolumn{1}{|c|}{ System } & \multicolumn{1}{c|}{ Land Development Benefits } \\
\hline Adelaide Busway & Tea Tree Gully area becoming an urban village \\
\hline Brisbane South East Busway & Up to 20\% gain in property values near the \\
& busway. Property values in area within \\
& 6 miles of station grew 2 to 3 times faster \\
& than those at greater distance. \\
\hline
\end{tabular}

Source: Levinson et al. (2003)

Park and ride and its impact on urban development around stations is less of an issue for the other BRT systems. Only 13 percent of the BSEB users drove a car (McCormick Rankin Cagney 2002), and less than 1 percent for SLPT (Parsons Brinckerhoff 2003).

There is little information on urban development associated with the SLPT, mainly due to its fairly recent opening. The low density suburban context of SLPT has been recognised as a difficult development environment (Warrell 2004). Also, initial low service levels on SLPT present a poor offering. Nevertheless, a pro-active approach to design development opportunities around major stations has been taken, notably at Prariewood (Faber 2004).

\section{Operational Impacts}

Travel time savings were a key feature of user perceived benefits of the BSEB (see Figure 4) and SLPT (fast travel time was rated as very important by $73 \%$ transitway passengers) (Parsons Brinckerhoff 2003). Travel time savings were:

- SLPT - up to 60-minutes (Levinson et al. 2003) for a complex feeder bus, rail, feeder bus trip, but generally lower for other (more common) trip types

- BSEB - a 60-minute motorway trip from Eight Miles Plains to the CBD has been reduced to 18 mins (a 42-min travel time saving) (Deutscher and Pasieczny 2003)

- ANEB - travel times from suburbs to CBD reduced from 40 to 25 minutes (minus 15 minutes), (Levinson et al. 2003).

Although reliability improvements are likely, little monitoring has occurred. Operational challenges associated with crowd handling and frequent vehicle movements at inner stations on the BSEB have been identified (Pasieczny 2003). 
Management of these issues has required careful segregation and deployment of vehicles and passengers to separate platform sections.

Safety issues in using driver "line of sight" as a means to separate fast-moving buses were identified on the ANEB (Bray and Scrafton 2000). Following a rear-end accident, flashing lights were installed on buses to indicate they are stopped. A special vehicle was also designed to recover broken down buses on the guided busway. This is virtually never used. A strong safety record for the guided busway is evident (Bray and Scrafton 2000).

"Tire scrubbing" was another operational lesson of ANEB. Tire wear on curved sections of the guided busway occurred. This was addressed via speed reduction at these points.

ANEB planners were concerned about the dwell time delays resulting from onvehicle ticket sales. Multi-door ticket validators and mandatory off-vehicle ticket sales would clearly assist but have not been implemented. The benefits of better boarding time need to be balanced against the potential to increase fare evasion. This concern has led to limited off-vehicle sales in Australasian BRT systems.

\section{Lessons Learned}

This section is based on interviews with BRT system planners and operators.

\section{Sydney Liverpool-Parramatta Transitway}

The lack of coordination between the opening of the transitway and the resolution of bus contract issues is the major issue affecting performance. In addition Parramatta interchange development and integrated ticketing has lagged behind transitway opening. Clearly, better coordination would have improved performance.

Initial marketing of the SLPT also has been a concern. Creating the "T-Way" brand was emphasised over providing practical details about how to use the system.

The use of at-grade pedestrian crossings seems to have been effective from both a safety and cost view. SLPT operators suggested a 2-minute headway threshold should be used to determine whether crossings should be grade separated. This view contrasts with the design of the ANEB, where at-grade pedestrian crossings are provided at headways much shorter than 2 minutes. No pedestrian safety issues have been identified with either designs to date. 
Some concerns with station design features are noted:

- Stations are not close enough to major trip generators.

- Sound barriers, safety concerns and cost issues have limited access paths from trip generators to stations.

- Stations are considered "over-designed" to be distinctive and attractive. Originality was considered to overly dominate cost and practicality issues.

- Too much glass was used. This is expensive and generated vandalism issues. Less glass with be used in the next T-Way system.

- "Lush" landscaping is expensive and can trap litter and garbage.

As a result of these lessons, stations on the next T-Way system will be 20 percent cheaper.

An interesting viewpoint was also expressed regarding the use of real-time passenger information (RTPI) systems. Planners expressed the view that the benefits of RTPI systems are small when frequent services are provided. Although RTPI is popular, it does not necessarily mean it is cost-effective.

\section{Adelaide Busway}

ANEB planners found the frequency advantage of busway stations makes them very attractive. Park and ride access was heavily under-estimated in original plans (e.g., Paradise Interchange had 160 parks on opening and now has 550). During the first 5-10 years, station parking lots were heavily over-subscribed, with much illegal parking.

Initial ANEB service levels were considered low due to funding limitations. Starting with high service levels is recommended. This point is reflected in the SLPT experience.

ANEB planners emphasize how the busway has substantially built ridership. The transfer free operation of buses from suburbs to downtown is considered a major advantage, compared to rail and light rail alternatives.

\section{Brisbane Busways}

In identifying areas where planning could have been better, the only major concern was the linking of busway station design into adjacent urban development. BSEB is a difficult environment for development integration since its location, adjacent to a freeway, was not an attractive one for TOD. The freeway corridor considerably reduced the walk on catchments and acts to dilute the quality of sta- 
tion environments (due to high traffic volume and noise). Good design has acted to partly reduce impacts.

Brisbane planners shared the views of those involved with the SLPT that RTPI systems were of limited value in an environment where high frequency services were offered.

BSEB has faced operational issues associated with platform crowding and managing large numbers of bus movements in inner stations. There also are concerns about capacity. Overloading on vehicles is an emerging issue. Short term plans for refurbishing inner stations have addressed many of these concerns. Use of highercapacity buses is being considered.

Capacity concerns are clearly linked to the success of BSEB. Success was a commonly used word in describing lessons learned. This has been evidenced by popularity with users and the ongoing commitment Brisbane authorities have made to new BRT systems.

\section{The Future}

There are two new fully committed BRT systems under construction in Australasia: the Sydney North West Transitway (SNWT) and the Auckland Northern Busway (ANB).

Table 4 shows some of the key features of these systems. In total, an investment of around $\$ A$ ust $700 M$ is expected within the next 2 years. New systems will increase Australasian BRT system size by around 47 percent ( of busway route kms). SNWT will follow the concept of the SLPT and will link in to the SLPT at Parramatta.

ANB incorporates a one-direction busway using tidal flow operations nearer Auckland CBD. This design is a compromise between constrained right-of-way width, particularly over the Auckland Harbour Bridge and other road demands. ANB also uses freeway shoulders as a right-of-way in outer suburban sections, as well as a more traditional two way "bus only road" busway design (much like BSEB) between these two sections. 
Journal of Public Transportation, 2006 BRT Special Edition

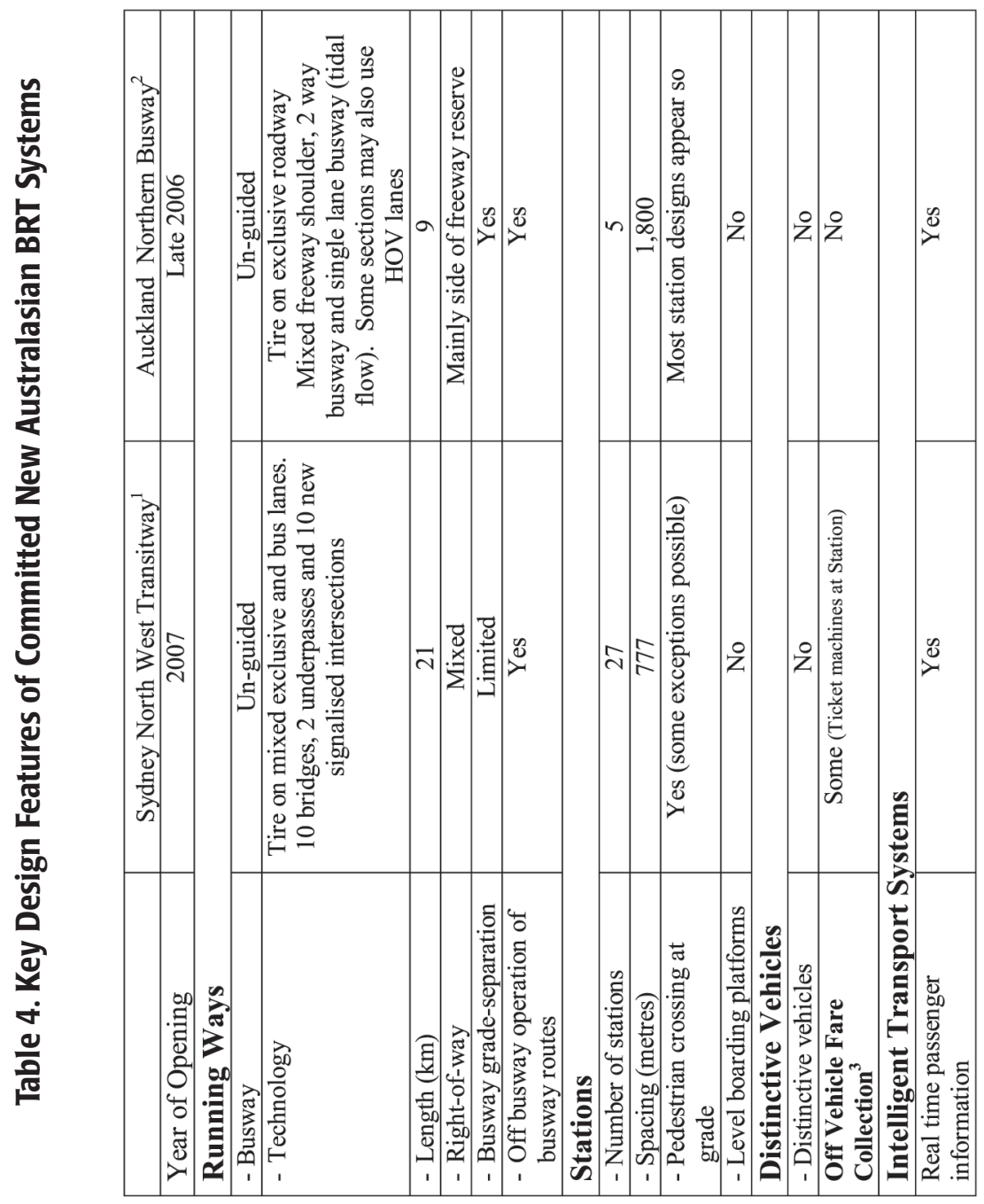




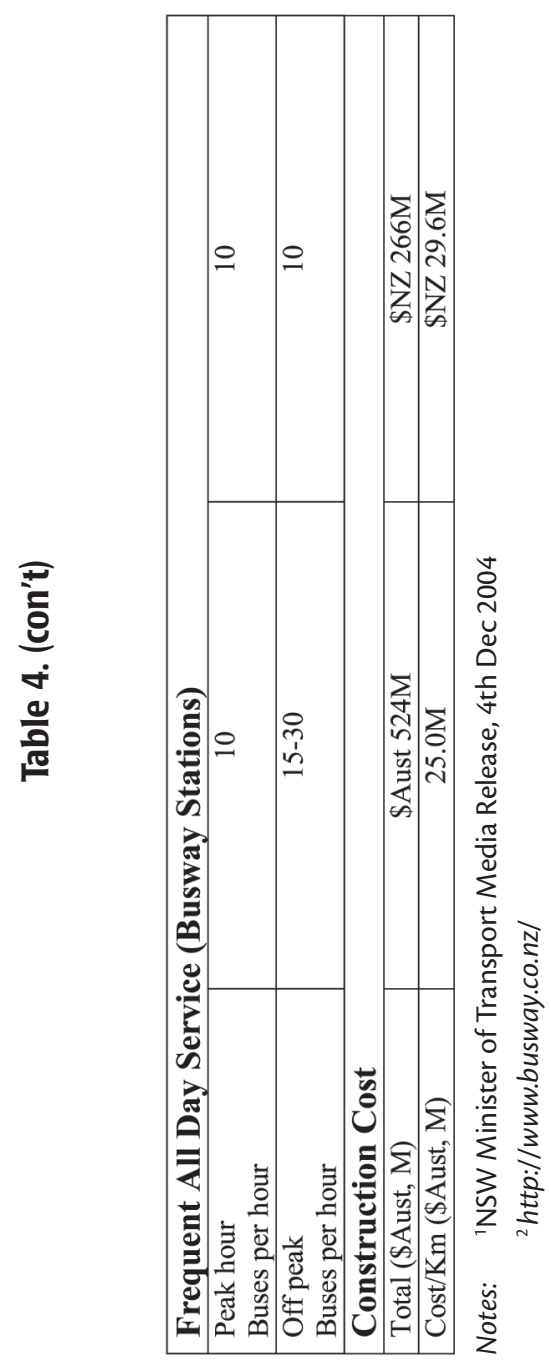


In terms of existing systems development, expansion is proposed for each of the Brisbane BRT's:

- \$Aust 460M-New Busway Station on the BINB (completed by 2015)

- \$Aust 25M-extension of the BSEB to Springwood (completed by 2009) (Queensland Government 2005)

The expansion of the existing SLPT is also a significant project in term of existing systems development. Bus operator contracting issues have considerably limited the initial operations. In addition, the redevelopment of Parramatta interchange and the introduction of integrated ticketing have lagged but should be fully addressed by the end of 2006. Much improvement in the performance of the SLPT is expected.

There are a very large number of planned systems (i.e., not fully developed or committed), which would represent more than a tripling of total Australasian BRT system size.

Networks of linked BRT systems are planned for in both Brisbane and Sydney. The recent Infrastructure Plan for South East Queensland (Queensland Government 2005 ) has identified a staged program for a further $\$$ Aust $1.2 B$ investment in new busway development.

The new Brisbane busways will involve more on-street bus lane operations than the existing busways (following the concept of the SLPT). This is because Brisbane has used available corridors for fully grade-separated busways. There is little opportunity left for using river, park corridors or space next to freeway reserves. New transit systems will have to be retro-fitted into existing urban areas-a more challenging task to implement effectively.

An interesting inter-modal development as part of the expansion of busways in Brisbane is the redevelopment of platforms at Roma Street Railway Station. Two rail platforms will become busway stations within a major rail station complex including mostly commuter and long distance rail platforms.

Auckland has a similar set of extensive network development concepts associated with rapid transit corridors, although transit modes for these corridors are undecided at this stage.

Canberra, Australia's capital, also has plans for the Belconnen to Civic Busway. This is a $10 \mathrm{~km}$ corridor where a combination of bus-only roads and bus lanes are envisaged. 


\section{Discussion}

Based on the findings of this review, a few conclusions can be drawn regarding four important questions associated with BRT.

Has BRT system development increased in Australasia? Yes. Despite early interest with the Adelaide busway, no large-scale systems were developed for over a decade. However, the last 3 years, and certainly the next 2 , will see substantial growth. Around \$Aust 2 Billion in investment in BRT system has occurred or will occur.

How have BRT systems performed relative to expectations? In interviews with staff from both Adelaide and Brisbane busways, it is clear that performance has been well beyond expectations. In Brisbane, long term maximum peak hour (peak direction) demand of 10,000 per hour was forecast. Current use is 15,000 per hour after only 5 years. The Sydney transitway is well below performance due to contracting problems. In effect, the service planned was not provided; hence, planned performance did not eventuate.

Has BRT replaced heavy and light rail as a mode of choice in Australasia? No. There are several heavy rail and some (small) light rail development projects. BRT has not replaced rail but it has become a viable option to examine alongside the alternatives. BRT's flexibility to expand to rail at a future date is a part of the justification for choice of BRT in most cases.

Has BRT become a more attractive mode choice than rail in Australasia? A qualified yes. The \$Aust 2 Billion investment in recent Australasian BRT systems is at least as large as the rail investment made over the same period. This demonstrates BRT's effectiveness in the difficult choice governments face in the quality, cost and funding availability trade-off. It is clear that more transit systems can be provided with BRT than with rail for the equivalent dollar. However, decisions to invest in rail are still being made. Clearly, rail is seen to be more appropriate in certain situations; governments are demonstrating their right to pay for a higher quality and more expensive systems if they wish. BRT has not proven a ubiquitous answer to all urban transit problems. Rather, it is a powerful additional tool to be used in appropriate circumstances.

An important perspective on the BRT systems identified is the large range of technologies and characteristics employed. There are more contrasts than similarities between systems. 
The relatively poor initial performance of the SLPT suggest the larger-scale, gradeseparated busway models are more appropriate. However, this view is simplistic. It fails to understand the problems Sydney faced in implementation. It also fails to recognise the different challenges and objectives being addressed by different types of system. SLPT is retro-fitting a new mass transit system into an existing suburban area, while the other busways are using largely undeveloped urban corridors with parks, rivers, or freeway rights-of-way. Retro-fitting is a more difficult challenge. Yet it is a challenge worth making since there are far more opportunities and a greater need for retro-fitting within suburban development than there are opportunities and needs for developing BRT systems in available river/park or freeway reserves. This is demonstrated by the new Brisbane Northern and Eastern Busway projects. These will follow the suburban retro-fit model due to a lack of available rights-of-way.

\section{Conclusions}

This paper has presented a review of BRT system in Australasia. Four major systems have been developed with varying characteristics and performance. All have achieved attractive patronage impacts and are well valued by customers. Within the next 2 years, Australasian BRT systems will increase by around 50 percent. Longer term expansion of BRT systems are being planned, including new systems in Canberra. Brisbane has plans for \$Aust 1.2B in busway development by 2026.

\section{Acknowledgement}

The author would like to thank Matt Faber, Terry Lee-Williams, Andrew Homburg, Dr. George Pund, Brian Bothwell, and Tom Wilson for their assistance in the development of this paper. The Adelaide Office of Public Transport, Sydney RTA Transitways, Brisbane City Council, Queensland Transport and the University of New South Wales were also very helpful in providing information used in this paper. Any errors or omissions are the responsibility of the author.

\section{References}

Australian Bus and Coach. 2005. 2 million in 2 years. March 7, pp.18-19. 
Bray, D., and D. Scrafton. 2000. The Adelaide O-Bahn: Ten years on. 8th Joint Conference on Light Rail Transit, Dallas, Texas. American Public Transport Association and the Transportation Research Board, CD-ROM, paper K-31.

Brisbane Transport. Annual Report (2002-3).

Brisbane Transport. Annual Report (2003-4).

Currie, G. 2005. Strengths and weaknesses of bus in relation to transit oriented development. Transit Oriented Development - Making it Happen Conference, Perth, Western Australia, July.

Deutscher, K., and J. Pasieczny. 2003. Brisbane's new bus priority and busway initiatives-government agencies in partnership. Smart Urban Transport Conference, Parramatta, Sydney, Australia 27-29 May.

Dittmar, H., and G. Ohland. 2004. Defining transit-oriented development: The new regional building block. In Dittmar, H., \& Ohland, G. 2004. The New Transit Town: Best Practices in Transit Oriented Development. Island Press.

Eppel Olsen. 2003. Cairns integrated public transport strategy. Queensland Transport, April.

Faber, M. 2004. Do transitways work? Putting busways to the test on Sydney's growth frontier. Engineers Australia Seminar, 7 September, University of New South Wales.

Fleming, D., M. Faber, G. Pund and P.Turner. 2001. Public transport solutions for low-density cities: The Australian experience. 54th UITP World Congress, May.

Levinson, H., S. Zimmerman, J. Clinger, S. Rutherford, R.L. Smith, J. Cracknell and R. Soberman. 2003. Bus rapid transit. TCRP Report 90, Transportation Research Board.

Market Equity. 2001. Customer satisfaction survey of Adelaide Metropolitan train, tram and bus service customers. Passenger Transport Board, Adelaide, April.

McCormick Rankin Cagney. 2002. Results of the annual Busway customer satisfaction survey 2002, Final Report.

Parsons Brinckerhoff. 2003. Liverpool to Parramatta Transitway passenger survey, draft report. RTA Transitways, August. 
Passenger Transport Board. 1999.Adelaide's O-Bahn Busway: Guiding transport into the future.

Queensland Government. 2005. South East Queensland infrastructure plan and program 2005-2026.

Queensland Transport. 2003. Annual Busway customer satisfaction survey 2003, Final Report. September.

Queensland Transport. 2004. Draft Translink Network Plan.

State Transport Authority.1992 Eastern Corridor market analysis. Adelaide Public Transport Network Study.

State Transport Authority.1994. North East (Busway) market analysis report. Adelaide Public Transport Network Study, February.

Travers Morgan.1991. Analysis of the Northern Suburbs customer survey.Adelaide Public Transport Network Study, October.

U.S. General Accounting Office. 2001. Bus rapid transit shows promise. GAO-01984, Washington DC.

Warrell, S. 2004. Do transitways work? The Planning and Implementation Phases' Engineers Australia Seminar, September, University of New South Wales.

\section{About the Author}

Professor Graham CURRIE (graham.currie@eng.monash.edu.au) is the Chair in Public Transport at the Institute of Transport Studies, Monash University, Australia where he undertakes research in transit planning and is developing postgraduate and industry programs in public transport education. He has over 26 years experience in transit planning and development. He was a planning officer at London Transport and also with the Midland Metro Light Rail project in the U.K. He has been a consultant transit planning specialist for the last 17 years and has worked on transit development projects in Europe, Asia and Australasia with Booz Allen Hamilton. Professor Currie is a member of Transportation Research Board committee AP050 on Bus Transit Systems and also committee AP075 on Light Rail Transit Systems. He is also a member of the UITP academic network. He holds a Masters Degree in Transport Planning and Management from Cranfield University U.K. and a Bachelors degree in Geography from Huddersfield University U.K. 


\title{
Bus Rapid Transit Plans in New York's Capital District
}

\author{
Stephen Falbel, Pilar Rodriguez, TranSystems Corporation \\ Herbert Levinson, Transportation Consultant \\ Kristina Younger, Capital District Transportation Authority \\ Sandy Misiewicz, Capital District Transportation Committee
}

\begin{abstract}
The Capital District Transportation Authority (CDTA) is seeking to implement Bus Rapid Transit service in the NY 5 corridor, which runs for 16.5 miles between Albany and Schenectady. The benefits of BRT will be to improve service for current riders, draw new riders to the system, help spur economic revitalization in the corridor, provide key nodes for new development, and improve the image of transit in the Capital District as a whole. When fully in place, the key features of BRT on NY 5 will include limited-stop service, substantial passenger facilities and amenities at each station, real-time passenger information, improved pedestrian environment, park-and-ride opportunities, priority treatment at intersections, queue jumpers at key points, offvehicle fare collection, and a specific brand image to distinguish BRT from other bus services. The cumulative impact of these types of improvements-in travel time, passenger comfort, passenger information, and image-will lead to an increase in transit ridership in the NY 5 corridor. Based on experience at other North American transit agencies that have implemented BRT, an increase of 22 percent to 29 percent is expected, depending on the ultimate travel time savings that is achieved.
\end{abstract}




\section{Background}

For over a century, New York State Route 5 (NY 5) has been one of the main travel corridors in the Capital District. Anchored by the two cities of Albany and Schenectady, the arrow-straight route running 16.5 miles from northwest to southeast has served bicyclists, pedestrians, horsecars, streetcars, automobiles, buses, and trucks.

In the post-war era, the character of NY 5 changed, reflecting shifts in employment, land use, transportation modes, and lifestyles. While still a critical transit corridor, with about 10,000 riders per day on CDTA's buses, most of the roadway is dominated by automobiles, whether in terms of traffic flow, pavement space, or automobile-related land use. Retail redevelopment has occurred in certain places in the corridor, such as at Colonie Center, but other segments of the corridor have lagged economically and are in need of revitalization.

The NY 5 Land Use and Transportation Study helped to develop a consensus vision for the corridor, called the "Preferred Future Scenario." This scenario combines significant investments to stimulate economic development, urban design recommendations to create a safe, attractive environment for all modes of transport, and the establishment of a Bus Rapid Transit (BRT) route in the corridor to tie the new development together with fast, convenient, and comfortable public transport.

During the last decade in the United States, BRT has gained interest as an effective way to improve conventional bus service to retain and attract ridership (Levinson et al. 2003). Often based on successful examples overseas, many U.S. cities have planned BRT solutions for their communities. The characteristics of urban areas in the U.S., however, are usually very different from the conditions found in the overseas cases; for example, lower densities, sprawl, and higher motorization rates (Rodriguez 2003). To some extent, NY 5 presents those characteristics typical of U.S. urban areas but it also has some special conditions that make it different and potentially more suitable for BRT. NY 5 connects two urban areas with relatively high population density and several important destinations are found along the corridor itself (see Figure 1 and Figure 2). As opposed to other corridors being studied for BRT, this corridor is multi-centric with most of its trip attractors within walking distance of the main roadway corridor. 
Bus Rapid Transit Plans in New York's Capital District

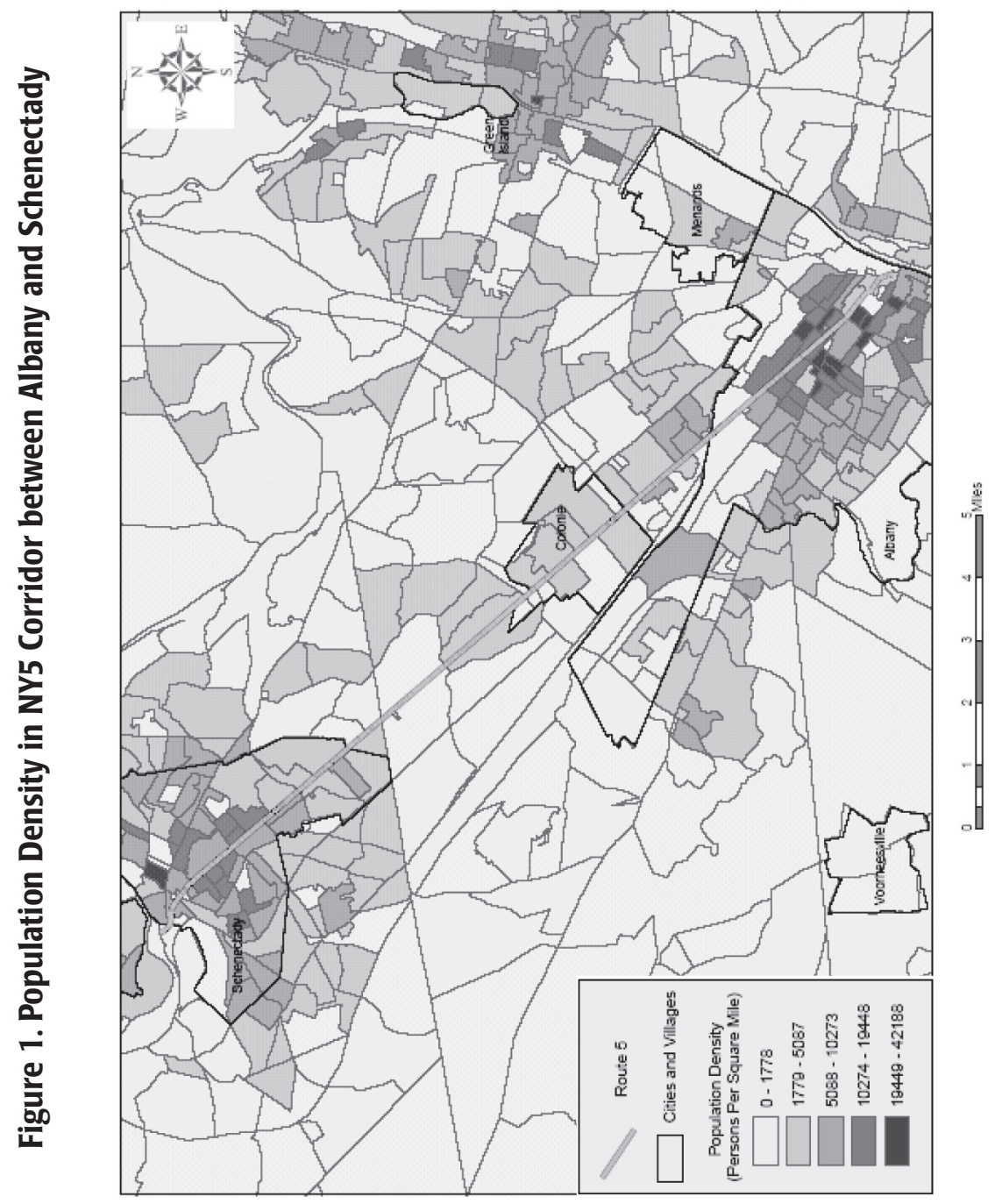

仓ั 


\section{Figure 2. Estimated 2000 Employment in NY5 Corridor between Albany and Schenectady}

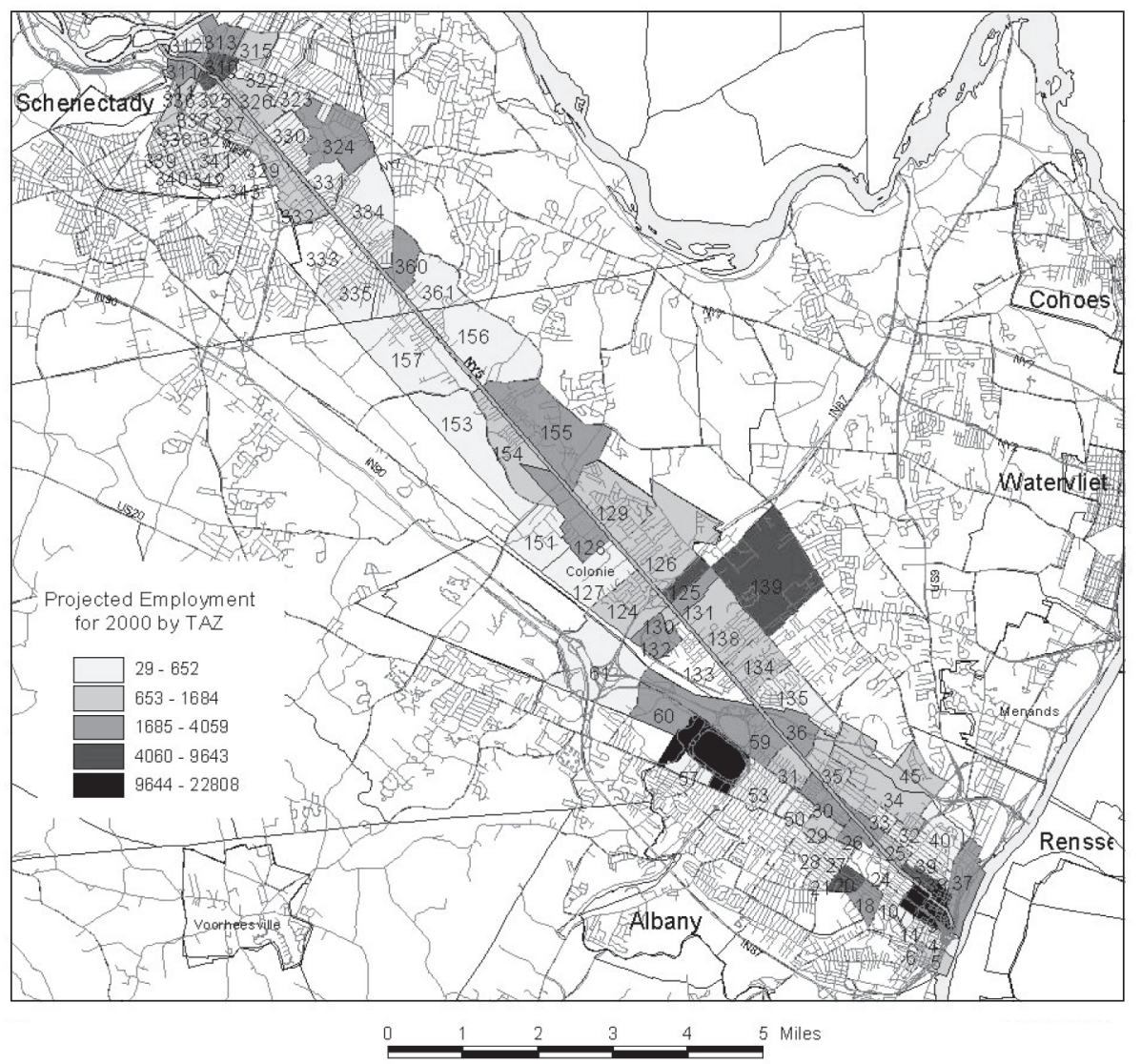

Source: CDTC

Currently, five routes run in the NY 5 corridor for a significant portion of their alignment, routes: 55, 1, 2, 55X, and 56X. Figure 3 shows a schematic of these routes. Routes 55 and 1 run at 15 -minute headways during peak periods. Route 2 runs at 20-minute headways during peak periods. There are two shuttle services that do not run on the corridor but provide complementary service to the riders of NY 5 bus routes. These shuttles do not have predetermined stops; they stop at the places requested by the passengers. 


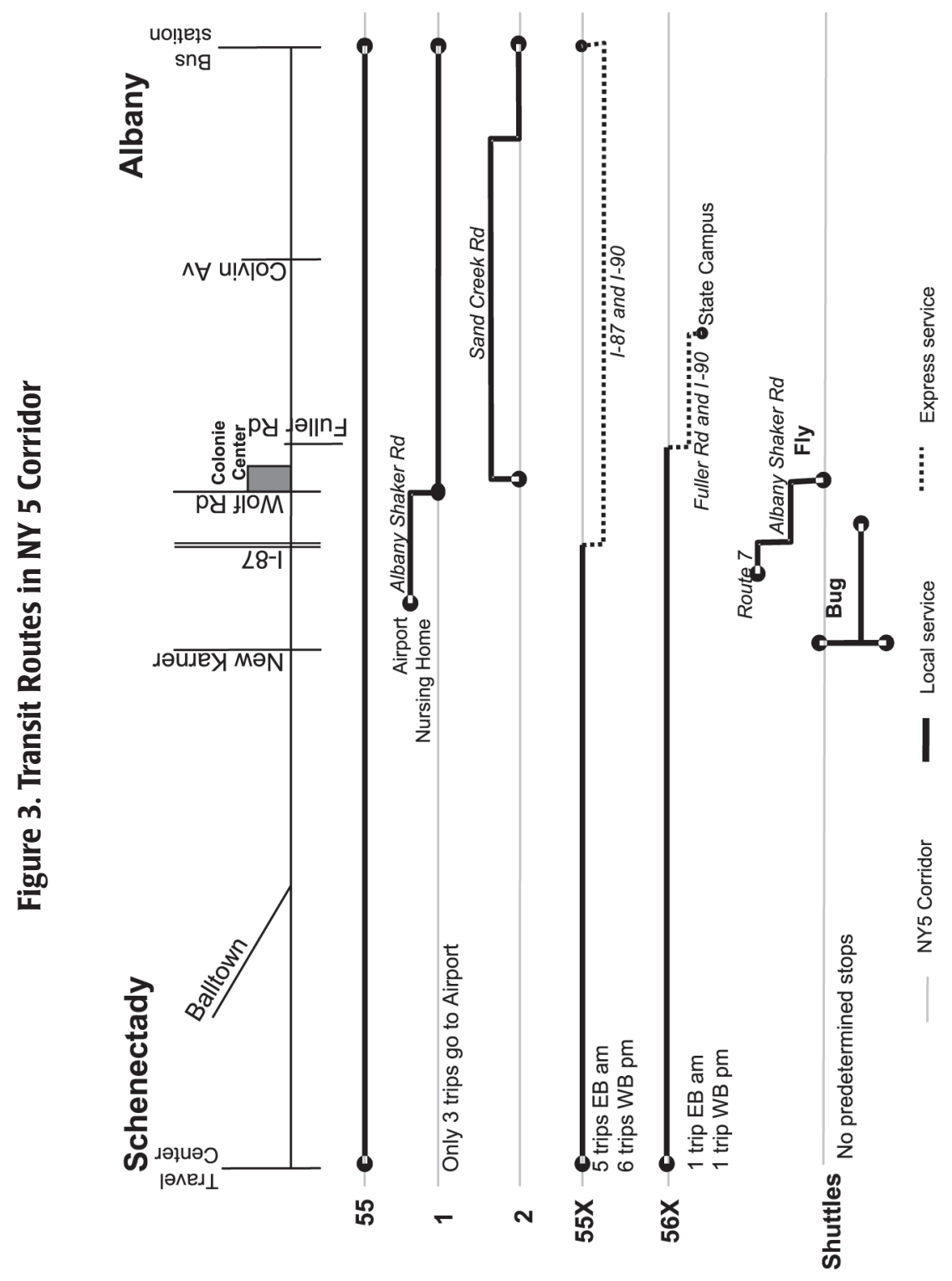


A boardings and alightings census along the NY5 transit routes was conducted. This census provided extensive data to understand the ridership behavior along the corridor and throughout the day. Table 1 shows the total weekday ridership by route. As observed, routes 55 and 1 carry almost 90 percent of the demand in the corridor.

\section{Table 1. Weekday Ridership in NY5 Transit Routes along NY5'}

\begin{tabular}{|c|r|r|r|}
\hline Route & \multicolumn{1}{|c|}{ Weekday } & \multicolumn{1}{l|}{ Saturday } & \multicolumn{1}{c|}{ Sunday } \\
\hline 55 & 5,860 & 4,220 & 2,870 \\
1 & 2,650 & 1,420 & 150 \\
2 & 1,120 & 270 & \\
$55 X$ & 290 & & \\
$56 X$ & 30 & & 3,020 \\
Total & 9,950 & 5,910 & \\
\hline
\end{tabular}

Due to differences in development densities, a ridership imbalance was observed between the eastern part of the corridor (Albany segment) and the western part of the corridor (Schenectady segment), with the former accounting for 70 percent of the total boardings. The most heavily used stops are in downtown Albany, at Lark Street and Pearl - Lodge Street, with 1,050 and 1,150 ons and offs per day in both directions, respectively. Based on the ridership census data, Figure 4 summarizes schematically the most important segments in NY 5 from a ridership standpoint.

\section{Figure 4. Higher demand segments in NY5}

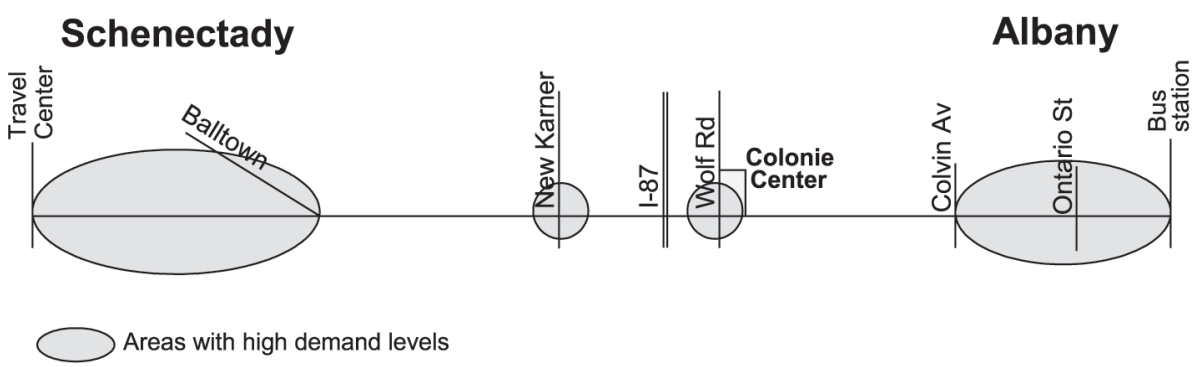


The temporal distribution of demand throughout the day was also considered. Figure 5 presents the hourly distribution of the demand for each of the NY5 bus routes. The afternoon peak for Route 55 occurs earlier (between 3:00 and 4:00 p.m.) than for the other routes (between 4:00 and 5:00 p.m.). The corridor shows a conventional temporal distribution of demand, with peaks in the $A M$ and PM periods. However, for Route 55 and Route 1, the PM peak is higher than the AM peak, which is unusual; generally, the AM peak is found to be the critical time period of the day. A more subtle but clear midday peak was also observed.

\section{Figure 5. Hourly Distribution of Demand on NY 5}

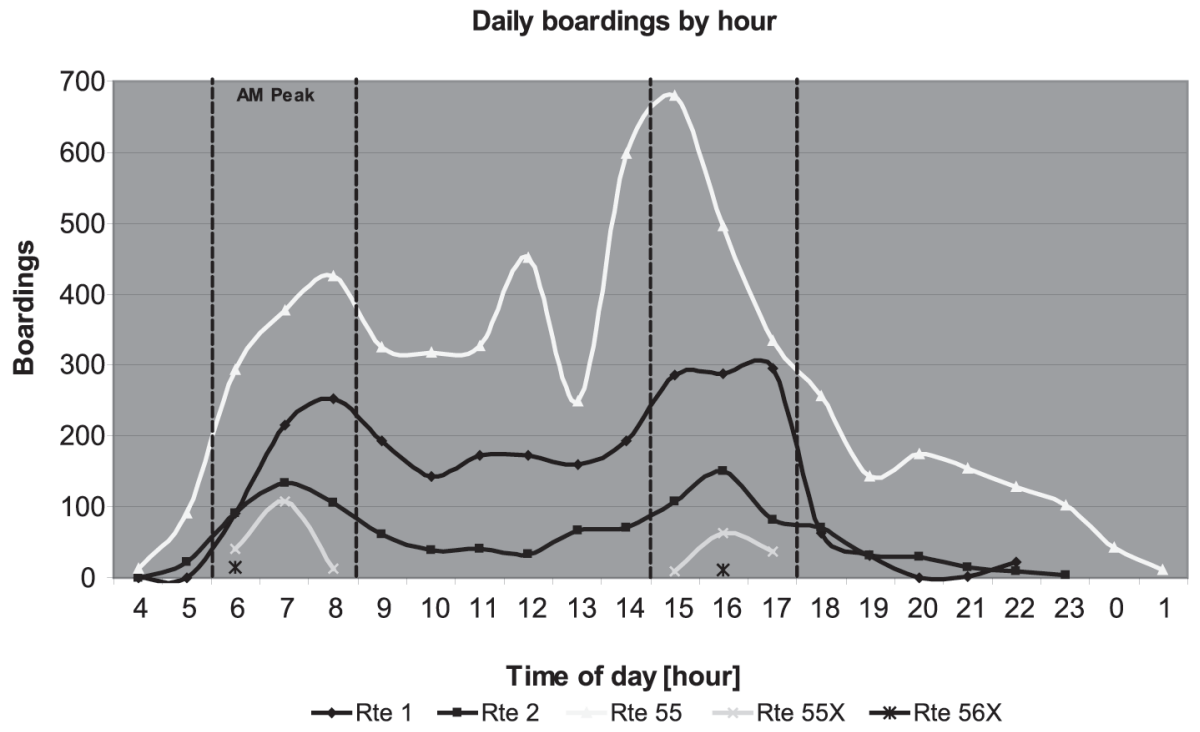

\section{Approach: Planning for BRT Service}

The approach taken to a conceptual plan for the BRT service on NY 5 had three main phases. The first phase consisted of developing a preferred service concept. This was a cooperative process between the consultant team, staff from CDTA and the Capital District Transportation Committee (CDTC), and the Study Advisory Committee (SAC) composed of representatives from municipalities, the State, and other interested parties. The second phase developed this preferred concept 
into a full operating and facilities plan. The third phase outlined an implementation plan for these operations and facilities. The following sections describe the approach taken during each of these phases of the planning process of the BRT system on NY 5 and the challenges and issues encountered.

\section{Developing a Service Concept}

There are three main conceptual service models for operating a BRT line. Figure 6 shows a schematic of these models. The Main Corridor model operates the BRT service on one main corridor with conventional connections and transfers to other routes in the transit network. This model is most appropriate when most or all of the area's development is located directly on the main corridor. Ridership is highest when the corridor is densely developed with mixed land use, creating opportunities for both origin and destination zones in the corridor.

\section{Figure 6. Conceptual Models for BRT Operations}

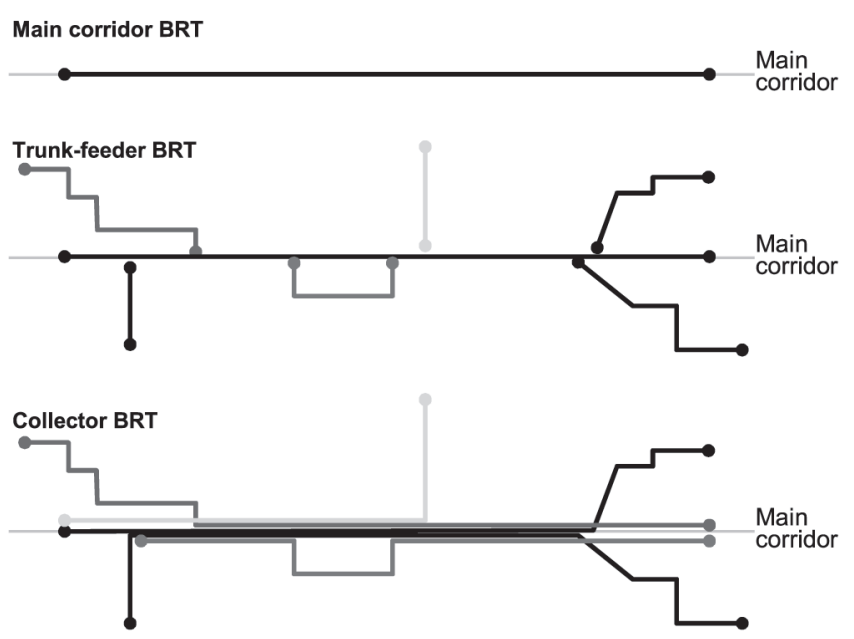

The Trunk-feeder model operates two types of routes - feeders and a trunk-forcing transfers among them. Trunk routes operate in the main corridor and feeders collect passengers in surrounding areas and transport them to transfer stations on the main corridor. The feeders are considered to be part of the BRT system itself, and are identified as such through vehicles, stations, schedules, maps, fares, etc. This model makes more sense than the collector BRT (see below) when the main corridor route itself operates at high frequencies, different types of vehicles may 
be appropriate for the feeder and trunk areas, and/or there are multiple important destinations along the main corridor.

In the Collector model, the same vehicles operate on both feeder and main corridors. The routes are designed to collect passengers in areas surrounding the main corridor and then enter the main corridor, usually, to make use of a transit priority treatment such as a busway. This model is more advantageous when lower densities are present, special priority treatments are provided in the main corridor or an exclusive busway is present, and/or there is one central main attractor area and lower density, sparse generator areas surrounding it.

Many NY 5-specific service alternatives were developed based on the conceptual models described above and on the understanding of the corridor's characteristics (i.e., current ridership, densities) mentioned in the background section. Although alternatives of the collector model were considered initially, they were discarded due to the characteristics of the NY 5 corridor: a multi-centric corridor with at least three primary destination areas-downtown Schenectady, downtown Albany, and Colonie Center-along the corridor. As mentioned earlier, the collector model is best suited to areas with a central business district that attracts riders from outer lower-density zones. NY 5 , however, has its two highest density areas at both ends of the corridor.

After evaluating many different service options, four alternatives were selected for detailed analysis. Of these resulting alternatives, the first two were based on the main corridor concept and the last two on the trunk-feeder concept. The four alternatives are presented schematically in Figure 7. These alternatives shared a common set of premises:

- The BRT service would run both directions all the time, and to the extent possible at higher frequencies than local parallel routes (Rodriguez, 2003).

- Regardless of the selected service alternative an effort should be made to develop a BRT "brand" including the vehicles, shelters, and, in general, all amenities of the system (Levinson et al. 2003; FTA 2000).

- The BRT service should operate on NY 5 all the way between Albany and Schenectady instead of using express highways because it increases the visibility of transit in the corridor creating incentives toward a better pedestrian environment and land use improvements while serving better the market along NY 5. (The running time difference between an express route on NY 5 and the highway system is not significant according to travel time runs. The expressways to downtown Albany are frequently congested.) 


\section{Figure 7. Alternative BRT Models for NY 5}

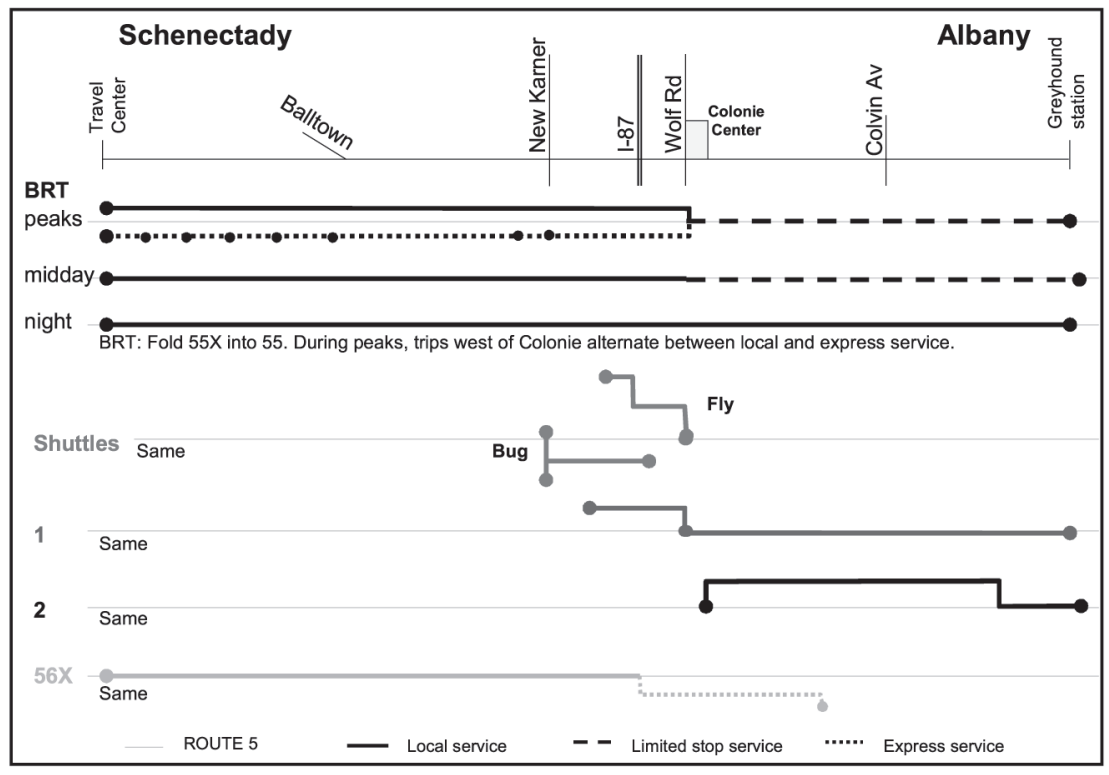

Alternative 1

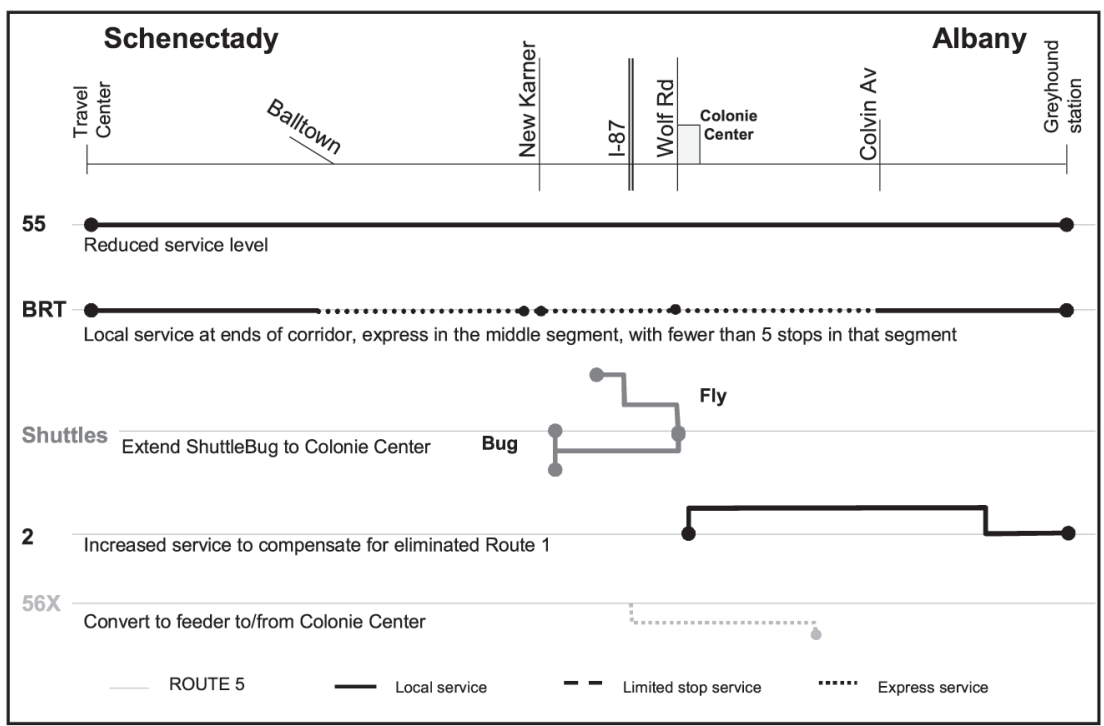

Alternative 2 
Figure 7. (cont.)

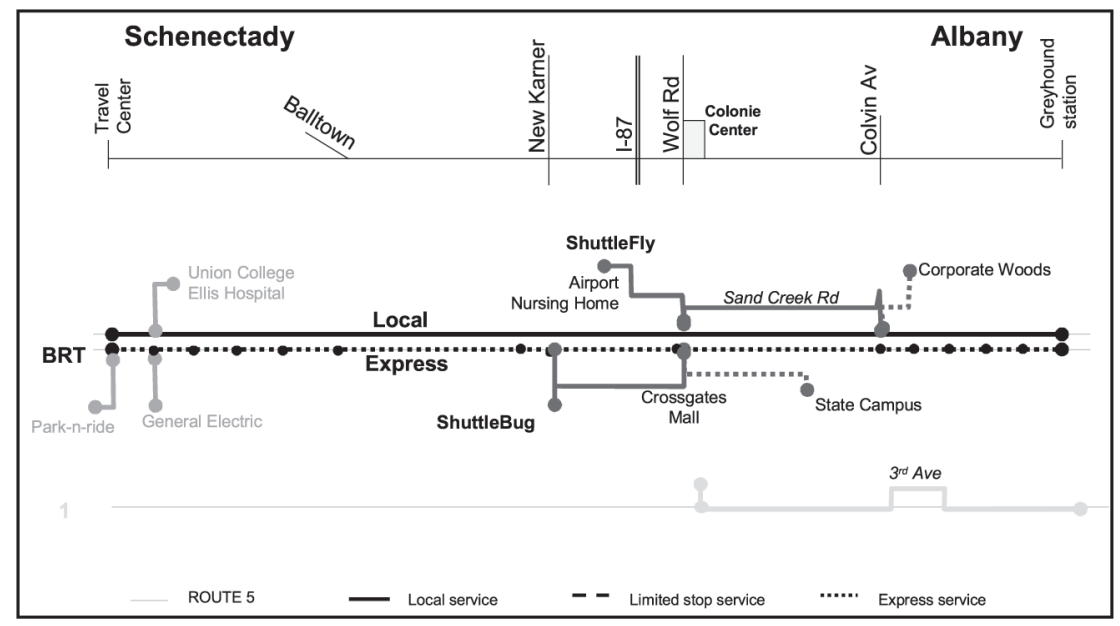

Alternative 3

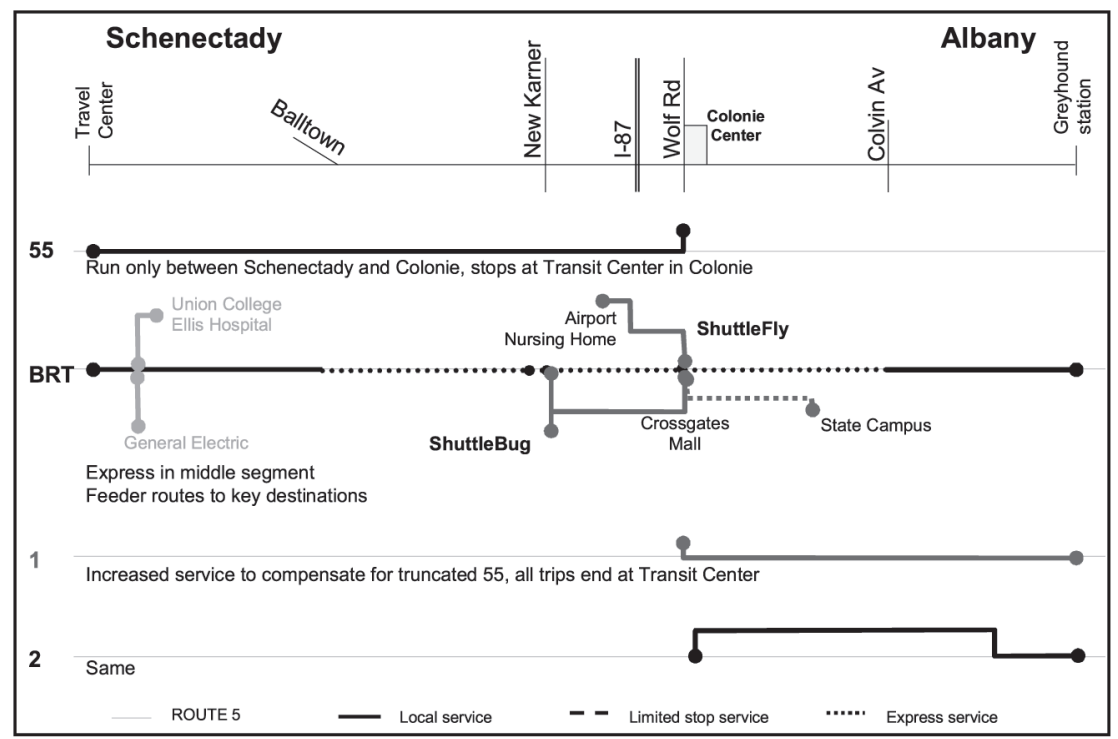

Alternative 4 
In Alternative 1, Route 55 and 55X are combined to become the BRT service. Most of the day, the BRT service operates limited stop between Albany and Colonie and local west of Colonie. During peaks, this latter portion alternates local and express service. At night, the entire corridor operates as local service. In Alternative 2, the BRT service runs locally in Schenectady and Albany and express in the middle segment. Alternative 3 introduces a super-limited express route that stops only at 20 locations in the corridor; distinctive infrastructure would be built at these locations. A parallel local route would serve the rest of the ridership in the corridor that does not use the 20 highest-volume stops. Alternative 4 is very similar to Alternative 2, but the local route 55 runs only between Schenectady and Colonie; thus, there is no local service that serves the entire corridor end to end.

The four alternatives presented above were evaluated using criteria that can be grouped into two categories: measures of effectiveness from the users' perspective and measures of effectiveness from the operator's standpoint.

The criteria used for the users' perspective are: on-board time, access (walking) time, waiting time, transfers, coverage, image/distinctiveness from current service, simplicity of representation, and service level between key origin and destination pairs.

The criteria used for the operator's perspective are level of operating expense (vehicle revenue hours), level of agency investment (e.g., ITS, vehicles), level of roadway investment, ease of implementation (physical, political, institutional), ridership, and net operating cost

Ultimately, Alternative 3 was selected as the preferred service concept due mostly to its simplicity and rail-like characteristics. The Study Advisory Committee liked the idea that the BRT service could be represented simply and clearly on a schematic map, showing a limited number of station stops. These stops would receive significant infrastructure treatments to raise the visibility of the service. The BRT express service in Alternative 3, with few stops along the route, also suited the ridership pattern observed with the ridership census data, which showed that demand is highly concentrated in Albany, Schenectady, and a few key points in the long middle segment. The limited-stop nature of the express service will result in a substantial decrease in travel time and thus make transit more competitive with private cars. Feeder routes serving the corridor at key transfer stations would be timed to meet BRT vehicles to enhance access to the corridor. This alternative involves the most change from current conditions and may be the most opera- 
tionally challenging for CDTA. However, it is the most easy-to-understand alternative for users and its impacts will be easily recognized by the community.

\section{Developing a Service and Facilities Plan}

To develop a service and facilities plan, three parallel efforts were performed: 1) station location and design, 2) operations design, and 3) roadway and physical improvements. Each of these efforts is described below.

\section{Station location and design}

This effort included locating the stations and stops of the BRT express and local services, determining the type of infrastructure and amenities at each location, and designing that infrastructure at a conceptual level.

The preliminary selection of the station locations for the BRT express service was based on ridership and stop spacing. An effort was made to select those locations with high numbers of boardings and alightings and at the same time, maintain reasonable spacing between stations (Levinson et al. 2003). A total of 20 locations were proposed. Figure 8 shows the approximate locations of the stations along the corridor.

These locations result in an approximate stop spacing of 0.4 miles in the downtown areas and 2.0 miles in the middle (suburban) segment. Most of the BRT stations were located at current high-volume stops. However, some locations with moderate ridership_such as Balltown Road-were recommended because too large a gap is undesirable in urban settings, and they have higher demand compared to their neighboring stops. Figure 9 shows the boardings and alightings in both directions and the location of the BRT express stations.

Of the 20 BRT express stations, 4 were identified to be key transfer stations. These locations will be designed to allow for minimal delay to the corridor services while providing convenient transfers to the feeder/distributor routes. The stations identified to be transfer points are Colvin, Colonie Center, New Karner, and downtown Schenectady.

At the locations where BRT express buses would stop, new stations would be constructed. These would be substantial shelters with significant passenger amenities recommended for BRT services (Levinson et al. 2003; Díaz et al. 2004). A standard set of amenities and an optional set of amenities were identified to be deployed at BRT express stations. The standard amenities are recommended at all BRT express 


\section{Figure 8. BRT Express Stations}

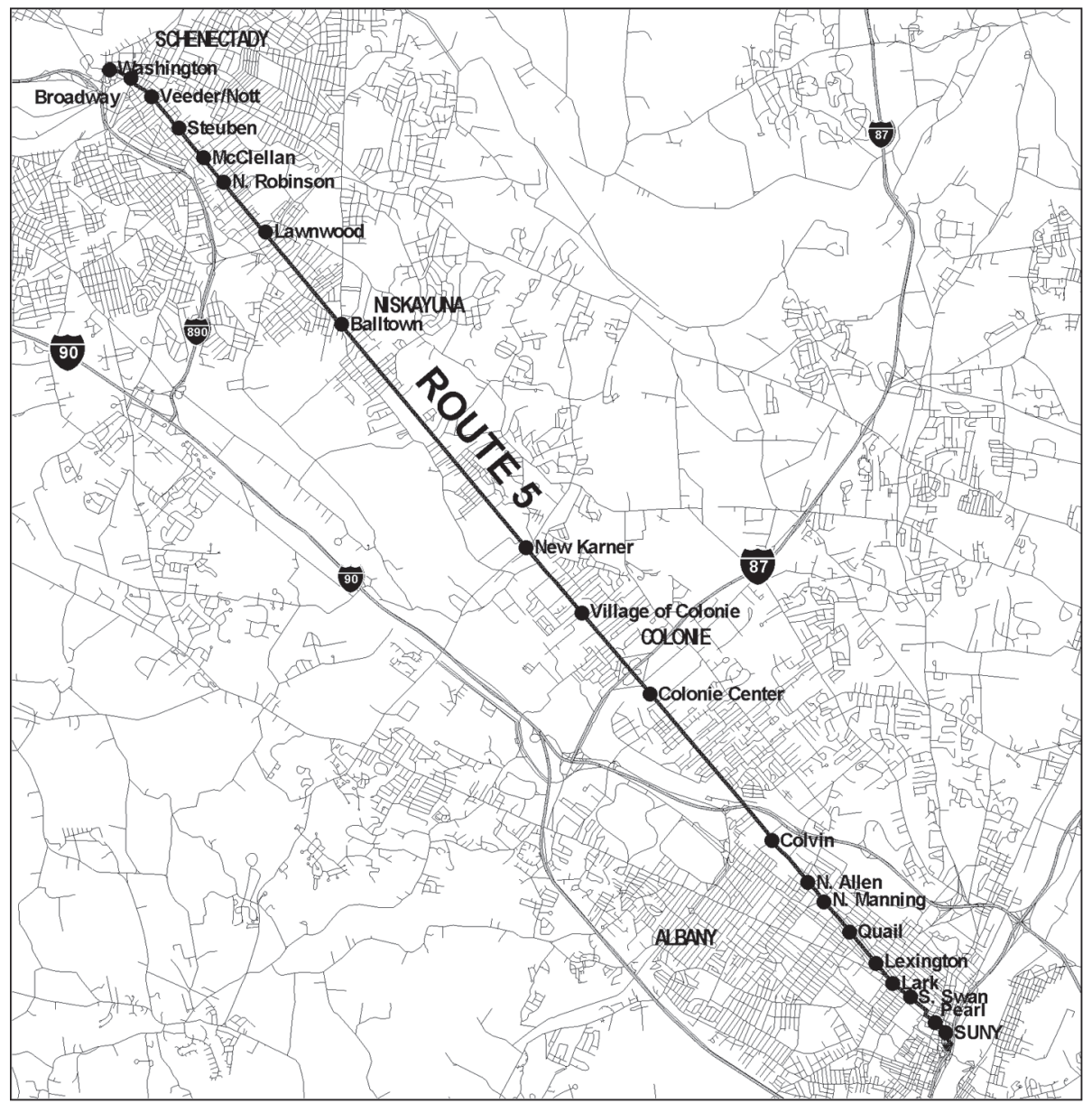

stations. Some amenities play a more important role at particular stations. For example, bike racks play a more important role at locations near low-density, single-family housing areas than in downtown stations. The standard amenities are shelter, station sign, renovated sidewalks, pedestrian lighting, benches, trash cans, newspaper dispenser boxes, customer information (static system information, real-time information, map of area), bike racks, bulletin boards, and emergency and public phones. 


\section{Figure 9. Boardings and Alightings on NY 5}
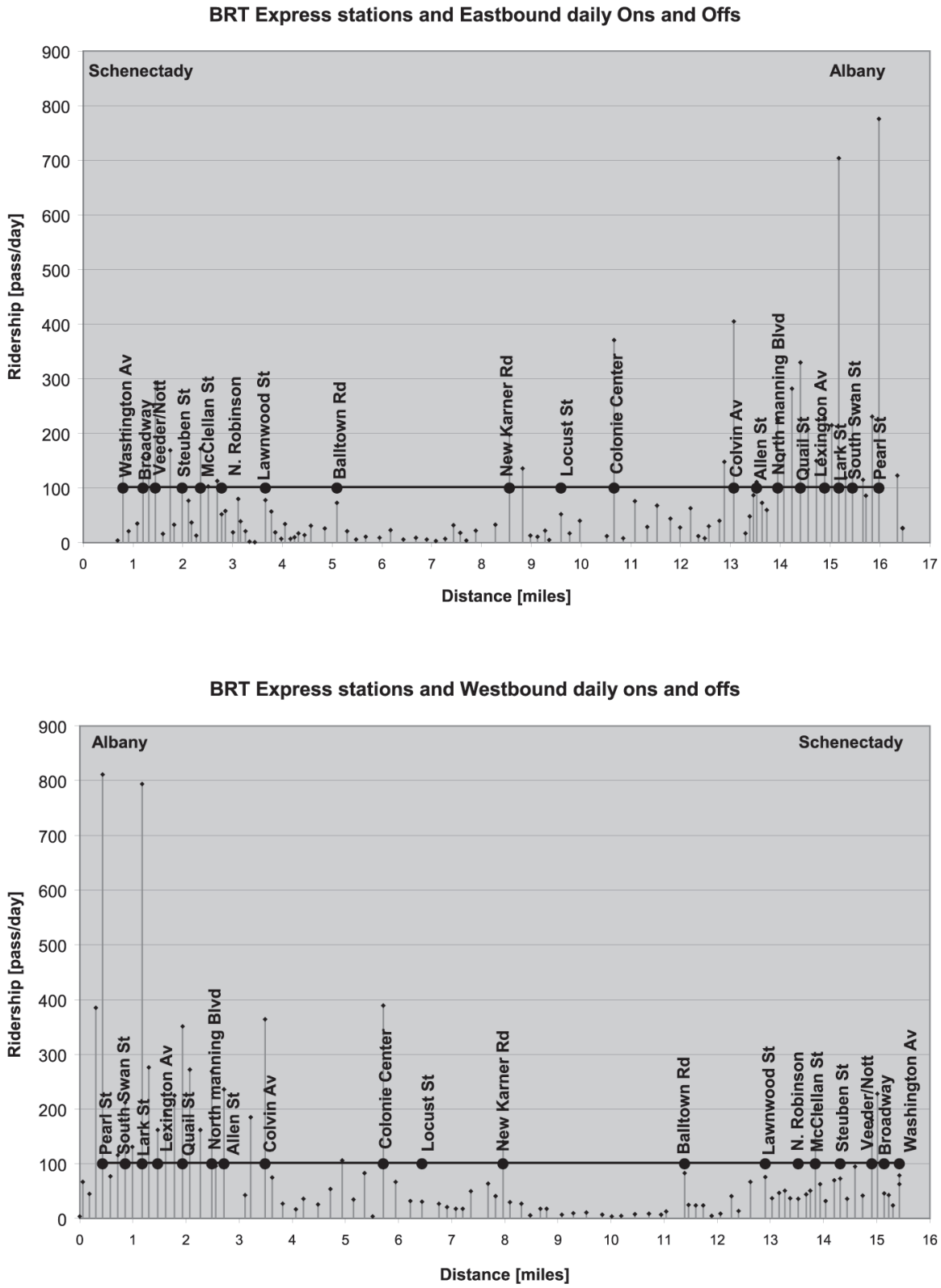
The optional amenities are recommended for deployment at certain stations according to their characteristics. For example, while vending machines and restrooms may be provided only at the higher volume transfer stations, security cameras may be deployed at stations located in areas with potential safety and security issues. The optional amenities are vending machines, security camera, closed circuit TV, and restrooms.

The shelter and all other amenities are proposed to be specifically designed for the BRT system aiming for consistency and a unique image. This may be provided by using similar materials, color scheme, and design style in all elements.

In addition, the specific location (e.g., far side, near side, mid-block) and curb design (e.g. bulb out, curbside, bus bay) of the stations also were addressed (Texas Transportation Institute et al. 1996). In general, far side stations were preferred and recommended at those locations where it was possible (Levinson et al. 2003). Bulb outs were recommended at some locations where sidewalk space is too narrow to provide sufficient space for the shelter. Two conditions were necessary to recommend a bulb out station: an existing curbside parking lane and at least two lanes available for through traffic to guarantee at least one open through lane (Fitzpatrick et al. 2001; Fitzpatrick et al. 2002).

The stop locations for the parallel local service were determined to be at most current Route 55 stops. Some consolidation of stops was recommended for the existing 99 eastbound and 91 westbound stops between Washington Avenue in Schenectady and the Greyhound Bus Station in Albany. The elimination of stops was based on three criteria:

- Stop spacing: stops with current stop spacing of less than $1 / 8$ mile

- Volume: those stops with current average movements per trip below 1.2 were considered for elimination. Movements per trip are total boardings and alightings divided by the total number of trips serving each stop during a period of time. Research has shown that stop elimination is most beneficial when the number of movements (ons + offs) per trip at a stop is about 1 . When movements per trip are much greater than one, too many people would be affected by the elimination of the stop. When movements per trip are much lower than one, the stop is hardly used and its elimination would not impact travel time significantly. ${ }^{2}$ However, if other circumstances are present (i.e., stops are too close, no corresponding stop in the opposite direction), low ridership stops are worth considering for elimination. 
- Alignment between eastbound and westbound stops: those stops without a corresponding stop in the other direction are considered for elimination. In general, it is recommended to provide corresponding stops in both directions. For many parts of NY 5 , this is a challenge due to the numerous one-side intersecting streets.

As a result of this consolidation effort, the local service would stop at 88 eastbound locations and 89 westbound locations, almost all of them with corresponding stops in both directions. Some of these stops already have shelters; new investment at the local stops would be limited to signage and a basic set of amenities.

The feeder routes would operate similar to the existing shuttles, without predetermined stop locations. The driver stops at any place along the route where a passenger requests it. However, it may be desirable to deploy BRT feeder signs at key destination sites to raise the visibility of the system and to show that the feeder connects to the BRT express route. Some potential users may be unaware of the shuttle services because they do not see a sign on the street referring to this service.

\section{Operations}

The operations design effort determined the routing, headway, span of service, ridership, and fleet requirements of the service. The routing of the parallel local service would be the same as the current Route 55 . The routing of the BRT express service was straightforward on NY 5 from the Travel Center in Schenectady to downtown Albany, but at the eastern end of the corridor, several routing options were explored. Ultimately, it was decided to use the Route 55 alignment for the BRT express as well, for the sake of travel time, layover, and market penetration.

A premise for determining the span of service and headways was to maintain or improve the existing service levels in the corridor for as many passengers as possible. The BRT express service is expected to operate approximately 15 hours between 6:00 a.m. and 9:00 p.m., whereas the BRT local service is recommended to operate similar to existing route 55 between 5:00 a.m. and midnight, with a few trips potentially running earlier than 5:00 a.m. and past midnight. The BRT will operate at 12-minute headways during peak periods, 20-minute headways during the midday, and 30-minute headways during the evening. The local service will operate every 15 minutes in peaks, every 20 minutes in midday, and every 30 minutes at night. In addition, on the eastern half of the corridor, a modified version of the existing Route 1 will continue to operate to accommodate the heavier 
demand east of Colonie Center. This route will operate with a 15-minute headway during peak periods and a 20-minute headway at other times. The Route 1 service will be coordinated with the corridor-length local service.

The vehicles required to operate the BRT express, parallel local route, and Route 1 services are full length (40-foot) buses, and the vehicles recommended for the shuttles are minibuses of no more than 30 feet in length and with a capacity of at most 40 passengers including standees. At some point in the future, articulated buses may be desirable for the BRT express.

\section{Ridership Forecast}

The approach to estimate the future ridership of the proposed routes in the corridor was based on seven steps. First, the current ridership was determined from the boardings counts obtained through the census data. Current ridership in the corridor was about 10,000 boardings per day.

Second, the trip origins and destinations were estimated by creating synthetic O/D matrices for each route based on the load profiles resulting from the ridership census data (Van Zuylen and Willumsen 1980; Willumsen 1994). The matrices were produced with a Visual Basic program written specifically for this purpose. The process is a repetitive loop that allocates each passenger to O-D pairs proportionally to the boardings and alightings for that particular station and considering that at any time, the passenger that has been on the bus the longest (i.e., boarded at the earliest station) is more likely to be allocated to the next alighting stop than any other passenger on the bus. Other restrictions were in place to ensure that the total number of boardings/alightings assigned to station $i$ equals the boardings/alightings figure for station $i$ in the load profile.

Third, the current trips that are likely to shift to the BRT express service were estimated. It was assumed that if both the current origin and destination stops of a certain trip are within walking distance of BRT express stations, the probability of using the BRT express is between 0 and 1 and follows a parabolic function. ${ }^{3}$ Walking distance was assumed to be 0.25 miles downstream and 0.15 miles upstream, accounting for the fact that passengers are more likely to walk longer if they are walking in the direction of travel. ${ }^{4}$ Since one current stop or point along the corridor could fall within the catchment area of two BRT stations, the final probability $P_{j}$ for each current stop or point $j$ along the corridor is the maximum of all probabilities to the different BRT stations: $P_{j}=\operatorname{Max}\left(P_{i j} \forall{ }_{i}\right)$. The situation is similar for the other end of the trip (destination). Thus finally, the probability that a trip cur- 
rently made between O-D pair $m$ and $n$ will be made on the BRT was expressed as $\mathrm{P}(m, n)=\mathrm{P}_{m}{ }^{*} \mathrm{P}_{n}$. To obtain the number of trips that are likely to use the new BRT service, the probability for every O-D pair was multiplied by the total number of trips currently made for that O-D pair. This process estimated that during weekdays 3,750 passengers that currently ride on the NY 5 routes are expected to use the BRT express service, which accounts for 38 percent of current ridership.

Fourth, the ridership change (increase or decrease) due to headway changes was estimated by calculating the combined headway differences of the current conditions and the proposed operations for each O-D pair. Industry-standard elasticities were used to determine the ridership impact due to headway changes. A mid-point arc elasticity formula was used in which the elasticities vary depending on the original headway (Barton-Aschman Associates 1981). As a result, the net expected impact on ridership due to headway changes is an increase of 781 passengers (approximately 8\%) during weekdays.

Fifth, the ridership change (increase or decrease) due to travel time changes was calculated similarly to the previous step. Current and future travel time for each O-D pair was calculated. The future travel time included the time savings that would be achieved through signal priority and queue jumpers. A transfer penalty was included for those trips that were forced to transfer between routes. Then, industry-standard elasticies were used to determine the ridership impact; a midpoint arc elasticity formula with an elasticity of -0.35 was used (Ecosometrics, 1980). Overall, a weekday ridership increase of 360 to 622 passengers is expected, which translates into an added weekday ridership increase of 3.6 to 6.4 percent, depending on the degree of travel time savings that can be obtained from signal priority treatments in the corridor.

Sixth, the ridership change (increase or decrease) due to other improvements (i.e., image, branding, and amenities) was estimated. Other systems were studied to determine a range of ridership boost that may be expected due to service enhancements other than frequency and travel time. The systems studied were the Silver Line in Boston, the MetroRapid system in Los Angeles, and the Vancouver B-Line. Using the elasticies mentioned above and the before and after ridership, service levels, and travel time, the expected ridership increase due to headway and travel time improvements was identified. Any remaining ridership gained in those systems was allocated to "other" enhancements, which usually include amenities, image, system identity, and branding. Table 2 shows the total weekday ridership increase obtained from different sources and the breakdown of 
the share due to headway, travel time, and other improvements. As observed, the ridership increase due to "other" changes, which could be attributed to branding, image, and amenities enhancements, ranges between 10 percent and 21 percent of original ridership. For the NY 5 corridor, a range between 10 percent and 15 percent was assumed. In the immediate term, before all amenities are implemented for the full corridor, a smaller ridership impact, on the order of 5 percent, would be expected.

Table 2. Case Studies in Ridership Change

\begin{tabular}{|l|c|c|c|c|}
\hline & \multicolumn{2}{|c|}{ LA MetroRapid } & Vancouver & Boston \\
\hline & $\begin{array}{c}\text { Vilshire / } \\
\text { Ventura } \\
\text { Blvd }\end{array}$ & $\begin{array}{c}\text { Whittier } \\
\text { Blvd }\end{array}$ & B-Line \#98 & Silver Line \\
\hline Weekday ridership increase riders & $2,850^{\mathrm{a}}$ & $20,660^{\mathrm{a}}$ & $4,000^{\mathrm{b}}$ & $2,290^{\mathrm{c}}$ \\
\hline Weekday ridership increase \% & $26 \%$ & $33 \%$ & $29 \%$ & $30 \%$ \\
\hline Ridership increase due to headway changes & $6 \%$ & $8 \%$ & $9 \%$ & $7 \%$ \\
\hline Ridership increase due to travel time changes & $10 \%$ & $12 \%$ & $6 \%$ & $2 \%$ \\
\hline Ridership increase due to other changes & $10 \%$ & $13 \%$ & $14 \%$ & $21 \%$ \\
\hline
\end{tabular}

a TCRP Report 90 Case studies in Bus Rapid Transit

${ }^{\text {b }}$ APTA Intermodal Operations Planning Workshop August 9 - 11, 2004 - Translink Welcoming Session

${ }^{c}$ MBTA counts

Finally, the total estimated ridership for the new system was calculated by adding up the different ridership changes discussed above to the current ridership, as shown in Table 3.

Table 3. Estimated Ridership on NY 5 with Proposed Service

\begin{tabular}{|c|c|c|c|c|c|}
\hline & \multicolumn{2}{|c|}{ Weekday } & \multicolumn{2}{|c|}{ Saturday } & \multirow[t]{2}{*}{ Sunday } \\
\hline & Lower & Higher & Lower & Higher & \\
\hline Current ridership & \multirow{2}{*}{\multicolumn{2}{|c|}{9,950}} & \multicolumn{2}{|c|}{5,910} & 3,020 \\
\hline Ridership increase due to headway & & & \multicolumn{2}{|c|}{417} & 0 \\
\hline Ridership increase due to travel time & 360 & 620 & 240 & 399 & 0 \\
\hline Ridership increase due to other improvements & 1000 & 1490 & 590 & 890 & 0 \\
\hline Total & 12,090 & 12,840 & 7,157 & 7,616 & $\mathbf{3 , 0 2 0}$ \\
\hline Total Increase \% & $22 \%$ & $29 \%$ & $21 \%$ & $29 \%$ & $0 \%$ \\
\hline
\end{tabular}




\section{Roadway Improvements}

Prior to the initiation of the BRT Conceptual Design Study, agencies in the Capital District had already made significant progress in moving toward the installation of a transit signal priority system in the NY 5 corridor. The purpose of the present study was to complement that effort with other roadway and transit priority treatments to help give buses in the corridor a competitive advantage over the rest of the traffic stream. This study considered a wide range of possible treatments, including bus-only lanes, HOV lanes, queue jumpers, and bulb-outs. Three specific improvements were identified for thorough analysis. These are a queue jumper at New Karner Road, a queue jumper at Wolf Road, and an exclusive bus lane in downtown Albany. An expanded transit signal priority program was also examined.

NY 5 at New Karner Road is a very busy intersection, with significant movements from westbound NY 5 to southbound New Karner. The proposed queue jumper at this location would allow westbound buses to bypass some of the congestion that forms at this location through a new lane. This new lane would serve both as a queue jumper and a right-turn-only lane for general traffic. The signal at the intersection would give westbound buses an advance green of some six seconds so that the buses could clear the intersection before the rest of the traffic begins to move.

Wolf Road is the busiest cross street in the NY 5 corridor. Exit 2 from 1-87 feeds directly into this intersection, and Colonie Center mall is located here. Commercial development along Wolf Road is extensive, even beyond Colonie Center. Westbound NY 5 currently has a right-turn-only lane at the Wolf Road intersection. In the westbound direction, it would be desirable to construct an additional lane so that a right-turn lane could be preserved, while the second lane from the curb would be reserved as the bus queue jumper lane. Signage and signal timing would be the key factors in successfully implementing a queue jumper at this location.

An exclusive bus lane in downtown Albany is one of the most controversial elements of this study and represents the greatest challenge among the roadway improvements. NY 5 is very congested in this part of the corridor, and it is relatively narrow here as well. Nevertheless, the very high volume of CDTA buses that funnel into this part of the corridor, particularly during peak periods, means that a de facto bus lane already exists, to some extent. Formalizing this bus lane may be feasible only if it is done in such a way as to minimize the loss of scarce park- 
ing spaces and the negative impacts on other traffic. This concept will be studied further in future stages of the project.

A project to install transit signal priority (TSP) at 35 intersections in the NY 5 corridor was underway when the Conceptual Design Study began. The study considered the benefits of expanding this program to all of the intersections in the corridor. Both conditional and unconditional priority were analyzed. Ultimately, the study recommended that full unconditional priority be pursued for the entire corridor.

Taken together, the operational changes (limited stop service) and the roadway improvements could result in a travel time savings of up to 17 minutes. Current one-way travel time for Route 55 ranges up to 68 minutes, so this savings represents a possible 25 percent improvement. This figure is in line with the experience of other North American BRT applications.

\section{Developing a Phasing Plan}

The final step in the Conceptual Design Study was to develop a phasing plan. The first phase was to be designed to create "critical mass" for the BRT, so that enough BRT elements would be in place to result in a noticeably different and improved service.

Because the BRT concept represents a flexible package of features that have been applied in various combinations in North America and around the world, the first step in developing the phasing plan was to define what will constitute BRT in the NY 5 corridor. The essential elements of BRT were determined to be the following, in descending order of importance:

- clearly identifiable stations with a rich set of amenities

- brand image applied to vehicles and signage

- new vehicles

- transit signal priority

- at least one queue jumper

- park-and-ride spaces 
Implementation of these six elements will allow the limited-stop BRT express service to operate efficiently with a significant travel time advantage over the local service and without the customer confusion and complaints that arose with past efforts at limited-stop service in the corridor. The following paragraphs provide more detail on the contents of the three implementation phases.

\section{Phase I (1 to 3 years)}

Phase I will include construction of the 20 BRT stations, though not all amenities at all stations would be included initially. A new BRT brand name and image will be created during this phase; this brand will be included on all BRT facilities and the new vehicles when the service first operates. The transit signal priority program currently underway in the NY 5 corridor will be expanded as quickly as possible to help reduce BRT travel times. Similarly, it is recommended to proceed with the queue jumper at Wolf Road to achieve travel time savings and a high degree of visibility of the new service. Up to 250 park-and-ride spaces should be provided to help improve access to the new service. Most of these would be provided through lease agreements with abutting landowners rather than through land purchase and new construction.

This implementation phase is already underway. CDTA has begun the process of procuring new vehicles and is seizing opportunities for station development as they arise. A focus of early efforts is the Colonie Center station, which in many ways will function as the central point in the system.

\section{Phase II (4 to 6 years)}

Phase II will include the completion of the 20 BRT stations, filling out the set of amenities described above. Assuming that the Wolf Road queue jumper is successfully implemented in Phase I, a second queue jumper at New Karner Road in the westbound direction will be implemented in Phase II. Additional park-and-ride spaces will be provided, likely through a combination of lease agreements and new construction.

\section{Phase III (7 to 10 years)}

The final phase of BRT implementation in the NY 5 corridor includes three elements: new vehicles for the feeder routes, additional park-and-ride spaces, and off-vehicle fare collection. 


\section{Implementation and Financing}

CDTA is in the process of pursuing funding for various portions of the project. Phase I is fully funded with a combination of earmarked funds, CMAQ funds designated by the MPO through the TIP process, and state and local match. Future phase funding will be subject to the success of Phase I as demonstrated by increases in ridership. With respect to station development, CDTA is taking an incremental approach, working with developers and municipalities as opportunities arise. The owners of Colonie Center and Northway Mall (across NY 5 from Colonie Center) are currently in the process of seeking permits for mall expansion; CDTA is working actively with them and the Town and Village of Colonie to secure right-of-way and accommodations for the keystone station in the system on NY 5 between these two malls.

\section{Conclusions}

Bus Rapid Transit is more than a new service concept, and it is more than the construction of facilities and the application of new technologies. It is all of that plus the development of a new transit "product" or mode. During the evaluation and selection process for the preferred service concept, a key factor turned out to be how this new service could be presented to the riding public. How would it be represented on maps and schematic diagrams? The Study Advisory Committee, project staff, and the consultant team all came to the conclusion that a limitedstop service with clearly-defined and substantial stations moved the corridor into the realm of a rail-like solution, without the high cost of rail.

The cumulative impact of the types of improvements associated with BRT (Levinson et al. 2003; Díaz et al. 2004) — travel time, passenger comfort, passenger information, and image - will lead to an increase in transit ridership in the NY 5 corridor. Based on experience at other North American transit agencies that have implemented BRT, an increase of 22 percent to 29 percent is expected, depending on the ultimate travel time savings that is achieved. These percentages translate into at least 2,000 new transit trips in the corridor each weekday, a substantial increase that will help reduce traffic congestion and improve the environment.

The implementation of Bus Rapid Transit in the NY 5 corridor will be the result of drawing together many types of transportation improvements to create a package of features that will be attractive to current and potential riders. These improvements will transform what is now a regular local bus route into a high- 
performance, premium service that will expand CDTA's market reach farther into the range of choice riders. The lessons that will be learned in this corridor can then be applied to other major ridership corridors in the Capital District, as well as in other metropolitan areas in North America.

\section{Endnotes}

${ }^{1}$ Ridership shown represents only those trips that boarded along the NY5 corridor; total ridership for Route 2 is higher.

${ }^{2}$ Correspondence with Peter Furth, Department Chair and Professor Civil and Environmental Engineering Northeastern University, on May 4, 2004.

${ }^{3}$ The probability function was also tested as a line, which means the probability is directly proportional to the distance between the current stop and the future BRT station. At the end, the results obtained from a parabolic function seemed more realistic based on the consultant's experience.

${ }^{4}$ Maximum walking distance is usually considered between 0.25 and 0.5 miles Rodriguez 2003, but in this case users may have already walked some distance before reaching the corridor (i.e., they have walked perpendicular to NY 5). Thus, it was considered realistic to assume that users would only be willing to walk an additional 0.25 or 0.15 miles along NY 5 .

\section{References}

Barton-Aschman Associates. 1981. Traveler response to transportation system changes.

Diaz, R., M. Chang, G. Darido. Characteristics of Bus Rapid Transit for decisionmaking. Federal Transit Administration, Washington, D.C.

Ecosometrics, Inc. 1980. Patronage impacts of changes in transit fares and services. September.

Fitzpatrick, K., K. Hall, S. Farnsworth, and M. Finley. TCRP Report 65: Evaluation of bus bulbs. Transportation Research Board. Washington D.C.

Fitzpatrick, K., K. Hall, S. Farnsworth, and M. Finley. 2000. Alternative bus stop configuration: an analysis of the effects of bus bulbs. Journal of Public Transportation, Volume 5, No. 1. Center for Urban Transportation Research. 
Federal Transit Administration (FTA). 2000 BRT Reference Guide. (http://brt. volpe.dot.gov/guide/index.html)

Goodman, J. and M. Laube. 1999. Issues in Bus Rapid Transit. Federal Transit Administration.

Levinson, H., S. Zimmerman, J. Clinger, TCRP Report 90 - Bus Rapid Transit Volume 2: Implementation Guidelines. Transportation Research Board, Washington, D.C.

Rodriguez, M. 2003. Moving from conventional bus service towards Bus Rapid Transit: Establishing priorities. Master's Thesis, Massachusetts Institute of Technology, Cambridge, MA.

Texas Transportation Institute, Texas A\&M Research Foundation, Texas A\&M University. TCRP Report 19: Guidelines for the location and Design of Bus Stops. Transportation Research Board. Washington D.C.

Van Zuylen, H. and L. Willumsen. 1980. The most likely trip matrix estimated from traffic counts. Transportation Research - B. Vol 14B.

Willumsen, L. Estimation of trip matrices from volume counts. Published in Ortuzar, J. de D., L. Willumsen. 1994. Modelling Transport. John Wiley \& Sons. Canada.

\section{About the Authors}

StePhen FALBel (smfalbel@transystems.com) was the Project Manager for the NY 5 BRT Conceptual Design Study. He has over 17 years of experience in transportation planning, focusing on transit service planning. He has been with TranSystems (formerly Multisystems) for six years, having previously been Manager of Transit Service Planning for the Central Transportation Planning Staff of the Boston Metropolitan Planning Organization. He has a Master of Public Policy degree from Harvard's JFK School of Government.

PILAR RodRIgUez (prodriquez@transystems.com) was the principal analyst for the NY 5 BRT Conceptual Design Study. With over six years of transit planning experience, she has been with TranSystems (formerly Multisystems) for nearly four years. Prior to attending graduate school at MIT, she was Director of Infrastructure for the Transmilenio BRT project in Bogotá, Colombia. 
HeRbert LeVinson (hslevinson@aol.com) is one of the nation's preeminent experts on Bus Rapid Transit and has had a long and illustrious career in transportation planning and engineering. Recent BRT-related projects include two reports for the Transit Cooperative Research Program on the costs and impacts of BRT and a large BRT study for New York City. He is currently an independent consultant based on Connecticut.

KRISTINA YoungeR (Kristina@cdta.org) is the Director of Strategic Planning for CDTA and is responsible for the planning and implementation of the NY 5 BRT project. She has been at CDTA for eight years and previously worked for six years at the Capital District Transportation Committee, the metropolitan planning organization for the Albany-Schenectady area. Prior to that, she was located in the San Francisco Bay area working at the Metropolitan Transportation Commission in Oakland and obtaining an MCRP degree from the University of California at Berkeley.

SANDY MISIEWICZ, AICP (smisiewicz@cdtcmpo.org) is a Senior Transportation Planner who helped manage the NY 5 BRT Conceptual Design Study for the Capital District Transportation Committee. She has been with CDTC since 1998 and holds a master's degree in Urban and Regional Planning from the University at Albany, State University of New York. She has been a certified planner for two years and serves as the Director of the Capital District section of the New York Upstate Chapter of the American Planning Association. 
Journal of Public Transportation, 2006 BRT Special Edition 


\title{
Analyzing the Impacts of Vehicle Assist and Automation Systems on BRT
}

\author{
Matthew Hardy, Susannah Proper \\ Mitretek Systems
}

\begin{abstract}
This paper summarizes research that was conducted to develop an analysis framework with which to analyze the cost effectiveness of implementing Vehicle Assist and Automation (VAA) applications, a category of Intelligent Transportation System technologies, in Bus Rapid Transit (BRT) systems. Seven typical BRT operating scenarios were developed based upon the Federal Transit Administration's Characteristics of Bus Rapid Transit for Decision-Making report. The seven scenarios are representative of BRT service throughout the U.S. and are used to demonstrate which VAA applications will be cost effective within the context of real-world operating environments. The analysis examined overall benefits in terms of increased operating speed and reduced travel time compared to the cost of deploying VAA. Based upon the analysis framework, most of the operating scenarios show positive benefits over the life of the technology. The analysis also showed that deploying applications together (e.g., precision docking plus vehicle guidance) provided greater benefits since both applications use the same vehicle-based equipment. National impacts of implementing VAA applications were also analyzed based upon 75 BRT systems throughout the United States.
\end{abstract}




\section{Introduction}

In 2004, the U.S. Department of Transportation initiated a project examining the cost effectiveness of deploying Vehicle Assist and Automation (VAA) applications, a category of Intelligent Transportation System technologies (ITS), for Bus Rapid Transit (BRT) systems. This paper reports on the short-term financial and operational benefits identified as part of that larger analysis for two VAA applications, precision docking and vehicle guidance, applied to the following seven revenue service operating scenarios. These scenarios are defined in greater detail in the Characteristics of Bus Rapid Transit for Decision-Makers (CBRT) report (FTA, 2004).

- Suburban Collector-Buses operating in medium-density environment, often utilizing a line-haul right-of-way (ROW) with service to more dense urban areas.

- Urban Circulator-Buses operating in limited public use areas such as airports, shopping malls, downtown areas, or gated communities.

- Mixed Flow Lanes-Buses operating on the same lane(s) as regular traffic on arterials roads.

- Designated Arterial Lanes-Buses operating on a dedicated lane, indicated by a paint marking or rumble strip, adjacent to mixed traffic lanes.

- Roadway Shoulder Operations-Buses operating on a narrow ROW or operating on improved roadway shoulder. The same VAA application used for this scenario can be applied to improve effectiveness of operations in situations with reduced visibility of road edge due to inclement weather.

- At-Grade Transitway-Buses operating within a dedicated ROW but still interacting with surface traffic at signalize intersections.

- Fully Grade-Separated Exclusive Transitway-Operating in a dedicated ROW that is physically separated from other traffic lanes.

This analysis examined overall benefits of VAA applications in terms of increased operating speed and reduced travel time compared to the cost of the technology. No one measure was used to determine whether an operating scenario was cost effective. Rather, the measures were examined as a whole. The eight measures used to determine the cost effectiveness of a given operating scenario included Annual Bus Operating Cost Savings, Total Annualized Cost, Annualized User Benefits, Annualized Net Benefits, Benefit-Cost Ratio, Net Benefits After 1 Year, Years to Break-Even, and Net Benefits Over Life of Technology. 


\section{Analysis Framework}

The analysis framework used for this study is based upon the Screening for ITS (SCRITS) tool developed for the Federal Highway Administration ITS Joint Program Office, (FHWA 1999). SCRITS is a spreadsheet-based model that takes into account major system characteristics including the operating environment and costs, to determine quantitative impacts of deploying VAA applications. SCRITS generates a rough estimate in terms of impacts, costs, and benefits. The modified SCRITS tool provides only an order-of-magnitude estimate for a corridor rather than a detailed network-based assessment.

The analysis framework focuses on the reduction in vehicle running time due to VAA applications and benefits to the individual rider due to the reduction in travel time. Three critical parameters are needed for the model in order to derive the costs and benefits. First, an assessment is made regarding the potential impact of reducing bus travel time due to ITS technologies. It was important to factor out benefits caused by roadway geometry alone. For example, a vehicle operating on a grade-separated ROW has already achieved a significant reduction in running time compared to one operating in mixed traffic. The impact of any ITS on this operating scenario (such as transit signal priority) will have little impact on further reducing running time. Thus, the impact of ITS in affecting travel time is low. However, if a vehicle is currently operating on an at-grade transitway, the impact of ITS could be much higher. Based upon the CBRT and the ITS Benefit-Cost Database, the following ITS impact factors were used for each operating scenario (FHWA 2006):

- Suburban collector, urban circulator, mixed flowlLanes and designated arterial lane-50\%

- Roadway shoulder operations-30\%

- At-grade transitway-25\%

- Fully grade-separated exclusive transitway-15\%

The second parameter estimates the sole impact of VAA applications on running time as a percent of the total ITS impact. Due to the lack of operational systems and comprehensive evaluation data, there is limited empirical evidence that shows the impact of precision docking and vehicle guidance on reducing running time. However, the city of Rouen, France, has deployed precision docking technology and estimated a reduction in travel time of 4 percent to 5 percent (FHWA/FTA, 2005). Therefore, it was estimated that precision docking would result in a $5 \%$ reduction in running time. With regards to vehicle guidance, the city of Eindhoven, 
Netherlands, estimated some travel time improvement due to the vehicle guidance system being used. Rouen observed that vehicle guidance provided significant travel time improvements in areas that were difficult to maneuver. While no quantitative data exist on running time reduction due to vehicle guidance, for the purposes of this analysis, a 10 percent reduction in running time figure was used. Since these estimates are based on early deployers of VAA, the estimates may be conservative, and future VAA deployments with next generation technology might in fact provide greater benefits.

The third parameter is cost data, separated into technology costs and BRT system characteristic costs. Technology costs are presented in Table 1 and were derived from the VAA Systems for Transit Operations Synthesis White Paper (FHWA 2005). Transit System Characteristic costs are presented in Table 2 and are taken from the Characteristics of Bus Rapid Transit for Decision-Making report (FTA 2003). The CBRT report gives a range of costs for various BRT elements (running way, stations, vehicles, etc.) and which were segmented into low, medium, and high costs.

\section{Table 1. Technology Integration Costs}

\begin{tabular}{ll}
\hline Precision Docking & \\
Infrastructure & $\$ 4,000$ per station \\
Vehicle & $\$ 20,000$ per vehicle \\
Integration & $\$ 5,000$ per vehicle \\
Vehicle Guidance & \\
Infrastructure & $\$ 20,000$ per mile \\
Vehicle & $\$ 20,000$ per vehicle \\
Integration & $\$ 5,000$ per vehicle \\
\hline
\end{tabular}

Excluded from this analysis is the impact that VAA has on safety. Currently, the definition of VAA does not include collision warning and avoidance systems (FTA 2003). Initial deployments of VAA will be on systems operating in exclusive lanes, thus reducing potential bus-vs.-passenger-car incidents. However, it is not clear whether collision warning systems would ever be required as a critical component of VAA, since many of the VAA-equipped systems operational in Europe do not include them (FHWA/FTA 2005). VAA applications do not pose a new safety threat to passengers since the vehicle driver will continue to be a critical element 
Table 2 BRT System Characteristics Costs

\begin{tabular}{lrrr} 
Running Way (per mile) & Low & Medium & High \\
\hline Mixed Flow Lanes & $\$ 100,000$ & $\$ 195,000$ & $\$ 290,000$ \\
Designated Arterial & $\$ 2,500,000$ & $\$ 2,700,000$ & $\$ 2,900,000$ \\
At-Grade Transitway & $\$ 6,500,000$ & $\$ 8,350,000$ & $\$ 10,200,000$ \\
$\quad$ Fully Grade-Separated Transitway & $\$ 12,000,000$ & $\$ 36,000,000$ & $\$ 60,000,000$ \\
Stations (per station) & & & \\
Simple Stop & $\$ 15,000$ & $\$ 17,500$ & $\$ 20,000$ \\
Enhanced Stop & $\$ 25,000$ & $\$ 30,000$ & $\$ 35,000$ \\
Designated Station & $\$ 150,000$ & $\$ 1,325,000$ & $\$ 2,500,000$ \\
Intermodal Terminal or Transit Center & $\$ 5,000,000$ & $\$ 12,500,000$ & $\$ 20,000,000$ \\
Vehicles (per vehicle) & & & \\
Conventional Standard & $\$ 300,000$ & $\$ 325,000$ & $\$ 350,000$ \\
Stylized Standard & $\$ 300,000$ & $\$ 325,000$ & $\$ 350,000$ \\
Conventional Articulated & $\$ 500,000$ & $\$ 550,000$ & $\$ 600,000$ \\
Stylized Articulated & $\$ 630,000$ & $\$ 790,000$ & $\$ 950,000$ \\
Specialized BRT Vehicles & $\$ 950,000$ & $\$ 1,275,000$ & $\$ 1,600,000$ \\
\hline
\end{tabular}

in the operation of the VAA-equipped vehicle and will remain responsible for ensuring that the vehicle avoids hitting passengers and obstacles.

\section{Operating Scenario Analysis}

Each scenario analysis includes a summary of the system characteristics that were used as inputs for the analysis and a brief description of how the VAA applications would be used. The descriptions and data for the operating scenarios were initially derived from the Characteristics of Bus Rapid Transit for Decision-Making report and were later refined with information from current operations of VAA and/or BRT systems (FTA 2004). System characteristics include running way, station, and vehicle type. Operating characteristics include average operating speed, bus frequency, number of daily passengers, average passenger trip length, elasticity of demand, value of time, operating cost per bus route hour and daily vehicle trips in corridor. 


\section{Suburban Collector}

This scenario represents a medium-density environment operating at lower speeds. The only appropriate VAA application would be precision docking to better facilitate passenger boarding and alighting, which could be particularly helpful for boarding passengers with physical limitations. Operational models for current suburban collectors typically feature relatively fixed routes, or free travel within a small fixed perimeter.

A suburban collector with VAA does not currently exist; therefore, a hypothetical system was developed and modeled based on a proposed system in Florida called FlexBRT. This system would operate on mixed flow lanes and require 16 buses. ITS technologies would have a 50 percent impact on travel time and the precision docking application would account for 5 percent of this impact. The results of this scenario are presented in Table 3.

Table 3. Suburban Collector Impacts

\begin{tabular}{|l|r|l|r}
\hline Cost Savings & & Benefits & \\
\hline Annualized Operating Cost Savings & $\$ 251$ & Benefit/Cost Ratio & 0.24 \\
\hline $\begin{array}{l}\text { Total Annualized Cost of VAA } \\
\text { equipment }\end{array}$ & $\$ 365,964$ & Net Benefits After 1 Year & $-\$ 2,171,915$ \\
\hline Annualized User Benefits & $\$ 86,049$ & Years to Break-Even & -7 \\
\hline Annualized Net Benefits & $-\$ 279,664$ & $\begin{array}{l}\text { Net Benefits Over Life of } \\
\text { Technology }\end{array}$ & $-\$ 4,131,322$ \\
\hline
\end{tabular}

The use of precision docking in this operating scenario appears not to be warranted. Based upon a technology service life of eight years, the use of the technology never provides a net benefit. Rather, the overall cost to install the technology far outweighs the benefits derived. One reason for this is that the projected ridership is low at 4,100 daily passengers. Additionally, the cost savings are very small, consisting of some minor savings on travel time at the BRT stop. If the number of passengers increased, the overall travel time savings could be more and the net benefits could increase. However, the 4,000 ridership level is a typical kind of service. Even if the ridership doubled, to 8,000 per day, the VAA applications would probably still not be cost effective. 


\section{Urban Circulator}

This scenario represents a high-density environment, such as the downtown circulator bus systems currently operating in major cities throughout the U.S. Circulator vehicles with VAA applications have been tested in both Europe and Japan, not so much for their projected cost or safety benefits, but as a low-risk way to demonstrate a new technology. Currently, the only two urban circulator systems operating with VAA applications include an amusement park in Japan and a highdensity business park in Rotterdam, Netherlands. The urban circulator systems that have been deployed with VAA so far are more typical of a free "people mover" operation, not revenue service public transport, but it is too early to predict the future trend for this operating scenario.

Urban circulator systems typically operate on some type of dedicated facility, either for exclusive use by the circulator system or for use by transit vehicles in general. The use of precision docking would be advantageous to better facilitate boarding and alighting passengers. It would be relatively simple to deploy vehicle guidance on a dedicated facility, which would reduce the need for a separate collision warning system to account for various types of obstacles and hazards from other vehicles and pedestrians.

The urban circulator system used for this analysis is modeled after an operational system in Orlando called the LYMMO. The system operates on an at-grade transitway and currently does not include any VAA applications. This operating scenario analyzed the impacts of adding precision docking and vehicle guidance, where ITS would have a 50 percent impact on travel time and VAA would account for 15 percent of this impact. The results of this scenario are presented in Table 4.

The urban circulator system was analyzed first using only precision docking and then precision docking and vehicle guidance. In both instances, the results are favorable. The use of precision docking generates a $\mathrm{B} / \mathrm{C}$ ratio of 2.65 , two years to break-even, and positive net benefits over the expected life of technology. Adding vehicle guidance applications further increases the benefits. The positive results can be attributed primarily to the reduction in travel time and to the higher ridership. 
Table 4. Urban Circulator Impacts

\begin{tabular}{|l|r|r|l|r|r|}
\hline Cost Savings & \multicolumn{1}{|c|}{$\begin{array}{c}\text { Precision } \\
\text { Docking }\end{array}$} & $\begin{array}{r}+ \text { Vehicle } \\
\text { Guidance }\end{array}$ & \multicolumn{1}{|c|}{ Benefits } & \multicolumn{1}{c|}{$\begin{array}{c}\text { Precision } \\
\text { Docking }\end{array}$} & $\begin{array}{c}\text { + Vehicle } \\
\text { Guidance }\end{array}$ \\
\hline $\begin{array}{l}\text { Annualized Operating Cost } \\
\text { Savings }\end{array}$ & $\$ 1,847$ & $\$ 5,540$ & Benefit/Cost Ratio & 2.65 & 7.28 \\
\hline Total Annualized Cost & $\$ 91,748$ & $\$ 100,268$ & $\begin{array}{l}\text { Net Benefits After 1 } \\
\text { Year }\end{array}$ & $-\$ 142,472$ & $\$ 275,560$ \\
\hline Annualized User Benefits & $\$ 243,276$ & $\$ 729,828$ & Years to Break-Even & 2 & 1 \\
\hline Annualized Net Benefits & $\$ 153,274$ & $\$ 635,099$ & $\begin{array}{l}\text { Net Benefits Over Life } \\
\text { of Technology }\end{array}$ & $\$ 1,221,279$ & $\$ 5,941,598$ \\
\hline
\end{tabular}

\section{Mixed Flow Lanes}

Mixed flow lane operations are typical of many transit systems in the U.S where transit buses operate in the same lanes as regular traffic on limited access highways, interstates, arterials, or local streets. Since there is no dedicated ROW, only precision docking is analyzed because, in the short term, it is unlikely vehicle guidance would be sufficiently mature to permit operations in mixed traffic.

The mixed flow lane operating scenario is modeled after an existing BRT system in Oakland, California, called the San Pablo RAPID. The operating scenario analyzed the impact of deploying precision docking at 22 stations where all vehicles would be equipped with the appropriate vehicle-based components. ITS would have a 50 percent impact on travel time and the precision docking would account for 5 percent of this impact. The results of this scenario are presented in Table 5.

The impact of installing precision docking on transit vehicles operating in mixed flow lanes is significant. Benefits are derived primarily through the reduction of dwell time at transit stops which reduces the overall running time of the bus, thus increasing the operating speed. In this scenario, the $\mathrm{B} / \mathrm{C}$ ratio is 2.43 , indicating benefits are greater than costs, and it would take approximately two years to realize net benefits. Over the estimated eight year service life of the technology, net benefits would be almost $\$ 900,000$. In this case, the higher ridership provided significant benefits even though only precision docking was used.

\section{Designated Arterial Lane}

U.S. cities are increasingly turning to designated arterial lanes for transit operations in order to improve transit service. However, many localities are encountering barriers to creating a designated lane due to ROW constraints. Vehicle guid- 
Table 5. Mixed Flow Lanes Impacts

\begin{tabular}{|l|r|l|r|}
\hline \multicolumn{2}{|l|}{ Cost Savings } & Benefits \\
\hline Annualized Operating Cost Savings & $\$ 4,813$ & Benefit/Cost Ratio & 2.43 \\
\hline Total Annualized Cost & $\$ 106,446$ & Net Benefits After 1 Year & $\$ 185,415$ \\
\hline Annualized User Benefits & $\$ 259,031$ & Years to BreakEven & 2 \\
\hline Annualized Net Benefits & $\$ 157,398$ & $\begin{array}{l}\text { Net Benefits Over Life of } \\
\text { Technology }\end{array}$ & $\$ 882,682$ \\
\hline
\end{tabular}

ance would enable vehicles to operate safely within a narrower lane width, thus reducing the infrastructure costs and design constraints of creating a designated lane in an already crowded environment. Vehicle guidance could also enable transit agencies to carve out a narrow transit lane within the existing ROW.

The designated arterial lane system used for this analysis is modeled after the Silver Line in Boston. The system operates on a dedicated lane that is striped and signed to differentiate it from the other travel lanes for 4.7 miles, and in mixed flow lanes for 3 miles. The operating scenario analyzed the impact of deploying precision docking at all 20 stations on the 7.3 mile route, and vehicle guidance along the 4.7 miles of dedicated lane. ITS technology would have a 50 percent impact on travel time and precision docking and vehicle guidance would account for 15 percent of this impact. The results of this scenario are presented in Table 6.

The designated arterial lane operating scenario was analyzed first using only precision docking and then precision docking and vehicle guidance. In both instances, the results are favorable. The use of precision docking generates a $\mathrm{B} / \mathrm{C}$ ratio of 2.90, two years to break-even, and positive net benefits over the life of technology. Adding vehicle guidance further increases the benefits. The $B / C$ ratio more than doubles, benefits would be seen within the first year of deploying the technology, and overall net benefits would increase by nearly five-fold. This scenario illustrates the significant benefits that VAA can provide, even on a relatively short BRT route.

\section{Roadway Shoulder Operations}

Roadway shoulder operations occur when a transit agency operates buses on a roadway shoulder in order to bypass congested areas. Currently, a few transit agencies operate buses on a bus-only shoulder lane, although not at full highway speeds. In all instances, transit agencies have teamed with the respective state and local DOTs to ensure that the existing roadway shoulder is suitable for buses to 
Table 6. Designated Arterial Lane Impacts

\begin{tabular}{|l|r|r|l|r|r|}
\hline Cost Savings & $\begin{array}{c}\text { Precision } \\
\text { Docking }\end{array}$ & $\begin{array}{l}\text { + Vehicle } \\
\text { Guidance }\end{array}$ & Benefits & $\begin{array}{c}\text { Precision } \\
\text { Docking }\end{array}$ & $\begin{array}{c}+ \text { Vehicle } \\
\text { Guidance }\end{array}$ \\
\hline $\begin{array}{l}\text { Annualized Operating Cost } \\
\text { Savings }\end{array}$ & $\$ 2,509$ & $\$ 7,528$ & Benefit/Cost Ratio & 2.90 & 7.57 \\
\hline Total Annualized Cost & $\$ 105,110$ & $\$ 120,808$ & $\begin{array}{l}\text { Net Benefits After 1 } \\
\text { Year }\end{array}$ & $-\$ 130,275$ & $\$ 369,697$ \\
\hline Annualized User Benefits & $\$ 304,835$ & $\$ 914,505$ & Years to Break-Even & 2 & 1 \\
\hline Annualized Net Benefits & $\$ 202,234$ & $\$ 801,225$ & $\begin{array}{l}\text { Net Benefits Over Life } \\
\text { of Technology }\end{array}$ & $\$ 1,267,800$ & $\$ 5,925,577$ \\
\hline
\end{tabular}

operate on. In a few cases where the roadway shoulders do not meet minimum design requirements, DOTs have made improvements to the roadway shoulder. Typically, buses only use the roadway shoulder during operating peak periods when congestion is present.

Minnesota's Metro Transit found considerable operating benefits in creating a bus-only shoulder lane (without VAA applications) (Metro Transit 2003). Passengers perceived that their trip on the shoulder was 15 minutes faster than driving in mixed traffic, although, in reality, their trip was only 8 minutes faster. There were also issues with "jealous motorists" in passenger cars blocking the bus lane or illegally driving in the bus lane, which has also been reported with similar operations in Europe. Anecdotal evidence suggests that operating buses in these conditions is stressful for bus drivers and that the use of vehicle guidance technologies could significantly reduce this stress especially during times of inclement weather, when congestion is at its worst and buses would derive the greatest benefit from using the roadway shoulder.

The roadway shoulder operation scenario is modeled after the Phoenix RAPID, which operates in both mixed flow lanes and designated arterial lanes (on the shoulder). The analysis included the impact of deploying vehicle guidance technology along the 43.8 miles of designated arterial lanes (roadway shoulder) on which the RAPID operates. ITS would have a 30 percent impact on travel time and the vehicle guidance would account for 10 percent of this impact. The results of this scenario are presented in Table 7.

The table clearly shows that, for this specific scenario using data based on realworld operations in Phoenix, implementing vehicle guidance would not be cost effective. It is possible that VAA would show benefit in a similar roadway shoulder 
Table 7. Roadway Shoulder Operations Impacts

\begin{tabular}{|l|r|l|r|}
\hline \multicolumn{2}{|l|}{ Cost Savings } & Benefits \\
\hline Annualized Operating Cost Savings & $\$ 57,965$ & Benefit/Cost Ratio & 0.88 \\
\hline Total Annualized Cost & $\$ 338,242$ & Net Benefits After 1 Year & $-\$ 1,767,851$ \\
\hline Annualized User Benefits & $\$ 296,391$ & Years to Break-Even & -41 \\
\hline Annualized Net Benefits & $\$ 16,114$ & $\begin{array}{l}\text { Net Benefits Over Life of } \\
\text { Technology }\end{array}$ & $-\$ 2,060,808$ \\
\hline
\end{tabular}

operational scenario with different numbers for passenger demand, operating speed, length, etc. There may be other benefits that were not taken into account, particularly ROW costs and reducing driver stress. The cost-savings for ROW acquisition, which were not taken into account in this calculation, could be considerable. In some situations, the use of vehicle guidance may be the key element that allows for the use of a narrow lane. Analyzing that type of scenario is difficult since land values vary considerably across the U.S. Vehicle guidance may reduce driver stress while operating on a narrow lane. However, this analysis framework was not designed to account for perceived human factors benefits.

\section{At-Grade Transitway}

In this scenario, transit buses operate on a dedicated transitway where only transit vehicles are permitted. The transitway is physically separated from other traffic lanes but is not entirely grade separated. Similar to the designated lane scenario, a benefit of vehicle guidance is the ability to have a smaller lane width thus improving the possibility of creating a new at-grade transitway in an already crowded environment. There are operational systems in Europe, Australia, and Japan that use at-grade transitways with vehicle guidance, though many of these systems use a mechanical guideway technology requiring specially designed lanes.

The at-grade transitway system analyzed here is modeled after South Miami-Dade Busway in Miami, Florida. The system operates on a dedicated transitway built adjacent to U.S. 1. The operating scenario analyzed the impact of deploying precision docking at all 23 stations and vehicle guidance along the entire 8 mile route. ITS would have a 25 percent impact on travel time and VAA applications would account for 15 percent of this impact. The results of this scenario are presented in Table 8. 
Table 8. At-Grade Transitway Impacts

\begin{tabular}{|l|r|r|l|r|r|}
\hline Cost Savings & $\begin{array}{c}\text { Precision } \\
\text { Docking }\end{array}$ & $\begin{array}{l}\text { + Vehicle } \\
\text { Guidance }\end{array}$ & Benefits & $\begin{array}{c}\text { Precision } \\
\text { Docking }\end{array}$ & $\begin{array}{c}\text { + Vehicle } \\
\text { Guidance }\end{array}$ \\
\hline $\begin{array}{l}\text { Annualized Operating Cost } \\
\text { Savings }\end{array}$ & $\$ 1,046$ & $\$ 3,137$ & Benefit/Cost Ratio & 1.25 & 3.75 \\
\hline Total Annualized Cost & $\$ 107,114$ & $\$ 107,114$ & $\begin{array}{l}\text { Net Benefits After 1 } \\
\text { Year }\end{array}$ & $-\$ 315,162$ & $-\$ 47,258$ \\
\hline Annualized User Benefits & $\$ 133,952$ & $\$ 401,856$ & Years to Break-Even & 13 & 1 \\
\hline Annualized Net Benefits & $\$ 27,884$ & $\$ 297,879$ & $\begin{array}{l}\text { Net Benefits Over Life } \\
\text { of Technology }\end{array}$ & $-\$ 127,295$ & $\$ 2,015,940$ \\
\hline
\end{tabular}

The at-grade transitway operating scenario was analyzed first using only precision docking, then adding vehicle guidance. Only the second technology package demonstrated positive benefits, indicating that precision docking alone will not provide benefits. In other words, precision docking must be combined with vehicle guidance to offset the cost of installing the technology. Since this system has many stations (23), there is a larger capital cost associated with the technology when using precision docking alone. Incorporating vehicle guidance will help to offset that initial capital cost. Of course, higher ridership, which may provide greater benefits, would improve the analysis even more.

\section{Fully Grade-Separated Exclusive Transitway}

In this scenario, transit buses operate in exclusive lanes separated by grade, concrete barriers, or other devices. This has similar benefits to narrow lane, at-grade transitway or shoulder operation, but with significantly greater infrastructure costs. Most current operations of VAA applications use an at-grade transitway, not a fully grade-separated exclusive transitway. There might be additional safety or mobility benefits to using fully grade-separated lanes versus an at-grade transitway, depending on the signalization issues, but with VAA applications, there are no real differences in terms of VAA technology required. A separated lane with no traffic signals would be faster than a separated lane where buses must stop at signalized intersections. A fully grade-separated lane would remove all possibility of SOV motorists encroaching or conflicting with the VAA-equipped bus, but at significant infrastructure cost.

Both precision docking and vehicle guidance (as well as full automation in the future) could be used for this scenario. Similar to the designated lane scenario, a 
benefit of vehicle guidance is the ability to have a smaller lane width, thus reducing the infrastructure cost and "footprint" for the transitway itself. Another potential benefit not factored into this analysis is that a fully grade-separated exclusive transitway would likely meet the eligibility requirements for a fixed guideway "New Start"; thus, there might be another funding mechanism to pay for the technology. However, the drawbacks are great: costs would be in the range of $\$ 12$ to 30 million per lane mile for aerial installations, and $\$ 60$ to 105 million for underground installations (FTA 2004).

The fully grade-separated exclusive transitway system is modeled after the West Busway in Pittsburgh. The system operates on a dedicated transitway for 4.6 miles and in mixed flow lanes for 0.4 miles. The operating scenario analyzed the impact of deploying precision docking at all 10 stations, with vehicle guidance along 4.6 miles of the dedicated transitway portion of the route. ITS would have a 15 percent impact on travel time, with precision docking and vehicle guidance accounting for 20 percent of this impact. The results of this scenario are presented in Table 9.

\section{Table 9. Fully Grade-Separated Exclusive Transitway Impacts}

\begin{tabular}{|l|r|r|l|r|r|}
\hline Cost Savings & $\begin{array}{c}\text { Precision } \\
\text { Docking }\end{array}$ & $\begin{array}{l}\text { + Vehicle } \\
\text { Guidance }\end{array}$ & Benefits & $\begin{array}{c}\text { Precision } \\
\text { Docking }\end{array}$ & $\begin{array}{c}\text { + Vehicle } \\
\text { Cuidance }\end{array}$ \\
\hline $\begin{array}{l}\text { Annualized Operating Cost } \\
\text { Savings }\end{array}$ & $\$ 1,009$ & $\$ 3,027$ & Benefit/Cost Ratio & 1.66 & 4.98 \\
\hline Total Annualized Cost & $\$ 110,955$ & $\$ 110,955$ & $\begin{array}{l}\text { Net Benefits After 1 } \\
\text { Year }\end{array}$ & $-\$ 291,809$ & $\$ 76,484$ \\
\hline Annualized User Benefits & $\$ 184,146$ & $\$ 552,439$ & Years to Break-Even & 5 & 1 \\
\hline Annualized Net Benefits & $\$ 74,200$ & $\$ 444,511$ & $\begin{array}{l}\text { Net Benefits Over Life } \\
\text { of Technology }\end{array}$ & $\$ 220,530$ & $\$ 3,166,870$ \\
\hline
\end{tabular}

The fully grade separated exclusive transitway operating scenario was analyzed first using only precision docking, then adding vehicle guidance. The use of precision docking and vehicle guidance generates a $\mathrm{B} / \mathrm{C}$ ratio of 4.98 , one year to breakeven, and significant net benefits over the life of technology. The net benefits are considerable, particularly for the vehicle guidance scenario. The main benefit is significantly reduced passenger travel time. For new systems with large ROW acquisition costs, additional cost savings would be gained since a narrower lane could be used. 


\section{Summary and Implications}

A summary comparing each operating scenario is presented in Table 10 in the order they were discussed. Overall, most of the operating scenarios produced a positive $B / C$ ratio, generated benefits within three years of deploying the technology, and generated positive benefits over the life of the technology. Based upon these criteria, five of the seven operating scenarios produced an overall positive benefit and are ranked as follows beginning with greatest level of benefits: 1) designated arterial lanes, 2) urban circulator, 3) fully grade-separated exclusive transitway, 4) at-grade transitway and, 5) mixed flow lanes.

The designated arterial, urban circulator, and fully grade-separated exclusive transitway all provide similar benefits in both type and magnitude. Essentially, these three scenarios are subtle variations of a single scenario of operating VAAequipped buses in lanes which are in some way separated from the flow of passenger car traffic. This separation permits the safe use of VAA in the immediate future. Mixed flow lanes ranked lower since the only VAA application appropriate at this time is precision docking. Therefore, mixed flow lanes are unable to take advantage of leveraging the VAA technology already installed on the vehicle for vehicle guidance as well.

Two scenarios were not able to demonstrate benefit from VAA. In the case of the suburban collector, ridership is not sufficient to generate significant cumulative travel time savings for passengers. In the case of shoulder operations, the bus is already providing faster travel time by operating on the shoulder; the addition of lane guidance does not provide significant extra travel time benefit in that case, using the numbers based on real world operations. However, there may be significant benefits in both operating scenarios for reduced ROW costs and improved driver comfort, neither of which could be accurately quantified for this analysis. For roadway shoulder operations, the most important benefit may be the ability to operate on the shoulder when it is most needed-during inclement weatherwhich is not captured in this analysis.

It is also important to understand the context in which VAA applications will be deployed and the commercial viability of developing the technology. To this end, those BRT sites either operating, under construction or in the planning stages were documented and classified according to the operating scenarios and are shown in Table 11. Data regarding the sites were gathered from various web resources. 
Table 10. Operating Scenario Analysis

\begin{tabular}{|c|c|c|c|c|c|c|c|}
\hline & 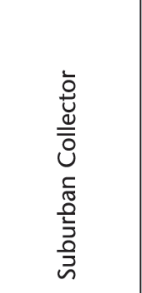 & 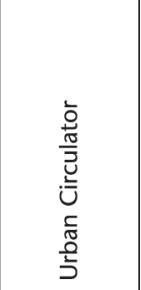 & 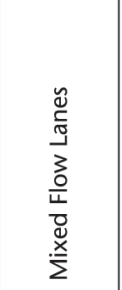 & 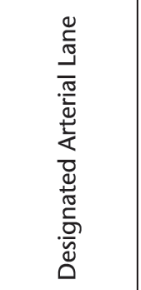 & 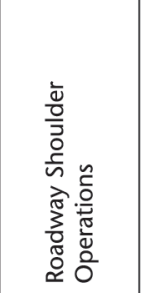 & 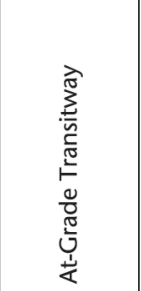 & 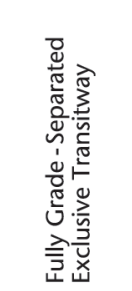 \\
\hline \multicolumn{8}{|l|}{ Cost Savings } \\
\hline $\begin{array}{l}\text { Annualized } \\
\text { Operating Cost } \\
\text { Savings }\end{array}$ & $\$ 251$ & $\$ 5,540$ & $\$ 4,813$ & $\$ 7,528$ & $\$ 57,965$ & $\$ 3,137$ & $\$ 3,027$ \\
\hline $\begin{array}{l}\text { Total Annualized } \\
\text { Cost }\end{array}$ & $\$ 365,964$ & $\$ 100,268$ & $\$ 106,446$ & $\$ 120,808$ & $\$ 338,242$ & $\$ 107,114$ & $\$ 110,955$ \\
\hline $\begin{array}{l}\text { Annualized User } \\
\text { Benefits }\end{array}$ & $\$ 86,049$ & $\$ 729,828$ & $\$ 259,031$ & $\$ 914,505$ & $\$ 296,391$ & $\$ 401,856$ & $\$ 552,439$ \\
\hline $\begin{array}{l}\text { Annualized Net } \\
\text { Benefits }\end{array}$ & $-\$ 279,664$ & $\$ 635,099$ & $\$ 157,398$ & $\$ 801,225$ & $\$ 16,114$ & $\$ 297,879$ & $\$ 444,511$ \\
\hline \multicolumn{8}{|l|}{ Benefits } \\
\hline Benefit/Cost Ratio & 0.24 & 7.28 & 2.43 & 7.57 & 0.88 & 3.75 & 4.98 \\
\hline $\begin{array}{l}\text { Net Benefits } \\
\text { After } 1 \text { Year }\end{array}$ & $-\$ 2,171,915$ & $\$ 275,560$ & $-\$ 185,415$ & $\$ 369,697$ & $-\$ 1,767,851$ & $\$ 47,258$ & $\$ 76,484$ \\
\hline $\begin{array}{l}\text { Years to } \\
\text { Break-Even }\end{array}$ & -7 & 1 & 2 & 1 & -41 & 1 & 1 \\
\hline $\begin{array}{l}\text { Net Benefits Over } \\
\text { Life of Technology }\end{array}$ & $-\$ 4,131,322$ & $\$ 5,941,598$ & $\$ 882,682$ & $\$ 5,925,577$ & $-\$ 2,060,808$ & $\$ 2,015,940$ & $\$ 3,166,870$ \\
\hline Ranking & 6 & 2 & 5 & 1 & 7 & 4 & 3 \\
\hline
\end{tabular}

The analysis showed that five of the seven operating scenarios demonstrated a positive benefit based upon the criteria. Therefore, 21 of the 27 systems in operation (78\%) may benefit from the use of VAA applications. Furthermore, all of the BRT systems in construction and 42 of the 46 systems in the planning stage (91\%) may benefit from VAA applications. This means that 65 of the 75 sites identified (87\%) may derive some benefit from the addition of VAA applications. 
Table 11. BRT Operating Scenario Summary

\begin{tabular}{|l|c|c|c|c|c|}
\hline \multicolumn{1}{|c|}{ Operating Scenario } & $\begin{array}{c}+ \text { or } \\
\text { Benefits }\end{array}$ & Operating & Construction & Planning & Total \\
\hline Suburban Collector & - & 2 & 0 & 1 & 3 \\
\hline Urban Circulator & + & 1 & 0 & 1 & 2 \\
\hline Mixed Flow Lanes & + & 5 & 0 & 21 & 26 \\
\hline Designated Arterial Lane & + & 2 & 1 & 9 & 12 \\
\hline Roadway Shoulder Operations & - & 4 & 0 & 3 & 7 \\
\hline At-Grade Transitway & + & 4 & 1 & 4 & 9 \\
\hline $\begin{array}{l}\text { Fully Grade -Separated Exclusive } \\
\text { Transitway }\end{array}$ & + & 9 & 0 & 7 & 16 \\
\hline Total & & 27 & 2 & 46 & 75 \\
\hline
\end{tabular}

As seen with some of the scenarios, benefits are sensitive to both ridership estimates and the value of time for the riders. A system with high ridership would probably generate greater benefits over a similar system with fewer riders. Yet, higher ridership does not necessarily equate to greater benefits. ROW length, number of stations and number of vehicles will impact the overall infrastructure cost associated with deploying VAA. These costs would then impact the overall cost/benefit breakeven point. In addition, there might be considerable local variation in the sensitivity of this analysis to ridership estimates and infrastructure costs.

The results of this analysis must be tempered with the knowledge that there is very little operational data to currently support some of the input data required by the model. Operational systems in Europe and Japan have demonstrated that the technology can be used for revenue service operations; yet very few comprehensive system evaluations have been conducted examining cost savings, ridership increases, travel time savings, or other possible benefits. Future research should address this issue as U.S. transit agencies begin to deploy VAA applications.

Overall, it is significant that this order-of-magnitude benefit estimation and planning exercise has been successfully completed and is available for others to use. 
Using empirical data for some benefits and rather conservative estimates for others, the model demonstrated positive impacts due to VAA applications for most BRT scenarios. It may now be appropriate for the many localities planning BRT systems to consider adding VAA applications to their projects.

\section{Acknowledgements}

This paper reports on analysis performed as part of the U.S. DOT ITS JPO Tier II research project called Multimodal Vehicle Assist and Automation Systems. More information regarding this project and final reports developed as part of this research are available at http://www.its.dot.gov.

\section{References}

BRT Sites identified via http://www.fta.dot.gov and http://gobrt.org. Accessed April 2005.

Federal Highway Administration. 1999. ITS Joint Program Office. Screening Tool for ITS (SCRITS). Available at http://www.its.dot.gov. Washington, D.C.

Federal Highway Administration. ITS Joint Program Office. 2005 Multimodal Vehicle Assist and Automation: VAA Systems for Transit Operations Synthesis White Paper. Washington, D.C.

Federal Highway Administration. 2006. ITS Joint Program Office. ITS Benefit-Cost Database. Available at http://www.benefitcost.its.dot.gov. Washington, D.C.

Federal Highway Administration and Federal Transit Administration. 2005. ITS Joint Program Office. Lane Assist Systems in Europe: Report on Technical Visit to Europe on Transit Lane Assist Technologies. Washington, D.C.

Federal Transit Administration. 2003. Office of Research, Demonstration and Innovation. Bus Rapid Transit Lane Assist Technology Systems, Volume 1, Technology Assessment. Washington, D.C.

Federal Transit Administration. 2004. Office of Research, Demonstration and Innovation. Characteristics of Bus Rapid Transit for Decision-Making (CBRT). Washington, D.C. 


\section{About the Authors}

MATTHEW HARDY (matthew.hardy@mitretek.org) is a Lead Transportation Engineer at Mitretek Systems based in Washington, D.C. He is a graduate of George Mason University in Fairfax, Virginia where he earned a Bachelor of Science in Urban Systems Engineering and a Master of Science in Transportation Policy, Operations and Logistics. He is currently pursuing a Ph.D. in Public Policy. He has conducted extensive research in the application of ITS technologies to Bus Rapid Transit Systems and Vehicle Assist and Automation systems for transit applications. He was co-author of the Characteristics of Bus Rapid Transit for Decision-Making report. He is a current member of the TRB Joint Subcommittee on Intersection Design, Safety and Operations, and the committee on Vehicle-Highway Automation.

SUSANNAh Proper (sproper@mitretek.org) is a Principal Engineer at Mitretek Systems based in Washington, D.C. She is a graduate of Northwestern University in Evanston, Illinois, with a Bachelor of Science in Economics and a graduate of the University of Maryland, College Park, with a Master of Public Policy degree. Past work has included advanced vehicle technologies, systems engineering, GPS modernization analysis, domestic and international standards, geospatial integration, human factors, economic and policy analysis, and advanced vehicle control and safety systems. 


\title{
The Issues and Realities of BRT Planning Initiatives in Developing Asian Cities
}

Moazzem Hossain, Transportation and Logistics Program

Malaysia University of Science and Technology (MUST)

\begin{abstract}
Successful Bus Rapid Transit (BRT) planning initiatives in Latin American cities involved complex interactions among stakeholders, politicians and planners. Asian cities under different geo-political settings may not be able to achieve successful BRT planning initiatives under similar circumstances. This paper reviews the recent mass transit planning initiatives, especially BRT planning initiatives, in Asian cities and identifies the issues and realities of such initiatives in different regions of Asia. The prospect, suitability and importance of BRT as a sustainable mass transit system for Asian cities are also discussed. Guidelines are suggested for probable successful BRT planning initiatives under different geo-political contexts of Asian cities.
\end{abstract}

\section{Introduction}

BRT has emerged as an economically self-reliant mass transit system with significant potential for budget-constrained developing cities. The successful BRT systems, particularly in Latin American cities, have evolved through broad-based participation of all the actors and fair distribution of costs, risks and benefits among the same (Ardila 2004; Wright 2005). Wright (2001) mentioned that Latin American busways show that the availability of capital is secondary to political and technical will. Patrick and William (2005) also emphasized the need for pub- 
lic-private partnership (PPP) in financing, implementing and operating successful BRT systems integrated with multi-modal transport networks. While such a broad participatory planning process has taken place under the umbrella of the powerful mayors of Latin American cities (Hook 2005; Ardila 2004), by tradition, mayors of most Asian cities do not enjoy that sort of power due to the bureaucratic central government influence and absence of proper city government structure, in many cases. Often, urban transport decision making involves multiple agencies such as ministries for communication, city mayors, city transport authorities, and sometimes even finance/prime ministries. While these are the top layer of decision makers, there is also a bottom layer of stakeholders such as transit operators, planners and civic groups. It is not easy to track a planning and decision making process in such a situation involving multiple parties. The case of BRT planning appears to be more intricate, as it needs a general acceptability among all parties because of the intrinsic characteristics of BRT system development. BRT systems need cooperation and participation from all quarters as successful BRT systems emerge from contributions of public-private partnership and collaboration. Hook (2004) mentioned that the relationship between BRT and regulatory and institutional reform is less understood, although it is one of the most important elements distinguishing BRT from normal busways. Even with all the advantages of BRT, such as low cost, flexibility and easy installation, it hardly generates any self-motivated interest group, as the system rarely allows favor to a particular party. So, the question now is, who would promote those advantages of BRT and work through the complex interactive roadmap of multi-agency planning tasks to ultimately see through the adoption of a comprehensive BRT system plan. This paper reviews the current mass transit planning initiatives of a few Asian cities in the light of the above issues. Recent institutional, political and planning dynamics in the cities are analyzed in detail. Finally, guidelines are suggested for the BRT planning process initiatives for Asian developing cities in the light of those experiences.

\section{Mass Transit Initiatives of Asian Cities}

Asia has almost 200 cities with populations over 1 million, including 98 cities in China and 35 in India (Singh 2005), two of the world's most populous countries. Most of these populations, especially the lower-middle to low income groups, are heavily dependent on public transportation. In the absence of an adequate public transportation supply, most of these cities' streets are crowded with two-wheelers and other motorized para-transits (Singh 2005; Hoque and Hossain 2005; Hossain 
et al. 2003; Hossain and McDonald 1998), which cannot substitute for a mass transit system appropriate to the demand volumes of these cities. Also, it is worth mentioning that some of the middle income cities, such as Kuala Lumpur, Bangkok, Beijing and Shanghai, are going through rapid motorization at an alarming rate (Townsend 2001; UN ESCAP 2005; Energy Foundation 2005). Although these cities invested heavily in road-based infrastructure, the rate of motorization always outpaces the supply of road network. Therefore, cities of both income ranges are facing the problems of congestion, safety, traffic-related air pollution, and excessive (80 to $90 \%$ in Asia) commercial energy consumption in the transport sectors (UNESCAP 2005). For example, approximately 60 percent of the Bangkok population suffers from throat irritation, apparently caused by air pollution; Dhaka's air pollution causes 10,800 premature deaths and 6.5 million extra cases of sickness per annum, with an estimated loss of US\$200-800 million and a simultaneous congestion and accident loss of US\$520 million per annum (Haque and Hossain 2004). Average one-way commuting trip time to work in Bangkok is about 1 hour. All of these put into question the future sustainability of these cities. With this sort of caution in the air for recent years, regional governments are trying to address the challenge through a combination of increased investment in road stock and the development of complementary public transport systems, with clear emphasis on public transport systems in recent time. Successful embracing of transit-oriented urban transport development and BRT initiatives by upper income cities like Seoul and Taipei (Pucher et al. 2005; Chang and Sun 2004) have created motivation for similar approaches by the developing cities. Such public transport initiatives and planning approaches undertaken by a number of developing Asian cities are discussed below.

\section{China}

Sustainable transport and other development initiatives in the world's most populous and rapidly growing economy, China, are important for the stability of the Asian region and the world as a whole. Phenomenal economic growth during the last two decades has resulted in a significant increase in car ownership with associated congestion, air pollution, and enormous increases in gasoline consumption (Energy Foundation 2005; Chang 2005; ADB 2001). Rising oil prices have set the energy security and overall viability of Chinese cities on an unsustainable course. Under the circumstances, after a series of meetings and consultations with scientists, policy makers, business leaders, and analysts in China and the United States, 
a consortium of international organizations consisting of the David and Lucile Packard Foundation, the Energy Foundation, and the William and Flora Hewlett Foundation launched the China Sustainable Energy Program (CSEP) recently. The mission of the program is to assist in China's transition to a sustainable energy future by promoting energy efficiency and renewable energy. Transport is the primary consumer of the majority of the country's mostly-imported oil and has understandably drawn the attention of the program. The CSEP team developed the China Transportation Program Strategy with three clear goals, including the identification of BRT systems as means toward sustainable transportation systems. This initiative worked as a catalyst in generating interest among local politicians, mayors and decision makers. Since November 2001, as many as 14 Chinese cities have implemented a few BRT corridors or are in the process of implementing or are actively planning for a BRT system, as shown in the Table 1. Chang (2005) reported five key factors for BRT success in China: support from mayor(s); support from city councils; coordinated efforts of the new transportation commissions; comprehensive planning/design; and contributions of international teams. This shows the importance of strong political support and knowledgeable planning teams in an environment of well-integrated institutional setups for successful BRT planning initiatives. In some cities, bus manufacturers also are included in the development of BRT plans. This will ensure availability of needs-based, welldesigned buses and help the development of local industries for an emerging large BRT market in China and the region, ultimately reducing BRT installation costs and making the system even more viable financially.

It is striking to see so many successful BRT planning initiatives in China within only three to four year's time; BRT planning initiatives took decades in Latin American cities. The success was possible largely due to the catalytic initiatives from the CSEP group and a new generation of open-minded politicians in China, as well as China hosting the 2008 summer Olympic Games and World EXPO 2010. The total investment in urban transport for China's major cities is expected to reach the equivalent of US\$97 billion during the next five years, according to Chinese government figures (Wynne 2004).

\section{India}

India is the second most populous country in the world and home to about 35 cities with populations of more than 1 million. This is another Asian region with serious need for sustainable urban transport development. India has had favor- 


\section{Table 1. BRT Initiatives in Chinese Cities}

\begin{tabular}{|c|c|c|c|}
\hline Chinese City & $\begin{array}{l}\text { BRT Route } \\
\text { Planned }(\mathrm{km})\end{array}$ & $\begin{array}{l}\text { BRT Route } \\
\text { Implemented (km) }\end{array}$ & Agency \\
\hline Bejing & 300 & 15.8 & $\begin{array}{l}\text { Beijing Transportation Commission } \\
\text { \& Beijing municipal government }\end{array}$ \\
\hline Kunming & 73 & $\begin{array}{l}4.5 \text { ( fully } \\
\text { developed) and } 42 \\
\text { (partially developed) }\end{array}$ & $\begin{array}{l}\text { Kunming Urban Traffic Research Institute } \\
\text { (KUTRI) \& Kunming municipal } \\
\text { government }\end{array}$ \\
\hline Jinan & 12 & Partly in operation & $\begin{array}{l}\text { Jinan Urban Planning \& Design Institute, } \\
\text { Jinan Municipal Civil Engineering } \\
\text { Design Institute, and } \\
\text { China Academy of Urban Planning }\end{array}$ \\
\hline Xian & 48 & Planning stage & $\begin{array}{l}\text { Local university and municipal } \\
\text { government }\end{array}$ \\
\hline Chengdu & 28 & Planning stage & $\begin{array}{l}\text { Chengdu Institute of Urban Planning and } \\
\text { Design }\end{array}$ \\
\hline Chongqing & 15 & Planning stage & $\begin{array}{l}\text { Chongqing municipal government, } \\
\text { Chongqing Bus Company, and Chongqing } \\
\text { bus manufacturer }\end{array}$ \\
\hline Shanghai & 250 & Planning stage & Shanghai Urban Transport Bureau \\
\hline Tienjing & 145 & Planning stage & Municipal government \\
\hline Shenyang & $16\left(1^{\mathrm{st}}\right.$ phase $)$ & Planning stage & Municipal government \\
\hline Hangzhou & 28 & $\begin{array}{l}\text { Construction in } \\
\text { progress }\end{array}$ & Municipal government \\
\hline Guangzhou & $\begin{array}{l}\text { Planning } \\
\text { stage }\end{array}$ & Planning stage & Municipal government \& ITDP initiative \\
\hline
\end{tabular}

able rapid economic growth for more than a decade now. Increased income has paved the way for rapidly increasing levels of motor vehicle ownership and use, particularly in city areas. The emerging traffic situation has resulted in alarming levels of congestion, air pollution, noise, and traffic danger (Singh 2005). For most segments of the population, mobility and accessibility have declined with time (Pucher et al. 2005). Although the four mega-cities (Delhi, Mumbai, Kolkata and Chennai) have rail-based mass transit routes, the limited coverage of systems in these cities and generally unorganized, poor-quality, inadequate bus services (similar to other Indian cities) have resulted in an improper public transport supply in Indian cities. Commenting on the existing public transport supply, especially the bus system of small- and medium-sized Indian cities, Pucher et al. (2005) 
described them as old and poorly designed, inadequately maintained, dangerously overcrowded, undependable, and slow. Also, it is claimed that the systems require increasingly large subsidies, in spite of extremely high passenger volumes, due to inefficiency, outdated technology, incompetent management, corruption, overstaffing, and low worker productivity. However, it would be unfair not to mention that this poor situation emerges from the background of government-regulated and politically-sensitive low bus fare structures (less than US $2 \mathrm{c}$ per $\mathrm{km}$ ). Also, apart from Delhi, no significant efforts have been made recently to improve bus travel, which accounts for over 90 percent of all public transport use in India. With sharply increasing income and car ownership levels in Indian cities, it is important to preserve the competitive position of public transit (in this case, mainly bus) in order to be able to retain and/or increase the patronage through improved quality of service.

Recent major rail-based metro investments have been made in Kolkata and Delhi. The first phase of the Kolkata Metro, with a route length of $16.5 \mathrm{~km}$, was completed in 1995, and construction for a second expansion phase of $8.7 \mathrm{~km}$ is now under way at a cost of about USD\$200 million (Kolkata Metro webpage 2006). The Delhi Metro, with three routes and a combined length of $65 \mathrm{~km}$, was implemented at an estimated cost of USD $\$ 2.5$ billion and has taken a construction period of about 7.5 years (DMRC 2006). As pressure on central and local governments mounts from other cities for implementing similar metro projects, initiatives are coming up in a few cities for suitable transit options. Referring to the successful BRT system of Latin America, researchers (Wynne 2004; Leal and Bertini 2003; Pucher et al. 2005) suggested improved bus services like BRT systems for large and medium cities of India as a cost-effective, quicker, or more feasible solution.

In 2004, a pre-feasibility study of BRT system in Hyderabad was made by ITDP, and findings were presented by the ITDP team to the city's Chief Minister, who was nearly convinced of the value of implementing a BRT system (ITDP 2005). In spring 2005, however, after a round of staff changes, Hyderabad's urban development authorities made an interim recommendation to pursue a three-corridor, elevated rail system based on a proposal from the Delhi Metro Rail Corporation (DMRC). While not yet finalized, the system will be financed through a buildoperate-transfer scheme. The ITDP pre-feasibility study found that, for the same $\$ 1.1$ billion capital investment required for the 37-kilometer elevated metro, a 294-kilometer BRT system could be built. However, political support for the BRT concept waned when decision makers faced some difficult decisions regarding the 
right-of-way. Also, India's big cities are looking at ways to emulate the grand system like Delhi Metro, charmed by its image factor. However, during the opening of the third line of Delhi Metro, the prime minister of India determined that it was not necessary that all Indian states emulate the same model, as each place had different requirements. "There are other cheap transport alternatives available. The Central government will encourage all proven technologies that are economically feasible," the prime minister explained. Delhi has now taken up a BRT scheme of about $300 \mathrm{~km}$ throughout the capital, realizing that, due to costs and lengthy implementation time constraints, only limited extension of rail-based systems are feasible. Other cities actively considering suitable forms of mass transit options are Bangalore, Ahmedabad and Pune.

An international initiative such as in China seems necessary in India also. ITDP has already started the initiative, but it probably needs more collaborators, as adoption of BRT planning in Indian cities by agencies involved might not be as smooth as in the cases of China because of the numerous parties and frequently changing power bases in Indian politics. There is no shortage of planning and technical capability in India to carry forward the required initiatives, but the institutional integration and political support could be a barrier, and an international team may act as a bridging media.

\section{Bangkok}

In Bangkok, a wide array of generally uncoordinated government agencies claim to be dealing with transport; there are at least 27 agencies (mostly public) with responsibilities related to urban transport (Townsend 2001). Even after creation of the Office of the Commission for the Management of Land Transport (OCMLT) in 1992, with a mission to regulate the plans and programs of all transport agencies, there is still lacking an authoritative multi-modal transport master plan. Some of the transport planning, approving and operation agents include Bangkok Metropolitan Administration (BMA): the local city government; Office of the Commission for the Management of Land Traffic; Office of Transport and Traffic Policy and Planning (OTP); Bangkok Mass Transit System Company (BTSC), the company that operates the Skytrain; Bangkok Metro Company (BMCL), the company chosen to operate the subway; and Bangkok Mass Transit Authority (BMTA). While at all governmental levels public transport has been given adequate priority, planning and adoption of a certain public transport technologies is always a difficult job in this sort of multi-agent planning platform. 
In recent years, Bangkok's planning bodies have come up with three different types of mass transit systems for Bangkok. The Skytrain (23.5km route length), the first rail transit system in Bangkok, has been in operation since December 1999 and is known as Green Line. This elevated train is currently operated by BTSC. An underground subway is the second component of Bangkok's mass transit network and is known as Blue Line ( $20 \mathrm{~km}$ route length); it is currently operated by BMC (Zhi Liu 2005). These two systems were implemented at a cost of US\$60 million and US\$155 million per km, respectively. Another $247 \mathrm{~km}$ of subway is also planned, of which the $29 \mathrm{~km}$ Purple Line extension is already under construction, with a budget of US\$1260 million. A project budget allocation of US\$15 billion is also earmarked for the remainder of the metro extension. The third transit establishment planned is the Bangkok BRT system, which is a part of the greater mass transit project.

The central government played the key role in implementing the two train-based systems, while the local bodies and directorates are entrusted with the responsibility of the BRT system. BMA and OTP are in a "tug of war" with BRT planning and adoption. OTP planned 9 routes with a total coverage of $380 \mathrm{~km}$, while BMA planned 12 routes with a total coverage of $185 \mathrm{~km}$. They also differed on the issue of station facilities, with BMA favoring busy stations furnished with escalators and air-conditioning. The Bangkok governor, apparently a BRT enthusiast, pressed forward the BRT plan on the background that per-km BRT route costs only onesixteenth of elevated Skytrain cost. Efforts were underway for construction of the first two lines of BRT with a total route length of $35 \mathrm{~km}$. Being operated by different operators and physically separated, the integration of the system, especially integrating BRT with the train-based system, is considered a challenge that must be met for the better performance of the system.

Also, BRT implementation is about to face resistance from general motorists in the upcoming election-time opinion campaign, as predicted in the local newspaper. The reason behind this is that BRT will directly interact with local motorists, thus shrinking lanes available for motorists and affecting flows. Rail-based transit does not cause this sort of friction as it is mostly developed without influencing the flow of local motorists. This initial friction could be a significant impediment to the implementation of BRT. But Taipei's experiences (Chang and Sun 2004) show that BRT effectively saves travel time for both bus and non-bus trip makers, as travel speeds of buses as well as general traffic have increased significantly after the implementation of BRT. This is because interference between buses and other vehicles sharply decreases due to segregated lanes for BRT. Therefore, the 
BRT planning body needs to be resilient enough to absorb these initial criticisms and also emphasizes the need for promoting modal shift, especially from motorist groups, as soon as possible after BRT implementation so the road and the BRT system together create a balance in traffic demand sharing for the corridor. A few tools helping in this regard could be creating park-and-ride facilities and pedestrian and bike facilities and integrating different forms of public transport. Obviously, the role of the media and promotional activities can be significant in making the BRT system popular in a short period.

Transit planning efforts in Bangkok include the progress of two different transit systems in parallel: a BRT system with a per $\mathrm{km}$ cost of about USD $\$ 1.3$ million, and the subway metro (Purple Line) with a per $\mathrm{km}$ cost of about USD $\$ 43.4$ million. Although the difference in implementation costs between the two systems is staggering, BRT can match the capacity of the metro with adequate fleet composition and road furnishings (Wright 2005). With all the potential of BRT, its future in Bangkok hinges on the enthusiasm of the City's governor. Bangkok had exclusive bus lanes introduced in 1980, with a result of either bus travel times or car travel times, or both, being improved significantly (Marler 1982). But the gradually slackened enforcement and encroachment by sharply increasing car traffic made them virtually ineffective (except the contra-flow lanes) by late 1980s. This somehow has created a poor image for the Bangkok bus system, which the planned BRT system has to overcome for acceptance.

In recent months, developments around BRT initiatives also took a stormy turn, and the governor apparently gave up the BRT project, blaming the government for its lack of support and deliberate delays in granting an operating license. Traffic police also seem to have played a role in this by complaining that the loss of one lane to BRT would only worsen traffic congestion. This shows the necessity of strong political backing to ensure government collaboration, or at least no interference, and a professional planning team to overcome the doubts brought forward by different parties.

Comparing this setback to the successful ongoing BRT initiatives of Jakarta, it seems the governor of Jakarta has substantial control over the budget allocation required for the project. Jakarta allocated increasing funds of some Rp 140 billion (US\$14 million) in 2004 as compared to Rp 510 billion in 2005, and the governor has proposed Rp 876.70 billion for the four new busway corridor projects in 2006. The governor's team also has capitalized on the unsuccessful quest for a financier for the rail-based metro project (ITDP 2003). Recent ITDP studies $(2003,2005)$ in 
collaboration with the local universities also formed a basis for a sound BRT plan. The first BRT corridor of $12.9 \mathrm{~km}$ has experienced an increase in patrons from 20,000 per day to over 70,000 per day within less than two years of its operation. The Jakarta BRT team is now poised to see through a successful BRT network development.

\section{Kuala Lumpur}

Institutional fragmentation is commonly identified as a root cause of transport woes in Kuala Lumpur (KL), as in the case of Bangkok (Townsend 2001). There are a number of federal and local bodies, including 10 ministries, involved in transport related issues; however, there is no single agency to see through transport planning, regulation and implementation in KL (Saleh 2005). The lack of an institution with oversight and visions for the future of multi-modal transport development integrated with urban land use has encouraged individual public and private stakeholders to initiate uncoordinated transit projects. With a city governing body (including the mayor) appointed by the King, the local government lacks in strong political power. All this has led to a situation where the federal government and politicians, especially the Economic Planning Unit (EPU) of the prime minister, have emerged as the most influential forum for transportation planning initiatives in greater $\mathrm{KL}$.

The Klang Valley region (KV) went through rapid urbanization and sprawling development in the economic boom of the 1980s and 1990s. Increased income and sprawling land use development encouraged rapid motorization, and carbased traffic demand outpaced the expansion of expressways and toll roads. Under pressure from high traffic demand and congestion problems, a few railbased transit mega projects were initiated independently by politicians and private firms. As a result, the STAR LRT system, with two routes (combined length of $26 \mathrm{~km}$ ), was implemented at a cost of US\$1.4 billion during 1996-1998; the PUTRA LRT system, with route length of $29 \mathrm{~km}$, was implemented at a cost of US\$1.74 billion during 1995-1999; the KL Monorail, with a route length of $8.6 \mathrm{~km}$, was implemented at a cost of about US\$0.5 billion during 1996-2003; and two conventional commuting rail corridors of KTM were refurbished at an unknown cost. Although efforts were made to integrate these individual systems, only limited physical and almost no fare integration took place until 2004. Also, KL, a city of $243 \mathrm{sq} \mathrm{km}$ with sprawling development well beyond this boundary, has a network coverage of only six routes of mass transit, which seems inadequate; accordingly, the vast majority 
of the city and its outskirts are literally beyond transit coverage and linked only by bus services. Domination of the private-car-led congestion on the road and repeated failed attempts of bus service regulation, integration and improvement have resulted in a poor service image for the bus. With the dwindling patronage, bus operators suffered financial losses which further deteriorated service quality. As a result, transit modal share further declined to 16 percent in 2003 (BINAFIKIR 2005) from 19.7 percent in 1997, even after the introduction of three new railbased rapid transit systems during the early part of that period. Most transit investors ran into deep financial trouble. As a consequence, while traffic congestion has already become a perennial woe for $\mathrm{KL}$ residents, there is a looming prospect of doubling of the vehicle population in KV in next 7 to 10 years (NEAC 2003).

Although officially guided by a 1991 privatization master plan to rely on concessions granted to the private sector for infrastructure investments, the federal government played a supportive role through various means. One of these means was the provision of soft loans from the government to privately-financed projects (e.g., both LRT systems and several expressway projects). Under these conditions, there was an implicit guarantee against failure or "moral hazard" that has since caused problems in the wake of the economic crisis that began in 1997 (Townsend 2001). Therefore, the central government (not the local city councils) reacted to the above situation by forming a special task force for KV public transport under the prime minister's department, which guided a public transport restructuring plan (INSPAK) with the help of a private consultant study.

Accordingly, the federal government took up the responsibility of two LRT lines and a few major bus companies and, at the same time, undertook initiatives for restructuring KV's public transport system, with the objective of an integrated and efficient public transport system. A three-tier (regulating, asset owning and operation management) setup was planned to be introduced as a step towards the solution, of which only asset owning (SPNB) and operating (Rapid KL) management modules were put in place recently. SPNB, suggested to be a purely government-owned entity, has the responsibility of asset owning, funding and procurement. RapidKL, currently government-owned, has the responsibility of operation and asset maintenance. It has also the obligation to meet certain performance criteria based on key performance indices. In the first year of operation, RapidKL is going for a full-scale restructuring of the KV bus network without any substantial demand pattern study. However, it will acquire 800 new buses through SPNB, arranged by government funding for establishing the changed new network 
service. But the important institutional, planning and regulatory body is not commissioned yet, which might allow loopholes in the implementation of the INSPAK initiative. Also, this regulatory body is supposed to handle the planning, research and development initiatives, which are clearly currently missing.

It is evident that, even with all initiatives to have the public transport investment liability on the private sector, it has bounced back to the government's shoulder. Although the private road concessionaires are still surviving with the increased motorist patronage, the government is providing a nationwide fuel subsidy of around USD\$3.5 billion. The only way out for the government is increasing the public transport patronage through an integrated wide coverage network with good quality service. At the same time, it must look for a financially self-sustaining transit system. With a lower per $\mathrm{km}$ cost of implementation and financially selfsustaining experience, a BRT system can provide such wide-scale coverage without much financial liability on the government (Hook 2004; Ardila 2004). However, with the BRT initiatives in the two neighboring cities of Bangkok and Jakarta, the authority is clearly unmoved regarding any sort of BRT initiative. Clearly, a strong planning team and enthusiastic political will are missing, which were ingredients for successful BRT planning initiatives in Latin American cities. Although formation of the planned regulatory body and capacity building can fill the gap of the required planning team, the political will is unlikely to be generated from the currently appointed local government. The most probable political power source may come from the federal government, especially politicians working with the economic planning unit of the prime minister's department.

\section{Dhaka}

Dhaka, the capital of Bangladesh, is now a city of about 12 million people, and the population is expected to increase to 18.5 million in the year 2015 (MOC 2004; DITS 1994). In an ideal situation, roads and lanes would be constructed on 25 percent of the city's surface area, but in Dhaka it is only 8 percent (DCC 2002), as Dhaka grew from a provincial capital to a national capitol in an unplanned way. Dhaka is perhaps the only city of its size without a well-organized, properly scheduled bus system or any other mass transport system. The transport system in Dhaka is characterized by different types of modes, with both motorized transports (MT) \& non-motorized transport (NMT) using the same carriageway. The city transport system is now in a quagmire, with traffic congestion, delays, inadequate traffic management, conflict of jurisdictions, poor coordination among 
organizations, and increasing air pollution problems. The city's traffic problems have reached a crisis proportion-delays have tripled in the last three years and automobile-related air pollution has become a major health problem-such that these shortcomings seriously compromise the ability of the transport sector in the Dhaka metropolitan area to sustain economic growth and a reasonable quality of life (DTCB 2004). In many respects, the distribution of modal choices in Dhaka is unique among cities of comparable size in Asia. Almost 60 percent of the 8.5 million weekday person trips are walk trips, and about 19.2 percent are by rickshaw (tricycle). For the remaining 20 percent of trips on motorized modes, 1.4 percent use an auto-rickshaw (three-wheeler), 9.2 percent travel by bus, 3.1 percent travel by private car, and 6.7 percent travel by various other modes. In terms of passenger $\mathrm{km}$, the share of buses is 30.6 percent and those of rickshaw and walking are 21.7 percent and 17.7 percent, respectively (DTCB 2004). The high dependence on walking and rickshaw, which are both slow and typically best-suited for short trips on secondary roads, and a low dependence on buses in a city of 12 million people with an urban area of about 2,000 square $\mathrm{km}$ is a symptom of inefficient and ineffective transport operations as well as uncontrolled land-use.

Buses and minibuses are the main motorized public transport sub-mode within Dhaka. There are about 2,200 registered private buses and minibuses and 400 BRTC (Bangladesh Road Transport Corporation) buses. Recently, BRTC procured 50 modern EURO Engine Volvo double decker buses, which have a capacity of 160 (120 sitting and 40 standing). There are also 250 double decker buses of with a capacity of 103 ( 83 sitting and 20 standing). However, as buses negotiate mixed traffic including NMT, the operating speed of the buses is reduced to such an extent that NMT has almost become competitive in terms of speed in shorter trips, and a motorized three-wheeler is definitely advantageous for all trips. This situation has encouraged the growth of approximately 9,500 taxis, 10,000 auto rickshaws, and an unknown number of pedal rickshaws (in the range of 300,000 to 500,000), all of which cater to personalized services for passengers. A preliminary estimate of vehicular trip demand on the city's 18 major bus routes showed a demand range of 150,000 to 350,000 per day, with peak hour per direction demand in the range of 4,500 to 9,000 per hour (Hossain and Hossain 2003; Hossain et al. 2003). This sort of demand can be comfortably handled by any modern BRT system. Also, considering the affordability of residents and government financial constraints, BRT could be an ideal choice for Dhaka. 
Deteriorating traffic conditions have prompted several popular public campaigns to find urgent solutions. An important step taken by the government in was the formation of the Greater Dhaka Transport Planning and Coordination Board (DTCB) in 2001 to integrate activities, coordinate stakeholders, and formulate policy and planning options for the city. The city mayor is the chairman of DTCB board, which also includes members from 17 other public and private bodies, including the chairmen of three peripheral local municipalities. But the organization lacks capable manpower and other resources and, as such, has not been able to establish a foothold until recently. Due to this and competition among politicians to deal with mega projects, most of the mass transit planning proposals and initiatives revolve around the communication ministry and the prime minister's office, bypassing DTCB. During the tenure of earlier government (1996-2001), elevated metro rail project biddings were almost to the final stages. Although initially 32 firms expressed interest in that build-operate-transfer (BOT) bidding, at later stages the number decreased to only two, and a later change of government buried the whole initiative.

During the current government tenure, a number of proposals for rail-based metro have come up, which include both subway and elevated rail systems. No final decision has yet been made, and the current government tenure will end in October 2006. During the last three five-year periods, Bangladesh has seen the alternation of two political parties in power and, due to unhealthy political animosity, one party does not seem to appreciate the ideas adopted by the other party. This single issue has created risk for mega projects such as the urban metro, so the planning and implementation of any such project could extend over more than a five-year period. This highlights the importance of the window of opportunity for adopting and implementing a transit system in Dhaka, as mentioned in Ardila's study (2004). But to prepare for and grab that window of opportunity, there must be a professional setup with good institutional backup. DTCB could take that initiative, but, as mentioned earlier, the organization lacks adequate human resources, monetary support and motivation. With an adequate planning team setup, this situation is more suitable for adopting a BRT system, as it can be planned and implemented within the tenure of a government and possibly alleviate transport problems, thus even helping the government's political cause. Again, some kind of catalytic influence from international initiatives such as ITDP or the Energy Foundation Group in China and other countries may well help DTCB in rising to the cause of BRT development in Dhaka. 


\section{Lessons Learned}

BRT planning initiatives involve multiple agencies in a complex stakeholders' setup based on rationality and equity. Therefore, a BRT proposal is unlikely to generate any special or vested interest group to drag through the planning and adoption initiatives. More and more, Asian city authorities and politicians, especially in China, are realizing the potential and importance of BRT systems in low to middle income city situations. Still, a number of rail-based metro systems are in progress in many parts of Asia, where BRT could have been a much better alternative in terms of lower fares and financial liability for the fund constrained governments. Governments and city authorities should be realistic in selecting a mass transit technology, focusing their considerations on actual needs, implementation and financial issues rather than emphasizing the image factor. Public transport professionals and BRT enthusiasts should take the window of opportunity offered by changes in government, the funding crisis for metro projects, rising oil prices, and international events concerning national pride. A knowledgeable planning team backed by strong political support seems necessary for defending the doubts put forward by critics and making progress through the initial period of chaos and resistance created mainly by car lobbyists. Whereas political backing is a key ingredient for success in all BRT systems, this sort of support appears to be transient in Indian subcontinent. Required institutional, technical and management skills for BRT planning initiatives seem lacking in most Asian cities. International initiatives such as the Energy Foundation, the Hewlett and Packard Foundation in China, and ITDP initiatives in a number of cities should continue in the future years to help Asian cities develop sustainable transport initiatives using BRT technology.

\section{Acknowledgments}

The author would like to acknowledge helpful comments on an earlier version of this paper from two anonymous reviewers, as well as a few colleagues at MUST. Thanks are also due to on-going MUST-MIT collaboration through which Ardila's $\mathrm{PhD}$ thesis was made available to this author, which was the inspirational source for writing this paper. However, the author alone is responsible for any errors or omissions in the paper. 


\section{References}

Ardila, G. A. 2004. Transit planning in Curitiba and Bogotá. Roles in interaction, risk, and change. Ph D thesis, Department of Urban Studies and Planning, Massachusetts Institute of Technology.

Asian Development Bank (ADB), 2001. Assessing the impacts of transport/energy infrastructure on poverty reduction: Country case study of the People's Republic of China. Inception report (draft), available at ADB wesite www.adb. org.

Bangkok Post. 16 February 2005. www.bangkokpost.net. 2005.

BINAFIKIR. 2005. INSPAK: Restructuring Klang Valley's urban public transportation system. Presented at Public Transport Integration: A Special Workshop Organized by Rapid KL on September 13, 2005, Kuala Lumpur.

Chang, J. 2005. BRT Developments in China. Environment 2005 Conference,

Sustainable Transport and Cities: Improving Transit Systems, Pre-Conference Workshop, Abu Dhabi, UAE. Jan 29, 2005. http://www.cleanairnet.org/caiasia/1412/article-59535.html accessed 02/02/2006.

Chang, J., and J. Sun. 2004. Progress and prospect of BRT in Taiwan. Report prepared by National Taiwan University and THI Consultants Inc.

Delhi Metro Rail Corporation (DMRC), website www.delhimetrorail.com.

Dhaka City Corporation. 2002. Structure plan, master plan, and detailed area plan for Dhaka City. Volume-1, Dhaka, Bangladesh.

DITS.1994. Greater Dhaka Metropolitan Area integrated transport study, final report: Volume 1. Planning Commission and Department of Economic and Social Development, Government of Bangladesh, and United Nations Development Program.

Dhaka Transport Coordination Board (DTCB). 2004. Dhaka urban transport project 1998-2004. accessible at http://www.dtcb.gov.bd/dutp_backgroundmain. htm.

Energy Foundation. 2005. Studies on international fiscal policies for sustainable transportation: The China Sustainable Energy Program. March 2005.

Hindu. 13 December 2005. www.hinduonnet.com. 
Hindustan Times. 2 January 2006, website www.hindustantimes.com.

Hoque, M., and T. Hossain. 2004. Augmentation of mass transit mode in Dhaka, Bangladesh. Presented at CODATU XI in Bucharest, Romania. Available at www.codatu.org/francais/publications/ actes/conferences/codatu11/Papers/ hoque.pdf.

Hossain, M., and M. McDonald. 1998. Modelling the impacts of reducing the non-motorised traffic on urban corridors of developing cities, International Journal of Transportation Research, Part A. Elsevier Science Ltd, Vol.32, No. 4, pp. 247-260.

Hossain, S, and M. Hossain. 2003. Mass transit corridors identification and demand forecasting for Dhaka City using GIS. Proceedings of 2nd International Conference and Annual Paper Meet, Institution of Engineers, Dhaka, Bangladesh. July 2003.

Hossain, M., A. Ali, and M. Ansary. 2003. Study of mass transit options for major cities of Bangladesh. Ministry of Science, Information and Communication Technology, Government of the Peoples Republic of Bangladesh.

Hook, J.W. 2005. Institutional and regulatory options for bus rapid transit in developing countries: Lesson from international experience. Presented at the 2005 Annual Transportation Research Board Conference, January, 2005.

Hook, J.W. 2004. Bus rapid transit planning, institutional reform, and air quality: Lessons for Asia. Presented at the 2004 Better Air Quality Conference in Agra, India.

Institute for Transportation and Development Policy (ITDP). 2005. Pre-feasibility study for bus rapid transit Hyderabad. Accessible at http://www.itdp.org/ read/Hyderabad_BRT.pdf.

Institute for Transportation and Develeopment Policy (ITDP). 2003. Trans-Jakarta bus rapid transit system: Technical review. Accessible at http://www.itdp. org/read/.

Institute for Transportation and Develeopment Policy (ITDP). 2005. Making Trans-Jakarta a world class BRT system: Final recommendations of the Institute for Transportation and Development Policy. Accessible at http://www. itdp.org/read/. 
Lean, M., and R. Bertini. 2003. Bus Rapid Transit: An alternative for developing countries. Institute of Transportation Engineers, 2003 Annual Meeting, Seattle, Washington.

Jakarta Post. December 2005. www.thejakartapost.com.

Marler, N.W. 1982. The performance of high-flow bus lanes in Bangkok. TRL research report SR723, Transportation Reseach Laboratory, Berkshire, UK.

Ministry of Communications. 2004. National land transport policy. Government of Bangladesh.

Nation. February 2006. www.nationmultimedia.com.

National Economic Action Council (NEAC). 2003. National transport policy and strategy study, final report. Minconsult SDN BHD.

Patrick, D. S., and G.B. William. 2005. Innovative public-private partnership models for road pricing/BRT initiatives. Journal of Public Transportation, Vol. 8, No. 1.

Pucher, J., M.H. Kim, and J. Song. 2005. Public transport reforms in Seoul: Innovations motivated by funding crisis. Journal of Public Transportation, Vol.8, No.5.

Pucher, J., N., Korattyswaroopam, N. Mittal, and N. Ittyerah. 2005. Urban transport crisis in India. Transport Policy, Vol. 12, Issue 3, pp. 185-198.

Saleh, R.A. 2004. Urban transportation in Kuala Lumpur: The challenges ahead. Presentation at the National Multimodal Transport Conference 2004, Connecting the Multimodal Chain, Le Meridien Hotel, Kuala Lumpur.

Singh, S. K. 2005. Review of urban transportation in India. Journal of Public Transportation, Vol. 8, No. 1.

Townsend, C. 2001. Roads before rail: Development of expressways and mass transit in Bangkok and Kuala Lumpur. Proceedings of 9th World Congress on Transport Research, Seoul, South Korea.

UN ESCAP. 2005. Review of developments in transport in Asia and the Pacific 2005, available at http://www.unescap.org/ttdw/Publications/TPTS_pubs/ pub_2392/pub_2392_fulltext.pdf.

Wright, L. 2005. Sustainable transport: A sourcebook for policy-makers in developing cities, module $3 \mathrm{~b}$ : Bus rapid transit. ITDP web publication. Available at http://www.itdp.org/read/brtplanningguidedec04.pdf. 
Wright, L. 2001. Latin American busways: Moving people rather than cars. Natural Resources Forum, JNRF 25:2.

www.citymayors.com/features/largest_cities.html.

Wynne, G. 2004. Bogota's BRT achieves farebox coverage of operating costs. International transit. January 19, American Public Transportation Association. Accessible at: http://www.apta.com/services/intnatl/intfocus/bogota.cfm.

Wynne, G. 2004. Transit investments spur China market ahead of 2008 Beijing Olympics. Passenger Transport, August 23, http://www.apta.com/.

Zhi, L. 2005. The institutional and policy dimensions of mass transit system integration. Presented at Public Transport Integration: A Special Workshop, organized by Rapid KL on September 13, Kuala Lumpur.

\section{About The Author}

Moazzem Hossain (moazzem@must.edu.my) is an Associate Professor of Transportation and Logistics at the Malaysia University of Science and Technology (MUST). His research and consultation interests include transport system simulation, public transport operation, and non-motorized transport. He has published extensively in various journals and conference proceedings and has developed a mixed traffic network simulation model, MIXNETSIM, for simulating urban road network with heterogeneous traffic. The simulation model has been applied in various developing countries, especially in Bangladesh, for simulation of bus lane and at-grade LRT operation under mixed traffic situations of developing cities. 
Journal of Public Transportation, 2006 BRT Special Edition 


\title{
Issues and Technologies in Level Boarding Strategies for BRT
}

\author{
David Kantor, Gregg Moscoe, and Cliff Henke \\ WestStart-CALSTART
}

\begin{abstract}
A variety of advanced docking technologies are now becoming available. However, some cities are still choosing low-tech alternatives over effective and more expensive new technologies that are well-proven elsewhere in the world. As a preview of an upcoming WestStart-CALSTART white paper, this report roughly surveys various technologies and strategies to achieve level boarding, as well as the legal and operational rationales for employing them, the policies supporting or impeding these strategies, the technology choices various cities have made, and why some cities have decided to forgo an advanced technology solution in favor of one focused on management strategies. Where available, operational experience will be provided, as well as a comparison of implementation costs. Examples are drawn from both domestic and international applications. The upcoming WestStart-CALSTART white paper will discuss all of these concepts in the appropriate depth.
\end{abstract}

\section{Introduction}

Perhaps the most important component to facilitating ridership is level boarding, which is a system that places boarding platforms on the same level as the floor of the bus. Level boarding eliminates the need to ascend steps onto the bus, which can be difficult for the elderly or persons with mobility impairments, thus decreasing dwell times for all passengers. Buses can then be automated to dock precisely at bus stops-"precision docking"- thus providing easy access and enhancing 
passenger safety. It also eliminates the need for wheelchair lifts or similar costly devices. The technologies included in level boarding and precision docking for BRT include intelligent transportation systems (ITS), satellite-based technologies, onboard bridgeplates, and even simple driver training techniques, among others.

Cities that are examining BRT as an option have looked at level boarding strategies to help them achieve faster boarding and travel times. The FTA-CALSTART FY03 Market Demand Study found that 36 percent of BRT communities in the U.S. would like to consider the use of an automatic docking system to achieve level boarding. However, while a variety of docking technologies are currently becoming available, some cities are still choosing low-tech alternatives over effective and more expensive technologies that are well-proven elsewhere in the world. For example, in the U.S., one current system and two as yet unopened systems recently have opted for manual approaches with some assistance by doorway bridgeplates that deploy when the vehicle doors are opened, in lieu of mechanical, optical, or magnetic technology.

\section{Background: Rapid Growth of Interest in Low-Floor Buses and BRT}

Low-floor buses enable faster boarding and alighting of passengers than high-floor buses. Boarding times for ambulatory passengers on a low-floor bus are reported to be from 0.2 to 0.7 of a second faster per passenger, while alighting times are reported to be from 0.3 to 2.7 seconds faster. The shorter dwell times are just one of the myriad benefits for low-floor buses, and, as more and more agencies are demanding BRT and low-floor buses, the need to address level boarding as the next challenge has increased.

Internationally, BRT is on the rise on virtually every continent. Examples of new BRT projects include guided busways in several U.K. cities; a BRT plan for Jerusalem; a BRT strategy to replace an abandoned metro expansion in Bangkok; BRT expansion in Colombia, which builds on the success of the mode in its capital of Bogotá; and massive BRT plans in China, which will have six lines covering $300 \mathrm{~km}$ (188 mi), scheduled to open in time for the 2008 Summer Olympics.

Domestically, more than 50 communities are now developing BRT systems, according to the United States Senate Banking Committee. Since that 2003 estimate, the number is believed to have grown by four to six cities per year, as data compiled by CALSTART for FTA has pointed out. The outlook for this new mode 
of public transportation - arguably the fastest growing mode since the early days of light rail development-is unquestionably bright.

Additionally, some of the funding blockages that have been holding back recent BRT deployments appear to be dissolving. A large part of this is due to the recently-enacted reauthorization of federal transit and highway legislation: the Safe, Affordable, Fair and Efficient Transportation Efficiency Act-A Legacy for Users ("SAFETEA-LU"). SAFETEA-LU earmarked a variety of new projects for future funding, some of them with guaranteed amounts, while also creating a streamlined review of projects that seek less than $\$ 75$ million in federal New Starts funding (so called "small starts"), including BRT projects. In the wake of this policy change, many observers expect more cities to re-examine the case for BRT. Table 1 shows the awarded cities listed in the bill.

\section{Table 1. Cities Receiving "Small Starts" Funding in SAFETEA-LU}

\begin{tabular}{|lll|}
\hline Gainesville, FL & West Covina, CA & Chula Vista, CA \\
Fairfax Co., VA & Las Vegas, NV (2) & Jacksonville, FL (2) \\
New York, NY & Baton Rouge, LA & Seattle (I-405) \\
Sonoma County, CA & Chicago, Il (Cermack) & Lakeville, MN \\
Sevier County, TN & Denver, CO (US-36) & Rockville, MD (2) \\
Monrovia, CA (Villages) & Tampa, FL & Miami, FL (2-3) \\
Broward County, FL & Houston, TX & Minneapolis, MN \\
Albany, NY & Pinellas County, FL & Sevierville, TN \\
AC Transit (New lines) & Syracuse, NY (University Corridor) & Toledo, OH (2) \\
Los Angeles, CA (Crenshaw) & Atlanta, GA (Memorial Dr.) & Provo-Orem, UT \\
Eugene, OR (Phase 2) & Harrison County, MS & Glendale, CA \\
San Fernando, CA (Reseda) & Mississippi Delta, MS (I-69) & Rock Island, IL \\
Woodland Hills, CA (Pierce) & Boston, MA (Urban Ring) & San Antonio, TX \\
Orange County, CA & Charlotte, NC (sev. corridors) & \\
\hline
\end{tabular}

* Financial guarantees specified in the bill are in bold.

On the technological front, strong interest has been shown in automatic guidance and precision docking technologies for bus rapid transit applications, yet no city has implemented any of these technologies in the U.S. so far. However, Lane Transit District in Eugene, Oregon, and the Greater Cleveland Regional Transit 
Authority have been evaluating various technologies and appear ready to take a step toward implementation on their BRT projects, the EmX starter line BRT in Eugene and the Silver Line along Euclid Avenue, in Cleveland.

Both systems are studying deployment of the mechanical guidance technology used throughout the world, including those in Leeds and other guided bus corridors in Great Britain; in Adelaide, Australia; and in Essen, Germany. Cleveland and Eugene also will look at more sophisticated guidance systems for future phases of their BRT systems, possibly including electromagnetic, optical, satellite, or some combination of systems.

\section{Technologies to Achieve Level Boarding}

Guided vehicles, used in conjunction with stations having platforms at the same height as the vehicle floor, can be expected to have boarding and alighting times similar to those on heavy rail or on some LRT systems, or approximately one second per person less than the passenger service times for conventional buses. Besides reducing average passenger service times, this stepless and gapless boarding and alighting can significantly reduce the time it takes for customers with disabilities or customers with children in strollers to board and alight from BRT vehicles. This precision docking, combined with wide aisles, can significantly reduce passenger service times for these customers, thus improving schedule reliability.

There are two forms of precision docking to ensure level boarding: vehicle-based and driver-based. Vehicle-based precision docking systems include opticallyguided steering (as used in Rouen, France), electromagnetically-guided steering (such as Eindhoven's Phileas vehicles or the service vehicles in the Euro tunnel) or mechanically-guided systems (as used in several British cities in Adelaide, and in Essen). These automatic guidance systems can accurately steer the vehicle into alignment with the platform, achieving a high degree of precision and consistency.

Optical guidance uses a video camera positioned on the front of the bus to acquire position data and then transmits that data to a computer that then steers the bus. Optical guidance systems allow close passing and automated steering along narrow roads, which leads to high-speed entry into and exit from stations, which can result in both consistent, precise level boarding and significant time savings in station service/dwell times over manual steering. The French cities of Rouen and Clermont-Ferrand have been using optical guidance since 2001. Las Vegas was 
scheduled to utilize optical guidance beginning in fall 2003, but the system was turned off because the city's road maintenance staff could not keep the pavement stripe clean and well-defined in the city's extremely hot, dry, and sunny desert climate. Moreover, the transit agency's management found that the vehicles' drivers could manually steer the vehicle into the stations with sufficient precision.

Electromagnetic guidance systems involve either magnets embedded in the roadway or electrified subsurface cables. The positives are that the infrastructure technology (magnets) is less expensive than the mechanical approach but not as cheap as the optical approach (since it is striping only) and the onboard technology is slightly less expensive than the optical system (less than $\$ 100,000$ for optical systems per bus). Because there are only a few installations, the technology for transit applications is unproven.

FROG Navigation Systems, which provides magnetic guidance systems for the Dutch-based company APTS (producer of the Phileas BRT vehicle), has now established a facility in Charlotte, North Carolina. The FROG system utilizes an onboard inertial guidance system, which relies on magnetic markers for guidance correction. Although it has begun to sell its system for industrial warehouse applications in the U.S., FROG is also seeking demonstration or commercialization opportunities for BRT applications in North America.

Among various mechanical guidance systems is a version that utilizes an arm with a small rubber wheel on one end. The other end of the arm is attached to the bus steering axle such that, when it runs up against a concrete curb, it helps the driver guide the bus closer to the platform edge. Mechanical guidance systems have the advantages of tight running trajectories, precision docking, and a high degree of safety, simplicity, and robustness under severe operating conditions. The disadvantages include vehicle weight and the additional infrastructure necessary for them to work.

Yet another emerging approach is the use of advanced ITS technologies to provide lateral vehicle guidance. GPS-based technologies are used in about 75 percent of all automatic vehicle location (AVL) systems in the U.S., making them the most widely used location technology in the United States. GPS systems can locate the position of a vehicle to within two to five centimeters and can be operated anywhere the signals can be received. The costs per vehicle are moderate and can also be used in combination with ground-based radio-frequency monitoring for further accuracy (so-called differential GPS). These technologies can also support precision docking. 
However, not all precision-docking technologies are high tech. Sometimes, the platform can be detailed enough to provide a precision docking interface. The Kassel Curb, for instance, is a concrete curb with a concave profile on its street face. The driver steers the bus so the tires are forced against the curb, which, in turn, places the bus in the proper alignment with the platform edge. This system has been shown to meet the ADA Accessibility Guidelines ("ADAAG") gap standard in regular use, but it is highly reliant on the skill and diligence of the driver. It may also accelerate tire wear because of repeated contact with the curb, and the curb height must be coordinated to avoid conflicts with wheel nuts and vehicle door operations.

Without a precision-docking system, another possible option is the use of retractable bridgeplates to provide a barrier-free boarding interface. The vehicle is manually steered as close to the platform as possible, and the plate is then deployed to bridge the remaining gap. Like lifts, retractable ramps and bridge plates adversely impact dwell times and require regular maintenance. The disadvantages of this approach are the inability to service stations and stops without the appropriate platforms, as well as the extra maintenance costs entailed by the ramps. Since the devices extend from one or more bus doors, this obstacle could be overcome by having doors on both sides of the vehicles, or bridgeplates installed in only some of the doors, to be deployed as needed. Ramps would then be deployed as they currently are on traditional bus service, i.e., from a designated door only upon passenger need. However, this approach could reduce seating capacity, and the system would suffer from increased dwell times at the off-line stations. Lifts can be used instead of ramps when a system departs from the currently established U.S. trend.

There are exceptions to the rule that low-floor buses are required for level boarding. In fact, many systems outside the United States perform well without automatic guidance and precision docking technology. While most of the world's BRT stations use low platforms to match their low-floor vehicles, Quito's Trolebus, Bogotá's TransMilenio, and Curitiba's all-stop and direct express services actually provide high platforms. Some of these buses are especially equipped with a large ramp that deploys at stations to allow level boarding and alighting.

All of the aforementioned technologies can provide advantages well beyond precision docking: they also enable full guidance along an entire BRT route, which improves speed and also allows narrower lanes, saving on infrastructure costs. Currently, these technologies are being used in Europe in combination with such 
infrastructure strategies as fully grade-separated roadways and lanes (e.g., Leeds and Rouen), as well as queue-jumping lanes around mixed traffic only (also in several British cities).

\section{Management Techniques for Level Boarding}

Expensive guidance technologies have not been the only strategies employed to achieve precision docking and level boarding in BRT applications. For example, as was alluded to earlier, Las Vegas purchased its Civis vehicles from Irisbus with its optical system developed by Siemens/Matra in France. However, because of the difficulties in keeping the pavement striping crisp and clean-a significant issue for any optically-based tracking system as it is dependent on the clarity of the image-the system has been turned off and its use suspended while Siemens Matra continues to refine the pattern recognition software in the tracking system.

In the meantime, the Regional Transportation Commission, which was responsible for the BRT project in Las Vegas, learned that its drivers for the Civis fleet could steer the vehicle well enough to achieve a consistent and sufficiently close gap between vehicle floor and platform without the use of the guidance technology. Thus, the combination of driver training, the center drive position of the Civis vehicle, and pavement striping (even faded, it could be seen by the human eye well enough) has enabled manual precision docking.

This experience is somewhat corroborated by operations in Brisbane, Ottawa, and Bogotá, which have no precision docking technologies. In the South American examples, drivers use a combination of training, experience and marks on their buses' side mirrors (that they line up with the platform edge) to achieve a minimum gap between platform and vehicle. Some cities also penalize drivers for repeated bus body damage if they continue to brush the bus against the platform edge.

Further analysis of the various costs and benefits of level boarding strategies will be incorporated into the FTA-funded WestStart-CALSTART Level Boarding report. The report is expected to be released by the end of June 2006. 


\section{Policy Rationales for Level Boarding}

There are two fundamental policy rationales for offering transit patrons level access from stops or platforms to the vehicles (whether buses or railcars). First, level boarding enables a faster passenger flow both on and off the vehicles, which minimizes dwell times and decreases journey times. Shorter travel times enable a faster throughput, which has productivity advantages since fewer vehicles can serve the same or even improved schedules. This was one of the realized objectives of the Metro Rapid demonstration project in Los Angeles. Because bus speeds were improved up to 30 percent, the Los Angeles County Metropolitan Transportation Authority was able to offer service that was both faster and more frequent. At the same time, the authority has continued its local service in the same corridor without any additional buses and without additional operating costs.

The second rationale for level boarding is compliance with accessibility policies and regulations. Although level boarding can enable faster dwell and journey times, transit service must first meet the operational requirements to suit all passengers, including those with disabilities.

According to the Transportation Research Board,

... the platform/vehicle interface has a strong influence on passenger experience and boarding speed. Level boarding minimizes the horizontal and vertical gap between the platform edge and vehicle door threshold. This speeds boarding for all patrons and also allows wheelchair users to enter the vehicle without a lift or other assistance. For wheelchair access on fixed-guideway systems, the ADAAG allows a maximum vehicle floor-to-platform gap of 3 inches horizontally and 5/8 inch vertically. Although the ADAAG requirement for buses is not as stringent, this is the standard to meet for the highest-quality, barrier-free access. For a bus and platform to meet this standard, some form of precision docking system (or a vehicle- or platform-mounted retractable ramp or bridge plate) is required, the platform height must match the vehicle floor height, and the platform must be located along a tangent section of roadway. (Levinson et al., TCRP Report 90, Volume II: pg. 102)

When these words were written, "level boarding" and "fixed guideway" in this content were intended to mean rail systems. However, many believe that these standards can also apply to BRT, if the aforementioned gap dimensions can be ensured. Again, the white paper will delve deeper into these issues. 


\section{Legal Issues Regarding BRT Level Boarding}

The ADA requires low-floor buses to have ramps, while standard-floor buses must use wheelchair lifts. Both are required to install at least two sets of wheelchair securements per bus. In many other countries, accessibility policies do not require securements. For example, Britain's Disability Discrimination Act (DDA) currently requires what is referred to as the "protected position," which is a somewhat less secured arrangement to accommodate wheelchair passengers, leading to potentially less stable positions for these passengers. The "protected position" offers many benefits: a greater sense of independence for the passenger in the wheelchair; liberation from the hooks or belts often required to secure their position; a high level of safety; and faster boarding and alighting times. However, it does not meet the ADA requirements for a $20 \mathrm{~g}$ deceleration. Thus, for BRT applications in the United States, a waiver of the regulations would likely be required. Additionally, wheelchair passengers in this position are forced to face toward the rear, which can be an issue in the United States, since most seating layouts do not employ rear-facing seats and the philosophy of most accessibility advocacy groups stresses treatment of mobility-challenged people as part of the "mainstream" population as much as possible. However, just as with railcar seating layouts accommodating multiple door boarding, this may become less of an issue as more of the industry gains experience with BRT. If it becomes a norm of operation as in railcar layouts, they would not be made to "feel different" if they were facing backward as some others would also be facing that way.

This disparity in disabled passenger policy for buses around the world might be attributed to the respective countries' views on the purposes of public and private transit. In the United States, which has developed transportation policies that are heavily dependent upon the automobile, most public transit outside a few densely populated cities has been considered to be a niche system meant to serve transit-dependent populations: the elderly, the mobility impaired, and the poor. In the rest of the world, where public transportation is more generally accepted as an important part of transportation for all residents, its focus is to move as many people as efficiently as possible; the needs of the mobility challenged are often subsumed to those of the majority. However, both Canada and the U.K. are now looking at tie-downs, ramps, and more extensive demand response services for the persons with disabilities.

If ADA policy for buses applies to BRT (requiring securements and ramps), the end result will increase dwell times and decrease the productivity gains of the system, 
running in the face of the very purpose of BRT. If the federal government will adapt rail regulations to BRT, however, then the rail-required use of level boarding and precision-docking would preclude these inefficiencies, as precision-docking helps to ensure a minimal gap for level-boarding and alighting, acting as rails do for rail transit. The end result would be greater accessibility and boarding speed for the disabled without negating the other benefits accrued by the BRT system as a whole. In fact, the BRT system would be even more efficient for all passengers, due to its shorter dwell times. And since American public transit serves to a ridership with a disproportionate number of elderly and persons with disabilities in comparison to its population ratios, the system's benefits would seem tailor-made for current U.S. transit demographics.

\section{Rail Regulations and Adaptability to BRT}

At a recent $B R T$ conference for persons with disabilities, it was recommended that, while regulatory needs for BRT can be largely met by drawing from existing bus and/or rail regulations, the federal government should provide a greater amount of guidance on which elements of the bus regulations and which elements of the rail regulations apply to BRT systems. Additionally, it was suggested that when a BRT bus "acts" like a train, rail regulations should apply, and that when it "acts" like a bus, bus regulations should apply. The upcoming white paper will explore this question further and help provide recommendations. Of course, the BRT vehicles will be used outside the guideway in mixed traffic as with traditional bus service, so it is clear that that the mobility-challenged community favors policies in which BRT vehicles have both tie-downs and some interface technology to ensure level boarding.

\section{Case Studies}

\section{Leeds and Bradford}

Several subsidiaries of the British multinational bus and train operator First Group have implemented level boarding with mechanical guidance technology, the same as that pioneered in Essen and Adelaide. The cost per station is minimal: in Leeds, less than $\$ 10$ million total was spent by city authorities for precast concrete guidance curbs at 200 stations in the Superbus guided bus network. As part of a publicprivate partnership called a quality corridor agreement, First Group contributed roughly $\$ 20,000$ per bus to install a mechanical guidance arm on the steering axle 
of each low-floor bus operating in the network. It was part of new orders for both 12 meter (40-foot) single-deck and double-deck low-floor buses with Volvo and Wright Group. Level boarding is achieved by the driver manually steering the bus between the guidance curb at the station platform edge. The guidance arm keeps the bus close to the platform edge and as the driver brings the bus to a stop, he or she can turn the steering wheel to provide more tension on the arm, bringing the bus closer to the curb if necessary. The Superbus guided bus network has been so successful that, in Leeds, the investments by both the public sector and the private operator were paid for by the increased ridership in the third year of operation. Future plans call for expansions of the network and upgraded passenger amenities, such as real-time information displays.

\section{Curitiba and Bogotá}

Like most BRT systems outside the U.S., both of these cities have systems that use high-boarding platforms with ramps for accessibility and standard-floor buses without tie-down positions for wheelchairs. Drivers manually guide buses close enough to the platform edge of each station. As mentioned earlier, in Curitiba, drivers often mark notches in their side mirrors to help them guide the buses in place at each station by lining the mirror notch to the platform edge in their mirrors. Some operators in these cities financially penalize the drivers for damage to their buses, so they have a strong incentive to bring the bus close to the platform edge without actually hitting it.

In addition, operators in Curitiba also deploy bridgeplates from the bus doors to facilitate easier access across the gap between vehicle and platform. These devices in some cases deploy manually; in others, they deploy automatically as the bus doors open. At roughly 1,000,000 passengers per day, Bogotá's TransMilenio BRT network carries nearly as many people per weekday as the Washington, DC metro system. Curitiba's system, while not as heavily used, nonetheless carries a market share of more than 70 percent of trips in and out of the metropolitan area per weekday, despite Curitibans having the second highest automobile ownership rates in Brazil.

\section{Conclusion}

Level boarding and guidance technology are critical components of BRT, as they support the basic goals of BRT by reducing dwell times and, consequently, travel times. Achieving speedy and consistent service is essential to attracting new riders, 
and ease of boarding and exiting affect customer satisfaction and system performance.

Currently, there is no uniform level boarding strategy. Transit organizations address level boarding in different ways. While low-floor buses are the norm in the U.S., some of the original BRT systems in Bogotá and Curitiba utilize elevated platforms and high-floor buses with excellent results.

As advanced guidance technologies are entering service in a number of locales here and abroad, many transit systems are relying on less-sophisticated but effective mechanical and driver-based solutions. Again, those early BRT systems, as well as the transit properties in Las Vegas, rely on driver training and simple manual guidance assists to achieve reasonably consistent boarding results. Systems in Leeds and elsewhere have garnered excellent results with mechanical docking mechanisms.

As with many things, considerations of existing conditions, local needs, and budgetary issues, as well as local policy and labor agreements, will affect the choices individual systems make regarding level boarding and guidance technology. However, higher-level issues-such as the application of rail or bus accessibility standards to BRT - may have a greater impact in the long run.

\section{References}

Arrillaga, B., L. Wnuk, F. Silver. 2004. Bus rapid transit vehicle demand analysis update. USDOT \& FTA Office of Research, Demonstration, and Innovation; Office of mobility Innovation, Service Innovation Division. FTA-CA-26-70442003.2.

Diaz, B., M. Hardy, M. Baltes, L. Wnuk, and S. Zimmerman. 2004. Characteristics of bus rapid transit for decision-making. U.S. Federal Transit Administration, Report number FTA-VA-26-7222-2004.1. Washington D.C.

Levinson, H., S. Zimmerman, J. Clinger, J. Gast, S. Rutherford, and E. Bruhn. 2003. Transit Cooperative Research Program, Report 90, Volume II: Implementation guidelines. Washington D.C.

No author. 2005. Draft report: Bus rapid transit and accessibility for persons with disabilities consensus conference, key points summary. 
Transportation Management \& Design, Inc. 2002. Final report: Los Angeles Metro rapid demonstration program. Los Angeles County Metropolitan Transportation Authority and Los Angeles Department of Transportation. Los Angeles, CA.

U.S. Federal Transit Administration. 2005. Proceedings of the bus rapid transit vehicle working group meeting. Washington, D.C.

\section{About the Authors}

Cliff Henke, Gregg Moscoe and David Kantor are, respectively, Senior Director, Publications Editor, and Associate Project Manager at WestStart-CALSTART, a Pasadena-based nonprofit advanced transportation technologies R\&D organization. 
Journal of Public Transportation, 2006 BRT Special Edition 


\title{
An Evaluation of Comprehensive Transit Improvements- TriMet's Streamline Program
}

\author{
Peter Koonce, Kittelson \& Associates, Inc. \\ Paul Ryus, Kittelson \& Associates, Inc. \\ David Zagel, TriMet \\ Young Park, TriMet \\ Jamie Parks, Kittelson \& Associates, Inc.
}

\begin{abstract}
Transit performance is influenced by a variety of factors in an urban environment. Making transit more convenient and competitive with automobile travel is a key objective for the Tri-County Metropolitan Transportation District of Oregon (TriMet). TriMet's goal is to have a "Total Transit System" that makes transit an attractive choice for riders. Portland's Streamline program has been a significant effort toward meeting these goals. The program has resulted in operating and capital cost savings for TriMet by delaying the need to add more buses to the fleet as well as operating savings due to reductions in running time variability. Further, the way the program was implemented resulted in a greater increase in ridership than would have been achieved had the service increases been spread more evenly around the system, confirming that the BRT approach serves transit agencies effectively by concentrating improvements on corridors.
\end{abstract}




\section{Introduction}

The Streamline program, a joint effort of TriMet and the City of Portland, is a package of capital projects and service improvements designed to improve service to all passengers and provide operating efficiencies to TriMet. The program resulted from a $\$ 4.5$ million federal earmark to the City of Portland under the Transportation Equity Act for the 21st Century (TEA-21), and was implemented through an Intergovernmental Agreement (IGA) between the City of Portland and TriMet, which was signed in July 2000 and which expired at the end of 2005.

This program required investments both on the part of TriMet and the City of Portland. Key investments on the City's part were the installation of transit signal priority at 275 intersections and installation of signal priority emitters on nearly the entire TriMet bus fleet. TriMet's key investment was an annual contribution toward the operating cost of the City's streetcar line. Other changes included installing curb extensions, consolidating bus stops, removing bus pullouts, and improving service quality.

The intended goal was that TriMet would recoup its investment through running time saved by streamlining -in other words, if four or five peak buses could be saved, the bus operating cost savings would offset the investment in transit preferential treatments paid for through TriMet's contributions to the overall program.

As little documentation could be found related to whether a transit system in the U.S. had tried a systematic streamlining program anywhere close to this scale before (the program included 12 routes), there was no past history to use to evaluate the validity of the program's expectations. However, now that five years have passed, it is possible to evaluate how the program has impacted TriMet.

\section{Streamline Program Summary}

The Streamline program supports TriMet's strategic direction by enhancing operating efficiency and improving service quality, thereby attracting new ridership. This section provides an overview of how streamlining accomplishes these objectives; subsequent sections provide the details.

\section{Operating Efficiencies}

Operating efficiencies arise through reductions in the time scheduled for buses to operate on a route. The cost of operating a route is directly related to the number 
of buses assigned to it. If it takes a bus two hours to make a round trip, including layovers, and a route operates at 15 -minute headways, it takes eight buses to serve the route. If the time required to serve the route increases, so must the number of buses if the headway is to be maintained. For example, if the round-trip time increases to 2 hours, 10 minutes, then 9 buses would be required to serve the route. Assuming the extra bus operates 8 hours a day (e.g., only during peak periods) and assuming TriMet's FY2004 bus operating cost of $\$ 69$ per vehicle hour, the extra bus would require an additional operating expense of approximately $\$ 140,000$ per year. In addition, the extra bus requires an addition to the fleet, with new buses costing approximately $\$ 300,000$ each.

In an ideal situation, the time saved through streamlining would allow TriMet to remove a bus from a route, allowing service to be increased on another route or the annual operating budget to be reduced. However, to achieve this reduction, the time savings must equal or exceed the route's headway-a maximum of 15 minutes on a Frequent Service route, and often less during peak periods. More commonly, streamlining saves time, but not enough to save a bus. However, the time saved postpones the year when a bus must be added to a route to maintain headways. The number of years saved depends on (1) the rate at which time is being added to the schedule to compensate for congestion and (2) the amount of time saved through streamlining. If, for example, congestion causes scheduled round-trip travel times to increase by one minute every two years, on average, and streamlining saves three minutes, then the need to add a bus is postponed by about six years. (Streamlining can also reduce the rate at which time is added to the schedule [e.g., in this hypothetical example, from one minute every two years to one minute every three years], which would make the time saved last longer before a bus would need to be added.)

The time saved by streamlining comes from two main sources: running time savings and recovery time savings. Transit signal priority, curb extensions, and queue jump lanes help a bus travel its route faster than it otherwise would have. Signal priority also helps reduce the variability in the time buses take to make a trip from one end of a route to the other, allowing schedulers to reduce the amount of recovery time provided between trips. Recovery time is an allowance for late trips, ensuring that a bus can depart on time for its next trip.

\section{Service Quality Improvements}

Many of the performance measures historically used in the transit industry reflect the business aspects of providing transit service. However, an emerging area of 
transit performance measurement addresses the impact that transit has on its passengers and the community as a whole. For example, the Transit Capacity and Quality of Service Manual (TCQSM) (Kittelson \& Associates 2003) provides measures that reflect the quality of service provided to passengers. It was with the customer point-of-view in mind that the Streamline program provided the following service quality improvements:

- Improved frequencies. All of the streamlined routes are also Frequent Service routes, operating at 15 -minute or better headways throughout the day, each day of the week. Of the 12 streamlined routes, 9 have had at least a 5 percent increase in service hours between 1999 and 2005, 7 have had at least a 10 percent increase, and 5 have had at least a 20 percent increase. In comparison, TriMet's non-Frequent Service routes have had a 2.4 percent reduction in service hours over the same period. Improved frequencies reduce the time that passengers wait for the bus (which passengers perceive as being twice as long as the actual time). Frequent service also makes short and spur-of-the-moment trips more feasible, as passengers can be confident of not having to wait long when they do not know the route's schedule.

- Improved travel times. Time saved through more efficient routings and through transit signal priority reduces passengers' overall trip times. Passengers board and alight low-floor buses more quickly than high-floor buses, allowing a bus to continue its trip sooner. Consolidating bus stops also reduces delays due to bus deceleration/acceleration at stops and delays merging back into traffic. Although the number of passengers served at a given stop increases, the overall time spent serving passengers should not change over the length of the route, as the extra passengers would simply have been served at a nearby stop before.

- Improved reliability. Transit signal priority helps maintain schedule reliability. The system gives late buses an opportunity to recover time, while maintaining the schedule for on-time and early buses (which are not granted priority). More reliable service reduces passenger wait time at stops and also helps maintain even loads across buses, as late buses tend to pick up more passengers than usual and thus fall farther behind schedule. Consolidating bus stops also helps reduce travel time variability, as buses are more likely to stop each time at the remaining stops. Reductions in travel time variability allow reductions in schedule recovery time at the end of the trip. 
If the combination of recovery time and travel time savings is at least one headway, a bus can be saved.

- Improved passenger infrastructure. Items like TriMet's new blue bus stop poles, ADA concrete landing pads, and shelters help announce the presence of bus service even when buses are not in the vicinity at that moment. Stops can sometimes be moved to locations that favor signal priority and provide more room for passenger infrastructure. New sidewalk construction, curb ramps, and ADA landing pads make stops more accessible for all persons; therefore, these features likely reduce riders' reliance on much more costly paratransit service and provide greater flexibility for when riders can travel.

- Improved information. The on-board automatic vehicle location (AVL) system is at the heart of TriMet's TransitTracker ${ }^{\text {Tm }}$ real-time passenger information system, which provides bus arrival information over the Internet, by phone, and at nine bus stops equipped with electronic signs. The upgrade of TriMet's communications system, made possible with Streamline funds, will provide buses with Automated Stop Announcement (ASA) capabilities, similar to what already exists on TriMet's light rail vehicles.

- Curb extensions. Curb extensions reduce the distance that pedestrians are exposed to traffic while crossing the street on their way to or from the bus stop. They also make passengers more visible to bus operators, and provide additional area to place bus stop amenities.

\section{Ridership}

Between 1999 and 2005, the number of vehicle-hours allocated to the 12 streamlined routes increased 16.3 percent, while ridership on those routes increased 18.2 percent. In contrast, over the same period, the number of vehicle-hours allocated to non-Frequent Service routes decreased 2.4 percent and ridership on those routes decreased 0.7 percent.

The change in ridership on the non-Frequent Service routes corresponds to an elasticity of 0.30 - that is, for every 1 percent increase or decrease in service hours, ridership increases or decreases by 0.3 percent. In the absence of other changes, this observed elasticity would be typical for urban systems with routes operating at 30-minute or better headways (Evans 2004). In contrast, the elasticity observed for the streamlined routes was 1.11 -that is, ridership increased at a faster rate than service was added. Elasticities this high are normally only seen in suburban systems that operated at 60-minute headways prior to the service increase. This 
high level of ridership increase on urban routes suggests that other factors were at work beyond the service frequency increase, although it undoubtedly played a large role.

Over a six-year period, there are a number of external factors that can also affect ridership, including fare increases, population growth, and service restructuring (e.g., due to the opening of new light rail lines). The first and third, of these factors should generally affect Frequent Service and non-Frequent Service lines equally, given TriMet's fare system and route structure that has most routes serving downtown Portland and/or connecting to light rail. While the population of the Portland region, where many non-streamlined routes operate, has grown, the population of the city of Portland itself, where most streamlined routes operate, has held relatively steady, with only a 0.8 percent increase from 2000 to 2004 (Bureau of the Census 2004). The area of Portland that experienced strong population growth during that time-the Pearl District-is served by streetcar rather than by streamlined routes. Finally, the rate of ridership growth relative to service changes on the streamlined routes from 1999-2005 was greater than the rate of growth on the light rail system, which included the effects of three line extensions. Therefore, it can be concluded that other changes implemented at the same time as the service increases (e.g., Frequent Service branding and streamlining improvements) also contributed to the much greater change in ridership seen on the streamlined routes, compared to the non-Frequent Service routes.

\section{Methodology}

The evaluation of four specific measures is considered in support of our documentation of benefits for the Streamline program. These measures include a review of the following: ridership changes, additional fare revenue, on-time performance, and round trip time savings.

\section{Ridership Changes}

TriMet's 1999 bus ridership was 200,040 passengers per weekday. Ridership has increased over time and, as a part of this, vehicle hours increased by 3.6 percent between 1999 and 2005. If the service increase between 1999 and 2005 had been spread throughout the TriMet system, and not accompanied by streamlining and marketing activities, the change in ridership likely would have been similar to that observed for the non-Frequent Service routes. Given the 3.6 percent increase in overall bus service hours from 1999 and 2005, and applying the observed non-Fre- 
quent Service elasticity of 0.30, weekday bus ridership would have been expected to increase from approximately 200,040 passengers in 1999 to 202,200 in 2005, all other things being equal. Instead, weekday ridership increased to 214,230 passengers, a difference of approximately 12,000 passengers per weekday

\section{Additional Fare Revenue}

Fare revenue is closely related to ridership data, but, as it is a different source of data, it is relevant to our assessment of the program. Based on 2004 National Transit Database data, TriMet's average bus fare per boarding was $\$ 0.57$. (This value includes discounted fares, boardings that were transfers, and boardings in the downtown Fareless Square.) Multiplying 12,000 additional weekday passengers by 250 weekdays per year equals 3 million additional annual bus boardings. The corresponding fare revenue is approximately $\$ 1.7$ million.

\section{On-Time Performance}

The average on-time performance for streamlined routes (weighted by daily vehicle hours operated on each route) went from 80.6 percent in 2001 to 78.0 percent in 2005, a drop of 3.3 percent. On-time performance of non-Frequent Service routes went from 79.0 percent in 2001 to 74.2 percent in 2005, a drop of 6.1 percent.

\section{Round-trip Time Savings Compared to Non-Streamlined Routes}

On average, the 12 streamlined routes operate 0.8 minutes faster per round trip in 2005 than in 2000, while 7 comparative non-streamlined Portland routes operate 1.3 minutes slower. The difference is 2.1 minutes. The scheduled round-trip time of the non-streamlined routes has increased an average of 0.25 minutes per year. If the round-trip time of the streamlined routes increases at this rate from this point forward, it will take 8 years to use up the 2 minutes saved. Any recovery time savings that can be quantified in the future would postpone the need to add buses by additional years. This calculation assumes that the rate of increase in round-trip times will remain constant into the future-if future congestion causes scheduled times to increase at a faster rate, the years of savings will be less. The calculation also assumes conservatively that streamlining does not reduce the rate at which round-trip times increase due to congestion. The travel time reduction is associated with signal priority and curb extension delay savings, each of which are described in the following paragraphs. 


\section{Signal Priority}

The street with bus service typically has a green signal $40-50$ percent of the time, which means that the signal is red 50-60 percent of the time (ignoring the relatively small time the signal is yellow). With 50 percent red time and a 70 -second cycle, a bus could be delayed up to 35 seconds. With 60 percent red time and a 100 -second cycle, a bus could be delayed up to 60 seconds. There are more widely documented benefits elsewhere (Koonce et al. 2002).

\section{Curb Extension Delay Savings}

The TCQSM gives average delay values for buses merging back into a street, where vehicles are arriving randomly (Kittelson \& Associates 2003). The delay ranges from 1 second for streets with 100 vehicles per hour in the curb lane to 15 seconds for streets with 1,000 vehicles per hour in the curb lane.

At traffic signals, with no compliance with yield-to-bus laws, a bus would need to wait for the queue of vehicles to clear once the signal turned green (a process that takes approximately 2 seconds per car), and then wait for a sufficiently long gap in traffic to safely merge back into traffic (determined from the TCQSM). For example, with a 250 -foot queue (10 vehicles) and moderate traffic volumes on the street (500 vehicles per hour), it would take 20 seconds to clear the queue, and an additional 5 seconds on average to get a long-enough gap.

If a curb extension extends the width of the parking lane ( 8 feet), then two curb extensions reduce the crossing distance by 16 feet. At a pedestrian speed of 4 feet per second, the pedestrian crossing time is reduced by 4 seconds.

One cannot simply add up the potential savings of each streamlining improvement along a route to determine how much time might be saved. Some of the localized time savings will not translate into actual travel time reductions over the length of the route, generally depending on whether a bus is able to get through a downstream traffic signal that it otherwise would have missed in the absence of streamlining treatments. Because passenger boarding activity, traffic volumes, the allocation of green time to the bus street at traffic signals, and other factors vary from one trip to the next, it is generally not possible to be more definitive about the actual time that is saved by a given improvement. The streamlining improvements work in combination to give a bus the best possible chance of saving time along its route. 


\section{Results}

The following is a summary of the streamlining impacts that can be quantified to date:

- The time savings resulting from streamlining has not allowed TriMet to permanently reduce the number of peak buses on a route. As a result, there have been no short-term operations savings.

- The 12 streamlined routes, on average, operate a round trip 0.8 minutes faster now during the weekday a.m. peak than they did in September 2000. In comparison, 7 non-streamlined routes that mainly operate in the city of Portland operate a round trip 1.3 minutes slower on average, and 4 primarily suburban routes operate a round trip 2.3 minutes slower on average.

- The full impacts of streamlining on running time variability have not yet been quantified. A study conducted by Portland State University (Kimpel et al. 2005) compared travel time variability on six routes $(109,12,112,14$, 72 , and 94). This study found minimal reductions in recovery time on average ( 0.1 minutes per trip), although Routes 12 and 94 outbound during the weekday p.m. peak showed substantial reductions (10 to 14 minutes per trip, respectively). However, the study did not address changes in peakperiod, off-peak-direction variability (which impacts round-trip times), net increases in ridership, or changes in running time variability on other routes. Furthermore, the study's timeframe was before other streamlining improvements were implemented and before the threshold for activating signal priority was reduced from 90 seconds late to 30 seconds late.

- The running time savings that have been achieved through streamlining have postponed the need to add buses to streamlined routes by eight years, at the current rate that scheduled times are increasing due to congestion. Assuming an annual $\$ 140,000$ operating cost saved per peak bus, multiplied by 12 routes over 8 years, equals about $\$ 13.4$ million in long-term savings in present dollars. The value of postponing the purchase of 12 additional buses for 8 years would be an additional capital cost savings. Any recovery time savings that can be quantified would be an additional operating cost savings.

- The combination of focusing service increases on Frequent Service routes, accompanied by streamlining and marketing efforts, has resulted in 12,000 more weekday bus boardings than would have occurred had the service increases been spread system-wide and no other efforts made. These addi- 
tional riders translate into $\$ 1.7$ million additional farebox revenue annually.

- On-time performance has declined systemwide from 1999 to 2005. However, the on-time performance of streamlined routes has declined at half the rate of non-Frequent Service routes.

In summary, the Streamline Program is a long-term investment for TriMet. The payoff will primarily be in the future, as additional service will not need to be added as soon to streamlined routes. Because ridership has increased on the streamlined routes by a substantially larger percentage than can be attributed to just the increase in service, some portion of the $\$ 1.7$ million additional annual farebox revenue can be attributed to streamlining, although the exact contribution cannot be quantified.

\section{Conclusions}

This study found that the intended short-term benefits of reducing operating costs to offset TriMet's contribution to the program were not achieved, mainly because of the difficulty of accumulating enough time to save a bus on a route. On TriMet's Frequent Service routes, 15 minutes of time savings (a typical headway) are needed to be able to save a bus, and streamlining has not yet been able to achieve that level of savings.

However, the time savings that streamlining has achieved to date will result in long-term benefits for TriMet, as it postpones the year when a bus needs to be added to a streamlined route. Over time, these time savings will result in operating and capital cost savings for TriMet. At the current rate at which round-trip times are increasing in Portland due to congestion, the need to add a bus to streamlined routes has been postponed by eight years on average, equating to a long-term $\$ 13.4$ million operating savings. There will be additional savings from postponing the need to purchase additional buses for these routes by eight years. There are likely additional long-term operating savings due to reductions in running time variability (allowing scheduled recovery time to be reduced); however, these savings have not yet been quantified.

In addition, the way that service was increased-focusing added service on Frequent Service routes, in combination with Frequent Service marketing and streamlining improvements-resulted in a greater increase in ridership than would have been achieved had the service increases been spread more evenly 
around the system. Approximately 12,000 more passengers ride TriMet buses each day than would have otherwise, resulting in $\$ 1.7$ million in additional fare revenue annually.

\section{Next Steps}

There is much that can still be done with streamlining to further expand its benefits. Within the city of Portland, some of the program pieces have yet to be implemented (e.g., additional bus stop consolidation, transit signal priority activation points, etc.). Some of the next steps are technical in nature, while others are institutional.

\section{Continuing Partnership with the City of Portland}

One of the key accomplishments of the Streamline program has been the establishment of a partnership between the City of Portland and TriMet. This relationship has eased the implementation of signal priority and construction of physical improvements that lead to operational efficiencies. These investments have lead to institutional cooperation that will allow continued improvements in productivity of the system, leading to a more sustainable transit network.

\section{Building Partnerships with the Suburban Agencies and ODOT}

Much of TriMet's service area lies outside of the city of Portland. In fact, scheduled round-trip times on suburban routes appear to be increasing at nearly twice the rate as routes operating primarily in Portland. Potential suburban routes to apply streamlining on are being considered. Longer routes offer the greatest potential for time savings that can allow TriMet to achieve its initial objective related to saving peak buses on routes.

\section{Reinvestment in the System}

One of the benefits of the Streamline program lies in technology investments that have resulted in long-term improvements to the system. Features such as the Automated Stop Announcement and Real-Time Passenger Information systems, among others, result in improved customer satisfaction and in some cases, compliance with federal accessibility guidelines. Integrating these devices has reduced overall procurement costs and ongoing maintenance activities. Continued technological advancements, such as the integration of trigger points for signal priority activation and more closely integrated scheduling into the process, would further improve the system and allow more effective operations to meet tomorrow's chal- 
lenges. TriMet's Automatic Vehicle Location system has been further strengthened by its use as an integrated system for bus data, which results in improved planning and scheduling for the agency.

\section{References}

Bureau of the Census. 2004 population estimates. Washington, D.C.

Evans, John E., et al. 2004. TCRP Report 95: Traveler response to transportation system changes. Chapter 9, "Transit Scheduling and Frequency." Washington, D.C.: Transportation Research Board.

Kimpel, Thomas J., J. Strathman, R. L. Bertini, and S. Callas. 2005. Analysis of transit signal priority using archived triMet bus dispatch system data: Final report. Portland, Oregon: Portland State University.

Kittelson \& Associates, Inc., KFH Group, Inc., Parsons Brinckerhoff Quade and Douglass, Inc., and K. Hunter-Zaworski. 2003. TCRP Report 100: Transit Capacity and Quality of Service Manual, 2nd Edition. Washington, D.C.: Transportation Research Board.

Koonce, P., B.Kloos, and S. Callas. 2002. "Bus Priority at traffic signals in PortlandVersion 2.0: The streamline project." In Compendium of Papers from the 72nd Annual Conference of the Institute of Transportation Engineers. Philadelphia.

\section{About the Authors}

Peter Koonce (pkoonce@kittelson.com) is an associate engineer with Kittelson \& Associates, Inc. in Portland, Oregon. His experience includes planning, operations and design of transit signal priority systems throughout the United States and Canada. He has earned an undergraduate degree at Oregon State University and a Master of Science degree from Texas A\&M University.

PAUL RYUS (pryus@kittelson.com) is an associate engineer at Kittelson \& Associates, Inc. in Portland, Oregon. His interests include transit performance measurement and BRT service design. He is a co-author of TCRP Report 100: Transit Capacity and Quality of Service Manual, 2nd Edition and lead author of TCRP Report 88: A Guidebook for Developing a Transit Performance-Measurement System.

Young PARK (parky@trimet.org) is the manager of Capital Projects for TriMet in Portland, Oregon. In this capacity, he has managed several large transit investment 
projects and programs. Before joining TriMet, he worked as a consultant for a variety of transit and transportation projects.

DAVID ZAGEL (zageld@trimet.org) is a Capital Projects Planner for TriMet in Portland, Oregon. Implementing many elements designed to improve the efficiency and attractiveness of its transit system, he started with TriMet on its westside light rail project after graduating in architecture from the University of Oregon.

JAMIE PARKS (jparks@kittelson.com) is a transportation analyst at Kittelson \& Associates, Inc. in Portland, Oregon. His interests include developing transit strategies that promote sustainable urban communities. He has experience in transit signal priority studies and long-range transportation planning. 
Journal of Public Transportation, 2006 BRT Special Edition 


\title{
Simulation of Transit Signal Priority Using the NTCIP Architecture
}

\author{
Hongchao Liu, Texas Tech University \\ Alexander Skabardonis, University of California, Berkeley \\ Meng Li, University of California, Berkeley
}

\begin{abstract}
Transit Signal Priority (TSP) is an important element of Bus Rapid Transit (BRT) that involves coordinated efforts between transit vehicle detection systems, traffic signal control systems, and communication technologies. Successful deployment of TSP requires thorough laboratory evaluation through simulation before field implementation. This paper presents the development and application of a simulation model specifically designed for the design and evaluation of TSP systems. The proposed simulation tool models in detail all the TSP components in accordance with the National Transportation Communications for ITS Protocol (NTCIP) standard for TSP systems. The study is intended to shed light on how the variety of TSP elements can be addressed in microscopic simulation in a structured and systematic fashion. Sample applications of the model on a real-life arterial corridor in California demonstrate its capabilities and features.
\end{abstract}

\section{Introduction}

Although past research and experience have demonstrated the benefits of Transit Signal Priority (TSP) to transit vehicles, skepticism still remains regarding its effectiveness among various parties. To address these skepticisms, evaluation 
methodologies that satisfy the concerns of a diverse set of stakeholders are needed (Gifford 2001). While field evaluation provides real world assessment, traffic simulation is advantageous in conducting "what if" studies before implementation and "before and after" analysis in evaluation. It is also a more economical way as compared to the cost of field evaluation.

A TSP system is difficult to address in traffic simulation (Sunkari et al. 1995). Basic requirements for simulating TSP involve emulating the logic of fixed time/actuated traffic signals under the normal operation and during transit signal priority, detection of bus at the check-in and check-out points, priority generator, priority server, communication links between buses and traffic signals, bus movements in the traffic stream, and the dwell time at bus stops. Advanced features needed to be modeled include but are not limited to adaptive signal control, Automatic Vehicle Location (AVL) systems, additional priority treatment options (e.g., queue jump, transit phase, recall, green hold etc), on-line event monitor to record and report the status of buses and signals, bus arrival time predictor, on-line bus schedule checking, and passenger counting systems.

TSP impact analysis relies greatly on simulation (Smith et al. 2005, Dale et al. 2000). Several commercial simulation software packages such as VISSIM (PTV 2003), CORSIM (FHWA, 2003), and PAMRAMICS (Quastone 2004) provide, to some extent, functions for simulating traffic signals and transit vehicles. Evaluation of TSP has been conducted mainly through these simulation tools. Recent examples of this include the work of Balke et al. (2000), Davol (2002), Shalaby et al. (2003), Dion et al. (2004), and Ngan et al. (2004) who used CORSIM, PARAMICS, and VISSIM to evaluate the effectiveness of the early green and the extended green strategy.

Most simulation models currently available lack most of the characteristics and capabilities for realistically modeling real-life TSP systems. Application of oversimplified simulation models may draw inconvincible conclusions and sometimes mislead the implementation. In addition, the extensive use of AVL data in transit management, planning, and operation has presented a challenge to the development and application of next generation traffic simulation tools (Chu et al. 2004). A new NTCIP standard (NEMA/ITE/AASHTO 2005) is being developed that aims to define communication protocols and the logical architecture of a transit signal priority system. It is extremely important for the design of future TSP simulation models to comply with the NTCIP definitions so that the diversity of the transit signal priority systems can be addressed in a systematic manner. 
This paper presents the development and application of a simulation model specifically designed for the design and evaluation of various TSP systems. The proposed simulation tool models virtually all the TSP components in accordance with the NTCIP definitions. The model was developed in support of a study for developing advanced bus signal priority strategies sponsored by the California Department of Transportation (Caltrans) in cooperation with the San Mateo Transit District (SamTrans) in the San Francisco Bay Area.

\section{Logical and Physical Structure of a TSP System}

\section{Logical Structure of TSP}

NTCIP provides both communication protocols and the vocabulary (called objects) necessary to allow electronic traffic control equipment from different manufacturers to operate with each other as a system. Two main NTCIP standards that are related to traffic signal control and transit signal priority control are NTCIP 1202 and NTCIP 1211. The former defines the commands, responses and information necessary for the management and control of actuated traffic signal controllers. The NTCIP 1211 Signal Control Priority standard provides the framework and communication protocols for the design of a signal priority system.

One of the significant contributions of NTCIP 1211, aside from the description of the "computer objects" for communication, is the definition of the functional entities of a TSP system. As shown in Figure 1, the logical structure of a TSP system is composed of a Priority Request Generator (PRG), a Priority Request Server (PRS), and a Coordinator. The primary functions of the PRG are to determine the

\section{Figure 1. Logical Structure of a TSP System (NTCIP 1211)}

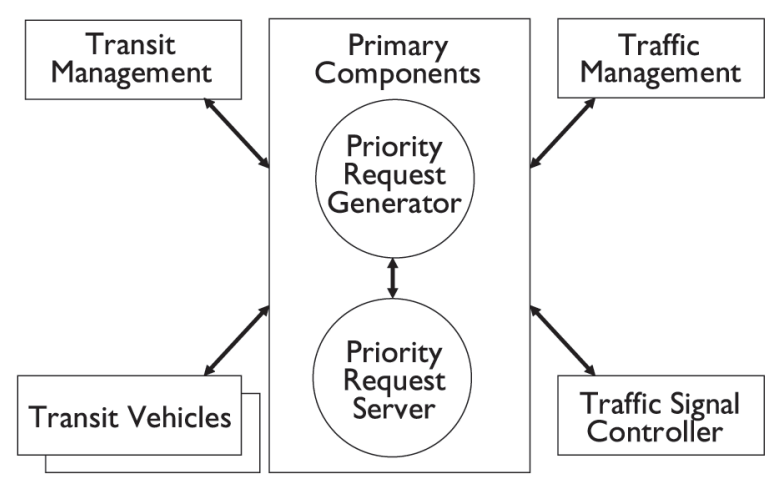


necessity for generating a priority request, to estimate priority service time, and to communicate the request to the PRS. The final decision is made in the PRS. It receives priority requests from multiple PRGs, processes the requests based on importance and priority, and sends the selected requests to the traffic signal controller for priority operation.

\section{Physical Structure of TSP}

According to the Intelligent Transportation Society of America (ITSA) (2003), a physical TSP system is composed of three major components: the vehicle detection system that detects transit vehicles and generates priority requests, the traffic signal control system that receives and processes the request for priority at the intersections, and the communications system that links the vehicle detection system with the traffic signal control system.

The bus detection system is further categorized into point detection or selective vehicle detection (SVD), zone detection, and area detection systems. As illustrated in Figure 2, inductive loops and radio frequency (RF) tags with readers are two typical point detection devices. The vehicle-to-controller communication is achieved through on-vehicle equipment (either a transponder or a RF tag) and a road-side receiver. The on-vehicle device contains a data packet that is sent to the receiver when a bus passes through the detection point. Upon the detection of a transit vehicle, signal priority can be operated at the local or the central level.

Unlike point detection devices that sense the presence of transit vehicles at fixed locations, zone and area detectors may extend the detection area to a certain distance from the intersection. The OpticomTM system from $3 M$ is probably the most widely implemented traffic signal priority control system that enables signal priority operation to both emergency and transit vehicles. As shown in Figure 3(a), the system works by an emitter mounted on the vehicle. When activated, it sends an optical flashing signal at a certain rate and at an exact duration, emergency vehicles and buses are differentiated by different flashing frequencies. Figure 3(b) depicts an AVL based system, in which a bus provides schedule adherence and passenger information along with the priority request continuously to the traffic/ transit management center, where the central computer in return makes decision upon whether and how the transit vehicle should be served.

A major distinction between the zone/area detection based and the point detection/SVD-based TSP lies in the control logic with regard to the initiation time of the priority operation. SVD-based systems initiate the priority operation upon 


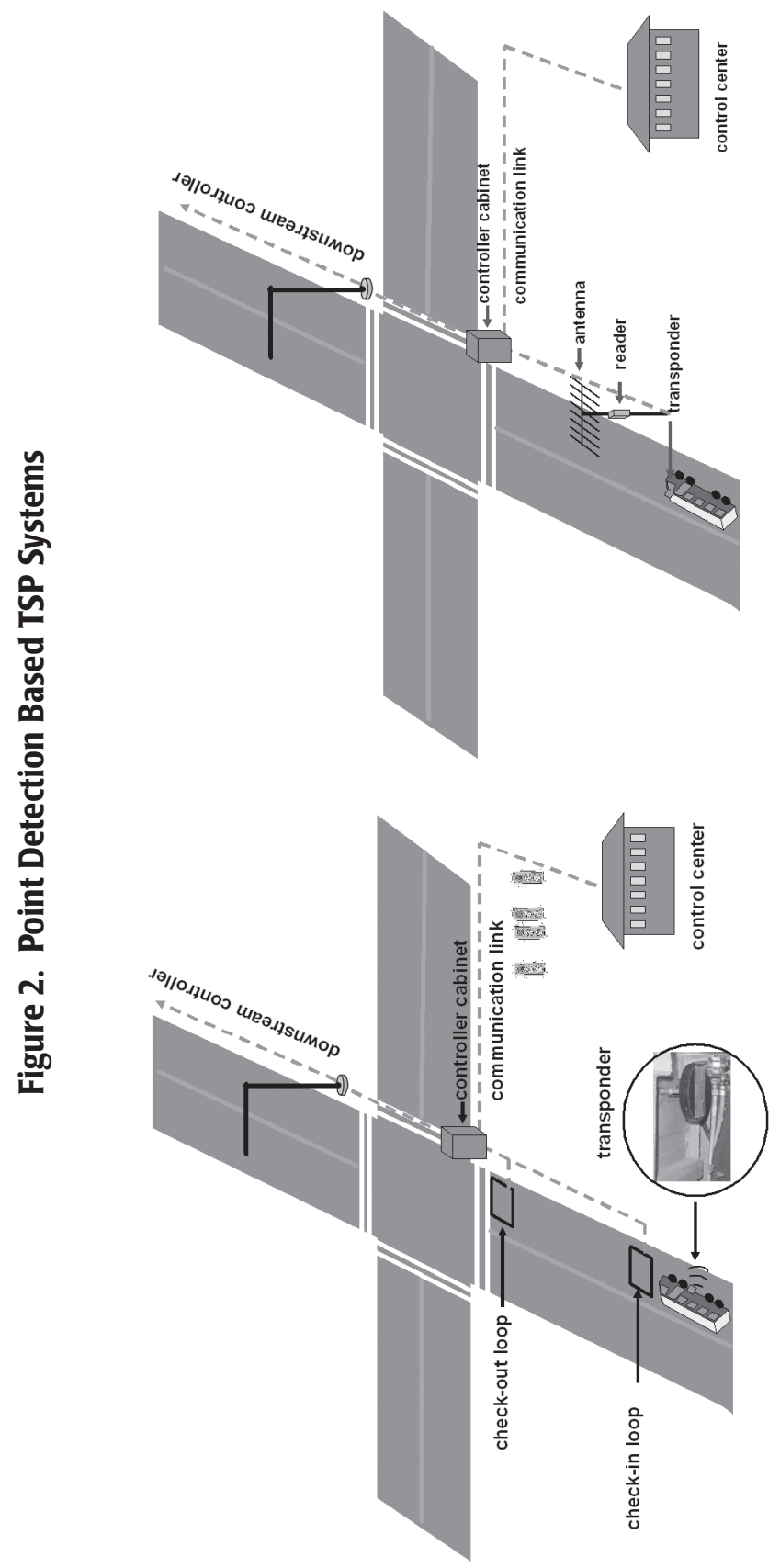


Journal of Public Transportation, 2006 BRT Special Edition

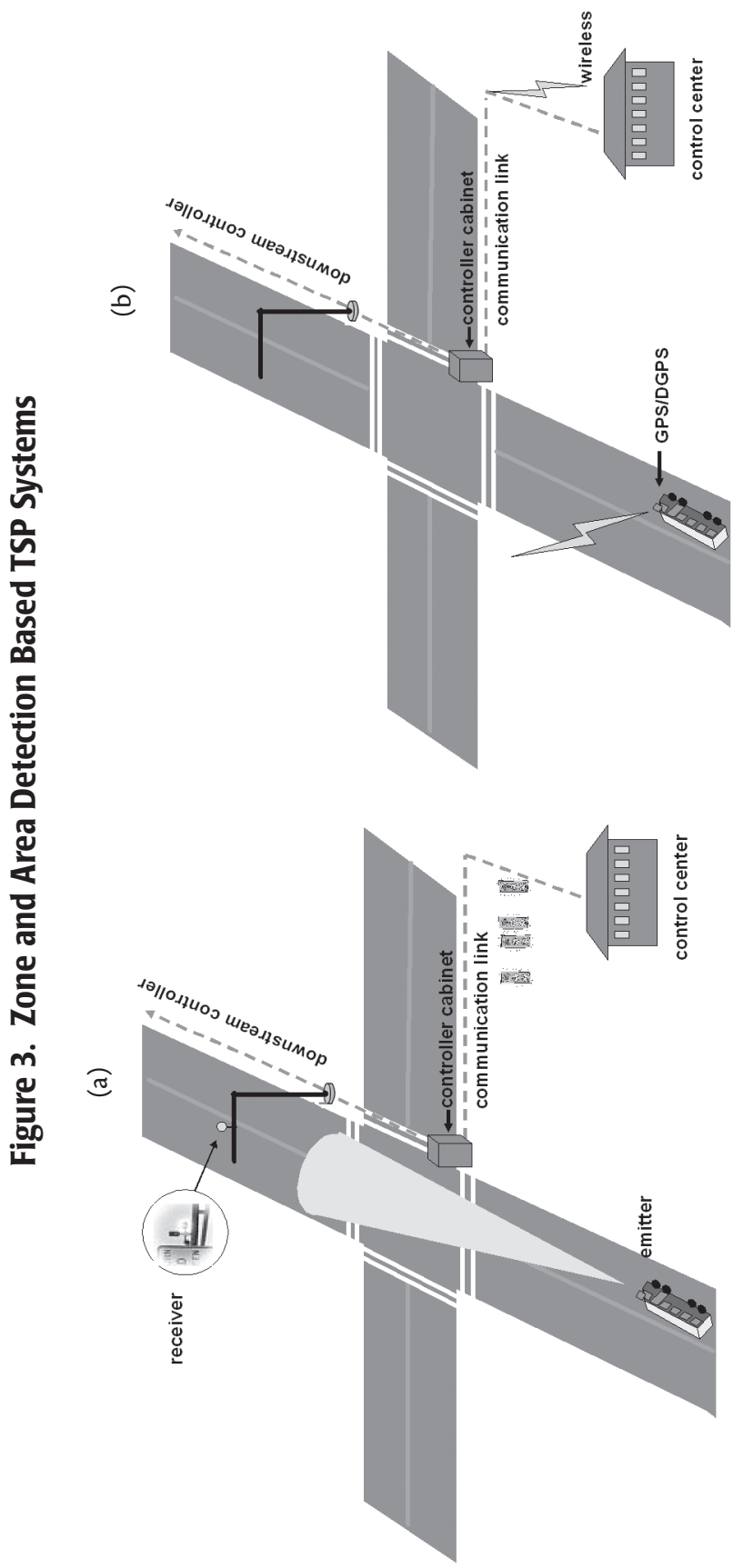


detecting an approaching bus at the single-point location where the detector is located. The AVL-based system has the advantage of placing priority calls at any time while a bus approaches the intersection. As a result, the priority operation may be started at flexible times. It is of great importance for a TSP simulation to be able to realistically represent these two different control configurations.

\section{Simulation Design}

\section{Simulation Architecture}

Figure 4 illustrates a recommended architecture design for TSP simulation models. It is composed of three layers with each of them functioning as a dependent element of the whole system in accordance with the definitions described in the foregoing section. The operational layer consists of the bus detection module, the PRG, the PRS, the Coordinator in correspondence to the bus detection system, the communication system/priority requestor and the traffic signal control system.

The monitoring layer consists of various virtual recorders to record special events during simulation and transfer the information to the Event Logger in the Analysis layer, which is designed to highlight the events through a viewing window and write outputs to the MOE Analyzer. The MOE Analyzer is the analysis module for processing and summarizing the outputs of the measures of effectiveness (MOEs). It obtains outputs from the PRS and the Event Logger and imports the results into spreadsheets for analysis.

Two sub-modules under the bus detection module replicate the SVD-based and the zone/area detection-based-systems separately. The PRS is where the built-in priority control algorithm resides. The time buffer called "delay timer" in PRG is to differentiate the SVD-based systems from AVL-based systems. The default setting is zero, which replicates the instantaneous reaction logic for SVD-based systems. The user selectable scope is from 0 to the length of one signal cycle with the consideration that the priority operation cannot be delayed over one cycle in an AVL-based system. Setting up the "delay timer" is the only decision made at the PRG level.

Most of the functional TSP elements are supported by analytical models that were developed through the development of the simulation model (Liu et al. 2005). Key developments include a recursive least- square approach that estimates bus arrival time at the intersection by using historical and real-time bus movement data, a 


\section{Figure 4. The Functional Architecture of the Simulation Model}

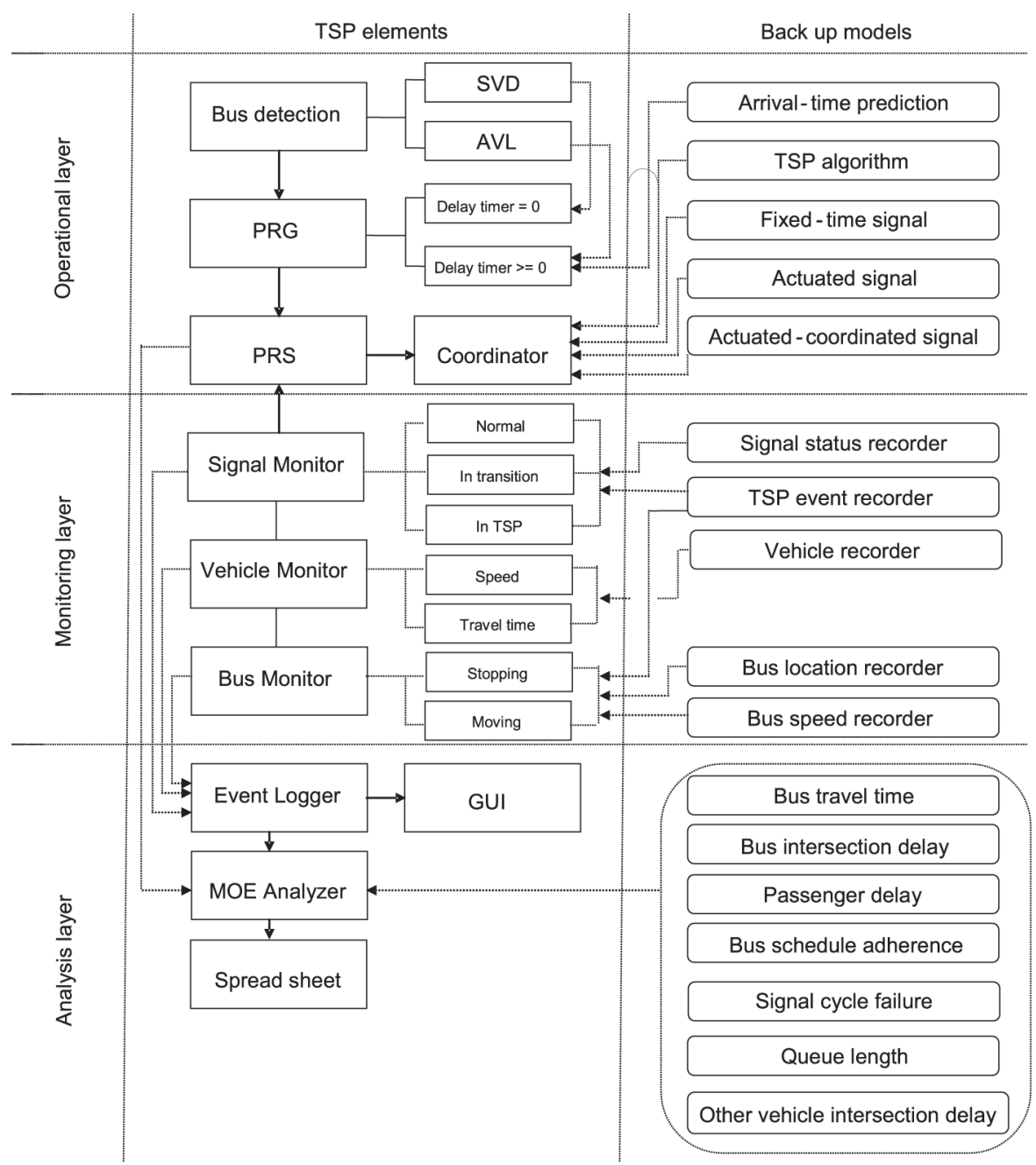

model assisting PRS in selecting the optimal time to initiate priority operations for AVL based systems, and a TSP algorithm defining the built-in control logic.

\section{The Priority Request Server}

The Priority Request Server is where the priority requests are processed and final decisions are made with regard to whether and how a priority request needs to be 
served. It is recommended that all TSP strategies and control policies be defined in the PRS. For instance, the built-in priority logic in this model is defined as the following:

- Signal priority applies to main street phases 2 and 6 and minor street phases 4 and 8.

- One priority service in every other cycle; the cycle following the TSP cycle is considered the transition cycle.

- In case of multiple priority requests, the "first come first serve" principle applies.

- Green extension initiates at the end of a signal phase only if the check-out call has not been received during normal green.

- The minimum guaranteed green of a signal phase equals the Max (minimum green time | pedestrian interval).

- The maximum extension equals 15 percent of the signal cycle in coordinated signal operations and 25 percent in free signal operations and isolated intersections.

\section{Signal, Pedestrian, and Bus Dwell Time}

The signal control module defines various functionalities of virtual signal controllers. At minimum, it should be able to replicate the NEMA eight phase dual-ring control logic. An input interface needs to be provided so that the critical signal timing parameters along with a common signal timing sheet can be read into simulation. The following parameters are required: Minimum Initial, Passage, Minimum Gap, Maximum Gap, Max Green, Red Clearance, Yellow, Offset, Walk, Flashing Don't Walk. Optional inputs may include Max recall, Min Recall and Pedestrian Recall.

Despite their significant impact on various TSP operations, pedestrians have been ignored in most current TSP simulations due to the complexity of modeling. A recommended approach is to model the pedestrian demand through signal timing parameters. For instance, the Walk and Flashing Don't Walk in this model were associated with the phases 2, 6, 4, and 8 and could be activated according to a predefined frequency to represent the presence of pedestrians. The default setting assumes that the pedestrians arrive at the intersections following a Poisson distribution. Dwell time for a bus is the time it spends at the bus station for boarding and alighting passengers and is a function of passenger demand and type of passengers (e.g., with bicycle or wheelchair, monthly pass, or pay per trip, 
etc). The Poisson distribution is also a suitable representation of bus dwell time (Skabardonis 2000).

\section{Event Logger}

Simulating TSP is a complicated process. The Event Logger allows users to check online whether the simulation is correctly replicating the predefined control logic. As shown in Figure 5, the Event Logger updates to a viewing window the current status of selected signals including current phase, cycle and the local cycle timer, if in coordination. If the AVL is "ON" in the PRG, it updates bus ID and location every second or at a frequency specified by the user. If SVD is "ON," it highlights the time, location and bus ID upon the detection of a bus. If priority requests are present, the Event Logger records and outputs to the window the ID number of the signal requested for priority, bus check-in time, requested priority type, the moment when the priority process is initiated and the bus check-out time. A priority request may be rejected for a signal in transition and/or during the pedestrian interval. In either case, the Event Logger reports the reason for the rejection.

\section{Figure 5. Snapshot of the Event Logger}

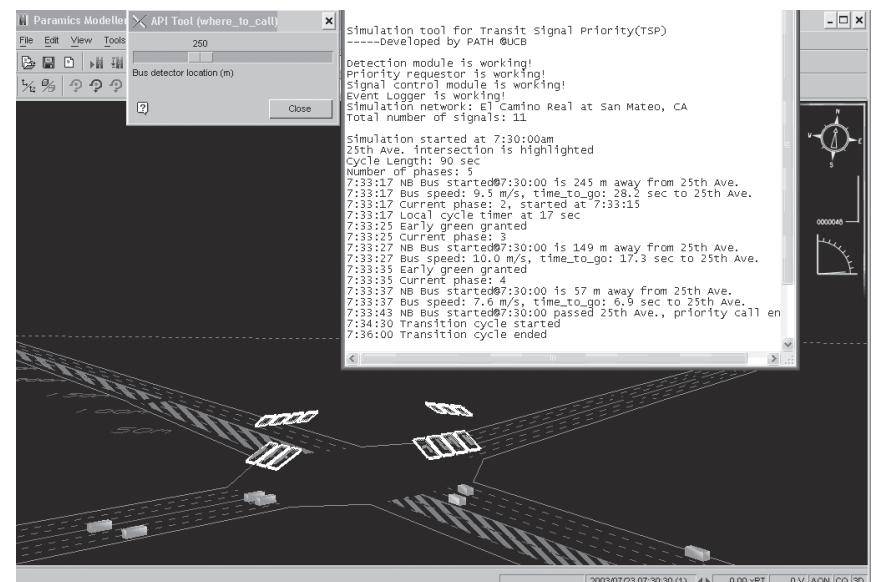

\section{MOE Analyzer}

The MOE analyzer provides a tool to process the simulation output and summarize key statistics of MOEs to facilitate the evaluation of proposed TSP strategies. 
The following MOEs are involved in the proposed simulation and recommended for consideration in TSP simulation models: bus travel time; bus intersection delay; passenger delay; bus number of stops at signalized intersections; vehicle intersection delay; vehicle number of stops at signalized intersections; signal cycle failure; queue length; and bus headway deviation.

To provide bus MOEs, the simulation needs to record the times (1) when a bus is released into the network (2) when a bus stops at a signalized intersection (3) when a bus stops at a bus stop (4) when a bus leaves a bus stop (5) when a bus passes the stop line of an intersection and (6) when a bus ends the trip. The link travel time of bus $k$ on the link $(i, j)$, say, $T_{i j}^{B}(k)$, is therefore defined as the time difference between the two time stamps recorded when the bus passes the intersection $i$ and the intersection $i$. Hence, the total link travel time for all buses during the simulation becomes $\sum_{k} T_{i j}^{B}(k)$.

Figure 6 gives a sample output for two sets of bus trajectories obtained from the proposed simulation model.

\section{Model Application}

The sample model was developed in support of a study for developing advanced traffic signal priority strategies, a project sponsored by the California Department of Transportation in cooperation with the San Mateo Transit District in the San Francisco Bay Area. As mentioned before, one of the principal distinctions between the SVD-based and the AVL-based TSP system lies in the control logic with regard to the initiation time for the priority operation. The sample application investigates the effect of detector locations (for SVD-based system) and actuation time (for AVL-based system) on the overall performance of TSP.

As shown in Figure 7, the test site is comprised of 12 signalized intersections from 2nd Ave. to 28th Ave. to the south of El Camino Real. The traffic signals are vehicleactuated and coordinated on the El Camino Real. Bus dwell time was defined based on the real data from SamTrans's GPS equipped buses (Liu et al. 2004). The pedestrian demand was emulated by the Walk and Flashing Don't Walk, which were assumed to be activated once on every approach every five signal cycles. The bus frequency was set at 6 buses/hr during the analysis period. 
Journal of Public Transportation, 2006 BRT Special Edition

Figure 6. Sample Bus Trajectories from Simulation

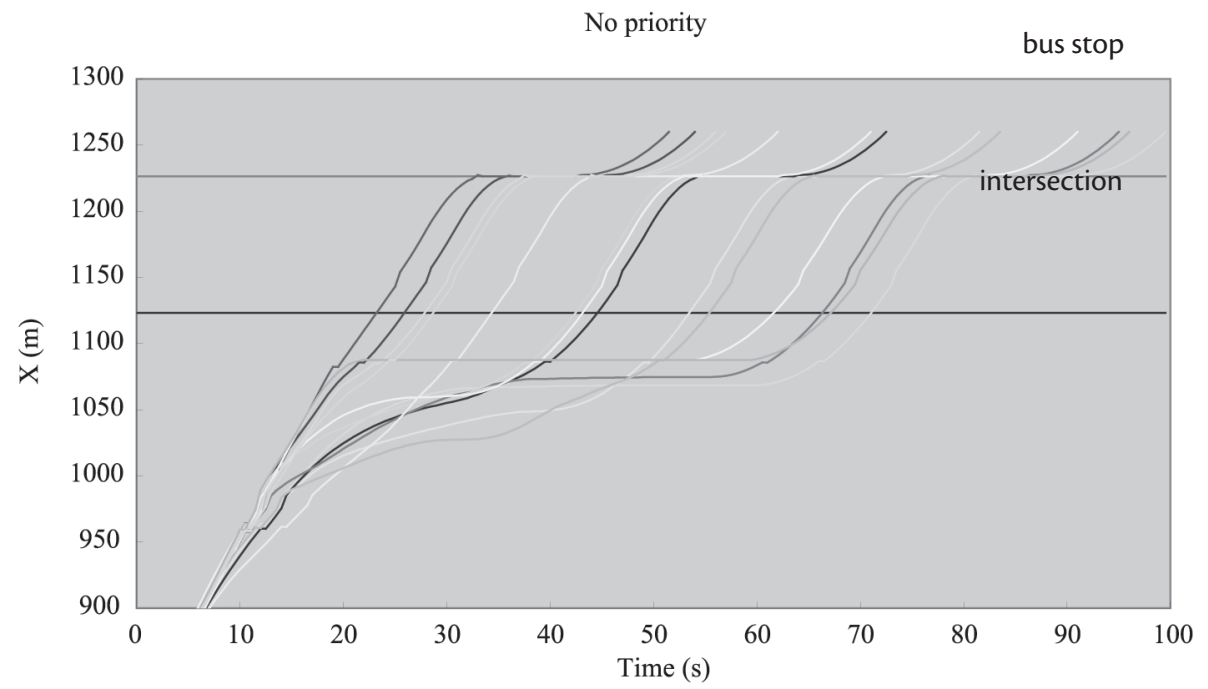

Without Priority

Call at 250 meter

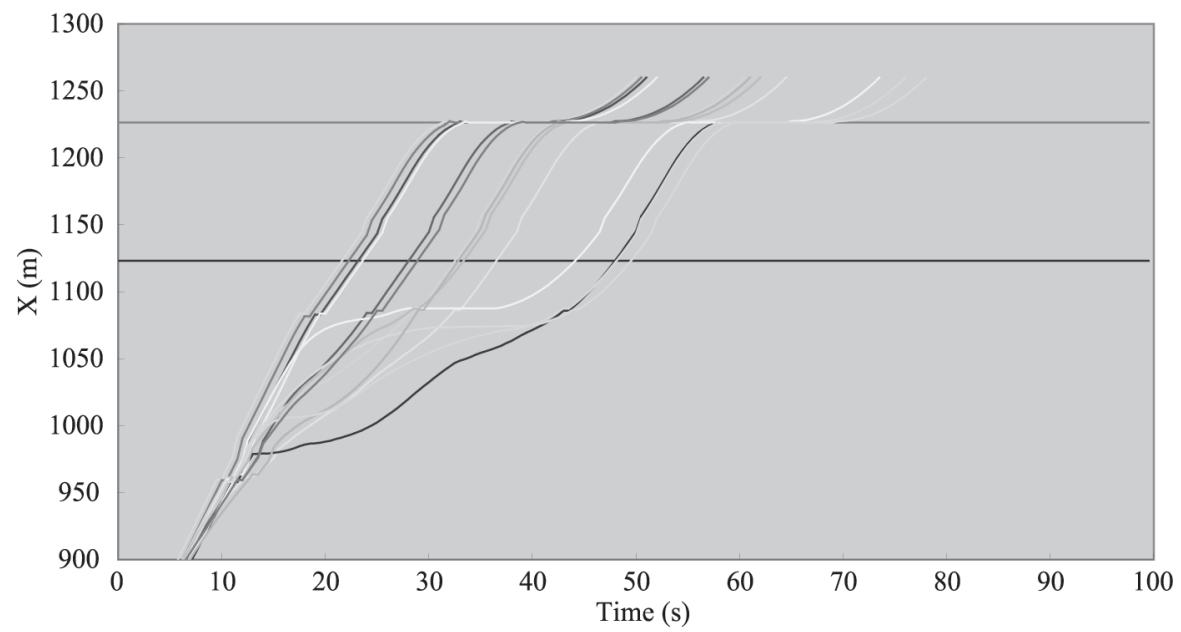

With Priority 


\section{Figure 7. Studied Segment of CA Highway 82}
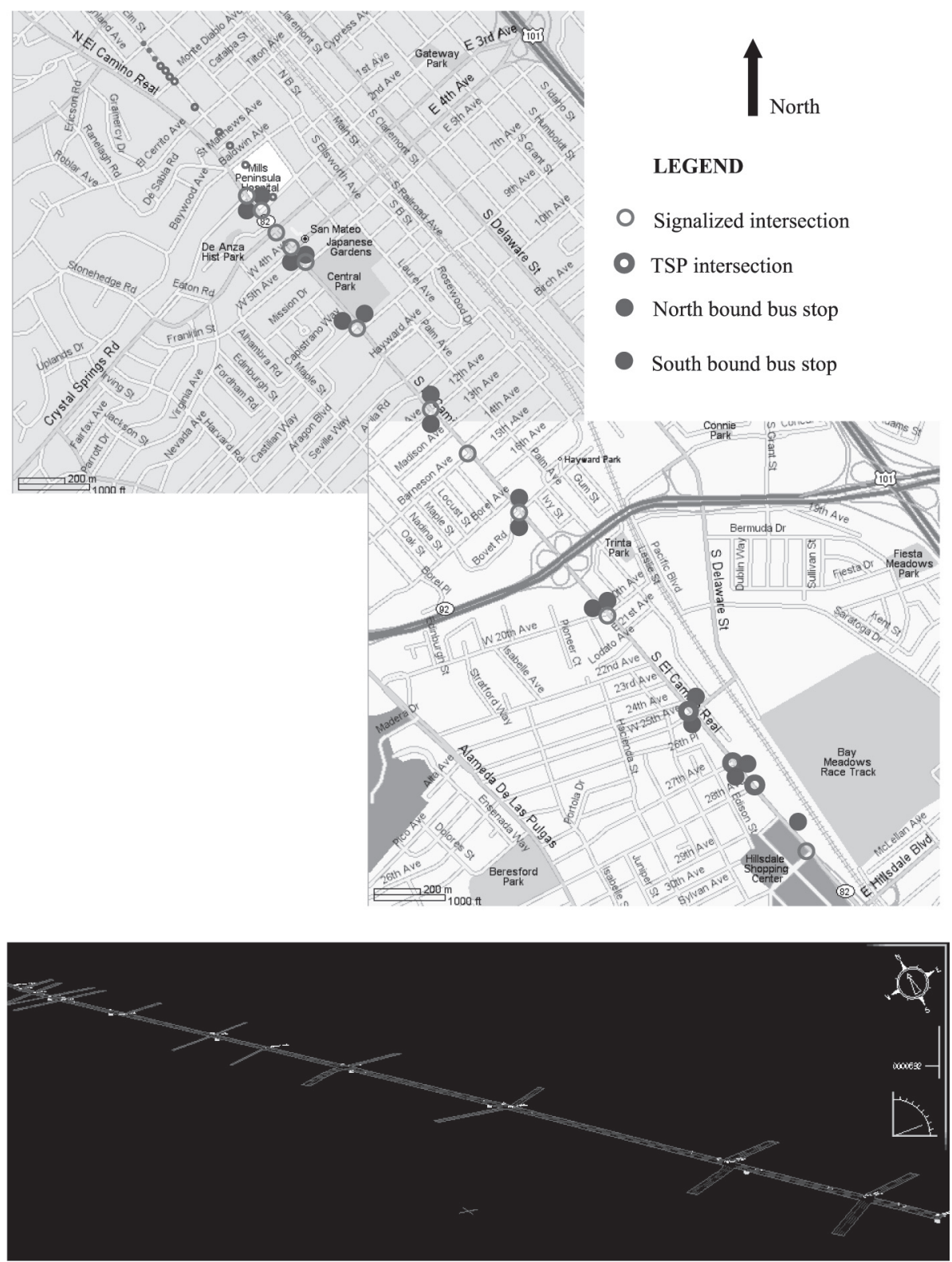
For SVD based simulation, the check-in bus detectors were placed 150 meters, 200 meters, and 250 meters upstream of the intersections, where applicable. If the spacing between two intersections was shorter than 150 meters, the check-out detector of the upstream intersection was used as the check-in detector of the downstream intersection. For the AVL-based approach, priority calls were placed when buses were 15, 20, 25, and 30 seconds away from the intersection. In total, eight scenarios were simulated:

(1) No priority

(2) AVL (15) registering priority calls when buses are 15 seconds away from the intersections

(3) AVL (20) registering priority calls when buses are 20 seconds away from the intersections

(4) AVL (25) registering priority calls when buses are 25 seconds away from the intersections

(5) AVL (30) registering priority calls when buses are 30 seconds away from the intersections

(6) $\mathrm{SVD}(150)$ placing bus detectors 150 meters upstream the intersections

(7) $\operatorname{SVD}(200)$ placing bus detectors 200 meters upstream the intersections

(8) $\mathrm{SVD}(250)$ placing bus detectors 250 meters upstream the intersections

The result, illustrated in Figure 8, reveals that placing the bus detectors 200 meters upstream of the intersections and triggering the signals when the buses are 25 seconds away from the intersections gave the minimum bus intersection delay. The average vehicle delay on El Camino Real and the cross streets is depicted in Figure 9, which shows that the intersection delay of non-transit vehicles along the arterial and the cross streets do not seem to vary significantly with the various signal priority strategies.

Figure 10 illustrates the effectiveness of various signal priority strategies in terms of the reduced bus headway deviations. Table 1 summarizes the average bus speeds, bus travel times, bus dwell time and signal delay in total bus travel times, and the time savings because of signal priority (in seconds and percent of total travel time). 


\section{Figure 8. Average Bus Intersection Delay}

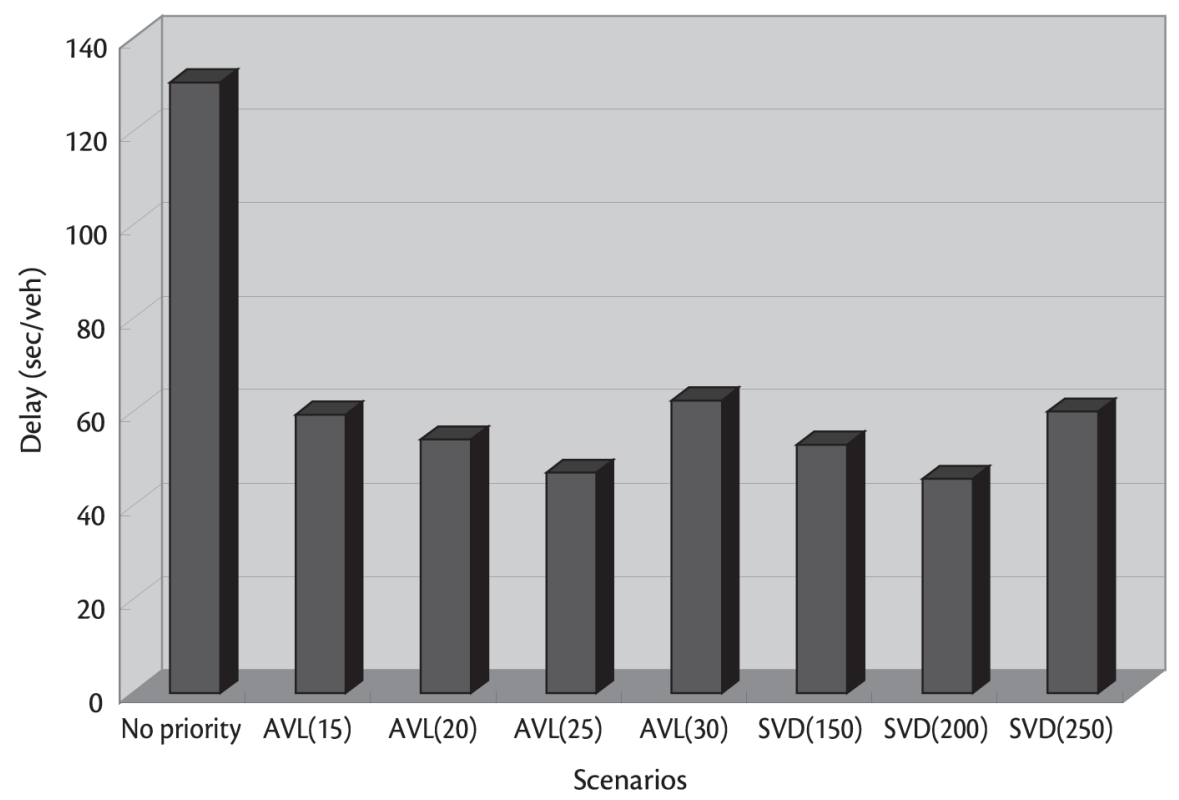

\section{Conclusions}

Although traffic simulation has been widely used in evaluation of TSP systems, the development of TSP simulation models has been approached differently by researchers and traffic engineers on the basis of their specific needs and interpretation of the elements of a TSP system. The development and application of TSP simulation models has been thought of as a project-based function rather than as a systematic process. As a result, many simulation models were created independently, and some of the models were discarded upon completion of the specific projects. The major purpose of the study was to demonstrate how the variety of TSP elements could be organized in microscopic simulation in a structured and systematic fashion in accordance with the NTCIP architecture. The logical and physical infrastructure of a TSP system was interpreted, and recommendations for design were made along with the development and application of the sample simulation model. The advantage of the proposed simulation in modeling both point-detection-based and area-detection-based TSP systems was demonstrated through a sample application to 12 signalized intersections on CA Highway 82. 


\section{Figure 9. Vehicle Intersection Delay}
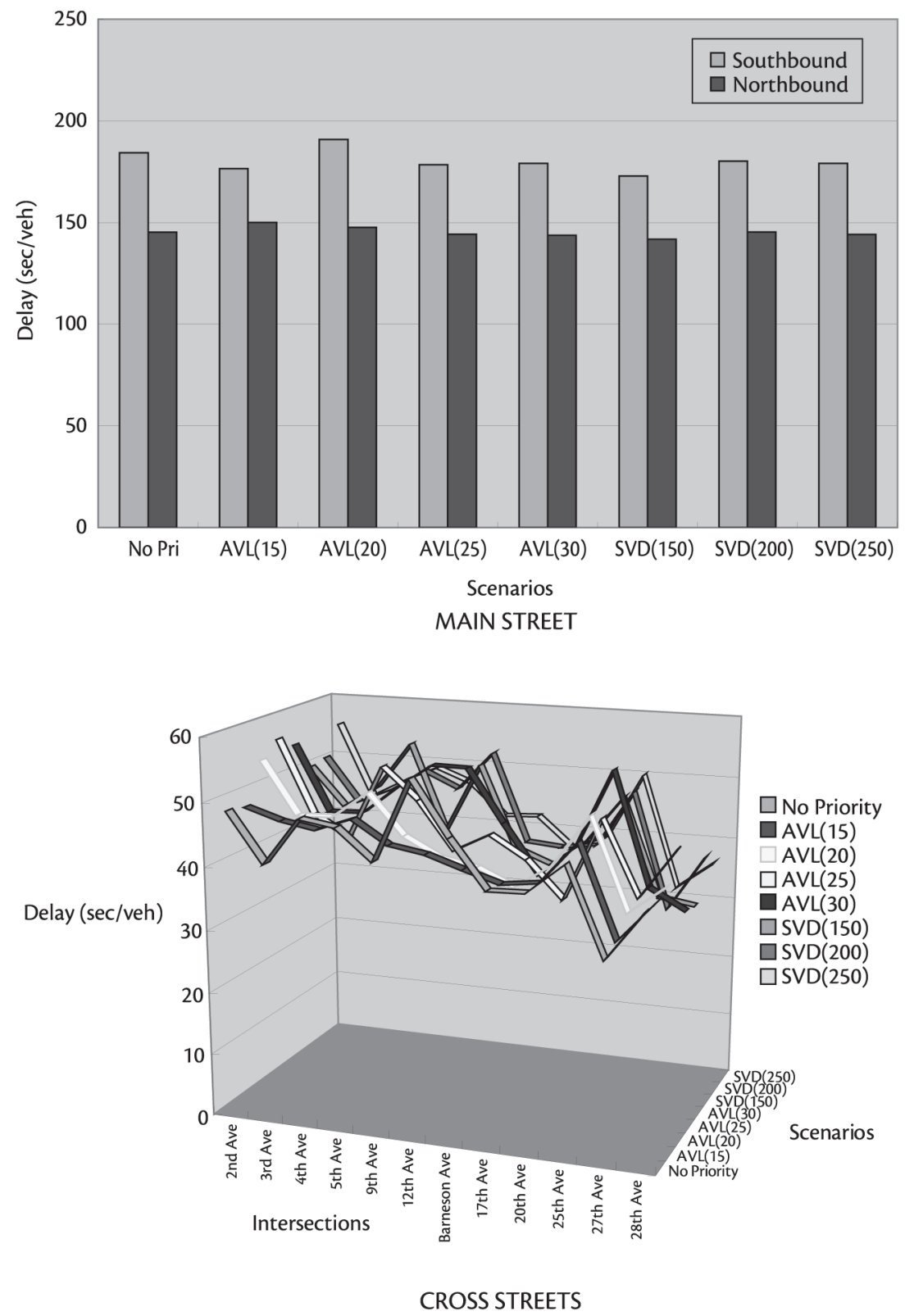


\section{Figure 10. Bus Headway Deviation}

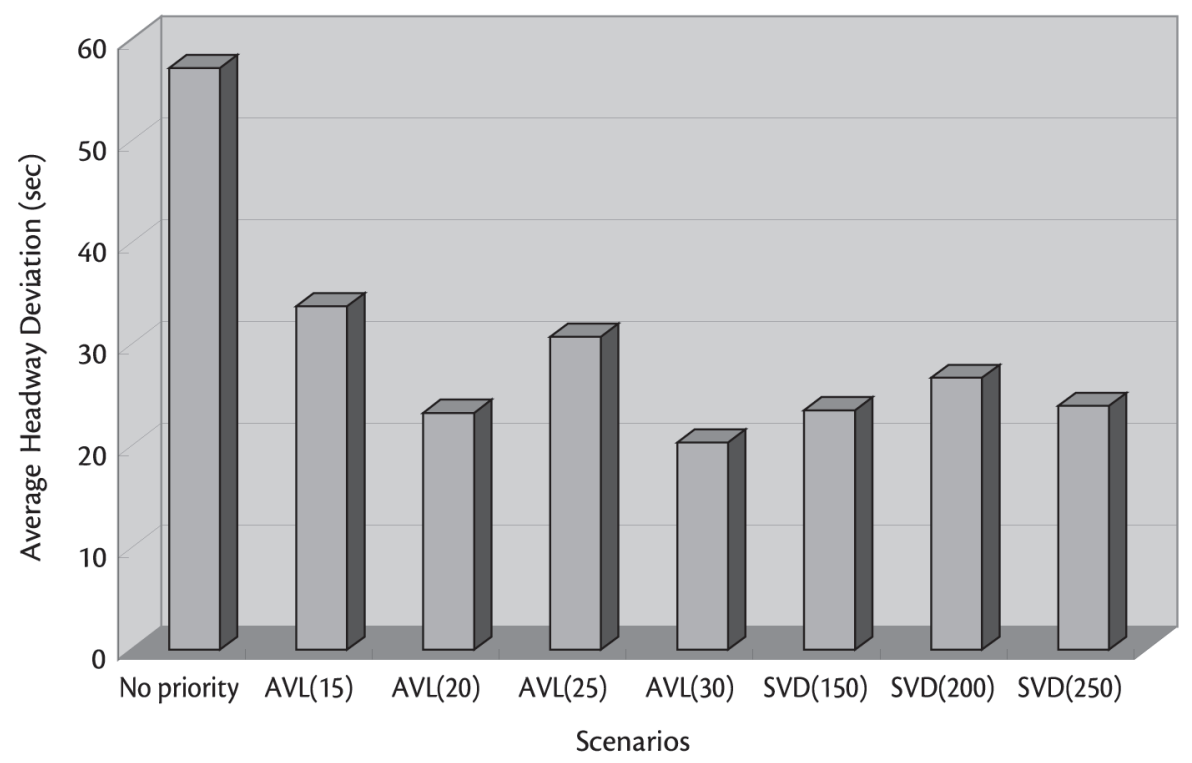

Table 1. Sample MOE Analysis

\begin{tabular}{|c|c|c|c|c|c|c|c|}
\hline \multirow[b]{2}{*}{ Scenarios } & \multirow{2}{*}{$\begin{array}{l}\text { Average } \\
\text { travel time } \\
\text { (sec) }\end{array}$} & \multirow{2}{*}{$\begin{array}{c}\text { Average } \\
\text { Speed } \\
\text { (mph) }\end{array}$} & \multirow{2}{*}{$\begin{array}{c}\text { Dwell time } \\
\text { (\% of travel time) }\end{array}$} & \multicolumn{2}{|c|}{ Signal delay } & \multicolumn{2}{|c|}{ Time savings* } \\
\hline & & & & (sec) & $(\%)$ & (sec) & (\%) \\
\hline No priority & 576 & 21 & $21.7 \%$ & 131 & $22.7 \%$ & 0 & $0.0 \%$ \\
\hline AVL(15) & 505 & 25 & $24.8 \%$ & 60 & $11.8 \%$ & 71 & $12.3 \%$ \\
\hline $\mathrm{AVL}(20)$ & 509 & 25 & $24.5 \%$ & 54 & $10.6 \%$ & 77 & $13.4 \%$ \\
\hline $\operatorname{AVL}(25)$ & 492 & 26 & $25.4 \%$ & 47 & $9.6 \%$ & 84 & $14.5 \%$ \\
\hline AVL(30) & 508 & 25 & $24.6 \%$ & 63 & $12.3 \%$ & 68 & $11.8 \%$ \\
\hline SVD(150) & 498 & 26 & $25.1 \%$ & 53 & $10.7 \%$ & 78 & $13.5 \%$ \\
\hline SVD(200) & 491 & 26 & $25.5 \%$ & 46 & $9.3 \%$ & 85 & $14.7 \%$ \\
\hline SVD(250) & 505 & 25 & $24.7 \%$ & 60 & $11.9 \%$ & 70 & $12.2 \%$ \\
\hline
\end{tabular}

\section{Acknowledgements}

The authors would like to thank the following for their generous assistance and extensive contributions to our research: Mr. Wei-bin Zhang of the California PATH 
program; Sonja Sun of Caltrans' Division of Research and Innovation; Kai Leung of Caltrans' Division of Traffic Operation; Frank Burton of San Mateo Transit District; and Shuaiyu Chen of the TRANSTECH lab of Texas Tech University.

\section{References}

AASHTO/ITE/NEMA. 2005. National transportation communications for ITS protocol: Objective definitions for signal control and prioritization. NTCIP 1211, V01.37b. Available at: www.ntcip.org/library/documents/pdf/1211v01-37b. pdf (2006-1-12).

Balke, K.N., C.L. Dudek, and T. Urbanik II. 2000. Development and evaluation of intelligent bus priority Concept, Transportation Research Record 1727: 12-19.

Chu, L., Liu, H., and W. Recker. 2004. Using microscopic simulation to evaluate potential intelligent transportation system Strategies under nonrecurrent congestion, Transportation Research Record 1886: 76-84.

Davol, A P. 2002. Modeling of traffic signal control and transit signal priority strategies in a microscopic simulation laboratory. Master's Thesis, Massachusetts Institute of Technology.

Dale, J.J., R.J. Atherley, T. Bauer, and L. Madsen. 2000. A transit signal priority impact assessment methodology-Greater reliance on simulation. Proceedings., 78th TRB Conference. Transportation Research Board, Washington D.C.

Dion, F., H. Rakha, and Y. Zhang. 2004. Evaluation of potential transit signal priority benefits along a fixed-time signalized arterial. Journal of Transportation Engineering, 130(3): 294-303.

FHWA. 2001. CORSIM User's Guide (Software Help Manual). U.S. Department of Transportation, Washington, D.C.

Gifford, J., D. Pelletiere, and J. Collura. 2001. Stakeholder Requirements for Traffic Signal Preemption and Priority in the Washington D.C. Region. Proceedings, 80th TRB Conference. Transportation Research Board, Washington, D.C.

ITS America. 2003. An overview of transit signal priority, Advanced Traffic Management System and Advance Public Transportation System Committees, Washington, D.C. 
Liu, H., A. Skabardonis, W. B. Zhang, and M. Li. 2004. Optimal detector location for transit signal priority. Transportation Research Record 1867: 144-150.

Liu, H., et al. 2005. Development of adaptive transit signal priority systems-Volume B., Theoretical approach, University of California, Berkeley: Institute of Transportation Studies, Research Report UCB-ITS-PRR-2005.

Ngan, V., T. Sayed, and A. Abdelfatah. 2004. Impacts of various traffic parameters on transit signal priority effectiveness. Journal of Public Transportation, Vol. 7(3): 71-93.

PTV. 2003. VISSIM User Manual-V.3.7.0. Karlsruhe, Germany.

Quadstone Ltd. 2005 Paramics user guide-Version 3.0.

Shalaby, A., B. Abdulhai, and J. Lee. 2003. Assessment of streetcar transit signal priority options using microsimulation modeling. Canadian Journal of Civil Engineering, Vol. 30(6): 1000-1009.

Skabardonis, A. 2000. Control strategies for transit priority. Transportation Research Record 1727: 20-26.

Smith, H R., B. Hemily, and M. Ivanovic. 2005. Transit Signal Priority (TSP): A Planning and Implementation Handbook. ITS America.

Sunkari, S.R., P.S.,Beasley, T. Urbanik, and D.B. Fambro. 1995. Model to evaluate the impacts of bus priority on signalized intersections. Transportation Research Record 1494: 117-123.

\section{About the Authors}

HONGCHAO LIU (hongchao.liu@ttu.edu) is an assistant professor at the Department of Civil Engineering of Texas Tech University. Prior to joining Texas Tech University in 2004, he spent three years working as a staff researcher and Principal Investigator at the Institute of Transportation Studies at University of California, Berkeley. During his time with Berkeley, he was the key developer of California's first adaptive transit signal priority system on El Camino Real corridor in San Mateo County. His major research interests and areas of expertise include traffic management and control systems, intelligent transportation systems (ITS), design and operation of Bus Rapid Transit (BRT) facilities, and microscopic traffic simulation. He is a member of ITE, ASCE, and subcommittee member in the TRB Com- 
mittee of Traffic Signal Systems. He has published over 20 papers and research and technical reports.

Alexander Skabardonis (Skabardonis@ce.berkeley.edu) is the Director of California Partners for Advanced Transit and Highways (PATH), Adjunct Professor in the Department of Civil Engineering, and Research Engineer at the Institute of Transportation Studies, University of California at Berkeley. He has worked extensively in the development and application of models and techniques for traffic control, performance analysis of highway facilities and applications of advanced technologies to transportation. He has served as Principal Researcher for more than 40 extramurally funded contracts and grants totaling over $\$ 8 \mathrm{M}$. He has published over 130 papers and research and technical reports, which have been widely disseminated and used in design and analysis problems. His research on traffic modeling and simulation techniques led into successfully incorporating several enhancements into existing simulation models, and the formulation of widely used guidelines for modeling tools calibration and validation. He also developed a modeling framework linking conventional planning models and operations simulation models for estimating vehicle emissions in planning studies.

MENG LI (meng_lee@berkeley.edu) is an assistant development engineer with California Partners for Advanced Transit and Highways (PATH), Institute of Transportation Studies, University of California at Berkeley. He obtained his Master of Science degree in University of California at Berkeley in 2004. His areas of expertise are in microscopic traffic simulation, design and evaluation of transit signal priority systems. 


\title{
Impact of Bus Priority Attributes on Catchment Area Residents in Dublin, Ireland
}

\author{
Simon McDonnell, Susana Ferreira, and Frank Convery \\ University College Dublin
}

\begin{abstract}
In many jurisdictions, political and infrastructural restrictions have limited the feasibility of road pricing as a response to urban congestion. Accordingly, the allocation of dedicated road space to high frequency buses has emerged as a second-best option. Analyses of the evidence emerging from this option emphasize the engineering and technical issues and do not systematically interrogate the customers, those in the bus catchment area that use or could potentially use the service. This paper attempts to correct for this asymmetry in focus by analyzing characteristics and preferences of users and non-users through a survey of 1,000 households for a particular quality bus catchment area in Dublin, Ireland. Preliminary findings are encouraging, both for the use of this policy instrument as one which can yield considerable consumer satisfaction, and in terms of modal share analysis, especially because the corridor under scrutiny represents a much higher socio-economic profile than Dublin or Ireland as a whole.
\end{abstract}

\section{Introduction}

Bus priority applications ${ }^{1}$ as a policy response to road congestion have a long history, going back to the 1930s, but it is in the last two or three decades that bus 
priority measures have become a central element in tackling the externalities associated with increased urban road use.

Studies related to bus priority have explored a wide degree of topics (see, for example, Polus 1978, Bokinge and Hasselström 1980, Balke, Dudek and Urbanik 2000). However, as the Transportation Research Board (2003) notes, the focus has been on mechanical and engineering issues, and performance of bus priority measures has typically been assessed using the numbers of passengers carried and the travel speeds of the vehicles. In contrast, the individual preferences of bus users and potential users within the context of transport choice have received relatively little academic focus. As Wardman (2001) notes, valuations of a wide range of public transport travel and service quality attributes have not received the level of attention that they warrant. Moreover, within the literature investigating individual preferences, relatively little attention has centred on the attitudes and underlying factors influencing the behavior of the population of most likely users, i.e., those living within the catchment area of such bus priority measures. Authors such as Hensher et al. (2003) and Baltes (2003) assess the impact of attributes on present bus users through the provision of on-bus surveys. This paper extends these studies by assessing the impacts on modal choice for the population living in the catchment area of a corridor with bus priority measures-both bus users and non-users.

The motivation of this paper is to address this issue, and the focus is threefold. First, it aims to cover a gap in an under-researched area of public transport by investigating the perceptions, attitudes and behavior characteristics of 1,000 respondents living in a Geographic Information Systems (GIS) constructed catchment area. Second, we analyse the determinants of modal choice which impact users and potential users - this is particularly interesting given that the catchment population under investigation has an educational and socio-demographic profile that is higher than either the Dublin or Irish average and, therefore, would be regarded a priori as a relatively difficult group to "get out of their cars." Finally, differences in the perceptions of bus-specific attributes, based on bus usage, were tested.

The Quality Bus Corridor (QBC) analyzed, the N11 QBC running from Dublin City Centre through South East Dublin City and County (see Appendix 1 for a map), has experienced rapid growth in passenger numbers since its upgrade in 1999. Despite a widespread view by both policymakers and the public at large that the 
corridor has been a success, there has been a lack of research to confirm this perception.

The outline of this paper is as follows; the next section outlines some key literature relating to bus priority. Section 3 outlines the policy responses to traffic congestion in Dublin. Using the survey data collected in the catchment area of the QBC under investigation, Section 4 investigates the modal share, performance and user attitudes. Section 5, through the use of probit analysis, identifies the key factors influencing bus usage along the QBC. Section 6 assesses how the perceptions of 9 bus-specific attributes vary across bus users and non-bus users. Section 7 concludes.

\section{Literature Review}

Traffic congestion is one of the most contentious urban issues facing policymakers today, and the associated costs can be high. ${ }^{2}$ In Dublin there has been reluctance on the part of policymakers to implement 'push' pricing policies (shifting car users to other modes through increasing the average cost of a car trip) and, despite longer term proposals to increase the attractiveness of public transport in the city (i.e., light rail transit or metro options), continued urban congestion has demanded more immediate and flexible policy responses. It is in this context that bus priority measures have become one of the major instruments used by policymakers to affect modal shift.

The use of buses to provide rapid transit is, however, far from a new concept. Proposals for such measures go back to the 1930s (for an extensive review, see the Transportation Research Board 2003a). Despite its long history, a clear definition of Bus Rapid Transit remains, as the Transportation Research Board (2003a) notes, elusive. It is seen to include bus services that are, at a minimum, faster than traditional "local bus" services and that, at a maximum, include grade-separated bus operations.

Engineering and implementation issues arising from bus priority schemes are a well-researched topic. The Transportation Research Board (2003a, 2003b) has set out implementation guidelines for researchers and practitioners in the U.S. Similarly, the UK Department for Transport (DETR 2004) has set out implementation best practices. Authors such as Wardman (2000) and Horn (2002) analyze service improvements and passenger transport performance. In Ireland, Caulfield and 
O'Mahony (2004) measure performance by assessing level of service attributes such as headway, transit/auto comparison and service coverage.

Despite the variety of topics investigated by researchers, there is relatively little focus on the impact of bus priority measures on the urban transport consumer. Recently, bus priority measures have started being assessed in the wider context of modal and route choice. Rodríguez (2002) investigates bus dwell times in a competitive busway. Alpizar and Carlsson (2003) assess a policy of improving bus attractiveness in San José, Costa Rica, to those already commuting by car and note a state dependence variable which captures the reluctance of existing car users to switch. This is in the same line as previous studies (Bhat 1998; Swait and Eskeland 1995, Asensio 2002). Hensher and Reyes (2000) also identify car availability as a significant barrier to public transport use in the context of trip complexity. O'Fallon et al. (2004) identify actions such as transporting children and off-peak mobility requirements as barriers.

Friman (2004) also assesses customer satisfaction with quality improvements in public transport. Currie (2005) adopts a trip attribute approach to compare the passenger attractions of BRT relative to other public transport modes and finds that rail holds an advantage over normal on-street bus services but that, in general, no such advantage exists over BRT.

Hensher et al. (2003) and Prioni and Hensher (2000) have investigated service quality management through the use of on-bus surveys to assess the impact of 13 attributes on bus customer satisfaction. This research focuses on the ability to compare quality levels within and between bus operators but does not specifically deal with the issue of bus priority. Baltes (2003) does investigate service attributes related to bus priority. Comfort and travel time attributes were seen amongst the most important by existing users of the service. In the context of experimentation connecting consumer attitudes to behaviour, Parkany et al. (2004) outline recent transportation-related attitudinal data applications. However, none of these studies investigates attitudes of catchment area respondents to bus priority attributes.

As far as the authors are aware, where the impact of bus attributes has been investigated, (i.e., Hensher et al. 2003; Baltes 2003), it has tended to focus on wider modal choice issues or be restricted to existing bus users. These investigations do not capture the perceptions of attribute importance of non-bus users (among them, potential users). Moreover, the use of bus-surveys introduces an additional restriction, namely, the limited time available to survey each respondent, reduc- 
ing the ability to capture background information such as socio-economic and demographic characteristics. Our research, investigating survey data of 1,000 residents in a catchment area of a bus priority scheme, assesses the views of transport consumers-both bus and non-bus users. In this way, influences on modal choice for those most likely to use the bus priority corridor-catchment area residents -are interrogated.

\section{The N11 Quality Bus Corridor and Catchment Area Infrastructural Context}

As the capital of one of the fastest growing economies in the developed world since the mid-1990s, Dublin has faced major infrastructural bottlenecks. Associated with the rapid economic growth has been a rapid growth in private car ownership, which in turn has resulted, due to inadequacies in public transport, in increased car-commuting and increasing congestion in the Greater Dublin Area (GDA). ${ }^{3}$

Despite early attempts at introducing Bus Priority in Dublin (see, for example, CIE 1984), the primary policy driver for change in Dublin has been the Dublin Transportation Initiative strategy (DTI 1995). As part of this, an ambitious program of dedicated bus corridors has been mapped out and partially implemented. ${ }^{4}$ This has spurred an interest in "reinventing" buses, through bus priority measures, as an important contribution to solving the congestion and externality problem associated with private-car use.

The bus market in Dublin is a state-owned monopoly. Although a number of small operators carry passengers from outside the city, the vast majority of scheduled bus journeys were made on Bus Atha Cliath-Dublin Bus.

This paper focuses on the N11 QBC, which runs from Dublin City Centre through south eastern suburbs along the route of the N11 Road, a main arterial route into the city. The route was upgraded to a quality bus corridor in 1999 (see Appendix 1 for a map of the $\mathrm{QBC}$ and its catchment area). For most of the route, the corridor is segregated from general traffic. ${ }^{5}$

Table 1 is based on results from the 2004 annual traffic count by the Dublin Transportation Office (DTO 2005) and indicates the comparable journey times for bus and car for the stretch of the N11 Road from Foxrock Church to Leeson Street in the City Centre. The table indicates the minimum and maximum recorded times 
of the bus and the car on this route. For instance, for AM Peak Inbound, the quickest bus time recorded was 20'24" (20 minutes and 24 seconds) and the slowest is $34^{\prime} 12$ " (34 minutes and 12 seconds). The DTO carries out traffic counts and reports the ranges of recorded bus times. ${ }^{6}$

Table 1. Bus and Car Journey Times, November 2004 (Range)

\begin{tabular}{|l|c|c|c|c|}
\hline \multirow{2}{*}{ Time of Travel } & \multicolumn{2}{|c|}{ BUS Recorded Journey Times } & \multicolumn{2}{c|}{ CAR Recorded Journey Times } \\
\cline { 2 - 5 } & Minimum & Maximum & Minimum & Maximum \\
\hline AM Peak Inbound* & $20^{\prime} 24^{\prime \prime}$ & $34^{\prime} 12^{\prime \prime}$ & $15^{\prime} 49^{\prime \prime}$ & $47^{\prime} 41^{\prime \prime}$ \\
Off Peak Inbound* & $24^{\prime} 32^{\prime \prime}$ & $28^{\prime} 28^{\prime \prime}$ & $14^{\prime} 05^{\prime \prime}$ & $23^{\prime} 53^{\prime \prime}$ \\
PM Peak Outbound* & $20^{\prime} 46^{\prime \prime}$ & $34^{\prime} 15^{\prime \prime}$ & - & - \\
\hline
\end{tabular}

Notes: 1. Based on journeys from Foxrock Church to Leeson Street in the City Centre (See Appendix 1 for a map)

2. Minimum refers to minimum DTO recorded journey time for bus and car on this route, maximum is the highest recorded journey time.

Variability in journey times is far lower for the bus than for the car on this route and peak bus journey times can be considerably quicker. The modal share of the bus along the corridor has increased by 239 percent between 1997 and 2003 (representing a modal share of $46.76 \%$ ). Over that same period, the modal share of the car along the route has fallen by over 40 percent to 29.10 percent (DTO 2004). In comparison, the Dublin area has a bus modal share of less than 20 percent (CSO 2004b).

The $\mathrm{N} 11 \mathrm{QBC}$ is not the best performing $\mathrm{QBC}$ in the city in terms of relative journey times or modal share; however, when looking at passenger growth between 1997 and 2004, the N11 QBC has recorded, by far, the strongest growth amongst all QBC's. In addition, the socio-demographic and education profile are higher than for either the Dublin or Irish average. This makes it an interesting case study.

\section{The N11 QBC Catchment Area}

For the purpose of this research, a survey was carried out over a sample population drawn from residents in the catchment area of the N11 QBC. As a passenger can generally access the bus service only at a bus stop, the catchment area radius was centered on each bus stop itself. Each bus stop along the corridor was mapped using GIS technology. A buffer zone centred on each bus stop was created using data inputted into Arcview. Murray et al. (1998) and Murray (2001) have sug- 
gested and tested a catchment area of 400 metres (or $1 / 4$ of a mile) from each bus stop for bus travel, but 800 metres was chosen instead.' In the model used by the DTO, it is assumed that a 10-minute walking distance (or 800 metres) is a typical reasonable distance for QBC commuters (at a walking speed of $5 \mathrm{~km} / \mathrm{h}$ ). Using census data, 31,556 residential addresses (corresponding to a population of 87,936 persons) were identified in the catchment area. ${ }^{8}$ It is from this population that the sample population for the survey is drawn.

The sample population has a higher proportion of respondents falling into the upper socioeconomic categories and are either the Dublin or the national average; nearly two fifths of this sample have a 3rd level degree or higher compared a quarter of the general Dublin population (CSO 2004a).

\section{Modal Share and Performance on the N11 Quality Bus Corridor Modal Share and General Travel Characteristics of Sample Population}

The survey of catchment area residents was conducted in summer 2005. Respondents were interviewed in their home, face-to-face, by a survey company and each interview lasted approximately 20 minutes. The survey included questions relating to the sample population demographic and transport characteristics and their attitudes to bus travel and the N11 QBC. The survey population was representative in terms of gender and age breakdown of the catchment area population and was restricted to those residents between 13 and 75 .

Over 87 percent of the sample travelled along the N11 Road by any means of transport at least once a week. The proportion of respondents who report themselves as "bus users" and "non-bus users" is outlined in Table 2. A total of 41.80 percent are bus users and, of the remaining 58.20 percent non users, car users account for 51.10 percent of the sample.

The N11 is the primary commuting artery for the vast majority of sample (almost $80 \%$ of respondents cite one or two members of their household using it). Bus and car users are disproportionately represented in the survey sample, compared to the general Census trends. The proximity of the sample to a main commuter artery and the $\mathrm{QBC}$ may explain a large part of this.

In terms of frequency of N11 use, a majority of those who travelled 5 days a week or more on this road, used the car while 37 percent travelled by Dublin Bus. Dublin 
Table 2. What mode of transport do respondents primarily use along the N11?

\begin{tabular}{|c|c|c|c|}
\hline Mode & Percentage & & \\
\hline Dublin Bus on QBC & 41.40 & \multirow{2}{*}{$\begin{array}{c}\text { Bus Users: } \\
41.80\end{array}$} & \multirow{2}{*}{$\begin{array}{c}\text { BUS USERS: } \\
41.80\end{array}$} \\
\hline Other Bus on QBC & 0.40 & & \\
\hline Private Car Unshared & 40.30 & \multirow{2}{*}{$\begin{array}{c}\text { Car Users: } \\
51.10 \\
\end{array}$} & \multirow{6}{*}{$\begin{array}{c}\text { NON BUS USERS } \\
58.20\end{array}$} \\
\hline Private Car Shared & 10.80 & & \\
\hline Motorbike & 0.80 & \multirow{4}{*}{$\begin{array}{c}\text { Other Modes: } \\
7.10\end{array}$} & \\
\hline Taxi/Hackney & 0.40 & & \\
\hline Walk & 2.10 & & \\
\hline Bicycle & 3.80 & & \\
\hline
\end{tabular}

Bus is the most popular mode of transport for those who use the road between 1 and 4 days a week. In terms of destination, almost 44 percent of the sample gave the city center as their primary destination when travelling along the N11. The spread of destinations is wider, the further from the city center the respondent's origin is. Only 10 percent of the sample made an intermediate stop with car drivers being most likely to be stopping. Almost 50 percent of those stopping did so for leisure reasons or for shopping.

Bus users account for a third of the 5-day-a-week commuters. Bus users are also more likely to restrict their use of the N11 to the rush hours with half of all bus users who travel northbound using it in the morning rush hour, compared with only one third of the car users. A majority of bus users cite the city centre as their primary destination.

Car users are the most frequent users of the N11 and have travel times and destinations that are more varied than other modes. Of car users who switch to other modes on occasion (almost 50\%), a higher proportion of car sharers than solo car drivers switch. Females are also more likely to switch modes. A total of 60 percent of car users who switched either had problems with parking or wished to drink alcohol (with younger males more likely to cite the latter).

\section{Most Realistic Options and Fastest Modes}

Half of respondents cited the car, either as driver or passenger, as their most realistic transport option, followed by the bus at 40 percent (with a close correlation between this and a respondent's reported modal choice). Two fifths of bus users 
cite being a car passenger as their second option, a quarter would drive. Car drivers would switch to being a car passenger (60\%) followed by the bus (at 30\%). Of car sharers, almost 70 percent view the bus as the next option; fewer than 20 percent would switch to driving.

The bus is perceived as the fastest peak-hour mode along the corridor by all socioeconomic, geographical, transport and demographic groups. However, this trend is reversed for travel in off-peak periods, with no group citing the bus as the fastest mode in these time periods. ${ }^{9}$ All respondents show overwhelming support for the retention of the QBC - despite a perception, especially among car users, that traffic levels have increased moderately or significantly.

\section{Determinants of Modal Choice along the N11 Road}

\section{Bus Users: What Factors have the Biggest Impact on Usage?}

The sample was separated into bus and non bus users. Self-reported bus users were asked to identify the factors that have the biggest impact on their decision to use the bus. In total, 62 percent cite lack of car availability as a reason for using the bus. ${ }^{10}$ These users are thus not "choice" riders in the sense that they have less flexibility in their travel behaviour than respondents with access to a car. The next three factors are bus "pull" factors (i.e., the quality/proximity of the bus apropos other modes): bus reliability/congestion, presence of a nearby bus stop and presence of a QBC along the route. Nearly a quarter of bus users cite either one or both of the latter two factors.

\section{Non-Bus Users: What Factors have the Biggest Impact on Not Using the Bus?}

Users of all other modes (mostly car users) were asked about their motivations for not using the bus. ${ }^{11}$ Almost 60 percent of this group cited the availability of a car as a reason for not using the bus; 18 percent of non-bus users cite push factors such as the quality of public transport in terms of reliability and comfort. ${ }^{12} \mathrm{~A}$ total of 13 percent of non-bus users said that they did not use the bus because they either made multiple stops or had children with them (all of the latter were female), 9 percent view other modes as faster than the bus and one in seven mentioned the availability of parking facilities. 
Table 3. Reasons for Using the Bus on the N11

\begin{tabular}{|lcc|}
\hline \multicolumn{1}{|c}{ Factor } & $\begin{array}{c}\text { Total } \\
\text { Responses \# }\end{array}$ & $\begin{array}{c}\text { \% of Bus Users } \\
\text { Citing Factor }\end{array}$ \\
\hline No Car Available & 262 & $62 \%$ \\
Traffic Congestion- Bus Most Reliable & 69 & $16.51 \%$ \\
Presence of a Bus Stop Nearby & 58 & $13.88 \%$ \\
Presence of a QBC Along the Route & 58 & $13.88 \%$ \\
Lack of Parking Facilities & 44 & $10.63 \%$ \\
No Other Suitable Public Transport Available & 37 & $8.85 \%$ \\
Cost of using Car Exceeds Public Transport & 31 & $7.42 \%$ \\
Ease of Transfer to Other Public Transport & 18 & $4.31 \%$ \\
Quality of Waiting and On-Bus Facilities & 12 & $2.88 \%$ \\
Environmental Concerns & 11 & $2.63 \%$ \\
Other & 23 & $5.50 \%$ \\
Don't Know & 7 & $1.68 \%$ \\
Total Responses: & 630 & - \\
Total Number of Respondents & 418 & - \\
\hline
\end{tabular}

Note: Percentages do not add up to 100 as respondents could cite more than one factor.

\section{Determinants of Modal Choice along the N11 Quality Bus Corridor}

Probit regression analysis was also conducted to determine the impact of sociodemographic and travel characteristics of the respondents on the probability of bus usage along the N11. The dependent variable is a binary variable which takes the value of 1 if the respondent is a self-reported bus user and zero otherwise. Appendix 2 describes the independent variables that were included in the probit analysis.

\section{Model 1: Demographic and Basic Transport Influences on Bus Usage:}

Table 5 (columns 2 and 3 ) outlines the results of a probit regression explaining the factors influencing bus usage in our sample. ${ }^{13}$ As expected, the coefficient on household income is negative and significant (at the $5 \%$ level) indicating that, as household income increases, the probability of being a bus user declines. This relationship is, however, very weak, possibly due to the fact that the population under investigation has a high socio-economic profile. Full or part-time employment reduces the probability of being a bus user by 16 percent and 10 percent respectively (in relation to those who are not working). The direction of this rela- 
Impact of Bus Priority Attributes on Catchment Area Residents in Dublin, Ireland

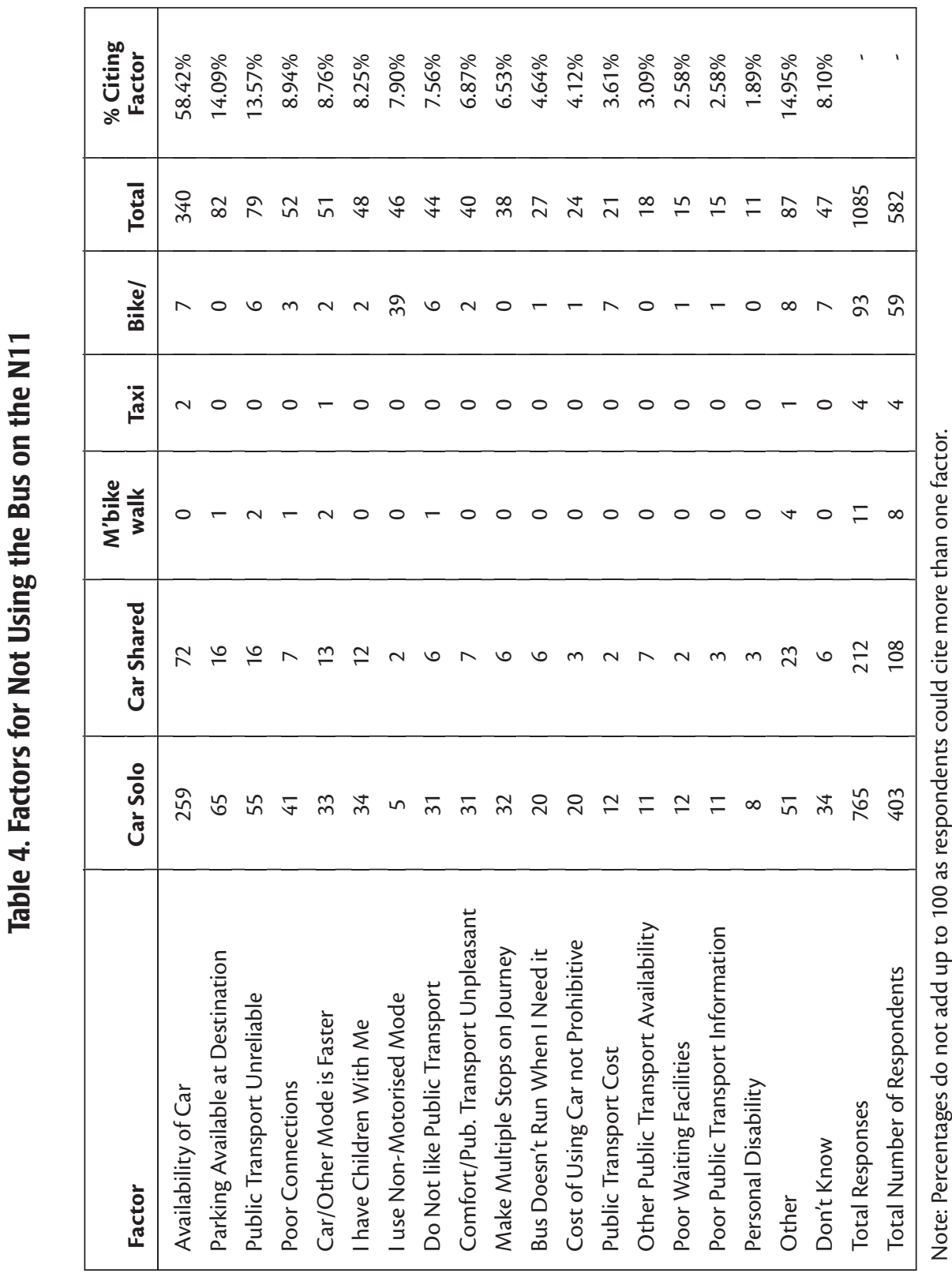


tionship is repeated for those having a mortgage and living rent free (relative to owner occupiers). Those who travel on the N11 3-4 days a week or less than once a week are also more likely to be bus users than those using the N11 5 or more days a week.

Table 5. Marginal Effects of Probit for Impacts on Bus Usage on the N11

\begin{tabular}{|c|c|c|c|c|}
\hline \multirow{2}{*}{$\begin{array}{l}\text { Operation: } \\
\text { Dep Variables: } \rightarrow \\
\text { Exp Variables: } \downarrow \\
\text { Hseincome }\end{array}$} & \multicolumn{2}{|c|}{$\begin{array}{l}\text { Model 1: Impacts on N11 } \\
\text { Bus Usage (dy/dx) } \\
\text { N11bususers }\end{array}$} & \multicolumn{2}{|c|}{$\begin{array}{l}\text { Model 2: Impacts on N11 } \\
\text { Bus Usage (Car Availability and } \\
\text { Location - dy/dx) } \\
\text { N11bususers }\end{array}$} \\
\hline & -1.55 e- $06^{* *}$ & $(.0000)$ & $-1.54 \mathrm{e}-06^{* *}$ & $(.0000)$ \\
\hline Empfull & $-.1652^{* * *}$ & $(.0406)$ & $-.1683^{* * *}$ & $(.0420)$ \\
\hline Emppart & $-.1014 *$ & $(.0557)$ & -.0878 & $(.0573)$ \\
\hline Hsemort & $-.1107^{* *}$ & $(.0433)$ & $-.1046^{* *}$ & $(.0449)$ \\
\hline Hserent & -.0327 & $(.0544)$ & -.0196 & $(.0566)$ \\
\hline Hserentfree & $-.1148^{*}$ & $(.0698)$ & -.0986 & $(.0733)$ \\
\hline Hsesocial & -.1246 & (.1677) & -.0340 & (.1981) \\
\hline Hselength2_5 & .0260 & $(.0624)$ & .0708 & $(.0656)$ \\
\hline Hselength6_10 & .0238 & $(.0681)$ & .0425 & $(.0705)$ \\
\hline Hselengthover 10 & $.0405^{*}$ & $(.0648)$ & .1169 & $(.0678)$ \\
\hline Edstud & .0487 & $(.0810)$ & .0443 & $(.0842)$ \\
\hline Ed2nd & .0085 & $(.0657)$ & .0280 & $(.0683)$ \\
\hline Ed3rd & -.0331 & $(.0694)$ & -.0055 & $(.0730)$ \\
\hline Age & $-.0805^{* * *}$ & $(.0130)$ & $-.0812^{* * *}$ & $(.0135)$ \\
\hline Male & $-.0858 * *$ & $(.0344)$ & $-.1011^{* * *}$ & $(.0356)$ \\
\hline Child14_18 & -.0003 & $(.0506)$ & -.0200 & $(.0519)$ \\
\hline Child6_13 & $-.1079^{* *}$ & $(.0508)$ & $-.0985 *$ & $(.0526)$ \\
\hline Childunder5 & $-.1201^{*}$ & $(.0632)$ & -.0771 & $(.0675)$ \\
\hline Hhn11users & -.0155 & $(.0172)$ & -.0175 & $(.0182)$ \\
\hline N11freqless & $.1273^{* *}$ & $(.0591)$ & $.2018^{* *}$ & $(.0617)$ \\
\hline N11freq1_2 & .0530 & $(.0487)$ & .0562 & $(.0507)$ \\
\hline N11freq3_4 & $.0923 *$ & $(.0499)$ & $.1021^{* *}$ & $(.0524)$ \\
\hline N11timesthvar & -.0619 & $(.0602)$ & -.0944 & $(.0612)$ \\
\hline N11timenthvar & $-.1381^{* *}$ & $(.0603)$ & $-.1107^{* *}$ & $(.0630)$ \\
\hline N11intermedtotal & $-.2861 * * *$ & $(.0445)$ & $-.2516^{* * *}$ & $(.0512)$ \\
\hline availablecar & - & - & $-.3312 * * *$ & $(.0385)$ \\
\hline Luas & - & - & $-.1644^{* *}$ & $(.0667)$ \\
\hline Dart & - & - & -.0119 & $(.0523)$ \\
\hline Extension & - & - & -.1780 & $(.0385)$ \\
\hline Pseudo R2 & & 0.1312 & & 0.2049 \\
\hline $\mathrm{N}$ & & 1000 & & 1000 \\
\hline
\end{tabular}

Notes: 1. Standard Errors in brackets constructed using the White-Heteroskedasticity-Consistent Variance-Covariance Matrix.

2. ${ }^{* * *},{ }^{* *},{ }^{*}$ denote significance at the $1 \%, 5 \%$ and $10 \%$ levels, respectively.

3. $\mathrm{dy} / \mathrm{dx}$ is for discrete change of dummy variable from 0 to 1 . 
Increasing age and being a male both reduce the probability of bus usage by approximately 8 percent. As we would expect from the analysis of the descriptive statistics, having a variable northbound commuting time and having children under 13 decreases the probability of bus usage. Those making an intermediate stop are 28 percent less likely to be bus users (the strongest reported relationship).

\section{Model 2: The Impact of Car Availability and Location Impacts on Bus Usage} In model 2 (columns 4 and 5), new dummy variables are introduced to the model. These include car availability, ${ }^{14}$ presence of a light rail (Luas) and heavy rail (Dart) station close to respondent origin, and, finally, whether the respondent lives beyond the Foxrock turnoff (where many services turn off the QBC; accordingly, bus frequency is reduced for commuters beyond this point). Car availability emerges as a significant variable explaining the probability of being a bus user on the N11 Road. Having a car available reduces the probability that respondents will be a bus user by 33 percent. This is a widely reported relationship. Previous studies, e.g., Hensher and Reyes (2000) and Alpizar and Carlsson (2003), have shown the importance of having a car and the inertias it generates on modal choice, i.e. the reluctance of those already using the car to switch to other modes. Looking at the other new explanatory variables, shows that while the presence of a heavy rail station within the catchment area of a respondent has no significant impact on bus usage; living near a Luas light rail station reduces the probability of being a bus user by 16 percent. This reinforces the findings of the DTO (DTO 2005) that the introduction of a light rail line in summer 2004 has impacted on patronage along the N11 QBC and is a significant finding of this research for policymakers in Dublin and elsewhere. The remaining results of Model 2 largely mirror the previous model, and mirror the findings of Hensher and Reyes (2000) for Sydney, which showed that income, age, full time employment, the availability of a car in the household, and the presence of more complicated trips (i.e., intermediate stops) act as barriers to public transport usage. The results are broadly comparable, this despite our sample population having a higher than average demographic profile.

\section{Determinants on Bus usage-Importance of Bus Attributes to Respondents}

Respondents were asked to rate the importance of nine attributes of a bus journey along the N11. These nine attributes (peak journey times, off-peak journey times, cost, seat availability, bus stop facilities, real time information, ticket machines at 
bus stops, park and ride and priority for buses at junctions) were selected after two focus group based discussions with catchment area residents. Interestingly, attributes, such as security, given importance by other researchers (e.g., Baltes, 2003), were not considered an important determinant by residents; thus, they were omitted from the analysis. This, again, may be due to the socio-economic make up of the area under investigation. The results are set out in Figure 1.

\section{Figure 1. Importance Rating of Attributes of Bus Use}

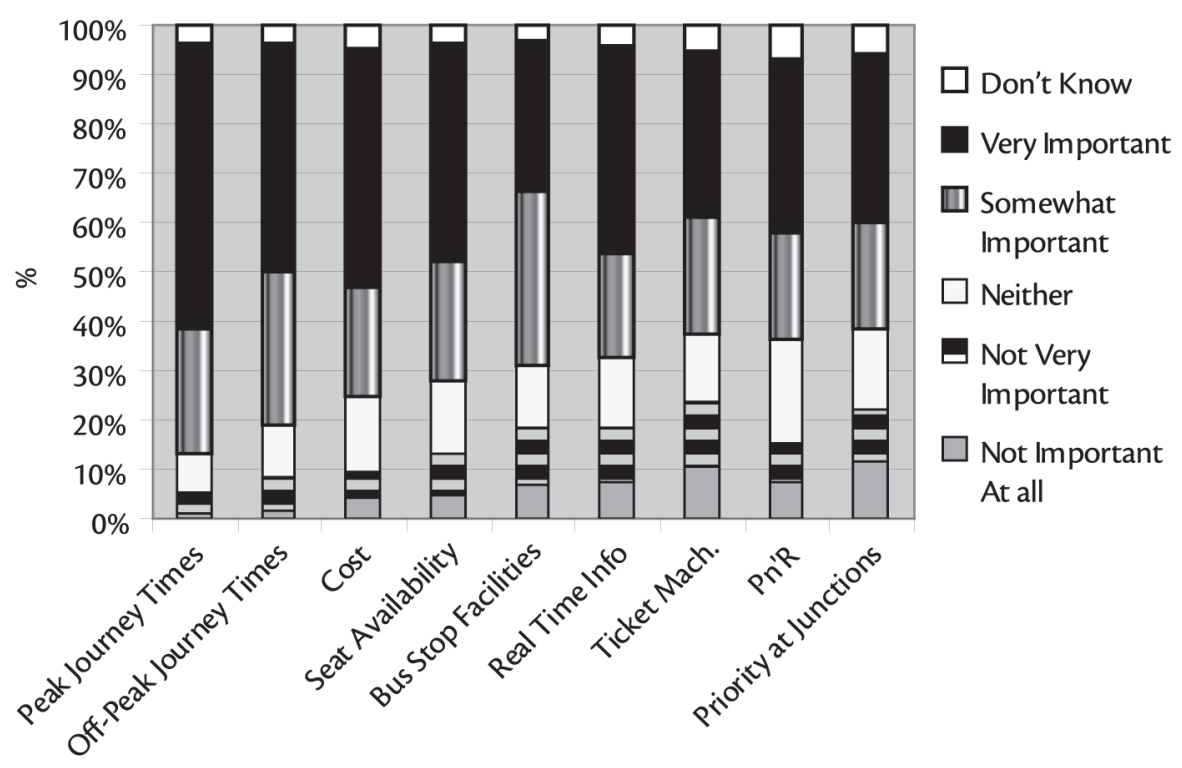

Journey times emerge as the most important attribute for the sample with peak journey times slightly outweighing off-peak journey times. Cost is also an important attribute. Interestingly, more priority at traffic junctions for buses was considered the least important attribute, which given the potential journey time savings, may seem paradoxical. However, when this attribute was presented at focus groups, the concept in itself was controversial. Most participants were unfamiliar with the concept (no such system presently exists in Dublin) and many were hostile, assuming that it would impact negatively on all traffic. Unfamiliarity may explain some of this contradiction. 


\section{Impact of Modal Choice on Perceptions of Attribute Importance}

When the difference in importance placed on different attributes across groups was analyzed, we found different patterns between bus users and users of other modes. We would expect that bus users who have frequent and first hand experience of the bus services would have different perceptions of the importance of bus-specific attributes than infrequent or non-users. To see if being a bus user impacted significantly on attribute perceptions, after controlling for other factors such as socio-economic and transport characteristics further probit analysis was conducted in which the probability of stating an attribute as important was explained, among other variables, by modal choice. ${ }^{15}$

Nine variables were created, which captured the importance of the 9 attributes of a bus journey to respondents. These binary variables took the form of 1 if the attribute was considered important and 0 otherwise. ${ }^{16}$ The influence we are investigating is the impact of being a bus user on the perceptions of the nine bus attributes, after controlling for the other socio-economic and transport-related characteristics (those included in Model 2 of Section 5).

Column 2 of Table 6 indicates the statistical significance and the direction of the relationship and the degree of influence that bus usage has on the attribute perceptions. These estimates come from 9 different probit regressions. ${ }^{17}$

Table 6. Bus Usage and Attribute Perceptions: Marginal Effects of Probit

\begin{tabular}{|l|c|c|}
\hline Attribute (Dependent Variable): & $\begin{array}{c}\text { Bus Usage Influence on } \\
\text { Attribute Perception (dy/dx): }\end{array}$ & $\begin{array}{c}\text { Standard } \\
\text { Error }\end{array}$ \\
\hline On-Peak Bus Journey Times & $.1325^{* * *}$ & .0242 \\
Off-Peak Bus Journey Times & $.1561^{* * *}$ & .0285 \\
Bus Cost & $.1142^{* * *}$ & .0324 \\
Seat Availability & $.2039^{* * *}$ & .0318 \\
Bus Stop Facilities & $.1988^{* * *}$ & .0331 \\
Real Time Information & .0153 & .0358 \\
Ticket Machines at Bus Stops & -.0206 & .0370 \\
Park and Ride Facilities & -.0274 & .0375 \\
More Priority for Buses at Junctions & $.0986^{* * *}$ & .0368 \\
\hline
\end{tabular}

Notes: $1 . \mathrm{dy} / \mathrm{dx}$ is for discrete change of dummy variable from 0 to 1 .

2. ${ }^{* * *}, * *,{ }^{*}$ denote significance at the $1 \%, 5 \%$ and $10 \%$ levels, respectively. 3. All 9 probit regressions included socio-economic and transport related characteristics as explanatory variables (not reported). 
According to Table 6, bus usage has a significant impact on the perception of six of the nine attributes so that those who use the bus have different perceptions of the attributes than users of other modes. For all six attributes where there is a significant difference in perceptions of the attributes, the relationship is positive. This indicates that bus usage increases the probability that respondents place importance on these attributes.

Being a bus user results in a 13 percent increased probability in placing importance on peak bus journey times and 16 percent increased probability in placing importance on off-peak bus journey times. Bus usage has the biggest impact on seat availability and bus stop facilities (20.3\% and $19.9 \%$ increases in importance, respectively). The probability of placing importance on bus cost is increased by 11 percent by being a bus user. The weakest significant influence is for an increase bus priority at traffic junctions.

The results that bus users place more importance on these characteristics is not surprising, since, unlike car users, it is bus-users who experience varying levels along these six attributes on a frequent basis. Moreover, there is no significant difference between bus users and users of other modes for the three remaining attributes. This may be a result of the fact that these attributes are not presently available on the route. Respondents are either unfamiliar with the attributes or simply, the views of both groups do not differ in relation to these three attributes.

To capture the potential difference in perception between "choice" and "captive" bus users (i.e., those without the availability of alternative motorised transport), we repeated the nine probit regressions including an additional variable that captured the interaction effect between bus users and car availability. ${ }^{18}$ In seven cases, this variable was insignificant, indicating no differences between the perceptions of "choice" and "captive" bus user regarding bus-journey attributes. Interestingly, we found a significant difference between both groups regarding bus stop and park-and-ride facilities. This can be explained by "choice" bus users being able to avail of park-and-ride facilities to combine car use and bus use on the corridor.

\section{Conclusions}

As noted at the outset of this paper, bus priority measures have typically been assessed using engineering and revealed preference techniques (i.e., the number of passengers carried and the travel speeds of the vehicles). Studies that have investigated individual preferences and perceptions have tended to do so in the context 
of wider modal choice models, or through analysing the impact of attributes to those already using the bus mode (e.g., Hensher et al. 2003, Baltes 2003). An additional downside of on-bus surveys is the restrictive time available to investigate wider issues such as the socio-demographic profile of the respondent.

This paper aims to cover a gap in an under-researched area of public transport by investigating the perceptions, attitudes and behaviour characteristics (as well as demographic characteristics) of 1000 respondents, comprising current users and potential users, living in the GIS constructed catchment area. The findings of our research demonstrate that it is possible, in a relatively high-income urban catchment, to provide a bus option that attracts over 40 percent of the commuter traffic, the key to this success being mainly shorter journey times at traffic peaks. However, it is also clear that for the remaining passengers-notably the car users - there are challenges in improving this ratio.

The descriptive statistics and probit analysis have highlighted influences on modal choice. As evidenced by previous studies, variables decreasing the probability of being a bus user include demographic features such as income, age, employment status and the presence of children in the household. We have also found that while the bus is perceived as the fastest mode in peak periods, its advantage diminishes significantly for the off-peak period. This perception is especially strong for car users and the loss of its journey time advantage indicates an additional barrier to public transport usage amongst car users on this corridor. Interestingly, this research has confirmed perceptions that light rail has acted as a substitute to bus priority for those living close to a light rail station-a particularly relevant finding for policymakers and researchers interested in such a relationship.

This study has also assessed the importance of modal choice on the perceptions of nine bus specific attributes. Results indicate that attributes and their importance are viewed differently by users of different modes. Being a bus user is likely to increase the probability of placing importance on the bus-journey attributes with which bus users have familiarity through frequent use.

This may also indicate that, for many car users, these attributes are considered as important only in the context of bus use and are not central to their decision making process. The primary determinant in the use of the bus is the availability of a car to the respondent. For both bus using and non-bus using respondents, the availability or otherwise of a car is the most cited factor. The probit analysis reinforces this finding. For car users specifically, the inertia effect-the reluctance of those already using the car to switch to alternative modes-discussed by Alpizar 
and Carlsson (2003) has been identified as the biggest single barrier to bus use on this corridor for those not already using the mode.

Since the proportion of households and commuters with access to a car is likely to increase in the future, the challenge of getting "choice" riders-those of relatively high income with a car-to switch or to continue to use the bus will intensify. Our analysis does give indications as to what policy changes are likely to be relevant. Availability of parking is the second most important reason given by respondents for choosing the car over the bus, and our analysis confirms that for "choice" bus users it is a more important factor than for "captive" bus users. Policy can restrict parking availability or make it more expensive. The perceptions that public transport is unreliable and slower are other areas where positive intervention would help. As of April 2006, passengers get on and off at the same door, leading to congestion, and many passengers pay cash, both of which increase the time delays at stops. These inefficiencies slow journey times, and both could be changed, and this in turn would increase the attractiveness of this option to "choice" riders.

\section{Endnotes}

${ }^{1}$ In this paper, we refer to "bus priority measures" as elements of Bus Rapid Transit (BRT) that have been implemented in Dublin, the area of study. The primary measures include grade-separated right-of-way, frequent, high-capacity services, high-quality vehicles, improved rider information. For more, see DTO (2005).

${ }^{2}$ A special advisory group to the European Union note an estimate for congestion at 2\% of GDP per annum (Nash and Samsom, 1999).

${ }^{3}$ Private car ownership in the GDA during the past decade has almost doubled (DTO 2002). AM peak hour travel demand increased by $65 \%$ and is expected to almost double again by 2016 (DTO 2000).

${ }^{4}$ From an interview with the Quality Bus Network Office: Approximately $120 \mathrm{~km}$ of bus priority have been developed, and there is a potential for up to $400 \mathrm{~km}$ to be developed.

${ }^{5}$ As of November $2004,86 \%$ of this section was segregated from general traffic (DTO 2005).

${ }^{6}$ Unfortunately, averages of these ranges are not provided as part of the reporting process. For more, see DTO (2005). 
${ }^{7}$ After consultation with Dublin Bus and the Dublin Transportation Office, it was decided that a $400 \mathrm{~m}$. limit was too conservative. Similarly, Bacon (1998) suggests a wider $(500 \mathrm{~m}) \mathrm{QBC}$ catchment area.

${ }^{8} 5,961$ of these addresses are in the 12 Dublin City Council electoral districts and 25,595 in the 38 Dun Laoghaire Rathdown electoral districts

${ }^{9}$ In the peak period, bus users consider the bus to be the fastest mode, $36 \%$ of solo car users also hold this view, compared with less than $30 \%$ who opt for the car. However, in off-peak performance, fewer than $50 \%$ of bus users view the bus as the fastest mode. Two thirds of car drivers opt for the car (with only $9 \%$ viewing the bus as the fastest mode in the off-peak).

${ }^{10}$ Ranging from about $70 \%$ for those under 24 to fewer than $50 \%$ for those $35-44$. Less than $50 \%$ of those in the highest socioeconomic class cite this reason compared to $70 \%$ of those in the lowest class.

${ }^{11} 87 \%$ of this group identify themselves as car users, of which four fifths are solo car drivers.

${ }^{12}$ Reliability is far more likely to be mentioned by those who are younger.

${ }^{13}$ Results shown indicate marginal effects analysis of probit regressions.

${ }^{14}$ The survey did not ask a direct question on whether the respondent had access to a car. Thus, the dummy variable for car availability takes the value of one for present car users and bus users who do not cite lack of car availability as a determinant for bus use.

${ }^{15}$ There is a potential issue of endogeneity with modal choice being explained by the importance of the characteristics. However, when these variables were included as regressors in Table 5 they were not significant. In addition, while authors such as Hensher et al. (2003) and Baltes (2003) have assessed the importance of attributes to bus users, we are investigating the influence of these attributes to a wider population and thus, how users of different modes view attributes is of central importance.

16 "Important" was assigned for respondents who considered a bus attribute "important" or "very important."

${ }^{17}$ Results for other explanatory variables in the regressions are available from the authors upon request. 
${ }^{18}$ We would like to thank an anonymous referee for suggesting this effect. Results from these additional regressions are not reported in the paper but are available from the authors upon request.

\section{Acknowledgements}

We are grateful to the Irish Research Council for the Humanities and Social Sciences (IRCHSS) for fellowship support and to Dublin Bus, Dublin City Council, and the Dublin Transportation Office (DTO) for providing the funding for the survey. We are also grateful to Owen Keegan, Derry O'Leary and Michael Warnock Smith for generously given advice. Thanks also to participants at the UCD GPEP Spring Seminar for comments. Finally, we appreciate the comments of two anonymous reviewers. Responsibility for content and analysis rests with the authors alone.

\section{References}

Alpizar, F. and F. Carlsson. 2003. Policy implications and analysis of the determinants of travel mode choice: An application of choice experiments to metropolitan Costa Rica. Environment and Development Economics 8: 603-619.

Asensio, J. 2002. Transport mode choice by commuters to Barcelona's CBD. Urban Studies 39(10): 1881-1895.

Bacon, P. 1998. An Economic assessment of recent house price developments, Report to the minister for housing and urban renewal, Dublin.

Balke, K.N., C.L. Dudek, and T. Urbanik. 2000. Development and evaluation of an intelligent bus priority concept: Advanced traffic management systems and automated highway systems. Transportation Research Record 1727, Transportation Research Board, Washington, DC.

Baltes, M.R. 2003. The importance customers place on specific service elements of bus rapid transit. Journal of Public Transportation. 6(4): 1-19.

Bhat, C. 1998. Accommodating variations in responsiveness to levels-of-service measures in travel mode choice modeling. Transport Research A 32:495-507

Bokinge, U. and D. Hasselström. 1980. Improved vehicle scheduling in public transport through cystematic Changes in the time-table. European Journal of Operational Research 5(6): 388-395. 
Caulfield, B., and M. O'Mahony. 2003. The application of the transit capacity and quality of service manual on a bus corridor in Dublin. Presented at the TRB Annual Meeting in January 2004.

CIE. 1984. Public transport in the Dublin conurbation. An Address by John F. Higgins, to the Chartered Institute of Transport (Scottish Section). 23rd Oct. 1984.

CSO 2004a. Census 2002, Volume 7 Education and Qualifications. Stationary Office, Dublin.

CSO 2004b. Census 2002, Volume 9, Travel to Work School or College. Stationary Office, Dublin.

Currie, G. 2005. The demand performance of bus rapid transit. Journal of Public Transportation 8(1): 41-55.

DETR 1999. From workhorse to thoroughbred: A better role for bus travel. Department of Environment, Transport and the Regions, March 1999.

DTI 1995. Final Report. Dublin Transport Initiative.

DTO 2004. QBC Monitoring Report. Dublin Transportation Office.

DTO 2005. QBC Monitoring Report. Dublin Transportation Office.

Friman, M. 2004. Implementing quality improvements in public transport. Journal of Public Transportation 7(4): 49-65.

Hensher, D.A., and A.J. Reyes. 2000. Trip chaining as a barrier to the propensity to use public transport. Transportation 27: 341-361.

Hensher, D.A, P., Stopher, and P. Bullock. 2003. Service quality-Developing a service quality index in the provisions of commercial bus contracts. Transportation Research Part A 37: 499-517.

Horn, M.E.T. 2002. Multi-modal and demand-responsive passenger transport systems: A modelling framework with embedded control systems. Transportation Research Part A 36: 167-188.

Murray, A., R. Davis, R. Stimson and L. Ferreira. 1998. Public transport access. Transportation Research D 3: 319-28.

Murray, A. 2001. Strategic analysis of public transport coverage. Socio-Economics Planning Sciences 35: 175-188. 
Nash C., and T. Samson. 1999. Calculating transport congestion and scarcity costs. Final report of the expert advisors to the high level group on infrastructure charging (Working Group 2).http://europa.eu.int/comm/transport/infrcharging/library/congestion-cost.pdf (accessed on 10th November 2005).

O'Fallon, C., C. Sullivan, and D.A., Hensher. 2004. Constraints affecting mode choices by morning car commuters. Transport Policy 11: 17-29.

Polus, A. 1978. Modelling and measurements of bus service reliability. Transportation Research 12(4): 253-256.

Parkany, E., R.Gallagher, and P. Viveiros. 2004. Are attitudes important in travel choices? Presented at the TRB Annual Meeting in January 2004.

Prioni, P., and D.A. Hensher. 2000. Measuring service quality in scheduled bus services. Journal of Public Transportation 3(2).

Rodríguez, D.A. 2002. An empirical exploration of bus travel time and dwell times in a highly competitive exclusive busway. Journal of Public Transportation 2(1).

Swait, J. and G. Eskeland. 1995. Travel mode substitution in Sao Paulo: estimates and implications for pollution control. Policy Working Paper 1437, World Bank.

Transportation Research Board of the National Academies 2003a. Transit Cooperative Research Program Report 90. Bus Rapid Transit, Volume 1: Case Studies in Bus Rapid Transit. Transport Research Board, Washington, D.C.

Transportation Research Board of the National Academies 2003b. Transit Cooperative Research Program Report 90. Bus Rapid Transit, Volume 2: Implementation Guidelines. Transport Research Board, Washington, D.C.

Wardman, M. 2000. Using existing stated preference data to analyse bus preferences. ITS Working Paper 555. University of Leeds.

Wardman, M. 2001. A review of British evidence on time and service quality valuations. Transportation Research Part E 37: 107-128. 


\section{About the Authors}

Simon McDonnell (Simon.McDonnell@ucd.ie) graduated with a BA in Economics from University College Dublin in October 2000. Subsequently, he worked for Deloitte \& Touche before returning to Ireland in 2002 to complete an MSc in Environmental Economics and Policy in UCD. This work focused mainly on environmental taxes, specifically related to the recent introduction of the plastic bag levy by the Irish Government. He is now pursuing a PhD. in the area of transport and environmental economics and policy. His specific research interest concerns the use of bus rapid transit and bus priority measures as a transport and environmental policy tool. He is currently an Irish Research Council of Humanities and Social Sciences (Government of Ireland) scholar.

SUSANA FerReIRA (Susana.Ferreira@ucd.ie) joined UCD after completing a PhD in Economics at University of California, San Diego in May 2004. She previously studied at Universidad de Navarra in Pamplona, Spain, where she completed a Bachelor of Sciences in Business. In addition, she was a visiting scholar at Universidad Colegio Mayor Nuestra Señora del Rosario in Bogotá, Colombia, and served as a Consultant for the World Bank. Her research interests include the impact of international trade in the environment, the role of institutions and natural resources in development, and the 'greening' of national accounts.

Frank Convery (Frank.Convery@ucd.ie) was educated at University College Dublin and the State University of New York and has degrees in forestry and resource economics. Prior to taking up his post at UCD, he was Assistant and then Associate Professor of Natural Resource Economics at Duke University, USA and Research Professor at the Economic and Social Research Institute, Ireland. He is active on a number of EU wide investigations and bodies, including membership of the Science Committee of the European Environment Agency and President of the European Association of Environmental and Resource Economists. He has written extensively on resource and environmental economics issues with particular reference to agriculture, forestry, energy, minerals, land use, urbanisation, environment and development in developing countries. At present, his research relates to European Union Environmental Policy with particular reference to the use, potential and effectiveness of market-based instruments. 


\section{Appendix 1. Route of N11 QBC and 800 metre Catchment Area}

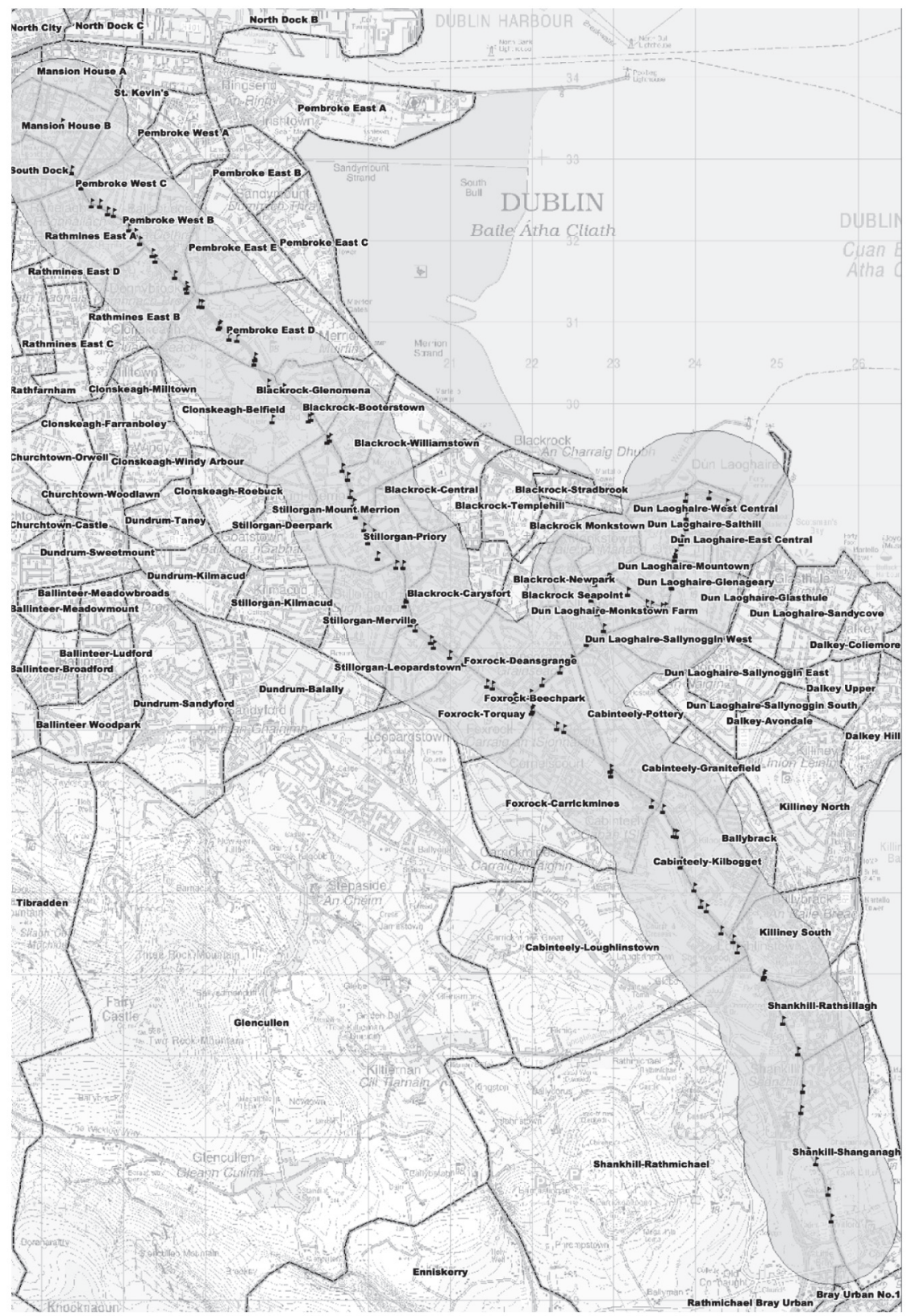




\section{Appendix 2. Variables Used in Probit Regressions}

N11Bususer
Hseincome
Empfull
Emppart
Empnot
N11freq5
N11freq3_4
N11freq1_2
N11freqless
Hseown
Hsemort
Hserent
hserentfree
Hsesocial
Hselength0_1
Hselength2_5
Hselength6_10
Hselengthover10
Edprime

Edstud

Ed2nd

Ed3rd

Age

Male

Hhn11users

N11timenthvar
Dummy variable for modal use on N11 ( 1 =bus user, $0=$ otherwise)

Self reported household income (with proxy for non-answers)

Dummy variable for employment status ( $1=$ full time, $0=$ otherwise)

Dummy variable for employment status ( $1=$ part time, $0=$ otherwise)

Dummy variable for employment status ( $1=$ other working status, $0=$ otherwise)

Dummy variable for frequency of $\mathrm{N} 11$ use ( $1=5$ times a week, $0=$ otherwise)

Dummy variable for frequency of $\mathrm{N} 11$ use ( $1=3 / 4$ times a week, $0=$ otherwise)

Dummy variable for frequency of $\mathrm{N} 11$ use ( $1=1 / 2$ times a week, $0=$ otherwise)

Dummy variable for frequency of N11 use (1=less than once a week,

$0=$ otherwise)

Dummy variable for House tenure type ( $1=$ own outright, $0=$ otherwise)

Dummy variable for House tenure type ( $1=$ mortgage, $0=$ otherwise)

Dummy variable for House tenure type ( $1=$ rent, $0=$ otherwise)

Dummy variable for House tenure type ( $1=$ live rent free, $0=$ otherwise)

Dummy variable for House tenure type ( $1=$ social housing, $0=$ otherwise)

Dummy variable for House length ( $1=$ one year or under, $0=$ otherwise)

Dummy variable for House length ( $1=$ two to five years, $0=$ otherwise)

Dummy variable for House length ( $1=$ six to ten years, $0=$ otherwise)

Dummy variable for House tenure type ( $1=$ over ten years, $0=$ otherwise)

Dummy variable for education attainment level ( $1=$ primary or below, $0=$ otherwise)

Dummy variable: education attainment level ( $1=$ second/third level student, $0=$ otherwise)

Dummy variable for education attainment level ( $1=$ secondary level, $0=$ otherwise)

Dummy variable for education attainment level (1=third or post third level, $0=$ otherwise)

Variable: age respondents $(1=13-18,2=19-24,3=25-34,4=35-44,5=45-54$, $6=55-64,7=65-74$ )

Dummy variable for gender of respondent ( $1=$ male, $0=$ female).

Variable: the number of N11 Users in household $(1=1,2=2,3=3,4=4,5=5$, $6=6,7=7$ or more)

Dummy variable: respondents travelling northbound at varied times ( $1=$ varied, $0=$ otherwise) 
N11timesthvar Dummy variable: respondents travelling southbound at varied times ( $1=$ varied, $0=$ otherwise)

N11intermedtotal Dummy variable: respondents making intermediate stops (1=intermed stop, $0=$ otherwise

Child14_18 Dummy variable: number of dependents in household aged 14 -18 (1=14-18, $0=$ otherwise)

Child6_13 Dummy variable for number of dependents in household aged $6-13(1=6-13$, $0=$ otherwise)

Childunder $5 \quad$ Dummy variable: number of dependents in household under 5 years (1=under 5, $0=$ otherwise)

Availcar Dummy variable: car users and bus users not citing car unavailability ( $1=$ car available, $0=$ otherwise)

Luas Dummy variable for respondents with origin close to Luas Light Rail Station (1=Important, $0=$ otherwise)

Dart Dummy variable for respondents with origin close to DART Heavy Rail Station ( $1=$ Important, $0=$ otherwise)

Extension Dummy variable for respondents with origin beyond Foxrock Turnoff, on this section of the $\mathrm{QBC}$, bus services are not as frequent (1=Important, $0=$ otherwise) 


\title{
An Update on Curb Guided Bus Technology and Deployment Trends
}

\author{
David Phillips \\ TranSystems Corporation
}

\begin{abstract}
The first Curb Guided Bus (CGB) route opened in 1980. Although initial introduction of this technology was slow, six routes have opened since 1998, and more are in the works, mostly in the U.K. This paper presents a comprehensive review of the technology and its deployment.

\section{Introduction}

The author has been a key participant in two Alternative Analyses where the available right-of-way width was very restricted. To keep Bus Rapid Transit (BRT) as an option, some form of guidance would be required to ensure that buses could operate reliably in a very narrow lane. A literature search identified several guided bus technologies, but all were, and still are, in the research and development phase. The exception was Curb Guided Bus (CGB). However, little information was provided. This is a report on the author's extensive research on system design and operation for this technology, including site visits to most of the systems in operation. These visits included meetings with people involved in the initial technology research, system design, funding, operation, and maintenance of the infrastructure and the vehicles. It has been confirmed that this technology is appropriate in situations where even a limited amount of right-of-way is available and that
\end{abstract}


it can be installed with low risk. This ability to operate in narrow rights-of-way is especially important in constricted environments such as medians of arterial streets or freeways, on an abandoned railroad alignment or alongside an active railroad, on bridges or elevated structures, in tunnels, or under buildings. These narrow rights-of-way can make it possible to create dedicated transit lanes where otherwise none would fit. In addition, it was found that there are more advantages to the use of CGB technology, compared to either conventional, manually-steered BRT and other guided bus technologies, than simply the narrower right-of-way configurations.

\section{Figure 1. Curb Guided Bus, Adelaide}

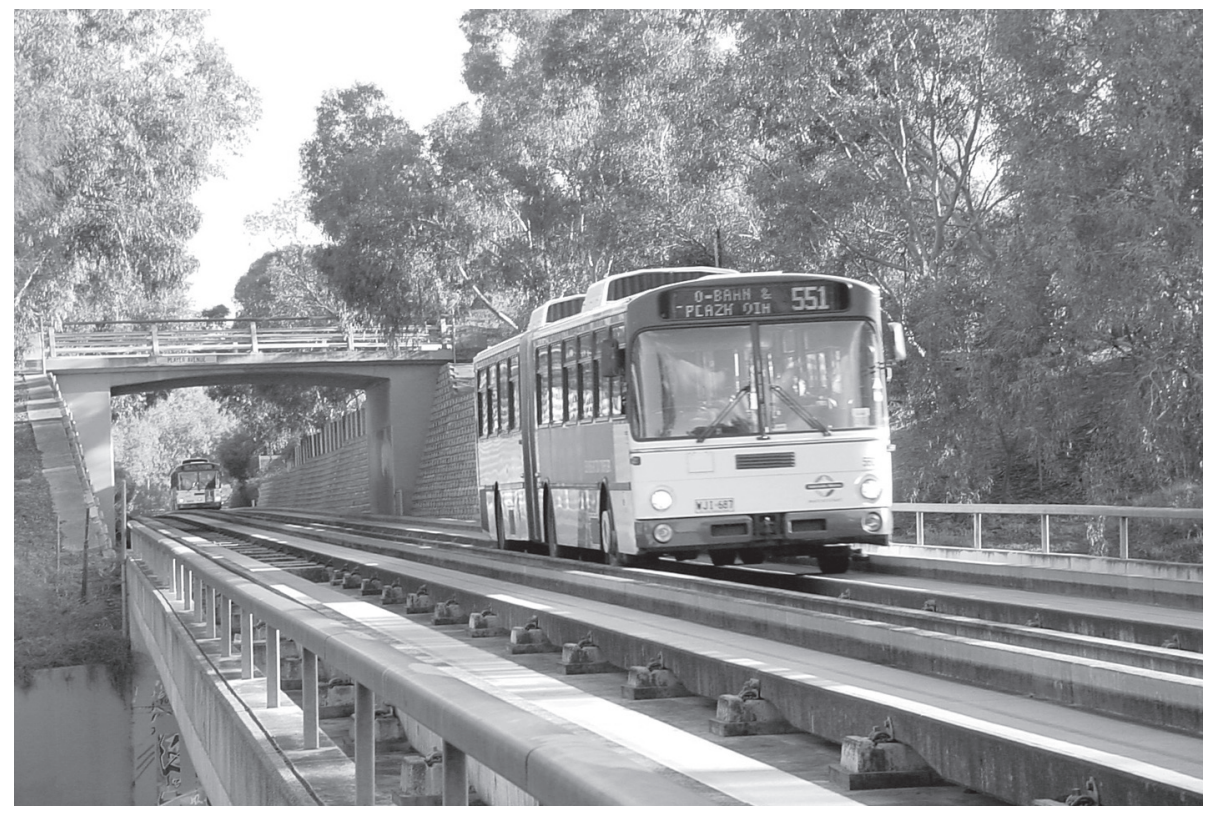

Source: TranSystems

\section{Curb Guided Bus Sytem Operations}

A major surprise in the research was the number of CGB systems in operation. None of the previous guidance technology articles had mentioned more than two or three routes. There are, in fact, 12 systems in operation, and two other well- 
advanced future systems. Site visits were made to most of them. Table 1 lists these Systems, in the order of their opening date. Table 2 lists future systems.

\section{Table 1. Curb Guided Bus Systems in Operation}

\section{0 - Essen, Germany}

Fulerumer Strasse - All of the system's routes started under a government demonstration program. EVAG now operates a 3 route system with 3.7 miles of bi-directional guideway in 3 separate segments. All were previously private right-of-way portions of streetcar routes. The first segment operates in a parklike setting that demonstrated operation through grade crossings and on a $6 \%$ grade.

\section{3 - Essen, Germany}

Wittenbergstrasse - This section was the test site for joint operation of dual mode buses with streetcars. Concrete and wood running surfaces were tested. Following the test, a section in tunnel, shared with streetcars, was operated for 11 years. Only guided buses operate in Wittenbergstrasse now.

\section{6 - Adelaide, Australia}

Operates the world's fastest guided busway, a 7.5 mile long line operated at $100 \mathrm{~km} / \mathrm{hr}$ (62 $\mathrm{mph}$ ). The "O-Bahn" was opened in two segments, in 1986 and 1989. The two intermediate stations are designed for passing. One-minute headways are operated in the peak hour.

\section{6 - Essen, Germany}

A40 Motorway - This section includes the sharpest guided busway curves (60 m, about 190 ft., radius), which requires the Essen buses uniquely to be equipped with guidewheels at each axle. It also has a ramp on structure with a $6 \%$ grade. All Essen routes were built with pre-cast concrete guideway sections, which still provide a very smooth ride. Essen expects to award a contract for a new generation of guided buses (its fourth) shortly.

\section{5 - Ipswich (Kesgrave), U.K.}

This guided busway is only about $600 \mathrm{ft}$. long, and is operated as part of the "Super Route 66" between Ipswich and Martlesham Heath. The guided busway segment is provided to ensure that only buses use the roadway, which provides a shortcut bypassing congested intersections.

\section{8 - Leeds, U.K.}

A61 Scott Hall Road Corridor - North of Central Leeds (includes a total of one mile of guided busway) this consists of single-direction busways located alongside parallel roads, "queue jumpers" (which provide priority access to roundabouts), a contraflow non-guided lane for the entry into the center city, and signal priority. This corridor includes a section on a $7 \%$ downgrade, the steepest CGB operation. Ridership on the routes that benefit from the facilities provided in these corridors has exceeded the performance of buses as a whole in Leeds. 


\section{0 - Nagoya, Japan}

The Nagoya Guideway bus (also known as the Yutorito Line) is a 4-mile-long guideway installed on a structure to separate buses from regular traffic. There are 9 stations on the guideway structure. At Obata-Ryokuchi station, buses descend a ramp and continue in mixed traffic on regular surface roads to serve Nagoya suburbs. Despite the short vehicle length, guidewheels are fitted both at the front and behind the rear axle due to sharp curvature. Operations are managed as a third-sector company, and the cost of building the elevated guideway infrastructure was borne by the Nagoya City roads budget.

\section{1 - Leeds, U.K.}

York/Selby Roads "Elite" Project - East of Central Leeds (1.3 miles of guided busway), this is served by buses of two different private operators, who paid a significant share of the project's construction cost. It was the first built using slipform concrete construction. The only section of bi-directional guideway in Leeds is included.

\section{2 - Bradford, U.K.}

The Manchester Road project (1.4 miles of guided busway) located south of central Bradford (itself about 10 miles west of central Leeds) is the newest busway in the Leeds-Bradford area. The guided sections are all in the center of the roadway, with signal priority for buses entering them from the curbside. It includes shelters that are intended as artwork.

\section{3 - Sussex, U.K.}

Two sections of guided busway were provided as part of Route 10 of the "Fastway" network of high quality bus services being established in this area south of London. This is currently the only guided busway project in which a dedicated fleet of buses, in distinctive colors and more stylish than the norm for the operator's standard buses, is employed. Other Fastway components include high quality passenger shelters with real-time information and signal priority.

\section{4 - Edinburgh, U.K.}

"Fastlink" is a 0.9-mile-long, bi-directional guided busway installed as part of Edinburgh Translink's program for transit improvements. The guideway includes two overpasses built to bypass complex intersections and roundabouts.

\section{6 - Sussex, U.K.}

The most recent section of guideway is for the Fastway system's Route 20. 


\section{Table 2. Future Systems}

\section{8 - Cambridge-St. Ives, U.K.}

This is expected be the longest guided busway system, consisting of 11 miles of guideway to be built on an abandoned rail line. The national government has committed to funding. The county is currently considering design/build proposals for this project, which is estimated to cost about $\$ 60 \mathrm{M}$, at current exchange rates.

\section{9 - Luton, U.K.}

This will consist of 8 miles of guideway, also to be built on an abandoned rail line. The public consultation process has been completed, and a government funding decision is expected shortly.

\section{Figure 2. Sussex, U.K., Fastway Bus}

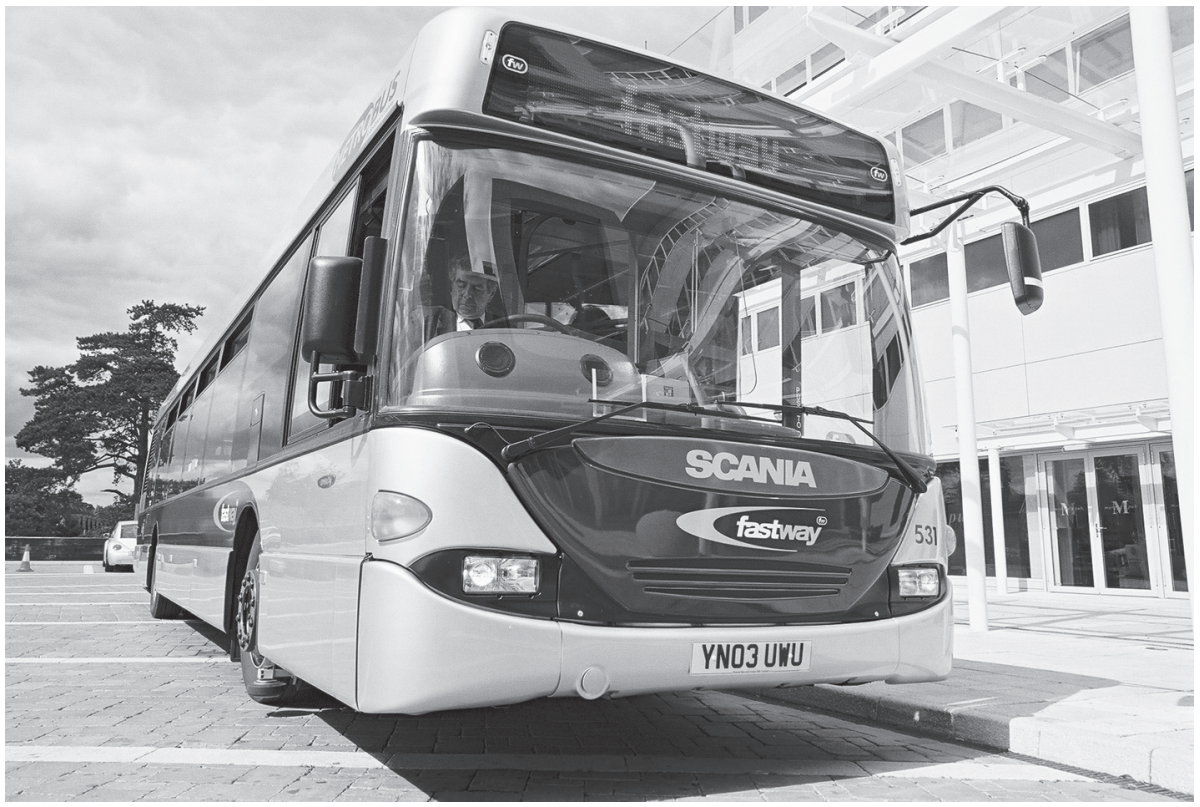

Source: Stevens Associates

Note: Sussex, U.K., Fastway Bus system combines stylish buses and shelters and real-time information at stops, with segments of guided and conventional busway to provide high quality service. System was completed in 2006. 


\section{CGB Infrastructure and Vehicles}

CGB technology itself is simple, non-electronic, and non-proprietary. The guideway consists of concrete running surfaces with vertical curbs about eight inches high. On all systems, the curbs are set 2.6 meters (102.4 in.) apart, being designed for the 2.55 meter (100.4 in.) wide buses that are standard outside North America. A bi-directional guideway, suitable for high speed operation with 102 inch wide North American buses, can be constructed in a right-of-way of less than 25 feet in width, including an emergency walkway on each side. The alignment of a lane constructed on an at-grade route would require only about a 10-foot right-of-way. This is much narrower than conventional busways designed for manually-steered buses.

In addition to at-grade alignments, CGB technology has been applied to routes in subways. The ability of CGB systems to operate safely at speed in narrow rights-ofway is particularly important in these cases, where minimizing the required width can greatly reduce the cost of constructing tunnels. Essen operated dual mode buses in tunnels for 11 years. It was particularly interesting that these tunnels and subway stations were shared with streetcars. Full block signaling was provided. Unfortunately, the pre-existing streetcar trackage used wooden ties on ballast construction. The bus trackways installed expeditiously as part of the demonstration project were also wood, bolted to the ties. Over time, the ties and trackways deteriorated. The operator did not have the resources available to install a concrete trackbed, as a new system designed for combined operation would be. The buses were removed, returning to their former surface street operation. A new system intended for combined operation could be built with rails embedded in the bus trackways. Essentially, this would be standard streetcar/LRT in-street track with the addition of curbs. Of course, a subway could be built for use only by CGB vehicles.

The same applies on bridges and elevated structures. The Nagoya, Japan, system operates on a four-mile-long guideway that is located entirely on an elevated structure located in an area of the city with heavy traffic congestion. Bus routes fan out on regular streets when they reach the end of the guideway. There are nine stations on the guideway, including the railroad interchange station. CGB technology was selected because of the narrower, lower cost structure requirements and the faster operation that can be permitted compared to a conventional busway.

The system is based on research funded by the German government in the early 1980s. There are no license fees involved. Anyone can build a roadway with curbs. 
A comprehensive handbook for design of CGB infrastructure, based on the experience of the practitioners in the field, was issued in 2004. Systems around the world utilize the same design for the "funnel" used at the entrance to guideways (see Figure 1). The speed limit for the funnel is typically set at $25 \mathrm{mph}$. Where it is necessary to allow pedestrians or other traffic to cross a guideway, the curbs can be gapped. Short gaps (less than 10 feet) can simply be crossed (at $30 \mathrm{mph}$ ). Longer gaps require a re-entry funnel. The handbook provides guidance on a wide variety of other design details.

\section{Figure 3. Typical Section of CGB Guideway, Showing Potential to Share with Streetcars}

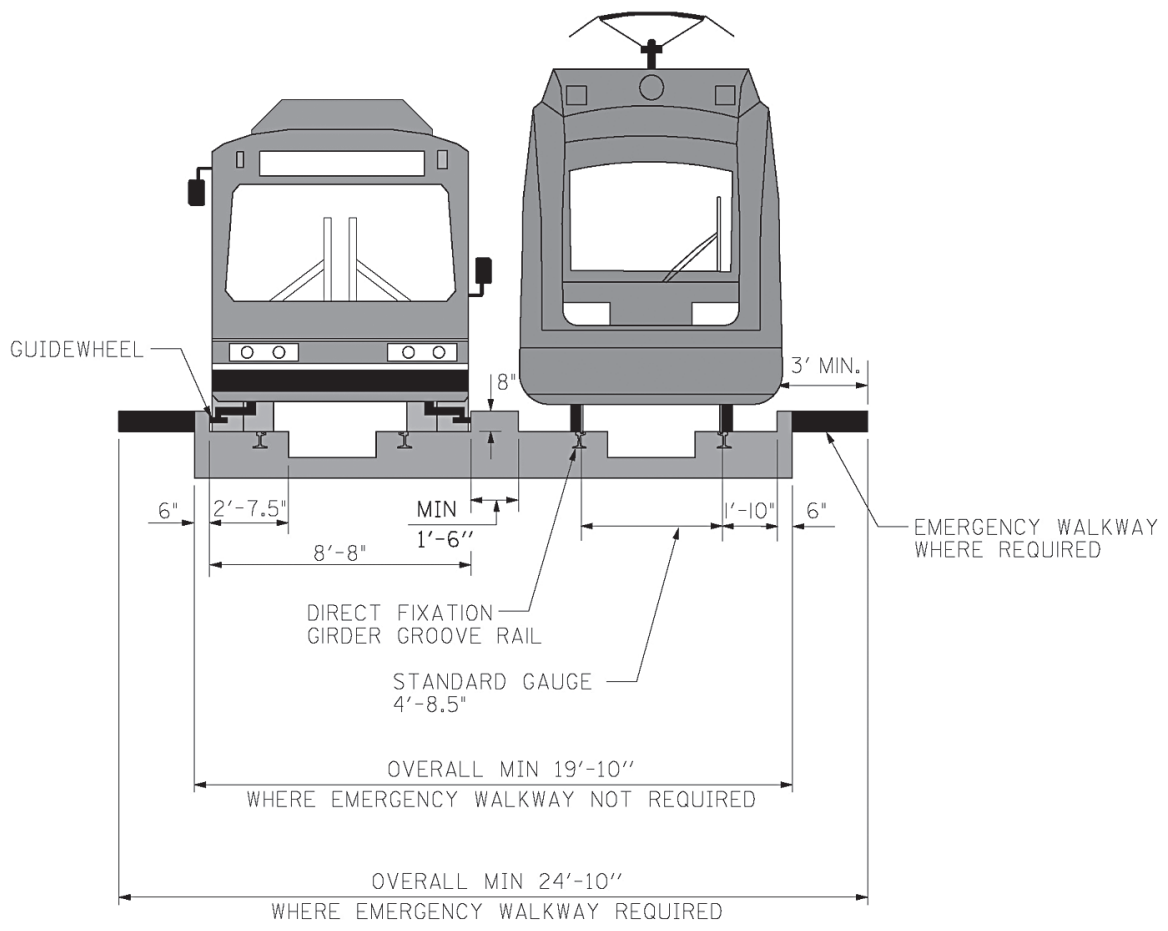

Source: TranSystems

Similarly, any bus manufacturer can design and build guidearms for its buses. While buses for CGB operation are, essentially, standard buses, the guidearms have always been designed by the bus manufacturer, with buses delivered complete 
with guidearms and guidewheels. CGB buses have been built by at least eight manufacturers worldwide. The first system in Essen, Germany, equipped its buses with guidewheels at each axle (virtually all of its buses have always been three-axle articulateds). All subsequent systems (except Nagoya, Japan) have used slightly less tight minimum curve radii, allowing their buses to be equipped with guidewheels only at the front axle, simplifying vehicle design issues. All systems use the same supplier for the horizontal guidewheels. After the design of the guidearm/ guidewheel for a particular bus type is complete, actual manufacture and installation cost is relatively minor. With the proliferation of CGB operation in the U.K., most new buses there are built ready for this installation.

All CGB systems currently in use are operated with diesel buses. Several systems have purchased buses with extra silencing packages, reducing noise inside and outside the vehicles. As noted above, Essen operated portions of its CGB system under electric overhead power wires for many years. This is an option for future routes. In the meantime, avoiding the cost of installation of an electric distribution system greatly reduces the cost of a new system compared to LRT and streetcars.

\section{Figure 4. CGB Guideway Entry Funnel, Adelaide}

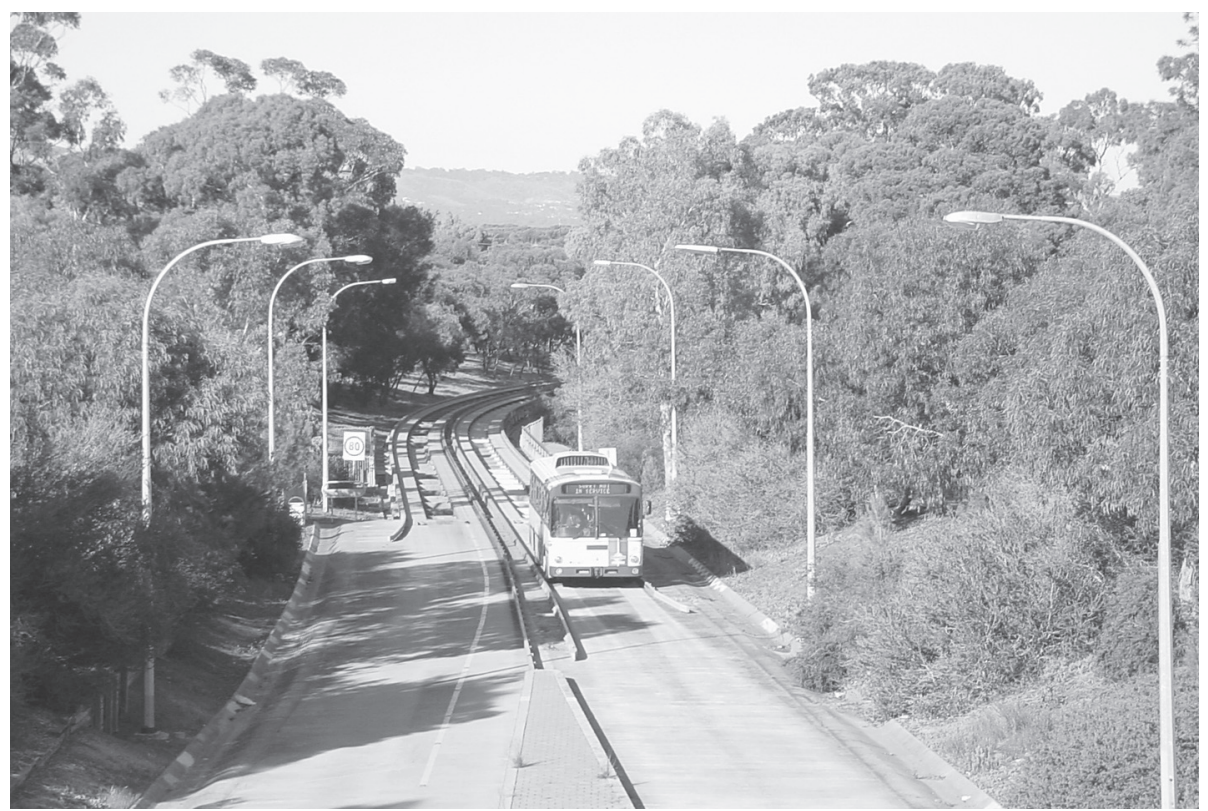

Source: TranSystems 


\section{Figure 5. Typical Guidearm/Guidewheel Installation- Mercedes Bus in Adelaide}

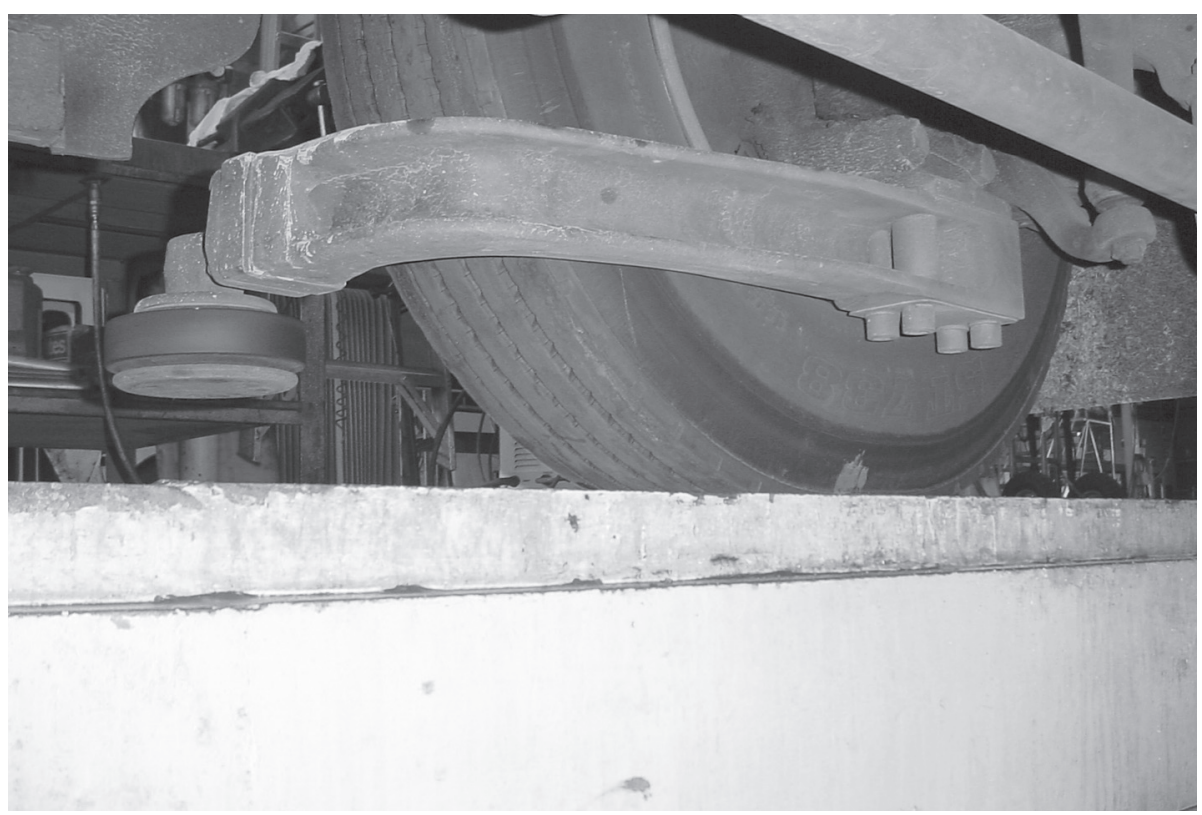

Source: TranSystems

\section{CGB System Operation}

A key advantage of CGB buses, compared to LRT and streetcars, is that that they can operate as standard buses when they are off the guideway. The guidewheels extend only about one inch beyond the body of the bus. All CGB routes combine guideway and normal on-street operations, avoiding the necessity for passengers to transfer from a feeder bus to another vehicle.

On most systems (notably Leeds, Bradford, Sussex-UK and Essen Fulerumer Strasse), guideways are provided only along street segments that regularly experience congestion, frequently only in one direction, further reducing right-of-way requirements. Transit signal priority is normally provided at the end of the guideway to facilitate the movement of the buses as they re-enter mixed traffic lanes. Speed limits on sections that run beside streets are normally set at the speed limit of the adjacent street. 
There are also long, high-speed systems. The best example of this type is the 7.5mile-long Adelaide O-Bahn. This route is fully grade separated and has only two intermediate stops. Because the guideway is so narrow, there was room to construct a beautiful linear park, with bicycle and walking paths along its entire length. The speed limit is set at $100 \mathrm{~km} / \mathrm{h}$ (62 mph), except where limited by curves.

\section{Figure 6. Paradise Interchange, Adelaide 0-Bahn}

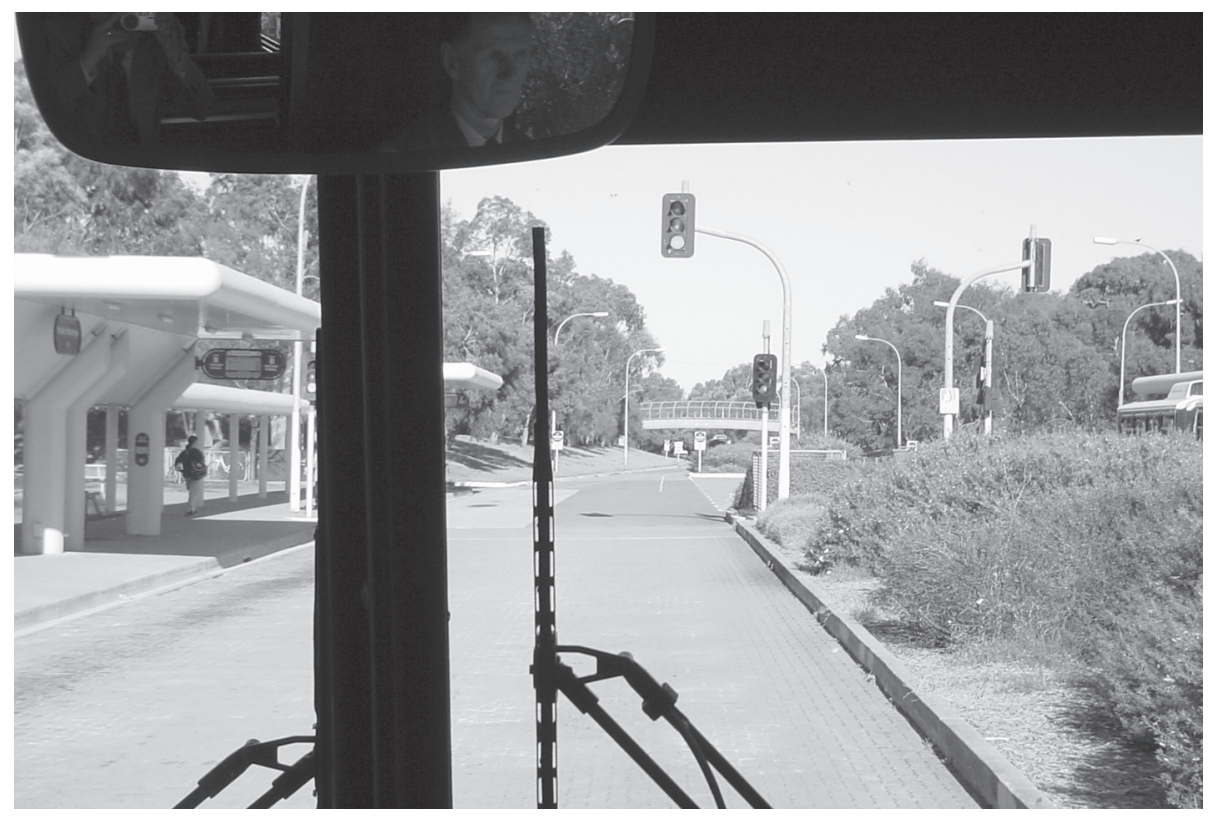

Source: TranSystems

At one of the intermediate stops, additional routes join the busway. It is expected that construction will start in early 2007 on the Cambridge-St. Ives system in the U.K., which will have a guideway 11 miles long, the world's longest guided busway. This is being procured as a design-build project.

A key advantage of CGB guideways is that they are completely self-enforcing. Unlike conventional bus lanes, non-guidewheel equipped vehicles cannot operate on them. Some sections of guideway have been installed specifically for this reason; they are shortcuts that can accommodate the relatively low volume of buses but that the authorities do not want open to general traffic. Examples include the 
entire Ipswich Guided busway, only 200 meters long, and some sections of the Sussex Fastway system.

\section{Figure 7. Subway in Essen, with Dual Mode Buses and Track Shared with Streetcars}

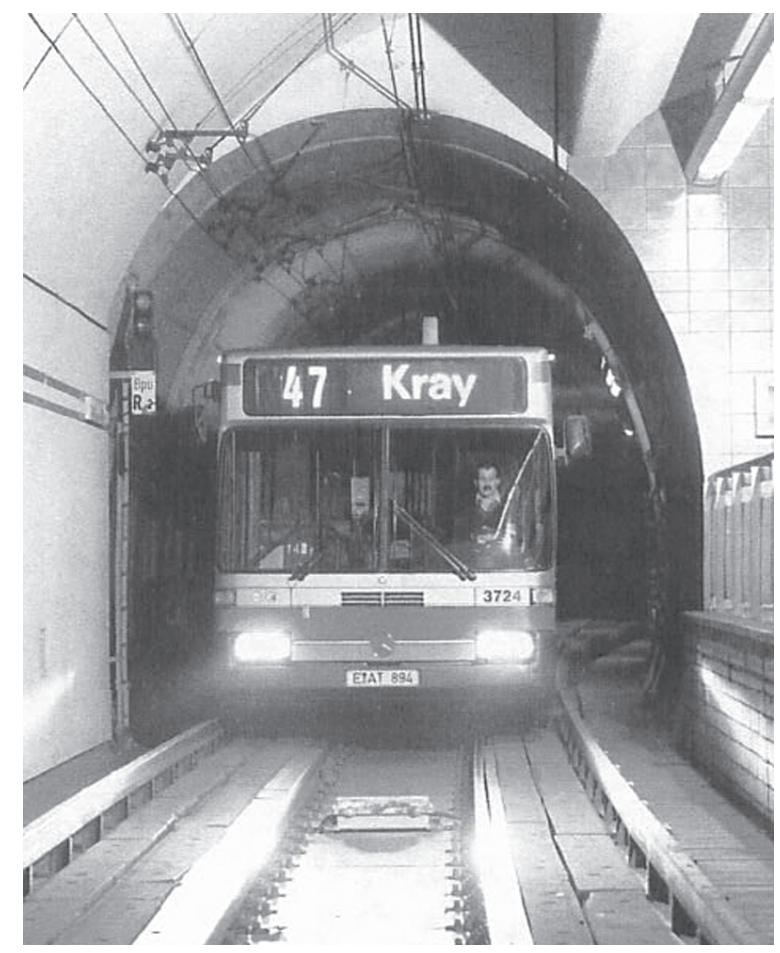

Source: EVAG

\section{Stations and Precision Docking}

CGB stops or stations vary from simple bus stops (usually with, at least, a simple factory-built shelter) to stations equal to sophisticated light rail stations, with full canopies, real-time passenger information, ticket vending machines, and park-andride lots. On most systems, stops made at intermediate stations are online; buses do not leave the guideway. All buses usually operate as locals, making all stops on request. However, on one of the Leeds busways and on the Bradford route, there 
are express bus routes to the suburbs that are not scheduled to stop at some bus stops. If they are behind a local bus that makes a stop, they wait briefly.

The two intermediate Adelaide O-Bahn stations are unique in that buses come out of guidance and the roadway widens, allowing express buses to pass, although few are scheduled. The Adelaide stations are the most expansive CGB stations, with long platforms and extensive canopies. The large park-and-ride lots are overflowing. Particularly during off-peak periods, feeder routes terminate at the O-Bahn stations, sharing a platform with through buses to/from downtown, allowing same platform transfers.

One of the principal justifications for implementation of guided bus operation is that it readily provides "precision docking" in the same way as a rail system. With the advent of low floor buses, full level boarding is provided. This allows meeting ADA accessibility requirements without deploying a lift or even, in many cases, a ramp. Even passengers on the older CGB systems, with platform heights that had been set to the level of the first step of conventional high floor buses, are now enjoying these benefits. When combined with off-board fare collection (typically, employed with proof-of-payment enforcement), passengers can board quickly, at any door.

The handling of stops for guided buses when operating off guideway has varied greatly. Because stops in Adelaide are offline, stations and street stops have low curbs. Leeds pioneered the use of raised boarding platforms at stops off the guideway. Operators are instructed to drive with the guidewheel against the curb. A section of raised curb is provided, resulting in level boarding. Such stops can only be served only by buses with guidewheels.

A new U.S. BRT system, the Euclid Corridor in Cleveland, will provide precision docking by installing guidewheels solely for this purpose on the buses being built for the route. Coincidentally, the corridor will have some center median stations, requiring left side doors to be installed. Thus, these will be the first buses in North America with guidewheels installed on both sides, although no guideway operation is currently planned.

In Leeds today, there has been a change in practice: all off-guideway bus stops are now being equipped with a partially sloped-curb, which allows all buses, with or without guidewheels, to be driven close to the curb at stops without damage due to contact with the curb to either the body or the tire sidewalls. This provides a narrow horizontal gap. Such curbs (off a guideway) are now being installed at a 
lower height, $180 \mathrm{~mm}$ (about 7 inches), since buses, when kneeled, are within 50 $\mathrm{mm}$ ( 2 inches) of the platform, the allowable vertical gap in the U.K. Thus, the sidewalk does not need to be raised significantly to serve as a platform.

In a similar way, Las Vegas is providing level boarding on its MAX system, with raised platforms and boarding permitted at all doors, using Proof of Payment enforcement of the off-board fare collection. It was planned to achieve precision docking on this system through the use of an optical guidance system. However, the system was unreliable and has been turned off since shortly after the start of service. Because the stations were equipped with sloped curbs, very similar to those in Leeds, it has been possible to continue to provide level boarding with satisfactory horizontal gaps with manual steering. This is facilitated by the lack of parking on the approaches to the stations.

\section{Figure 8. Level Boarding, Las Vegas MAX}

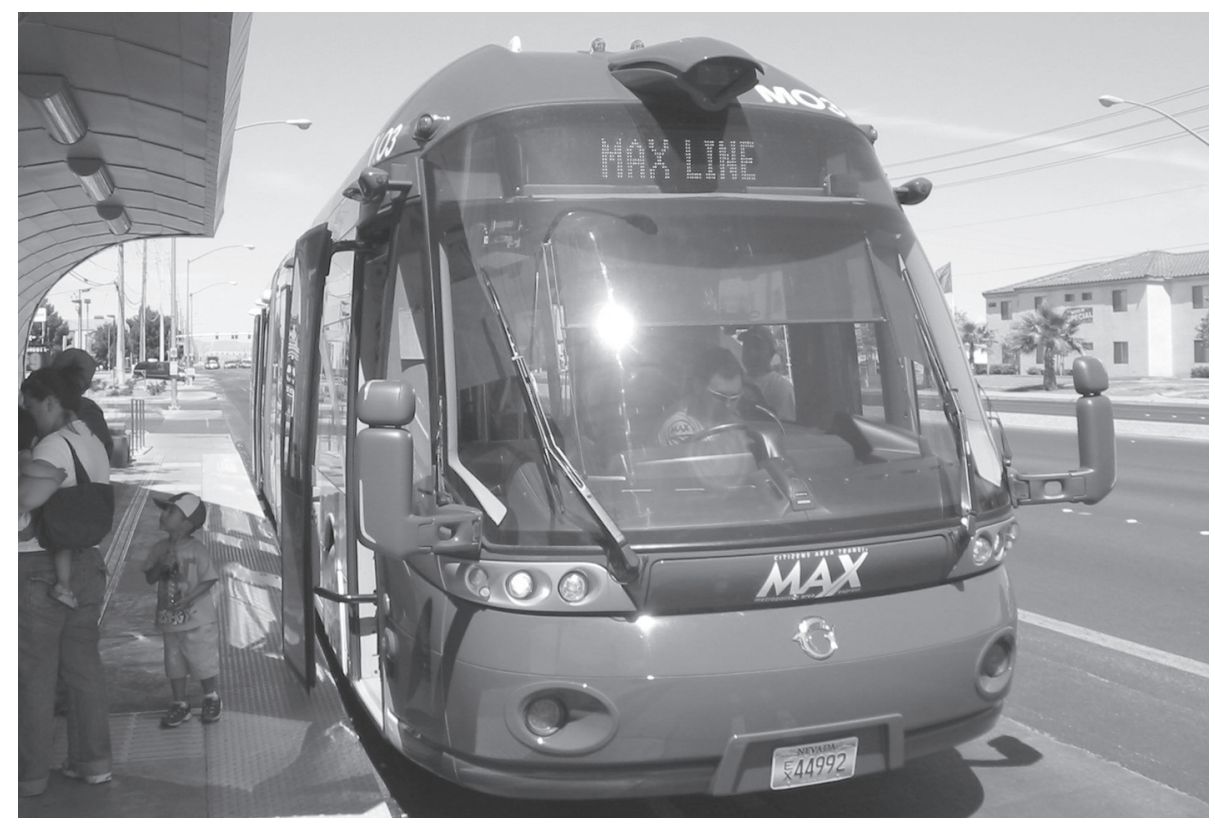

Source: TranSystems 


\section{Guideway Construction and Maintenance}

The first CGB route operated in revenue service was in Essen (1980). It uses the technique of precast segments mounted on "sleepers" (cross beams), mounted, in turn, on short drilled piles. Today, 26 years later, this line continues to provide an extremely smooth ride, and there is no structural deterioration of the concrete running surface or discernible wear. Subsequent sections of guideway in Essen were built using this technique, except for ramps, sharp curves and entries, which were poured in place. Since these sections are negotiated at lower speeds the slightly rougher surface is not noticeable. The Adelaide O-Bahn uses the same type of pre-cast guideway segments, built in Australia by the same manufacturer. However, due to the extremely silty soil along the alignment in the Torrens River Valley, each sleeper rests on two 3 meter (10 feet) deep piles. This technique has prevented any problem with settlement and provides very good ride quality.

\section{Figure 9. Precast Concrete Construction}

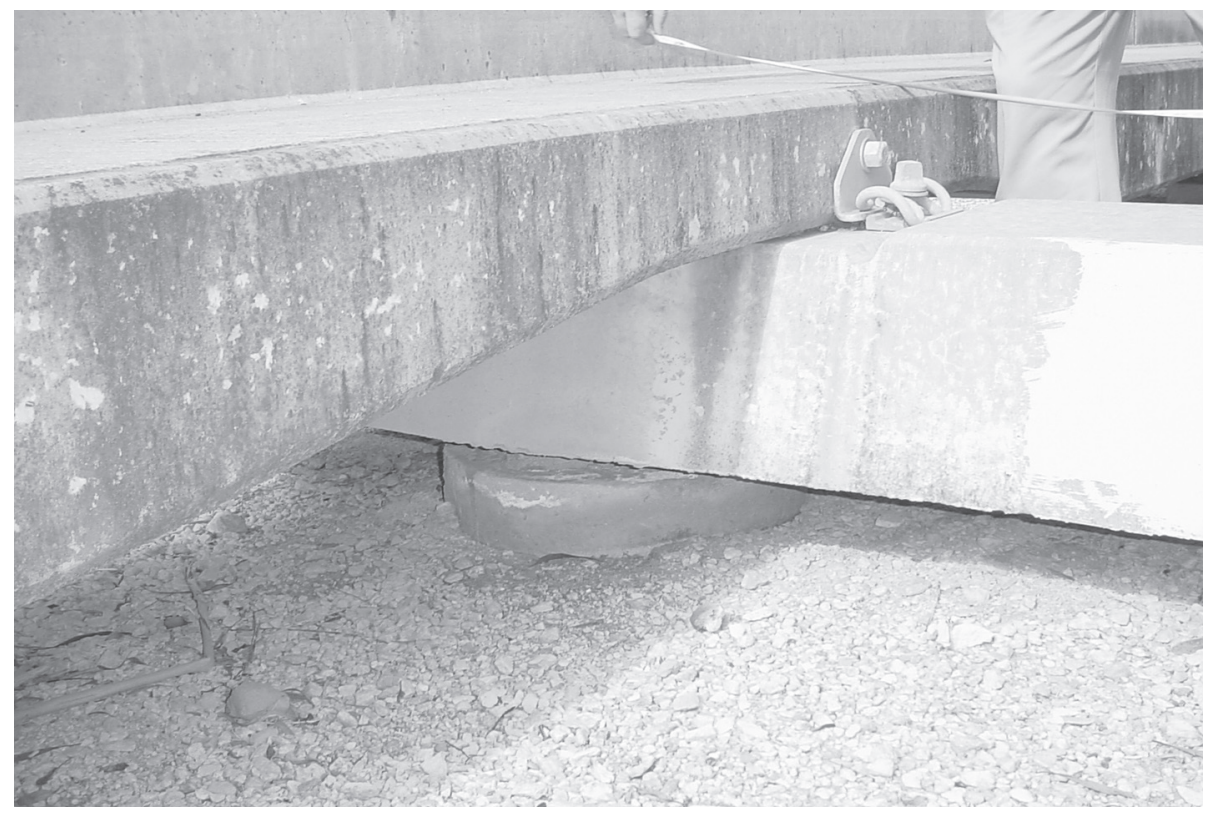

Source: TranSystems 
All of the U.K. systems use poured in place concrete. The early ones were constructed using conventional practice. A major innovation has been the use of slipforming machines for all of the U.K. CGB projects since 2001. For the Sussex Fastway, the most recent CGB project, construction tolerances for width were held to $+3 \mathrm{~mm}$ ( 0.12 inch) - $0 \mathrm{~mm}$, with installation over a base of $300 \mathrm{~mm}$ (12 inches) of recycled concrete. This process has resulted in a smooth ride quality and is expected to have a long life. This project was constructed with paving equipment made by Gomaco, a major American supplier. Rebar baskets for each track can be assembled in a mass production environment and connected in the field. Typical roadway slipform paving production is about 2500 lane-feet per day. It should be noted that quality control on the Edinburgh Fastway was inadequate, with the result that ride quality was substandard until corrective grinding was carried out by the contractor. Interestingly, drainage is greatly simplified compared to normal roadways because of the ability to leave the center strip unpaved. Overall construction cost should be essentially the same as construction of a normal roadway.

\section{Figure 10. Slipform Construction}

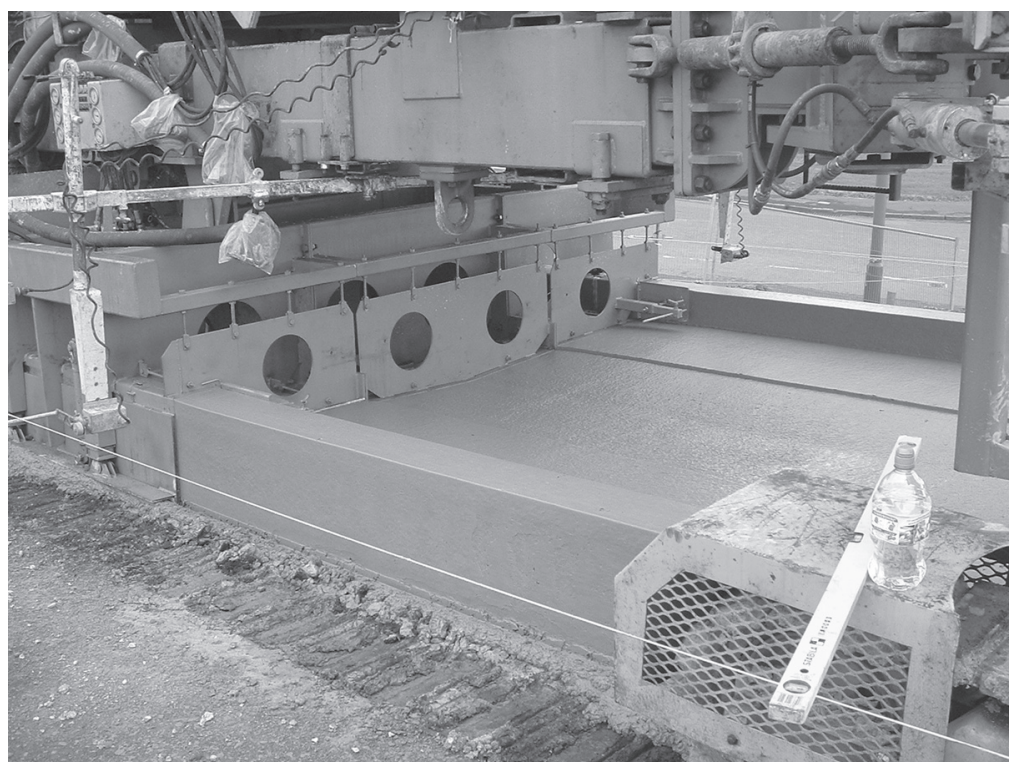

Source: British in-situ Paving Association 


\section{Special Considerations in CGB System Design and Operation}

While CGB technology is basically simple, there have been some adaptations over the years that are not immediately apparent. All systems provide specialized training and qualification procedures for CGB operators. One feature that is applied fairly universally is that "run-flat" rings are installed inside the front tires, allowing buses to continue to the first guideway exit point, at reduced speed, if air pressure is lost. Adelaide takes special precautions for its high speed operation. It has added an emergency button that operators must use if their bus is disabled to prevent rear end collisions. When activated, rotating yellow lights are started, and a prerecorded verbal "bus stopped" message is broadcast to all buses operating from the garage at which O-Bahn buses are based. All buses on the busway must stop until the originating operator is able to identify their location and direction.

There have been two pieces of specialized non-revenue vehicles constructed for CGB systems. Both have guidewheels on each end, allowing bi-directional operation. Adelaide has a recovery vehicle matched to its high-speed operation, with relatively long gaps between busway exits. It has cabs open both ends, facilitating rapid movement against the normal flow of traffic to reach the disabled bus. $A$ towbar and air brakes can be quickly connected. Essen has the equivalent of the Swiss Army knife: a multipurpose vehicle equipped with towbar and air brake connections on each end, a crane, a dump body (including a salt spreader insert), and a snow plow. Essen has significant snow/ice conditions and experienced serious problems at times in maintaining traction on the ramps prior to putting this vehicle into service. In most cases in Essen, disabled buses are simply pushed to the next guideway exit by the following bus. This solution may be facilitated by the multiple guidewheels on its buses.

\section{Curb Guided Bus Trends}

Installation of CGB routes has been slow. The Essen routes were constructed over a number of years as part of a demonstration program. Toward the end of this period, the Adelaide system was constructed, in two phases. The only new CGB operation that opened between 1989 (the completion of the Adelaide O-Bahn) and 1998 (opening of Scott Hall Road in Leeds) was the 600 foot long Kesgrave (U.K.) guideway. However, since then, about one new route per year has opened, and more are in the works. All of these, except the Nagoya system, are in the U.K. 


\section{Figure 11. Essen Multipurpose Truck}

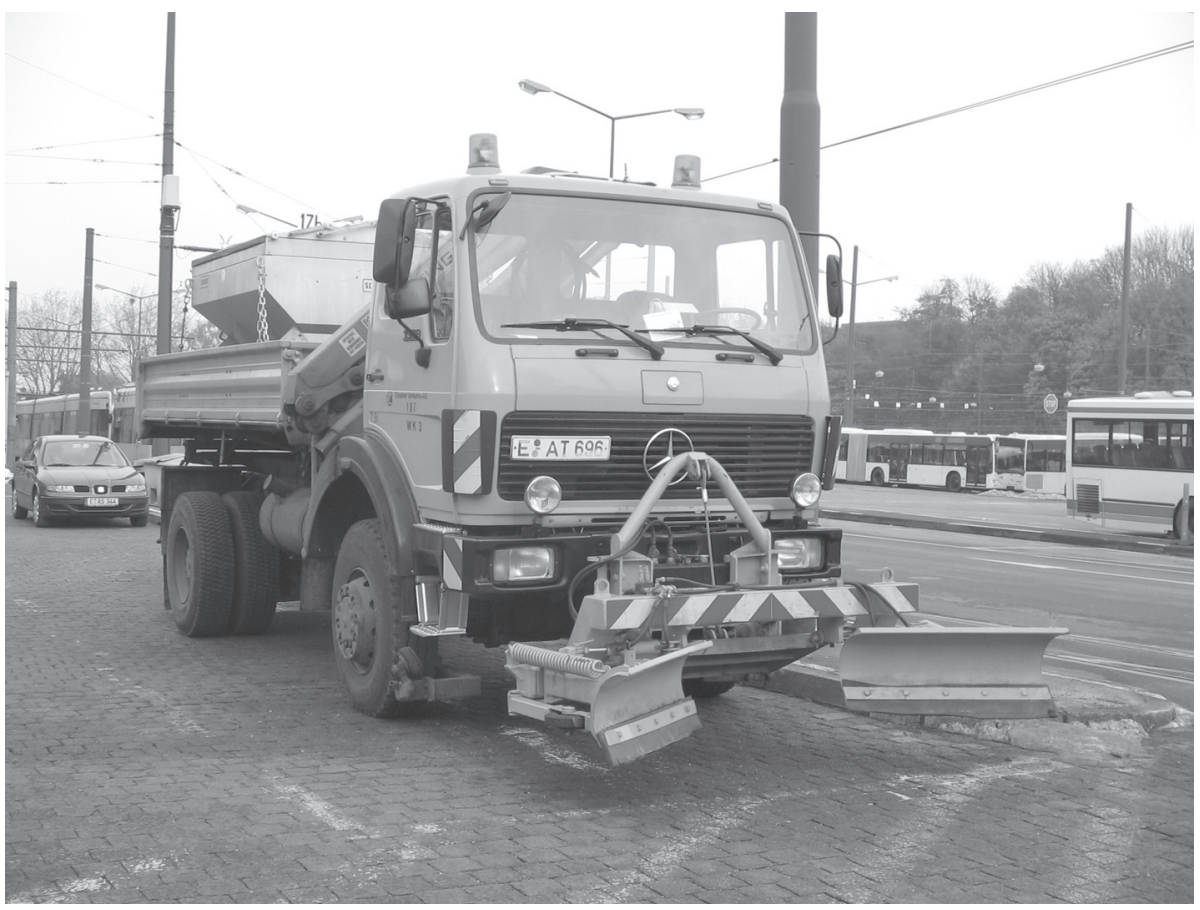

Source: TranSystems

CGB technology provides a means of providing BRT service with quality more like LRT, with fast operation and level boarding. It fits into rights-of-way where conventional BRT with dedicated lanes may not fit. It provides one-seat rides where LRT may require passengers to transfer to/from feeder buses. It can be implemented incrementally, starting in part of a corridor. Yet its installation cost is not significantly higher than conventional BRT and is significantly lower than LRT. With more awareness of this technology, its rate of growth, and geographical dispersion, may increase. 


\section{References}

Boegner, J., and M Starck. Undated. Guided bus essen, information on the research and development project. Essener Verkehrs-AG, Essen.

Bray, D.J. and D. Scrafton. 2000. The Adelaide O-Bahn: Ten years on. In 8th Joint Conference on Light Rail Proceedings (CD_ROM Paper K-31. pp1-16), Dallas.

Bray, D.J. 2000. The Performance of the Adelaide O-Bahn. In Smart Urban Transport Conference Proceedings, Brisbane.

Chapman, P.C. 1992. The Adelaide O-Bahn - How good in practice? Seventeenth Australasian Transport Research Forum Conference, Canberra.

Kim, E.J., G. Darido, and D. Schneck. 2005. Las Vegas MAX BRT Demonstration Project Evaluation, Federal Transit Administration, Washington. . 1999. Adelaide's O-Bahn Busway - Guiding transport into the future. Passenger Transport Board, Adelaide. 2004. Guided Busway Design Handbook. British in-situ Paving Association, Blackwater, Camberley, Surrey .2005. BRT lane assist technology systems. Metro Transit, Minneapolis.

\section{About the Author}

DAvid PhILlips (dphillips@transystems.com) has over 30 years of experience in all phases of transit operations planning projects including rail and bus operating plans, rail feeder bus networks, coordination with development, vehicle systems, real-time operational strategies, communications/vehicle location technology, and transit traffic signal priority. After 27 years at the Chicago Transit Authority (in Operations Planning and project management for technology projects), he moved to the private sector. At TranSystems, he has served as project manager for several major rail and bus infrastructure studies and design projects. 


\title{
Microscopic Simulation Approach to Capacity Analysis of Bus Rapid Transit Corridors
}

\author{
Abdul Jabbar Siddique, Ata M. Khan \\ Carleton University
}

\begin{abstract}
While a transitway can be built as an access-controlled, two-way rapid transitfacility outside the Central Business District (CBD), in the CBD, initially, the Bus Rapid Transit (BRT) service has to be based on exclusive bus lanes due to right-of-way, monetary, and other constraints. The strategy of providing Bus Rapid Transit on exclusive bus lanes in urban corridors is receiving policy attention. However, detailed studies on exclusive bus lane capacity for BRT operation in the CBD of a city have been scarce. In this research, using NETSIM as a microsimulator, BRT corridors in Ottawa (Canada) were investigated in terms of their capacity to handle high volumes of transit buses. For these corridors, scenarios incorporating 2021 traffic were analyzed for choke condition and the results were compared with the base case condition representing year 2001 traffic environment. Based on the results of network performance, conclusions were drawn on the capacity of $B R T$ corridors.
\end{abstract}

\section{Introduction}

Bus Rapid Transit (BRT) is increasingly viewed as an affordable and effective mode to increase mobility (BRT newsLane 2005). BRT often benefits from an exclusive busway (also called a transitway), which can be provided in a number of ways outside the Central Business District (CBD). The transitway can be built on its 
own right-of-way, or it can be accommodated in a freeway corridor. To expedite BRT development, the transitway can be built outside the CBD first. In the CBD, due to many constraints including space and money, the BRT service can be provided on exclusive lanes. This BRT development strategy was followed in Ottawa (Canada).

Realizing the importance of transit operation in the future growth of Ottawa's downtown (City of Ottawa 2003), a very important question for City policy makers and transportation planners is determining the state beyond which throughput of transit buses in exclusive bus lanes of BRT corridors could not be increased without making facility design changes. However, reliable and well researched information on capacity and service factors of BRT operation on exclusive bus lanes in a downtown environment is scarce. Therefore, this research was designed to answer this very question.

\section{Study Area and Research Challenge}

Figure 1 shows a part of the Ottawa downtown street network including two important public transit corridors. The study area encompasses these transit corridors, i.e., Albert and Slater streets, that facilitate West- and East-bound BRT operation, respectively. These corridors offer one-way traffic operation with single bus-only lanes in a mixed traffic environment and connect with East and West transitways outside the CBD. The link/node diagram (Figure 2) shows the streets with transit lanes and eight crossing streets. Total length of transit corridors between Elgin and Bronson (i.e., in the East-West direction) is $1.3 \mathrm{~km}$. Block lengths in the north-south direction, i.e., between Albert and Slater streets, are approximately $80 \mathrm{~m}$. However, in the east-west direction, it varies between $135 \mathrm{~m}$ and $255 \mathrm{~m}$, approximately.

The research challenge was to determine the choke level of bus traffic for exclusive lanes, which is defined in this research as a state in which throughput of transit buses could not be increased further under given traffic operating conditions. $n$ essence, choke level is the maximum throughput or capacity under prevailing conditions. For the Ottawa CBD case, it was intended to find maximum throughput of buses that can be accommodated on exclusive bus lanes of BRT corridors under various scenarios that reflect 2021 traffic operating conditions. 
In addition to finding answers for the Ottawa CBD bus corridors, it is of research interest to provide sufficient information on this topic so that other jurisdictions can use the methodology and findings.

Figure 1. Study Area and the Street Network in Downtown Ottawa

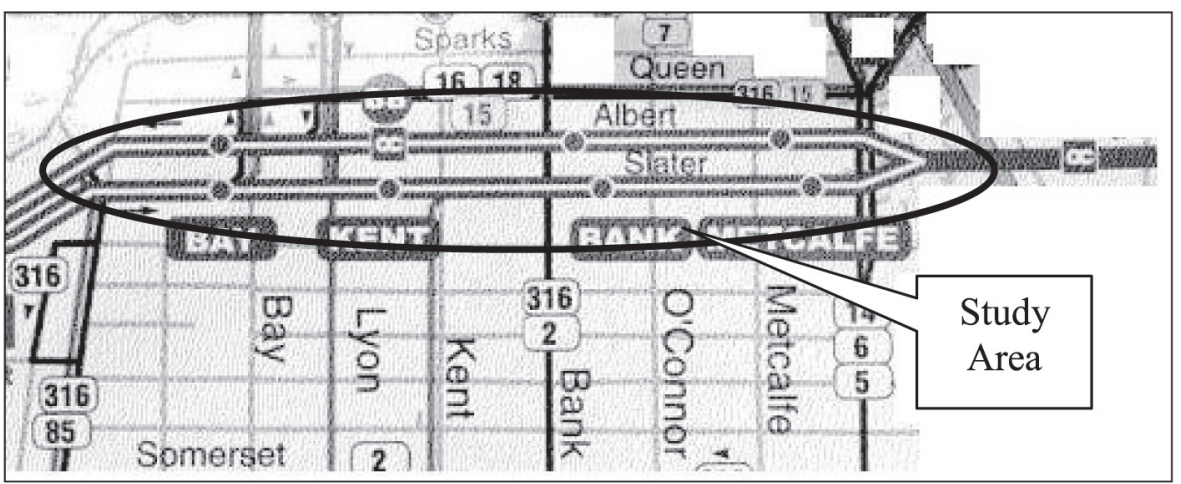

\section{State of Knowledge in Bus Corridor Capacity}

Literature review shows little information on bus flow capacity of an arterial with an exclusive bus lane for BRT operation in the CBD of a city. This deficiency was addressed to some extent by St. Jacques and Levinson (1997) in a study "Operational Analysis of Bus Lanes on Arterials," which contains guidelines for estimating bus lane capacities and speeds along arterials. Kittelson \& Associates (1999) contributed definitions, principles, practices, and procedures in the Transit Capacity and Quality of Service Manual (TCQSM).

A few authors provided observations on bus lane capacity or bus headways, mostly for uninterrupted flow conditions. For example, in case of New Jersey's Lincoln Tunnel, 735 buses are reported to have operated on exclusive right-of-way during morning peak hour in peak direction (Kittelson \& Associates 1999a).

Some South American cities reported bus volumes for exclusive lanes (City of Bogotá 1996, City of Carolina 2002). However, the operational features of the corridors were not clearly described. For instance, in the City of Bogotá, Columbia, a higher volume of buses ( 630 buses/hr in two lanes) was reported than the maximum number of buses calculated from simulation results (City of Bogotá1996). In 
Journal of Public Transportation, 2006 BRT Special Edition

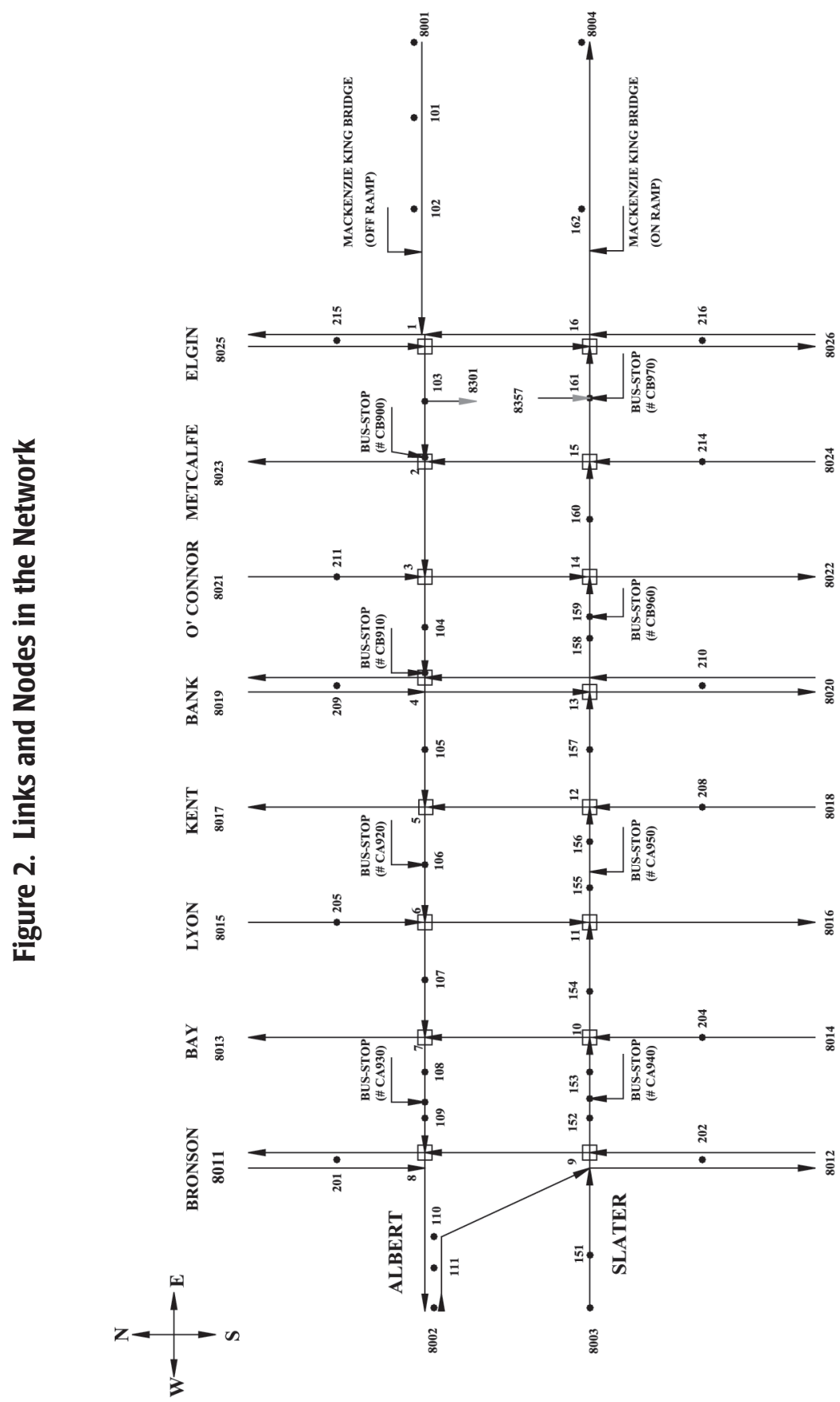


the case of Ottawa, the BRT is operating below capacity in the CBD corridors as well as outside the CBD. The 2001 highest bus volume in the CBD part of BRT was 225 buses/hr. Also, 225 buses/hr have been reported on the West Transitway.

In short, real life North American examples of BRT operation on exclusive bus lanes in interrupted flow environment operating at or above capacity are not available. From a capacity analysis perspective, there is little information on high volumes of buses operating in the form of a platoon in a CBD environment. Regarding capacity of a bus lane, there is not much literature available except the one item referenced earlier (St. Jacques and Levinson 1997), in which the authors noted the practical problems associated with high volume transit operations that need to be resolved while calculating capacity of a bus lane operating under interrupted flow conditions in a CBD.

The Highway Capacity Manual (HCM 2000) procedure, due to its rather coarse nature, is of limited use in the study of capacity and level of service of bus transit corridors in a CBD environment.

\section{Study Methodology: The Microsimulation Approach}

Due to the level of detailed analysis that was essential for finding answers, the dynamic microscopic analysis approach was adopted. Past research concluded that there is a need for the use of a microsimulation approach to study BRT planning, design and operational problems (Multisystems, Inc. 2000). A simulation tool is considered ideal for public presentation, evaluation of before and after studies, and routine planning and operations analysis. It offers users the opportunity to observe animated traffic conditions and evaluate alternative scenarios for roadway and signal system improvements in various traffic environments. Further, it is considered more practical than a field experiment (Federal Highway Administration 2001).

In this research, NETSIM, a stochastic microscopic traffic simulation tool (version 5.1) was employed to model and simulate BRT system operations in the downtown of Ottawa. This simulator can update the state of each vehicle and the system under study on a second-by-second basis (Liu et al. 1996). Behavior of vehicles is governed by car-following, queue discharge and lane switching logics (Transportation Research Board 2000). NETSIM has the capability to simulate transit bus operations up to a maximum of 2,000 buses. A wealth of data in the 
form of measures-of-effectiveness (MOE) is accumulated at the end of each simulation run.

In NETSIM, the car-following logic differentiates the operation of private vehicles from a public transit bus that is supposed to service passengers at bus stations. Kinematic properties of each vehicle such as speed and acceleration as well as its status (i.e., whether it is in a queue or moving) are also determined. Delays caused to the turning vehicles at intersections due to pedestrian traffic are also modelled in the network to represent real time traffic operations.

\section{Network and Traffic}

The 2001 operating conditions were regarded as the base-case scenario. To determine choke level in the network, auto traffic was projected to year 2021. Supply of transit buses was maximized by lowering mean headways and providing additional green time along transit corridors only until delays experienced by auto traffic movements on links intersecting transit streets reach a Level of Service $E$ or F. In this research, BRT operation was studied under passive priority measures in which fixed time plans of traffic signals were used and additional green time was allocated to transit streets. According to available information, the transit bus pre-emption signal strategy in the $\mathrm{CBD}$ is not regarded to be more effective than passive priority measure due to short block lengths and high volume of buses (Dillon M.M. 1993). Salient features of the study area are shown in the Table 1. In 2001, there were two types of buses operating in the network, i.e., standard bus (12 $\mathrm{m}$ long) and articulated bus (18 $\mathrm{m}$ long). Their proportions were 84 percent and 16 percent, respectively. There were eight bus stop locations in the study area, among which some are mid-block stops while others are near-side stops (located immediately before an intersection). Hourly volume of buses for each bus stop location is shown in Table 2.

\section{Table 1. Salient Features of the Study Area}

\begin{tabular}{|c|c|c|c|}
\hline No. of Traffic signals & 16 & Cycle Lengths & 60 and $120 \mathrm{sec}$ \\
\hline \multicolumn{2}{|c|}{ Pedestrian volume at intersection: } & \multicolumn{2}{|c|}{ Transit bus volume: } \\
\hline - Highest & 2177 & - Albert Street & $225 / \mathrm{hr}$ \\
\hline - Lowest & 130 & - Slater Street & $159 / \mathrm{hr}$ \\
\hline \multicolumn{2}{|c|}{ Passenger activity on any single bus station: } & \multicolumn{2}{|c|}{ Total passenger activity on: } \\
\hline - Highest & 2183 (On + Off) & - Albert Street & $6823($ On + Off) \\
\hline - Lowest & 430 (On + Off) & - Slater Street & 4841 (On + Off) \\
\hline
\end{tabular}


Table 2. Hourly Volume of Buses at Bus Stations

\begin{tabular}{|c|c|c|c|c|c|}
\hline \multicolumn{3}{|c|}{ Albert Street } & \multicolumn{3}{c|}{ Slater Street } \\
\hline S. No. & Bus Stop \# & Volume (vph) & S. No. & Bus Stop \# & Volume (vph) \\
\hline 1 & CB -900 & 218 & 1 & CA - 940 & 159 \\
2 & CB -910 & 217 & 2 & CA - 950 & 147 \\
3 & CA -920 & 225 & 3 & CB -960 & 149 \\
4 & CA -930 & 214 & 4 & CB - 970 & 148 \\
\hline
\end{tabular}

Dwell Time data are collected regularly by OC-Transpo using Automatic Passenger Counters (APC) installed on various transit buses. These data were utilized to simulate Base Case and other scenarios of bus operation across transit corridors. Table 3 shows average dwell times at respective bus stop locations.

Table 3. Dwell Time (sec) of Buses at Bus Stations

\begin{tabular}{|c|c|c|c|c|c|}
\hline \multicolumn{3}{|c|}{ Albert Street } & \multicolumn{3}{c|}{ Slater Street } \\
\hline S. No. & Bus Stop \# & $\begin{array}{c}\text { Average Dwell } \\
\text { Time (sec) }\end{array}$ & S. No. & Bus Stop \# & $\begin{array}{c}\text { Average Dwell } \\
\text { Time (sec) }\end{array}$ \\
\hline 1 & CB - 900 & 11 & 1 & CA - 940 & 5 \\
2 & CB - 910 & 12 & 2 & CA - 950 & 10 \\
3 & CA - 920 & 10 & 3 & CB - 960 & 9 \\
4 & CA - 930 & 3 & 4 & CB - 970 & 9 \\
\hline
\end{tabular}

Note: Data shown in tables above are for year $2001 \mathrm{AM}$ peak hour (7:30 am to 8:30 am)

\section{Description of Scenarios}

Three types of scenarios were defined, as shown in Figure 3. Case A represents the Base Case scenario (2001 traffic operating conditions). In Case B, auto traffic was projected to year 2021 but signal control settings were kept the same as in the base case. The supply of transit buses was increased until choke conditions appeared in the network. In Case C, 2021 auto traffic was assumed, and additional green time was assigned to transit streets. The supply of transit buses was again maximized until choke conditions appear within the network. Figures 4 and 5 show green/ cycle $(\mathrm{g} / \mathrm{C})$ ratios for Cases $\mathrm{A}, \mathrm{B}$ and $\mathrm{C}$ at each intersection along Albert and Slater Streets, respectively. The MOE obtained from Cases B \& $C$ were compared with Base Case A condition. 


\section{Figure 3. Scenario Categories and Description}

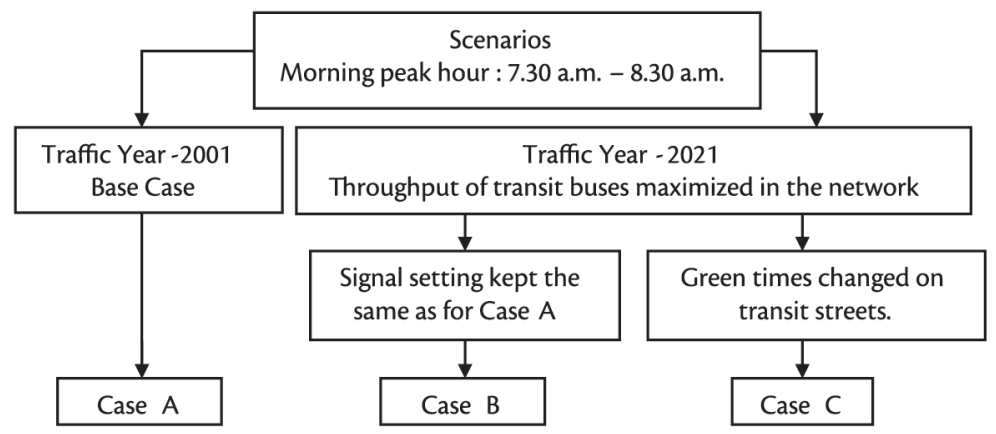

Figure 4. (g/C) Ratios along Albert Street in Cases A, B and C

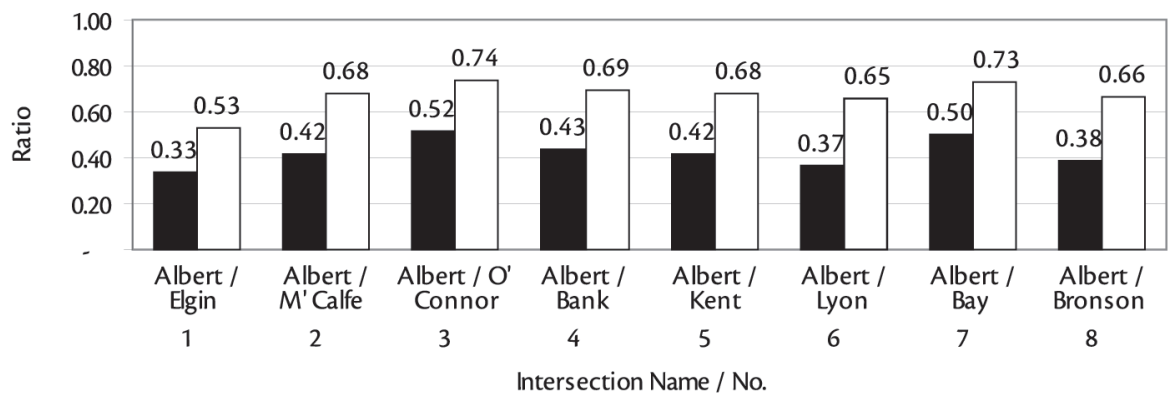

(g/C) Ratio in Cases "A and B" $\quad \square(\mathrm{g} / \mathrm{C})$ Ratio in Case "C"

Figure 5. (g/C) Ratios along Slater Street in Cases A, B and C.

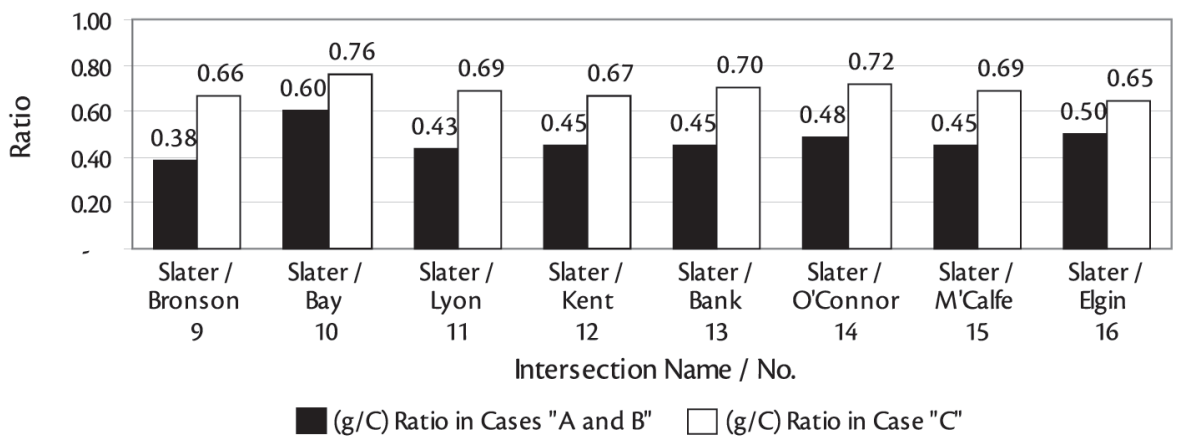




\section{Simulation Process}

Because of the stochastic nature of the simulator (NETSIM), the MOE obtained from a simulation run are the outcome of a specific set of random number seeds. A particular set of random number seeds may yield very conservative or avantgarde results. Therefore, simply relying on the results of a single simulation run of a scenario might be misleading. To gain a better understanding of network performance, each scenario was simulated 10 times, using different sets of random number seeds. The results of all the simulations were averaged and used for further calculations and analysis.

\section{Simulation Results}

The number of buses generated in all the three case scenarios reflects the exclusive bus lane operation in the CBD of Ottawa. As noted earlier, in Case B, while keeping all the operating characteristics same as in Case A, supply of buses along transit corridors was maximized by reducing the mean headway. An analysis of bus operation at mean headway of 8 seconds suggested that choke condition did not occur. Therefore, the headway was reduced to 7 seconds/bus. At a mean headway of 7 seconds/bus for Case B, choke conditions appeared at upstream side of Albert and Slater streets, shown in Figure 2 by links (101-1) and (151-9), respectively. At this headway level, throughput of buses was recorded as $442 / \mathrm{hr}$ and $449 / \mathrm{hr}$ on upstream links of Albert and Slater streets, respectively. These are shown in Figure 6 along with base case scenario (Case A).

\section{Figure 6. Number of Transit Buses on Albert and Slater Streets in Cases $A$ and $B$}

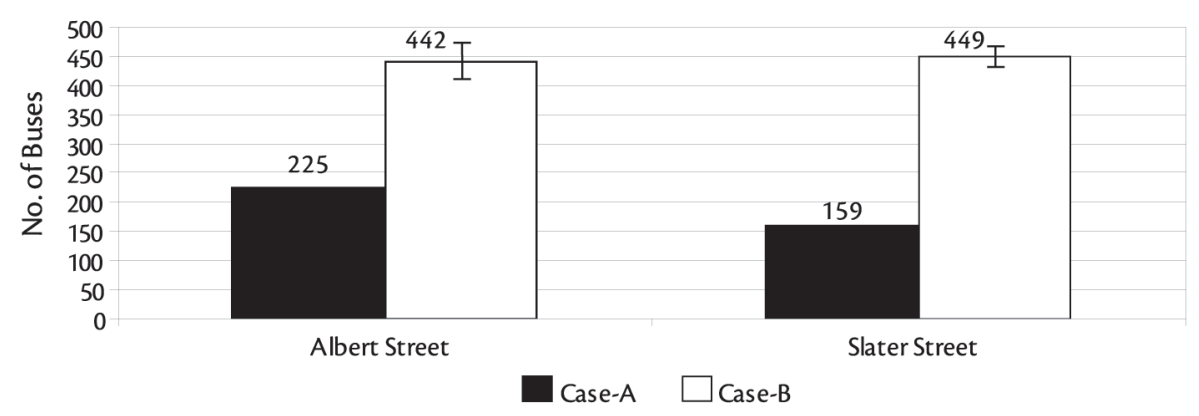

* Note: Symbol 'I' shown in this article represents Standard Deviation of 10 simulation results. 
It is important to note that in Case B, in theory at a 7-second/bus mean headway, 514 buses/hr (3600/7) were supposed to be generated during one hour simulation period. Similarly, in Case C, at a mean headway of $5 \mathrm{sec} /$ bus along with a significantly high green time (50 sec added to the base case) along Albert and Slater corridors, the number of buses discharged at the upstream links of these corridors were only 486 and 494, respectively, as opposed to 720 buses (i.e. 3600/5) that were supposed to be generated in a one-hour period. According to TCRP Report 26 (1997), this is an indication of the choke point and is explained in the next paragraph.

Figure 7 shows a comparison of buses generated in Case B vs. Case $C$ at different additional green times. The total discharge being well below the flow rate of buses defined as input in both Case $B$ and Case $C$ suggested that the capacity of exclusive bus lane in each case was reached. This observation is in accordance with the TCRP Report 26 (St. Jacques and Levinson 1997). The authors state that, "Two measures of performance output indicated the point at which capacity was reached: (1) simulated average bus speeds dropped significantly and (2) the number of buses serviced at the bus stop was less than the number of buses input as the bus flow rate. These two measures indicated a point at which no greater flow rate of buses would be achieved along the arterial and where buses queued excessively at the bus stop or at upstream signals."

When animation results generated by NETSIM for these cases were observed on screen, it indicated a long queue of buses on upstream links (101 - 1) and (151

\section{Figure 7. Transit Buses on Albert and Slater Streets at Different Green Times}

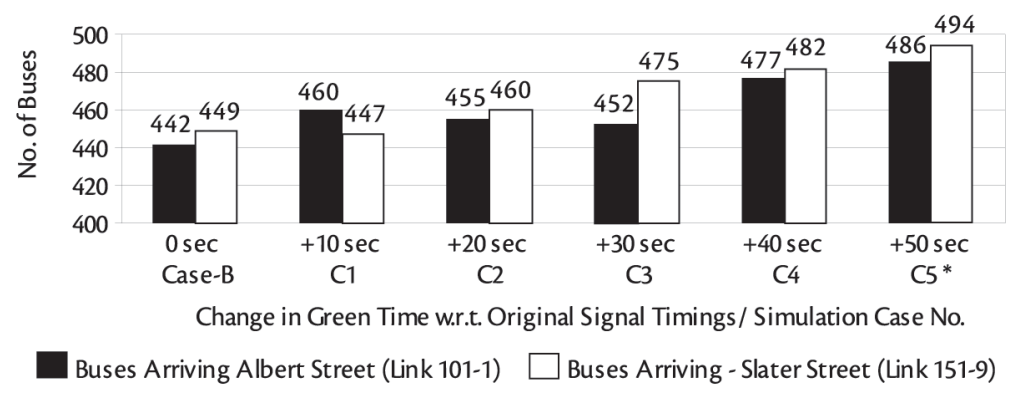


- 9). One hour simulation results also showed the average queue on these links as 10 and 8 vehicles, respectively. These queues of buses were unable to be served completely during a green phase of signal cycle. Thus, traffic flow was adversely affected, resulting in lower speed, and higher delay and travel time. It is important to mention that these upstream links are serving as a main supply source of transit buses to Albert and Slater streets. If these upstream links operate at capacity, the supply of transit buses cannot be increased at the downstream side of transit corridors.

\section{Analysis of Results}

To further understand the saturated state of bus transit operation in exclusive lanes at upstream links of Albert and Slater streets, results generated by NETSIM in all three case scenarios were analyzed. Among the measures selected for analysis and comparison were average speed, average delays, travel time (sec/bus) and average and maximum queues. These are commonly used measures for estimating effectiveness at signalized intersections (Roess, Prassas, and McShane 2004). Due to space limitations, only speed and delay results are shown in Figures 8 to 11 .

Results shown in each of these figures represent output in two different patterns. Under the first pattern, results are compiled and shown for the first 10-minute period in which output data are collected at every 10 -sec interval. In this way, we get a complete understanding of the fluctuations happening in transit operation due to the presence of control signals in the network. In the second pattern, results are compiled for rest of the 50-minute simulation period in which data are gathered at every 10 -minute interval.

It can be observed from Figures 8 and 9 that, in Case A, average bus speed along upstream links (101-1) on Albert and (151-9) on Slater streets get stabilized within first three/four minutes period and continue to operate at around $29 \mathrm{~km} / \mathrm{hr}$ and $26 \mathrm{~km} / \mathrm{hr}$, respectively, throughout the one hour simulation period.

The same phenomena can be observed (in Case A) for bus total delays shown in Figures 10 and 11. However, in Cases $B$ and $C$, bus operation is entirely opposite to Case $A$ and a sudden drop in average bus speed is seen during the first 10-minute period. The overall decrease in average speeds in Cases $B$ and $C$ is more than 70 percent (as compared to the base case) on both Albert and Slater streets. The obvious outcome of this reduction in average speeds is higher delays and longer travel times. 


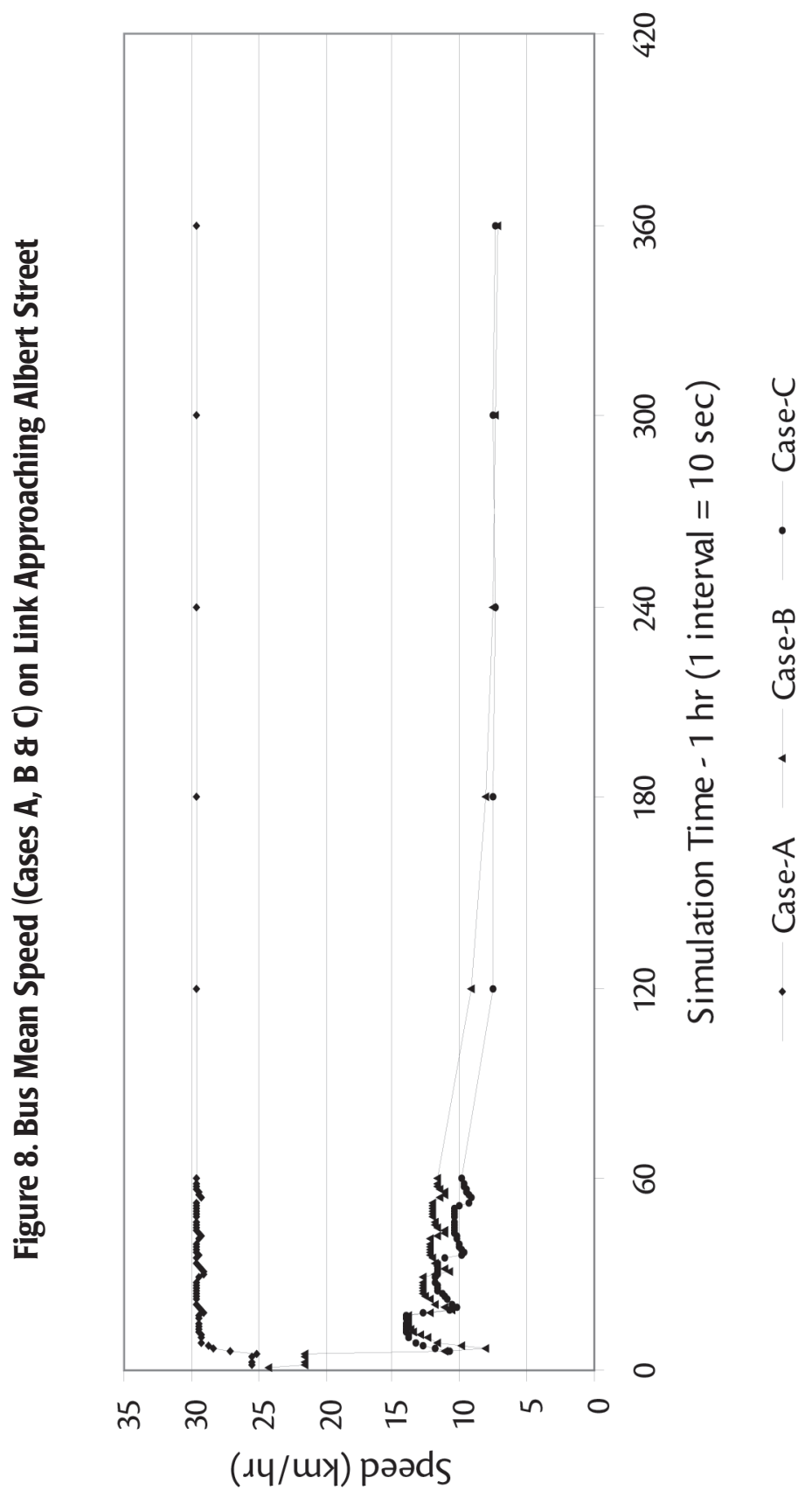




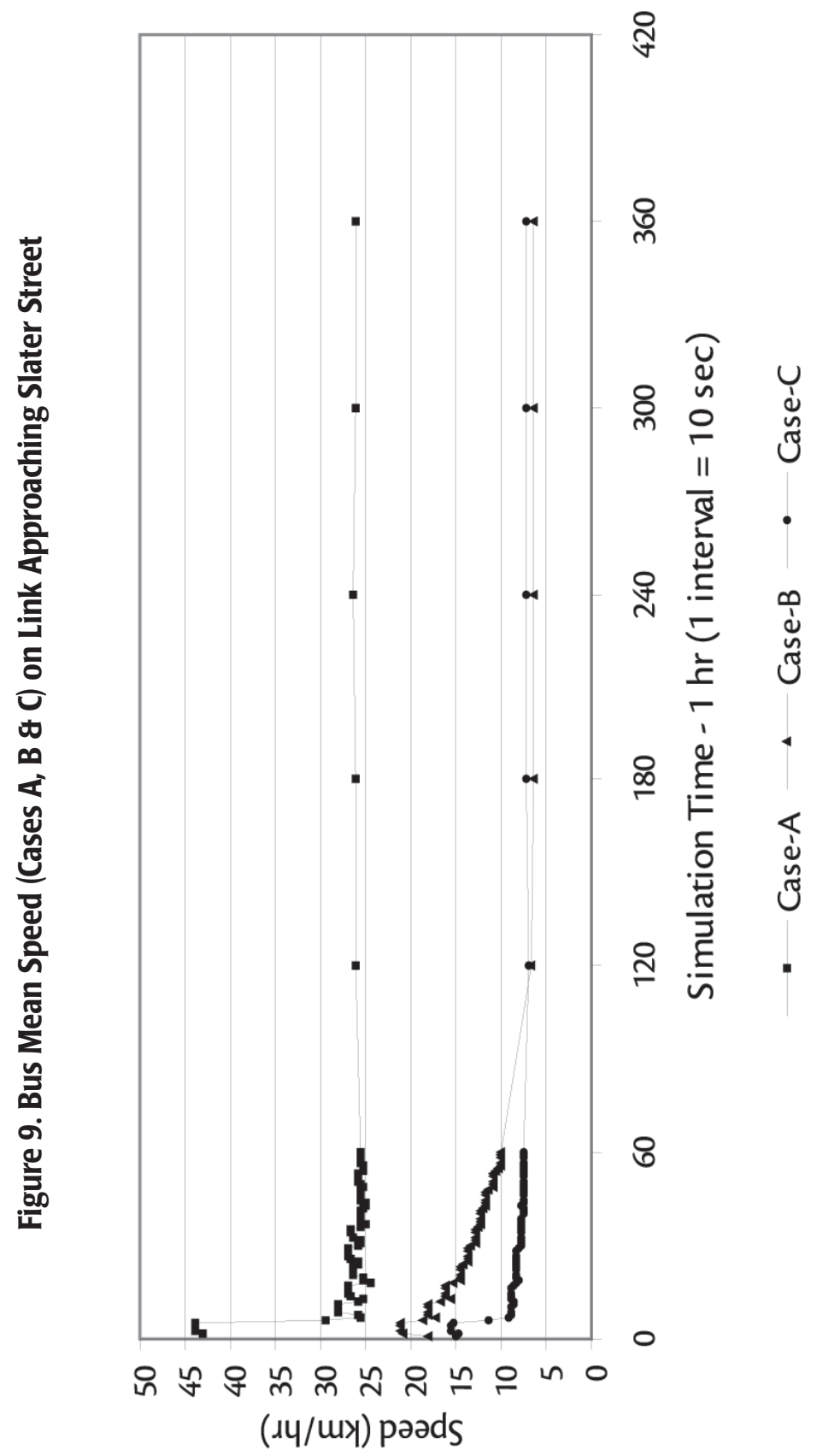




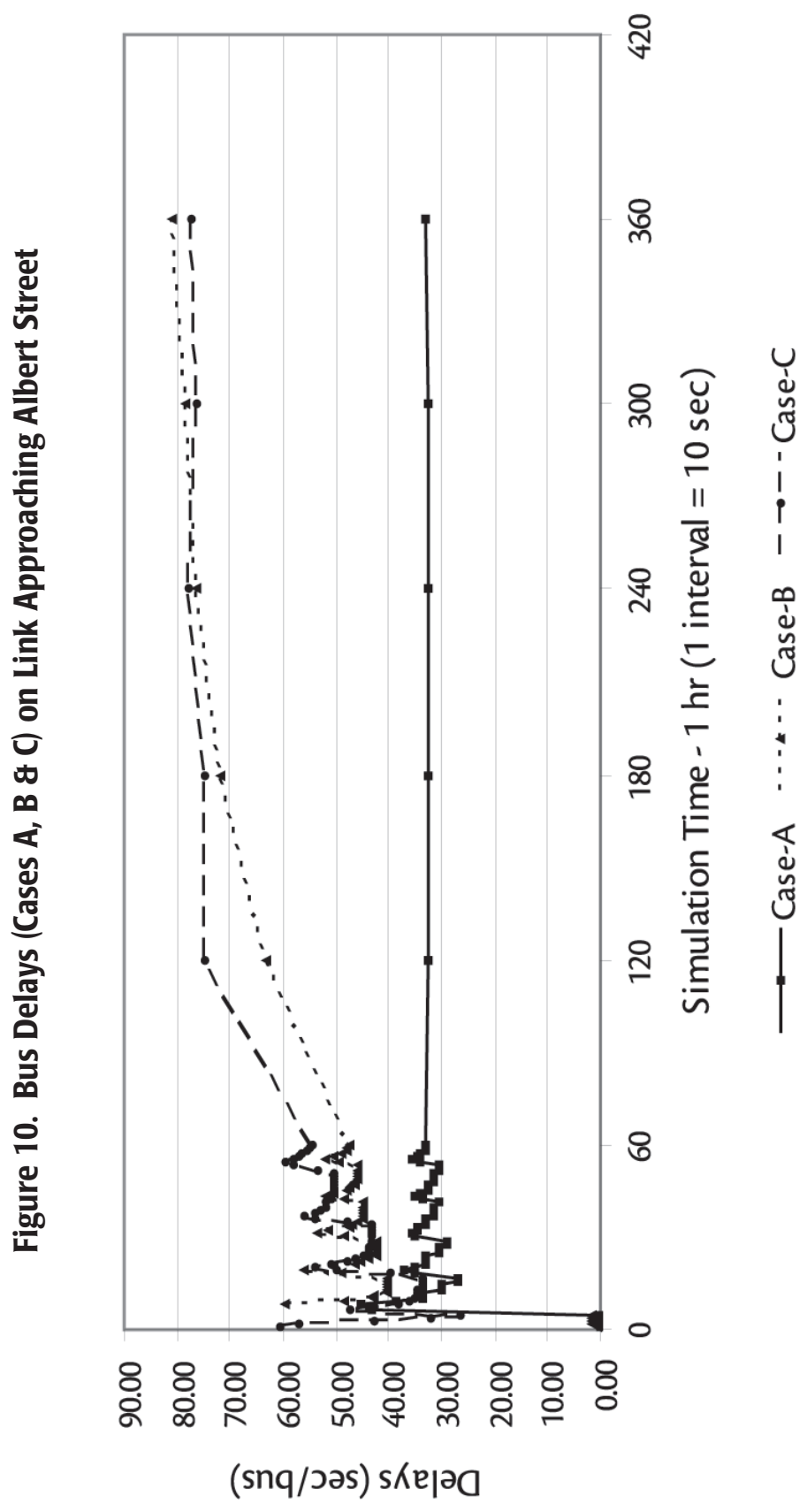




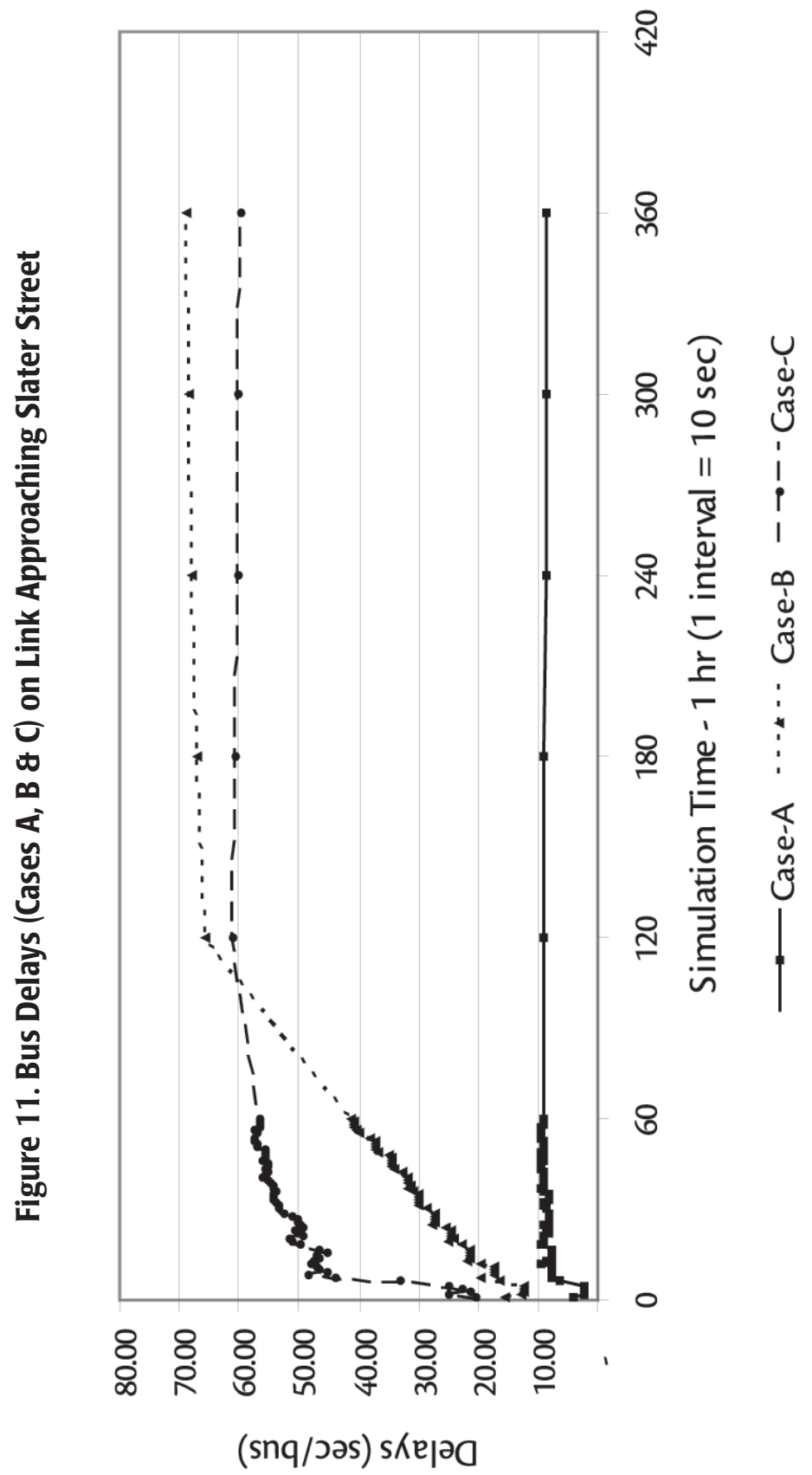


It is important to note that the queues of buses generated had already occupied the entire length defined for upstream links (101-1) on Albert and (151 - 9) on Slater streets. Regarding bus delays, we can notice from Figures 10 and 11 that these are continuing to increase with the passage of time in Cases $B$ and $C$ as opposed to Case A. A similar pattern was observed in bus travel times (not shown here due to space limitations).

Speed results were also plotted against bus delays as well as bus travel times. A regression analysis was also carried out in each of these cases. The regression equations and correlation coefficients $(r$ ) between two parameters (speed and bus delays or bus travel time) were calculated. As expected, a negative slope of regression lines showed an inverse relationship between the two parameters. High values of " $r$ " were found, which suggest a strong correlation between the two parameters. The speed vs. delay plots and regression equations are not shown in this paper due to space limitations.

From a network perspective, it is useful to assess the impacts of increasing bus volume at the expense of other traffic in the network. This can be achieved by the study of advantages of Case B over Case C (Table 4). These results indicate that as compared to Case $B$, in Case $C$ higher bus throughputs are achieved at the expense of adverse effects on the overall network operations.

\section{Table 4. Comparative advantage of Case-B over Case-C (at Network Level)}

\begin{tabular}{|c|c|c|c|}
\hline MOE $^{1}$ & $\%$ & MOE $^{1}$ & $\%$ \\
\hline Move Time & $15.2 \%$ higher & Total Veh-km travelled & $15.2 \%$ higher \\
Delay Time & $47 \%$ lower & Average speed & $80.7 \%$ higher \\
Total Time & $36.3 \%$ lower & Minutes $/ \mathrm{km}$ of Delay Time & $53.3 \%$ lower \\
Move/Total ratio & $82.3 \%$ higher & Minutes $/ \mathrm{km}$ of Total Time & $45.2 \%$ lower \\
Stop Delays & $54 \%$ lower & Total Fuel consumption & $12.8 \%$ lower \\
Queue Delays & $54.4 \%$ lower & - & - \\
\hline
\end{tabular}

${ }^{1} \mathrm{MOE}:$ Measure of Effectiveness 


\section{Conclusions}

Following are the main conclusions of this research.

1. Case B can accommodate 442 and 449 buses in exclusive bus lanes on Albert and Slater corridors, respectively, along with year 2021 auto traffic traversing through other lanes of these corridors. At this volume level, exclusive bus lanes will saturate at upstream sides of Albert and Slater streets represented by links (101-1) at intersection \# 1 and link (151-9) at intersection \# 9, respectively.

2. In Case $C$, an increase in green times of up to $+30 \mathrm{sec}$ (in addition to original signal times) along transit corridors attracts less than 6 percent of additional bus volume on transit corridors, as compared to Case B (with no additional green time on transit streets). Similarly, increase in green times up to +50 sec (in addition to original signal times) accommodates 486 and 494 buses on Albert and Slater streets, respectively, i.e., an increase of 10 percent on each of the streets. At this point most of the traffic movements on links intersecting transit streets will be operating at a LOS E or F, representing choke conditions in the network.

3. Capacity estimates of exclusive bus lane obtained from simulation results vis-à-vis from the Highway Capacity Manual (HCM) 2000 procedure show much difference. In Case B, capacity resulting from microsimulation is 55 percent and 35 percent higher on Albert and Slater streets, respectively, as compared to the figures calculated from HCM 2000. Similarly, in Case C, it is 22 percent and 11 percent higher on Albert and Slater streets, as compared to HCM 2000 results.

4. At saturated conditions, average speeds on upstream link (101 - 1) along Albert Street in Cases B and C will drop by 75 percent, bus total delays and bus travel time will increase by more than 135 percent and 96 percent, respectively, and average queue length will rise by 400 percent. Further, maximum queues will grow from 8 to 15 or higher on same links. Similarly on upstream link (151 - 9) along Slater Street, in Cases B and C, average bus speed will reduce by more than 72 percent, total bus delays and bus travel time will increase by more than 578 percent and 264 percent, respectively, and maximum queues will rise by 450 percent. Further, average bus queues will grow from 0 to 8 buses on same link.

5. Based on year 2001 average occupancy figures of transit buses, which is 32.5 persons/bus at the upstream links of Albert and Slater Streets, up to 28,960 
passengers in Case B and 31,850 passengers in Case $C$ can be transported to the downtown core through transit operation on Albert and Slater streets only.

6. Operational advantages of Case B over Case $C$ suggest that, if BRT has to operate on exclusive lanes in the CBD, allocation of additional green time to bus streets at the expense of other traffic is not effective from the overall system perspective. Here, all the vehicles and the study area network define the system. Effectiveness was gauged using a number of measures including speed, time, delay, km traversed, fuel consumption, and emissions.

\section{Recommendations}

1. Although the simulator NETSIM used in this research is reasonably well developed, further improvement can be made.

(a) Average dwell time of buses at each bus station may vary from real time situations, as many buses have different dwell times. Routes with higher dwell time impede transit traffic at upstream side. In NETSIM, a provision should be developed so that dwell times are defined according to the route demands instead of an average dwell time value applicable to all routes in the system.

(b) In NETSIM, option of two or more exclusive bus lanes should also be provided.

2. Since increase in green time along transit corridor as in Case $C$ is not significantly increasing the throughput of transit buses as compared to Case B, rather it is causing excessively high delays to traffic movements on intersecting streets, it is, therefore, recommended to continue transit operations at existing cycle lengths.

3. Another analysis incorporating two bus lanes and additional bus stations located at suitable points across the width of the corridor should be carried out.

4. Skip Stop strategy can be applied in future but it needs further study regarding the effect on dwell times (which might increase on some bus stops) and how to educate people, etc.

5. All high-floor buses can be replaced with low-floor buses, and an automated fare collection system can be used in order to speed up dwell times 
6. This study can be further extended to examine the prospects of using a larger share of the fleet comprised of larger vehicles. Such a study may provide the planners an insight into the relative vehicle performance of standard sized versus large BRT vehicles.

\section{Acknowledgements}

The Natural Sciences and Engineering Research Council of Canada (NSERC) provided financial support for research reported in this article. The authors gratefully acknowledge the availability of OC Transpo data used in this research. The views are those of the authors.

\section{References}

BRT newsLane. 2005. BRT year in review: Looking back on 2005. Vol.4, No.5, WestStart-CALSTART, supported by the Federal Transit Administration, USA.

City of Bogotá. 1996. Master Transportation Plan for Bogotá, (JICA)

City of Carolina. 2001-2002. Department of City and Regional Planning. Carolina Transportation Program, Report.

City of Ottawa. 2003 Ottawa Transportation Master Plan.

Dillon M.M. 1993. Review of the traffic signal operation on the Central Area Transitway. Final Report, Ottawa.

Federal Highway Administration (FHWA). 2001. CORSIM User's Guide - version 5.0. Office of Operations Research, Development and Technology, Washington, D.C.

Institute of Transportation Engineers. 1986. Urban traffic congestion: What Does the Future hold? ITE Publication No. IR-040, Washington, D.C.

Kittelson and Associates, Inc. 1999. TCRP web document 6 - Transit capacity and quality of service manual. Prepared for Transit Cooperative Research Program, Transportation Research Board, National Research Council.

Kittelson and Associates, Inc. 1999a. TCRP web document 6 - Transit capacity and quality of service manual (Chapter-2). Prepared for Transit Cooperative Research Program, Transportation Research Board, National Research Council. 
Liu, R., and D. V. Vliet,. 1996 DRACULA - a dynamic microscopic model of road traffic. Proceedings of the International Transport Symposium, Beijing: 160170 .

Multisystems, Inc. 2000. Bus Rapid Transit Simulation Model Research and Development. Final Project Summary Report for USDOT/SBIR Phase 1.

Roess, R.P., E.S. Prassas, and W.R.McShane. 2004. Traffic Engineering, Third Edition. Pearson Prentice Hall.

St. Jacques, K. and H. S. Levinson. 1997. Operational Analysis of Bus Lanes on Arterials, TCRP Report 26. Sponsored by The Federal Transit Administration and published byTransportation Research Board, National Research Council.

Transportation Research Board. 2000a. Traffic Analysis Software Tools, Circular Number E-C014. National Research Council.

Transportation Research Board. 2000b. Highway Capacity Manual 2000: Chapter 14-Transit Concepts. National Research Council.

\section{About the Authors}

Abdul Jabbar Siddique (ajsiddiq@connect.carleton.ca) is a Ph.D. student in the Department of Civil and Environmental Engineering at Carleton University, Ottawa, Canada, where he earned his M.A.Sc Degree in 2003. He is working at Carleton University as a Research and Teaching assistant. His research interests are public transit operations, traffic network modelling and simulations and traffic impact studies.

AtA M. KhAN (ata_khan@carleton.ca) received his doctorate from the University of Waterloo (Canada) in civil engineering (transportation). He is a professor in the Department of Civil and Environmental Engineering and director of the Transportation Research Centre, Carleton University (Canada). 


\title{
Ex-Ante Evaluation of Exclusive Bus Lanes Implementation
}

\author{
D. Tsamboulas, National Technical University of Athens
}

\begin{abstract}
This article presents a comprehensive approach for the ex-ante evaluation and the identification of relevant impacts related to the implementation of Exclusive Bus Lanes (EBL). It proposes indicators to measure the impacts related to key stakeholders: public transport operators, taxis, private vehicle drivers and passengers, as well as society regarding energy and the environment. Impact values are estimated from the application of relevant transportation planning models. The ex-ante evaluation method is based on cost-benefit analysis (CBA) and is designed to assist any decision regarding implementation of $E B L$ by determining whether it is beneficial. To demonstrate the capability of the approach, a numerical application is provided for an area in Athens where EBLs were introduced to accommodate traffic for the Athens 2004 Olympic Games.
\end{abstract}

\section{Introduction}

As part of transportation management planning, most cities have introduced exclusive lanes, initially for all high occupancy vehicles (HOVs) and later for buses, to facilitate traveling with public transport and to maximize the person-carrying capacity of the roadway by changing the usage of a specific traffic lane. Thus, exclusive lanes provide priority treatment for buses, resulting in reduced travel time and improved time reliability. 
Several studies specifically examined bus priority measures, including the introduction of exclusive bus lanes (EBL), since the 1960s (Hounsel et al. 1988; King 1983; Tee 1994; Denco 1995; Pitsiava-Latinopoulou et al. 1988; Frantzeskakis et al. 1997; Tsamboulas et al. 1999; Astrop et al. 1995). However, in most cases, a comprehensive method for the ex-ante evaluation of EBL implementation is not applied. Even when an evaluation is done, it is not applied separately, but in conjunction with other measures for mass public transport, usually as part of transportation management schemes (Horowitz et al. 1994; Mandl 1980; DETR 1997; Jacques et al. 1997; Environmental Protection Agency 2005).

This article presents a comprehensive approach that incorporates the analysis of impacts and the socioeconomic ex-ante evaluation regarding EBL implementation. The approach is based on the outputs of transportation model applications; for example, estimation of passenger and vehicle volumes on traffic assignment and mode choice models, costs elements related to EBL implementation and technical design studies; and benefits to tripmakers on travel times and operating costs. The implementation costs, in most cases, are negligible compared with the impacts related to vehicles and passengers/drivers. The ex-ante evaluation is based on the widely applied and well-documented cost benefit analysis (CBA; Tsamboulas et al. 1999).

\section{Methodology}

\section{Basic Principles}

The methodology comprises two stages: (1) identification of the impacts and their measurements and (2) the evaluation methodology based on the difference of total resource (economic) costs between the current conditions and the situation when EBL is implemented. If such difference is positive, then benefits are generated. Additional benefits are associated with operational elements (e.g., travel time, environment). The evaluation uses the well-established CBA method. Traffic-related inputs derived from the application of transport models are employed.

The innovative element of the methodology lies in the identification and measurement of impacts associated with the main stakeholders: (1) for public transport operators, the impacts relate to vehicle operating costs and driver working hours; (2) for drivers of taxis and other public-purpose vehicles (trucks, vans etc.), the impacts focus on whether acceptable working conditions are maintained; (3) for 
transport companies operating taxis, vans, trucks, etc., the impacts concern possible decreases in vehicle fleet costs; (4) for tripmakers (drivers or passengers), the impacts are about trip costs and travel time, and (5) for the general public, the impacts relate to energy consumption and the environment.

At the first stage, the measurement of impact values is based on the outputs of transportation simulation models (either generic or commercially available models, such as NETSIM, TRANSYT, CUBE, VISUM, EMME II). These models produce outputs that could be used for impact measurement if the appropriate variables are introduced in the models' configurations. The next critical step is to define the area where the models have to be applied. Itinerary routes and vehicles currently using the roadway segment where the EBL will be implemented are included in this step. This area could be extended to include any alternative route followed by private vehicles and transport modes when EBL is introduced. In brief, it is the area that comprises all possible alternative routes for all passenger O-D pairs currently using the roadway segment under consideration.

At the second stage, the ex-ante evaluation is applied. Decisions on two issues are required before the application: (1) choice of the criterion for CBA (i.e., selection of the Net Present Value [NPV] or B/C ratio or the Internal Rate of Return [IRR]); and (2) the time period for evaluation (usually three to five years since EBL is a low-cost transportation management measure, and as such changes could occur within this time horizon). The developed ex-ante evaluation compares the alternative (implementation of EBL) with the current situation (do nothing). Transportation simulation models are applied for both cases, and the corresponding values for the impacts are produced. The overall structure and components of the approach are presented in Figure 1.

\section{Tripmakers' Related Impacts}

Two broad categories of tripmakers are identified: (1) those who after implementation of EBL continue to use the same transport modes as before and (2) those who decide to change transport modes (usually taking buses that move along the $\mathrm{EBL})$.

All tripmakers' related impacts are calculated with the application of the relevant transport models for existing conditions (before application of EBL) and after application of EBL. The latter necessitates changes in the transport network employed by the models since the EBL should be considered as a change in one or more links of the transport network. 


\section{Figure 1. Methodology's Structure and Components}

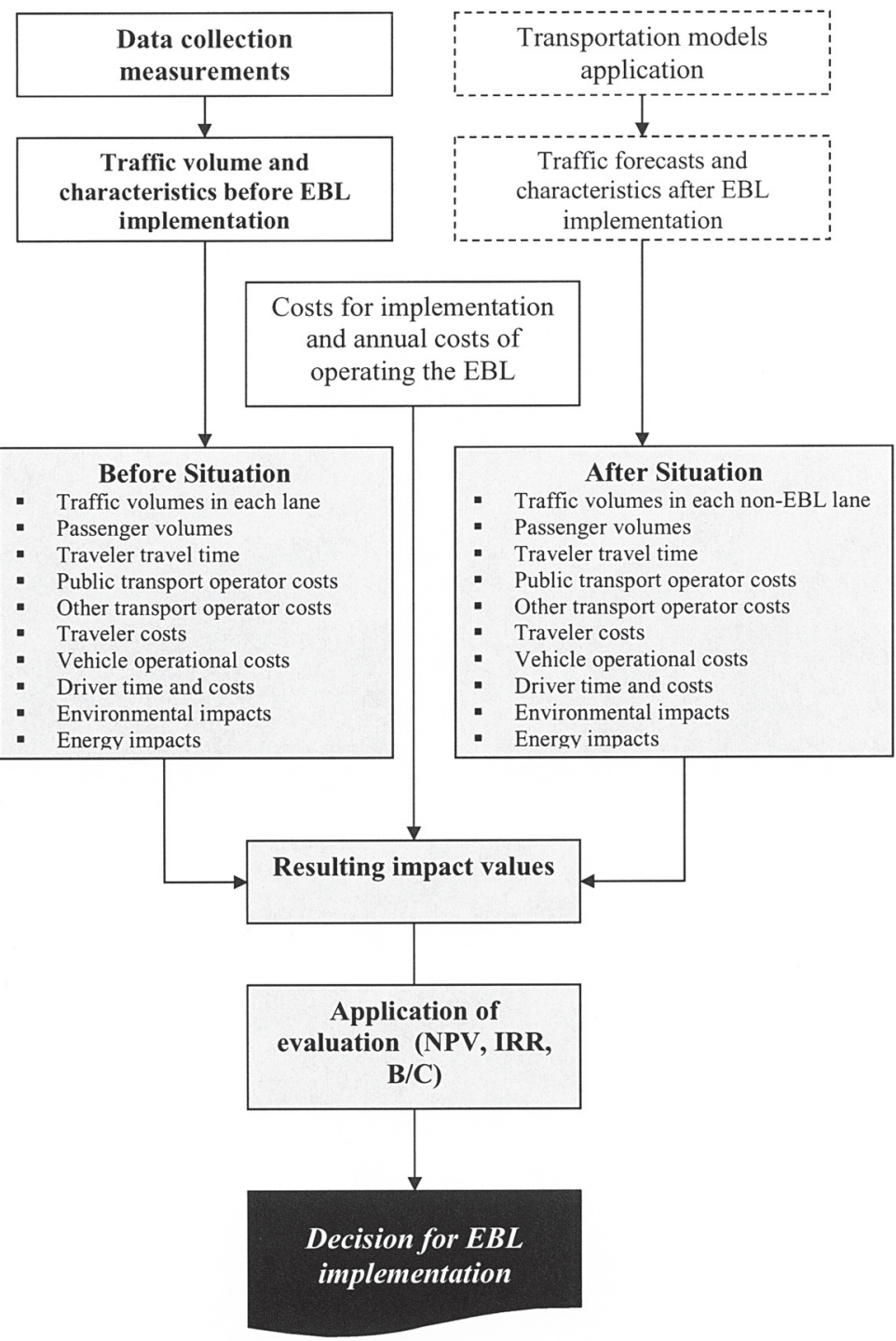




\section{Implementation and Operation Costs}

Costs related to implementation and operation of the EBL are identified below.

Construction $\left(C^{k}\right)$. EBL construction costs are associated with design studies, works for implementation (i.e., roadway signaling, vertical signs, traffic lights at intersections, pavements), other necessary interventions (i.e., road widening, pavement reconfigurations, bus stops changes); and possible modifications of infrastructure (i.e., catenaries for trolley buses).

Police Surveillance $\left(C^{a}\right)$. Police surveillance is related to observation for incident detection or violations by private vehicle or taxi drivers of EBL use. A minimum number of fines are imposed by the police to cover surveillance costs. Once the costs are covered, additional revenue could be used by the municipality or the public transport operator to finance EBL maintenance and improvements in public transport services.

Maintenance $\left(C^{\mu}\right)$. Maintenance includes any expenses related to the upkeep and efficient operation of EBL.

\section{Tripmakers' Travel Time Cost Impacts}

Travel Time Changes. Travel time changes concern tripmakers regardless of transport mode (passengers for buses and taxis, drivers or passengers for private vehicles) who currently use the roadway section where EBL will be implemented. Changes are based on travel time differences "before" and "after" conditions that exist for vehicles moving along the section of the road on which EBL is implemented.

Consequently, the change in travel time costs $(€ / \mathrm{hr})$ is

$$
\left.\left.\mathrm{DC}=\sum_{\mu} \sum_{\mathrm{i}} \sum_{\mathrm{j}}\left[\left(\mathrm{T}_{\mathrm{ij}}, * \mathrm{E}_{\mu}{ }^{\prime} * \mathrm{a}_{\mu}\right) / 60\right)-\left(\mathrm{T}_{\mathrm{ij}} * \mathrm{E}_{\mu} * \mathrm{a}_{\mu}\right) / 60\right)\right]
$$

See Table 1 for an explanation of symbols.

Changes in Passenger Waiting Time at Stops. The movement of buses along the EBL will trigger changes in passenger travel times, other than in-vehicle travel time. Thus, increases in frequency of bus service will result in changes in waiting times at bus stops, producing changes in time-related costs $(€ / \mathrm{hr})$. 


\section{Table 1. Variables Used in EBL Evaluation}

\begin{tabular}{|c|c|}
\hline Variable & Description \\
\hline$\mu:$ & $\begin{array}{l}\text { Tripmakers/passengers who will continue to use buses }(\mu=1) \text {, change transport mode and use } \\
\text { buses }(\mu=2) \text {, or continue to use other modes }(\mu=3)\end{array}$ \\
\hline $\mathrm{i}=\mathrm{m}, 1$ & $\begin{array}{l}\text { Public transport modes that move on } \mathrm{EBL}(\mathrm{i}=\mathrm{m}, 1) \text {, that move on remaining road lanes or routes } \\
\text { (e.g., metro, rapid light rail) }(\mathrm{i}=\mathrm{m}, 2) \text {, and that move on the remaining road lanes or routes (e.g., } \\
\text { metro, rapid light rail) }(\mathrm{i}=\mathrm{m}, 3)\end{array}$ \\
\hline$i=2,3, \ldots \mathrm{n}$ & Other vehicles not moving on the EBL (e.g., private vehicles, taxis, two-wheeled vehicles) \\
\hline $\mathrm{j}$ & Trip itinerary following the route of EBL $(j=1)$ or alternative routes $(j=2)$ \\
\hline $\mathrm{T}_{\mathrm{ij}}, \mathrm{T}_{\mathrm{ij}}{ }^{\prime}$ & $\begin{array}{l}\text { Average travel time (min) with transport mode } \mathrm{i} \text {, for route } \mathrm{j} \text {, "before" and "after" EBL } \\
\text { implementation, respectively }\end{array}$ \\
\hline$E_{\mu}, E_{\mu}^{\prime}$ & $\begin{array}{l}\text { Number of tripmakers (persons/hr) according to the category considered, "before" and "after" } \\
\text { EBL implementation, respectively }\end{array}$ \\
\hline$a_{\mu}$ & Value of travel time for tripmaker category $\mu(€ / \mathrm{h})$ \\
\hline h, h' & $\begin{array}{l}\text { Average headway between two successive arrivals of buses at the stop (in minutes) "before" and } \\
\text { "after"' EBL implementation, respectively }\end{array}$ \\
\hline $\mathrm{V}_{\mathrm{h},}, \mathrm{V}_{\mathrm{h}}$ & Variability factor of frequency of service "before" and "after" EBL implementation, respectively \\
\hline$\rho, \rho^{\prime}$ & Passenger arrival rate at the specific stop "before" and "after," respectively (passengers/minute) \\
\hline s, s' & Number of stops along EBL \\
\hline $\mathrm{N}_{1 \mathrm{ij}}$ & Traffic volume of vehicles of transport mode $\mathrm{i}$ on route $\mathrm{j}$, expressed in vehicles $/ \mathrm{hr}$ \\
\hline $\mathrm{d}_{\mathrm{ij}}$ & Length of route $\mathrm{j}$ followed by vehicles of transport mode $\mathrm{i}$, expressed in $\mathrm{kms}$ \\
\hline$C_{\lambda i j}{ }^{\prime}, C_{\lambda i j}$ & $\begin{array}{l}\text { Vehicle operating cost per transport mode } \mathrm{i} \text {, based on the average speed along route alternatives } \mathrm{j} \text {, } \\
\text { "before" and "after," respectively, application in route } \mathrm{j} \text {, expressed in } € / \mathrm{km}\end{array}$ \\
\hline $\mathrm{N}_{2 \text { ir }}$ & $\begin{array}{l}\text { Volume of vehicles of transport mode } \mathrm{i} \text {, which deviate from route } \mathrm{j} \text { (originally followed route) to } \\
\text { route } \mathrm{r} \text {, expressed in vehicles } / \mathrm{hr}\end{array}$ \\
\hline$d_{\text {ir }}{ }^{\prime}$ & $\begin{array}{l}\text { Length of route } r \text {, to which transport mode i deviates "after" EBL implementation, expressed in } \\
\text { kms }\end{array}$ \\
\hline $\mathrm{d}_{\mathrm{ij}}$ & Length of route $\mathrm{j}$ of transport mode $\mathrm{i}$ "before" EBL implementation, expressed in kms \\
\hline $\mathrm{E}_{2 \mathrm{io}}$ & $\begin{array}{l}\text { Passengers who move to public transport "after" implementation of EBL and who were using the } \\
\text { same route o, expressed as passengers/hr }\end{array}$ \\
\hline $\mathrm{E}_{2 \mathrm{ij}}$ & $\begin{array}{l}\text { Passengers who move to public transport "after" implementation of EBL and who were using } \\
\text { transport mode } \mathrm{i} \text { on other routes } \mathrm{j} \text {, expressed as passengers/hr }\end{array}$ \\
\hline$C_{\lambda_{0}}^{\prime}$ & Passenger travel costs for route o (where EBL is implemented) \\
\hline $\mathrm{C}_{\lambda \mathrm{j}}^{\prime \prime}$ & Passenger travel costs based on route $\mathrm{j}$ (other than the one where EBL is implemented) \\
\hline $\mathrm{F}_{\mathrm{m}}$ & Passenger bus ticket fare for route 0 \\
\hline$F_{m j}$ & Passenger public transport ticket fare \\
\hline $\mathrm{d}_{\mathrm{o}}$ & Length of EBL section, in $\mathrm{kms}$ \\
\hline $\mathrm{C}_{\lambda \mathrm{mo}}{ }^{\prime}$ & Operating cost for bus along EBL on route o, expressed in $€ / \mathrm{km} /$ bus \\
\hline $\mathrm{C}_{\mathrm{Tm}}$ & Bus driver costs, expressed in $€ /$ bus/hr for the specific itinerary \\
\hline $\mathrm{E}_{2 \mathrm{io}}$ & $\begin{array}{l}\text { Number of passengers of transport mode } \mathrm{i} \text { using road o who shift to bus in route o "after" EBL } \\
\text { application, expressed as passengers/hr }\end{array}$ \\
\hline $\mathrm{E}_{2 \mathrm{ij}}$ & $\begin{array}{l}\text { Number of passengers of transport mode } \mathrm{i} \text { of route } \mathrm{j} \text { who change route itinerary and will use bus } \\
\text { in route o "after" EBL implementation, expressed in passengers } / \mathrm{hr}\end{array}$ \\
\hline$\Pi$ & Capacity of public transport vehicle related to level of service, expressed in passengers. \\
\hline $\mathrm{R}_{\mathrm{mo}, \mathrm{n}}$, & Estimated by applying equation ( 8 ) for the nth year \\
\hline $\mathrm{DC}_{\mathrm{E}, \mathrm{n}}$ & Estimated by applying equation (6) for the nth year \\
\hline $\mathrm{DC}_{\lambda, \mathrm{r}, \mathrm{n}}$ & Estimated by applying equation (5) for the nth year \\
\hline $\mathrm{DC}_{\lambda \mathrm{i}, \mathrm{n}}$ & Estimated by applying equation (4) for the nth year \\
\hline $\mathrm{DC}_{\alpha, \mathrm{n}}$ : & Estimated by applying equation ( 2 ) for the nth year \\
\hline $\mathrm{DC}_{\mathrm{n}}$ & Estimated by applying equation (1) for the nth year \\
\hline $\mathrm{DE}_{\mathrm{n}}$ & Difference in external costs, expressed in $€ / \mathrm{hr}$ for the nth year \\
\hline $\mathrm{n}$ & valuation \\
\hline $\mathrm{e}$ & Opportunity cost of capital to be used for interest rate \\
\hline $\mathrm{Hd}$ & Daily operating hours for bus lane \\
\hline
\end{tabular}


$\mathrm{DC}_{\alpha}=\left[\left\{\left(\mathrm{h}^{\prime} *\left(1+\mathrm{V}_{\mathrm{h}}{ }^{2}\right) / 2\right) * \rho^{\prime} * \mathrm{~s}^{\prime} * \alpha_{\mathrm{a}}\right\} / 60\right]-\left[\left\{\left(\mathrm{h} *\left(1+\mathrm{V}_{\mathrm{h}}{ }^{2}\right) / 2\right) * \rho * \mathrm{~s} * \alpha_{a}\right\} / 60\right]$

\section{Vehicle Operating Costs}

Vehicle operating costs include all relevant costs such as fuels, lubricants, tires, maintenance/service, and parking expenses. In public transport modes, driver costs, as well as corresponding administration costs, have to be added. The following model could be used to estimate vehicle operating costs in urban areas (Mandl 1980):

$$
\mathrm{C}_{\lambda \mathrm{i} . .}=\mathrm{a}_{\mathrm{i}}+\mathrm{b}_{\mathrm{i}} / \mathrm{V}_{\mathrm{i}}+\mathrm{f}_{\mathrm{i}} * \mathrm{~V}_{\mathrm{i}}^{2}+\mathrm{C}_{\mathrm{Tm}}
$$

where:

$C_{\lambda \text {. }} \quad$ equals operating cost for a typical vehicle of transport mode $i$, expressed in $€ / \mathrm{km}$

$\mathrm{Vi} \quad$ represents average operating speed of a typical transport mode i vehicle on the road section examined, expressed in $\mathrm{km} / \mathrm{hr}$

$\mathrm{C}_{\mathrm{Tm}} \quad$ is 0 for nonpublic transport modes; hourly wages of drivers for public transport modes

$a_{i}, b_{i}, f_{i}$ are estimated (after model calibration) and are differentiated with transport vehicle type (i) and fuel

The above-presented model in equation (3) is an example of existing models calculating vehicle operating costs.

Consequently, changes in vehicle operating costs are for two cases identified: (1) tripmakers who continue to travel the same way and (2) tripmakers who change route after implementation of EBL.

Tripmakers Who Continue to Travel the Same Way (Transport Modes, Route Itineraries). Two cases are identified: (1) tripmakers who use the road where EBL is implemented (denoted by $\mathrm{j}=0$ ) and who are using transport modes other than bus; and (2) tripmakers who continue to move as before implementation of EBL along route itineraries that do not include the $E B L$ route $(j=1)$ utilizing the same transport mode as before.

Thus, the cost difference, $\mathrm{DC}_{\lambda j}$, is estimated by 
$\mathrm{DC}_{\lambda \mathrm{j}}=\Sigma_{\mathrm{i}} \Sigma_{\mathrm{j}} \mathrm{N}_{1 \mathrm{ij}} * \mathrm{~d}_{\mathrm{ij}} *\left(\mathrm{c}_{\lambda \mathrm{ij}}{ }^{\prime}-\mathrm{c}_{\lambda_{\mathrm{ij}}}\right)$

The impact on other public transport modes using fixed track (e.g., light rapid rail, metro, suburban rail) is negligible, and thus is not included in the calculations.

Tripmakers Who Change Routes After Implementation of EBL. In the case of tripmakers changing route itineraries after $E B L$ implementation, the impact on vehicle operating costs is attributed to possible increases in speed and vehicle-km traveled since alternative routes could be longer.

Change in total operating costs is estimated by

$\mathrm{DC}_{\lambda \mathrm{r}}=\Sigma_{\mathrm{i}} \Sigma \mathrm{rN}_{2 \mathrm{ir}} *\left[\left(\mathrm{C}_{\lambda \mathrm{ir}}{ }^{\prime} * \mathrm{~d}_{\mathrm{ir}}{ }^{\prime}\right)-\left(\mathrm{C}_{\lambda \mathrm{ij}} * \mathrm{~d}_{\mathrm{ij}}\right)\right]$

\section{Travel Cost Impacts of Tripmakers Changing Transport Mode}

The most probable case is that of tripmakers using transport mode i (usually private car or taxi) who become users of public transport $\mathrm{m}$, after implementation of EBL. Other cases (e.g., change of bus mode for metro) are rather negligible, and thus they are not included. It is evident that these tripmakers will no longer use their private cars or take a taxi, and thus there will be a decrease in traffic volumes.

Hence, changes in traveling costs are estimated as follows:

$\mathrm{DC}_{\mathrm{E}}=\Sigma_{\mathrm{i}} \mathrm{E}_{2 \mathrm{io}} *\left(\mathrm{C}_{\lambda \mathrm{o}}^{\prime}-\mathrm{F}_{\mathrm{m}}\right)+\Sigma_{\mathrm{i}} \Sigma_{\mathrm{j}} \mathrm{E}_{2 \mathrm{ij}} *\left(\mathrm{C}_{\lambda \mathrm{j}}^{\prime}-\mathrm{F}_{\mathrm{mj}}\right)$

Travel time costs are estimated by equation (1), and passenger and traffic volumes are estimated from the application of the well-known transport four-step process and the corresponding models.

\section{Additional Revenue to Public Transport Operators}

The modal shift from private vehicles to public transport generates the need for more frequent service to cover the increased passenger demand. The additional 
volume of public transport vehicles that will sufficiently cover the generated demand is estimated according to the available capacity of the buses.

These new bus services will result in additional operating costs for the transport operations, estimated by

$\mathrm{DC}_{\lambda \mathrm{mo}}=\left[\left(\Sigma_{\mathrm{i}} \mathrm{E}_{2 \mathrm{io}}+\Sigma_{\mathrm{i}} \Sigma_{\mathrm{j}} \mathrm{E}_{2 \mathrm{ij}}\right) / \Pi\right] *\left(\mathrm{~d}_{\mathrm{o}} * \mathrm{C}_{\lambda \mathrm{mo}}{ }^{\prime}+\mathrm{C}_{\mathrm{Tm}}\right)$

On the other hand, generated revenues from additional passengers on buses along route $o$ are

$\mathrm{R}_{\mathrm{mo}}=\left(\Sigma_{\mathrm{i}} \mathrm{E}_{2 \mathrm{io}}+\Sigma_{\mathrm{i}} \Sigma_{\mathrm{j}} \mathrm{E}_{2 \mathrm{ij}}\right) * \mathrm{~F}_{\mathrm{m}}-\mathrm{DC}_{\lambda \mathrm{mo}}$

\section{External (Noneconomic) Costs}

External costs mainly concern environmental impact (air quality, noise, and vibration) and energy-related costs. Potential impacts attributed to construction will not be considered since they are temporary impacts and will be mitigated through the use of best management practices. Conversion of physical units to monetary units is not an easy application. Thus, ways of converting physical units to monetary values have to be included.

Energy Consumption. Fuel consumption and emission rates per passenger-km depend on load factors. A bus with 50 passengers consumes about one tenth the energy per passenger-km as an average automobile, but energy consumption per passenger-km could be little higher for transit systems than private vehicles if low load factors are observed. A National Research Council study (Committee on the Science of Climate Change of the NRC 2001) estimates these externalities at about 30 cents per gallon on average.

Since the cost of energy consumption is already included in the operating costs, it will not be estimated separately to avoid double counting.

Noise Impacts. Motor vehicle traffic imposes noise pollution. Noise-related costs tend to be much higher on local urban roads where traffic tends to be closer to houses. Levels of traffic noise are quantified depending on the traffic volume and composition, speed, type of road (gradient, surface quality, and type) as well as the elements of the urban model that represent the geometry of the particular region. 
For all road sections, the level of noise at the reception point (facade of a building next to $E B L$ ) could be estimated by applying the equivalent 24-hour noise level based on traffic volumes.

On the other hand, the methodology introduces a threshold, the transgression of which produces the costs. This threshold corresponds to $50 \mathrm{~dB}(\mathrm{~A})$ for public transport vehicles at urban areas where EBL is implemented (Federal Transit Administration 1995; Environmental Protection Agency 1974). If construction and operation of the EBL results in changing the level of noise related to the $50 \mathrm{~dB}(\mathrm{~A})$ threshold, then the values produced in the Delucchi and Shi-Ling Hsu study (Delucchi and Hsu 1998) can be used with proper modifications in currency and distance units.

Atmospheric Pollution Impacts. Atmospheric pollution impacts are mainly determined by three factors: (1) carbon monoxide (CO), (2) nitrogen oxides (NOx), and (3) particulates (PM). Other possible pollutants, however, are to be taken into consideration (e.g., sulphur) if believed to be significant. For evaluation purposes, the number of persons affected by such emissions has to be considered. Determination of atmospheric pollution and the resulting benefits or costs could be based on the work by DETR (DETR 1999). Thus, atmospheric pollution impacts can be applied in the urban areas where the EBL is implemented for estimating pollution at each specific road segment. This will avoid the use of an average for the whole roadway system in an area. In addition, a threshold is determined, the transgression of which produces the respective costs. The introduced threshold corresponds to the following values (for the three pollutants) for public transport operations at urban areas where the EBL is implemented (European Environmental Agency 2003): (1) CO: 10 ppm per 8 h; (2) NO: 150 ppb per hour; (3) PM: 50 $\mathrm{mg} / \mathrm{m}^{3}$ per day.

\section{Ex-Ante Evaluation}

The above impacts constitute parameters for the ex-ante evaluation of EBL implementation. The remaining items to be considered are the evaluation period and the conversion of resulted values in present values. The evaluation criterion proposed is basically the NPV, and-if requested-the B/C ratio and/or IRR, which is based on NPV results. The evaluation period is usually three to five years, depending on the EBL implementation investment scale. As for conversion of hourly values to annual ones, daily hours as well as days per year are determined by the hours per day and days per year of the specific EBL operation (i.e., time periods when only buses are allowed to move along the specific EBL). 
Thus:

$\mathrm{NPV}=\sum_{\mathrm{n}}\left\{\left[365^{*} \mathrm{H}_{\mathrm{d}, \mathrm{n}} *\left(\mathrm{R}_{\mathrm{mo}, \mathrm{n}}+\mathrm{DC}_{\mathrm{E}, \mathrm{n}}+\mathrm{DC}_{\lambda \mathrm{r}, \mathrm{n}}+\mathrm{DC}_{\lambda_{\mathrm{i}, \mathrm{n}}}+\mathrm{DC}_{\alpha, \mathrm{n}}+\mathrm{DC}_{\mathrm{n}}+\mathrm{DE}_{\mathrm{n}}\right)\right] /(1+\mathrm{e})^{\mathrm{n}}\right\}$

where the values of the parameters are based on outputs of previous relations (see Table 1).

\section{Application \\ Overview}

The proposed methodology was applied to an EBL to be implemented in Athens on a principal arterial road. It was introduced primarily as a measure to accommodate the increased volumes of public transport expected during the Athens 2004 Olympic Games and as part of the traffic management measures introduced in the city. Therefore, the analysis and its results will be presented separately for the Olympic Games period (which lasts only 20 days) and for the post-Olympic Games period, to be considered as four years.

\section{Olympic Games Period}

Traffic data regarding situations "before" and "after" as well as input costs (implementation and operation) and other necessary data are derived from studies and research (Frantzeskakis et al. 1997; Polydoropoulou et al. 1998) and presented in Table 2. The criterion employed is that of the NPV. By applying equation (9) with only the relevant parameters, as specified in Table 2 and without the external costs, the resulting NPV is $12.305,71 €$. Since the NPV is positive, the specific EBL is viable. The resulting value is low though and is attributed to the considered 20 days of Olympic Games-a very short period of operation.

A separate analysis was conducted for environmental impacts. The air quality analysis was conducted at intersections with potential high traffic volume and vehicle delays. Only two noise-sensitive receivers could be impacted as a result of the introduction of additional buses associated with the EBL implementation. 


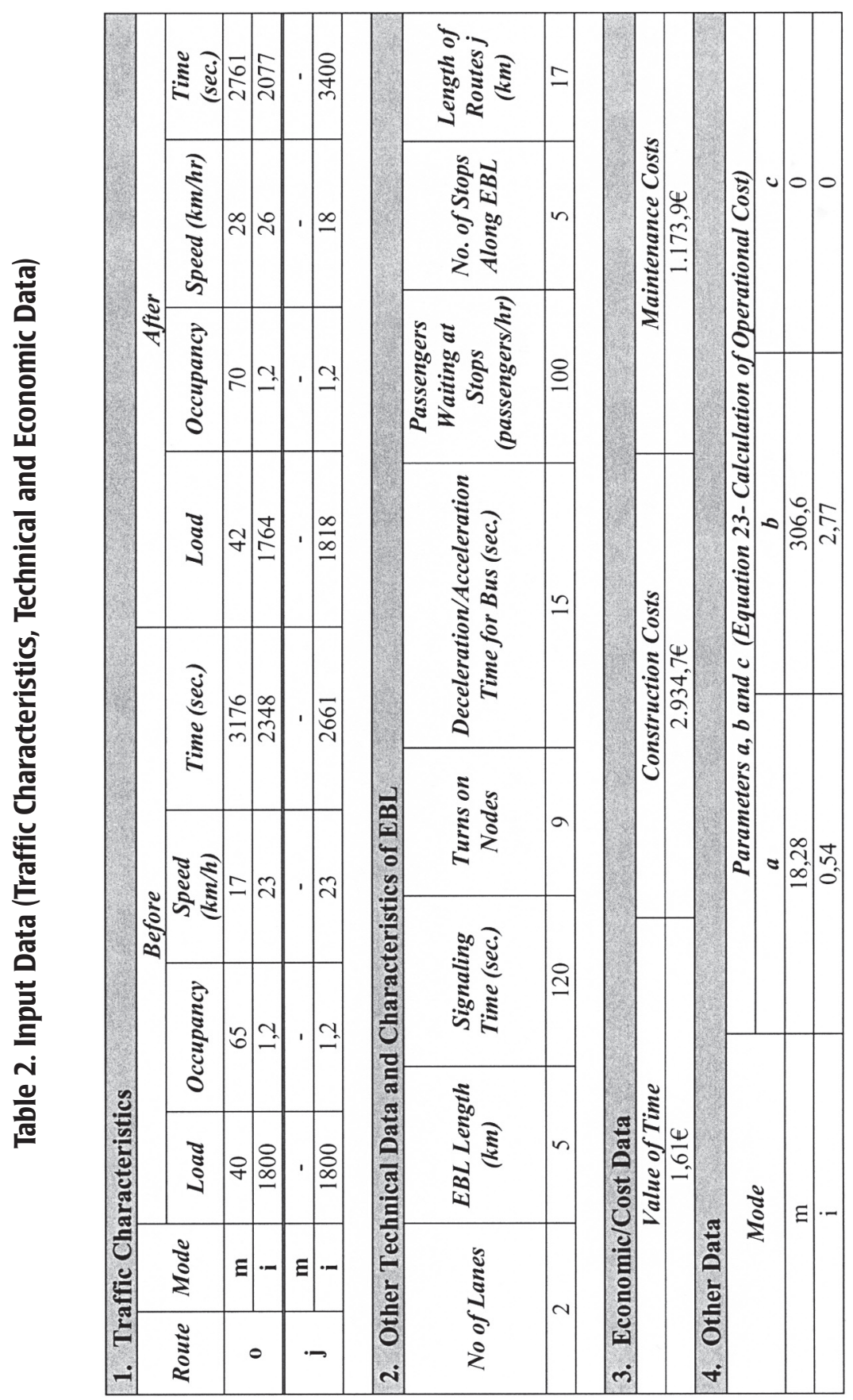




\section{Post-Olympic Games Period}

The traffic data regarding the situations "before" and "after" and the relationships used are the same as previously presented. In this case, using the criterion of NPV for evaluation with

n: 4 (Years of Construction: 1, Years of Operation: 3), i: 5\%,

the resulting NPV is $9.121 .618,30 €$.

The post Olympic Games evaluation resulted in higher NPV, and if the years of evaluation were more than four, then a higher NPV would be achieved. To examine the possible changes of NPV, a sensitivity analysis was performed related to the traffic volumes. It found that even if the change in private vehicles volumes is marginal (e.g., 0,5 - 1\%), the methodology application demonstrates that EBL is beneficial. By changing the second crucial parameter, the same conclusion is reached.

\section{Conclusions}

In most cities the available space for movements (road, rapid transit) is fixed, and any increases in capacity are time consuming, overly expensive, and most likely to trigger opposition for possible environmental impacts. Hence, transportation planners mainly try to implement transportation management schemes, aiming at increasing the capacity of the transportation system, measured in persons moved (not vehicle flows). Consequently, transportation planners look at generated impacts from the implementation of a specific strategy. It is within these transportation management measures that EBL implementation falls.

Any transportation management plan needs to be evaluated before its implementation to identify and measure its impacts. Thus, the resulted benefits, disbenefits, and costs will be assessed. Whether a specific EBL is evaluated as effective and beneficial depends on the criteria and assumptions used in its evaluation (Wellander et al. 2001).

In the present study, the required comprehensive methodology developed identifies all impacts related to the specific EBL implementation, and performs the ex-ante evaluation. By identifying all relevant impacts (e.g., travel time, transport operating costs, traffic diversion, bus ridership and service, environmental and energy), decision-makers can understand the positive and/or negative effects for each category of traffic and thus react accordingly. 
In addition, the methodology can be used as a tool to address community concerns. Thus, if the evaluation produces a positive NPV, EBL implementation produces positive results for society and as such it must be implemented. On the other hand, if a negative NPV is produced, EBL must be avoided and thus unnecessary spending is prevented.

The presented evaluation methodology is helpful to assess the contribution of EBL as a policy measure on its own and as part of a wider transport strategy. The proposed methodology should also consider different alternatives of EBL design and whether a specific bus route segment could be an EBL or a mixed-flow one. The latter is useful in view of the opposite opinions regarding EBL implementation at least for the cases that the currently observed traffic flows are low. As proven by the application of the methodology, the advantages of EBL over mixed-traffic lanes include increases in vehicle occupancies, reductions in delays, and low vehicle emissions.

EBL implementation promotes equity among travelers. Such measures generally provide the most benefit to commuters whose travel occurs during weekday peak periods. The distribution of costs and benefits depends on an area's situation. If existing capacity is redistributed, those who rely on mass transit and are able to join will receive time-savings benefits and potential financial benefits (e.g., employers may provide EBL parking subsidies). EBL facilities may benefit lowincome travelers while imposing costs on high-income travelers. For example, mass transit riders tend to be from lower income groups and value time savings less than high-income individuals.

Finally, one of the most critical components of implementing a successful EBL program is enforcement, which is addressed by the methodology. Surveys show that early and substantial enforcement of EBL rules on a new facility is the best determinant for long-term public compliance.

The proposed methodology, as it is the case for most generic ones, has to be adapted to existing conditions before its implementation. When used with real data, it can be a useful and powerful tool to any transportation planner. 


\section{References}

Astrop, A.I., and R.I. Balcombe. 1995. Performance of bus priority measures in Shepherd's Bush. Internal Report, No. 140. UK Transportation Research Laboratory.

Committee on the Science of Climate Change of the National Research Council. 2001. Climate change science: An analysis of some key questions. Washington, D.C.: National Academy Press.

Delucchi, M., and S.L. Hsu. 1998. External damage cost of noise emitted from motor vehicles. Journal of Transportation and Statistics 1 (3): 1-24.

Denco Ltd. 1995. Application study of exclusive bus lanes along main roads in the city of Athens. General principles of transport planning and their application on Kifisias Avenue. Ministry of Physical Planning, Environment and Public Works.

Department of the Environment Transport and the Regions (DETR). 1999. Localised air quality assessment. Design Manual for Roads and Bridges 11, Section 3, Part 1, Air Quality.

DETR. 1997. Guidance note-Annex B: Appraisal of bus priority measures. Recommended methods. UK, Department of the Environment, Transport and the Regions.

Environmental Protection Agency. 1974. Information on levels of environmental noise requisite to protect public health and welfare with an adequate margin of safety. Washington DC.

Environmental Protection Agency. 2005. TCP Program, High occupancy vehicle (HOV) lanes. Accessed at the Internet site in 2005: http://www.epa.gov/ omswww/transp/traqtcms.htm.

European Environmental Agency. 2003. http://www.eea.eu.int.

Federal Transit Administration. 1995. Transit noise and vibration impact assessment guidance manual. DOT-T-95-16.

Frantzeskakis, J.M., M.H. Pitsiava-Latinopoulou, and D.A. Tsamboulas. 1997. Traffic management. Papasotiriou, Athens. 
Horowitz, A.J., and E. Beimborn. 1994. Methods and strategies for transit benefit measurement. Transportation Research Record 1496. TRB, National Research Council, Washington, DC: 9-16.

Hounsel, N., and M. McDonald. 1988. Evaluation of bus lanes. Contract Report 87, Transport and Road Research Laboratory, Department of Transport, Crowthorne, UK.

Jacques K., and H. Levinson. 1987. Operational analysis of bus lanes on arterials. Report 26, Transit Cooperative Research Program, Transportation Research Board, Washington DC.

King, G.N. 1983. Bus priority in London-Techniques for the 1980s. Proceeding of Seminar K: Traffic Operation and Management, PTRC 11th Annual Meeting, London.

Mandl, C. 1980. Evaluation and optimization of urban public transportation networks. European Journal of Operational Research 5: 396-404.

Pitsiava-Latinopoulou M., M. Grigoriadou, E. Giannitsopoulou, and A. Kimoundris. 1988. Application of exclusive bus lanes on Mitropoleos Street for the Thessaloniki-Public Transport Organization. Inquiring Team APC, Thessaloniki.

Polydoropoulou A., A. Deloukas, and A. Anastasaki. 1998. Modal policies in Attica Region: An impact assessment study. Presented at the European Transport Conference, Loughborough University, UK.

Tee A., T. Cuthbertson, and G. Carson. 1994. Public Transport Initiatives in Survey Traffic Engineering and Control.

Tsamboulas, D.A., I. Williams, J. Larkinson, and P. Mackie. 1999. Assessing the socioeconomic and spatial impacts of transport initiatives: The EUNET Project. Selected Proceedings of the 8th World Conference on Transport research at Antwerp 4: 99-112.

Wellander, C., and K. Leotta. 2001. Gauging the effectiveness of high-occupancy vehicle lanes: Applying three criteria to available data reveals benefits, viability. TR News 214. Washington, DC: Transportation Research Board. 


\section{About the Author}

Dimitrios TSAmboulas (dtsamb@central.ntua.gr) is an associate professor in the Department of Transportation Planning and Engineering, Faculty of Civil Engineering, at the National Technical University of Athens (N.T.U.A.). He holds a diploma of civil engineer from the National Technical University of Athens, master of science and civil engineer's degree from Massachusetts Institute of Technology, and a PhD from the University of Massachusetts. He is chairman or member of several international committees and scientific committees, and a reviewer of papers in scientific journals, and the author of two books, co-editor of one book, and has published more than 130 papers in scientific journals and presentations at conferences. He has more than 30 years of professional experience in areas such as feasibility studies of transport infrastructure projects, transportation management, decision support systems, transport policies, modeling and forecasting, intermodality, new technologies and information systems for transport applications, and cost-benefit and multicriteria analysis. 
Journal of Public Transportation, 2006 BRT Special Edition 


\title{
The Potential for Bus Rapid Transit to Reduce Transportation-Related $\mathrm{CO}_{2}$ Emissions
}

\author{
William Vincent, Lisa Callaghan Jerram \\ Breakthrough Technologies Institute
}

\begin{abstract}
This article examines Bus Rapid Transit (BRT) as a near-term strategy for reducing $\mathrm{CO}_{2}$ emissions in a typical medium-sized U.S. city. The paper compares the expected $\mathrm{CO}_{2}$ emissions from three scenarios to meet the city's growth in work trips by 2011: a no-build option that relies upon private automobiles and a diesel bus fleet; building a light rail (LRT) system; and building a BRT system using 40-ft or 60-ft low emission buses. The paper calculates a $\mathrm{CO}_{2}$ emissions inventory for each scenario and finds that BRT offers the greatest potential for greenhouse gas reductions, primarily because BRT vehicles generally offer lower $\mathrm{CO}_{2}$ emissions per passenger mile than LRT. Lower capital costs for BRT infrastructure would enable cities to build more BRT than $L R T$ for a given budget, increasing opportunities to shift commuters to public transit. Further study to enhance a methodology to estimate expected $\mathrm{CO}_{2}$ reductions with $B R T$ would be valuable.
\end{abstract}

\section{Introduction}

There is general consensus among the world's climatologists that human activity contributes significantly to global warming (Pew Center 2006). More than 140 nations have signed the Kyoto Protocol, making a commitment to reduce their greenhouse gas (GHG) emissions by 5.2 percent from 1990 levels by 2012. A 
notable exception is the United States, the world's leading greenhouse gas emitter (EIA 2005).

In the absence of federal action, many states and municipalities are committing to GHG reductions on their own. As of March 2006, 28 states had adopted climate action plans, with 9 setting state-wide GHG emissions targets (Pew 2006). Seattle Mayor Greg Nickles initiated the Mayors Climate Protection Agreement, which to date has been signed by more than 220 U.S. mayors. This agreement commits cities to strive to achieve or exceed Kyoto GHG reductions targets by 2012 (City of Seattle 2006).

Public transportation often is seen as a GHG reduction strategy. In the U.S., the transportation sector accounted for 27 percent of total GHG emissions in 2003, second only to the electricity generation sector. Transportation emissions of $\mathrm{CO}_{2}$, the leading greenhouse gas, are on a dramatic upward trend, increasing from 1,461.7 teragrams $\mathrm{CO}_{2}$ equivalent in 1990 to $1,780.7$ teragrams $\mathrm{CO}_{2}$ equivalent in 2003 (US EPA 2005), a 22 percent increase. Passenger cars and light duty trucks are the most significant source of transportation $\mathrm{CO}_{2}$ emissions.

This paper compares the GHG reduction potential of Bus Rapid Transit (BRT) with light rail (LRT) in a "typical," medium-sized U.S. city. ${ }^{1}$ Although there has been some analysis of $\mathrm{CO}_{2}$ emissions from transit, there has been little direct comparison among modes (see Shapiro 2002 and FTA 2005). Moreover, the most recent assessment of $\mathrm{BRT} \mathrm{CO}_{2}$ reduction strategies focuses on developing countries, not the U.S. (see Wright and Fulton 2005).

The paper postulates a current-year, base-case scenario where mobility is highly dependent upon automobiles, and public transportation services are provided by a fleet of diesel buses. The paper then looks at three scenarios for five years in the future, assuming population growth of 5 percent during that time. In the first scenario, mobility needs continue to be met principally by automobile and diesel bus. In the second scenario, the city builds a light rail system, which attracts work trips from both the existing bus system and automobiles. In the third scenario, the city builds a BRT system that also attracts work trips from the existing bus system and from automobiles.

Our analysis focuses on work trips because these trips offer the greatest potential to use transit as a $\mathrm{CO}_{2}$ mitigation strategy. As shown in Figure 1, the 2001 National Household Travel Survey (NHTS) reported that work trips are the single largest component of total vehicle miles traveled in the United States. 


\section{Figure 1. Vehicle-Miles Traveled by Trip Purpose}

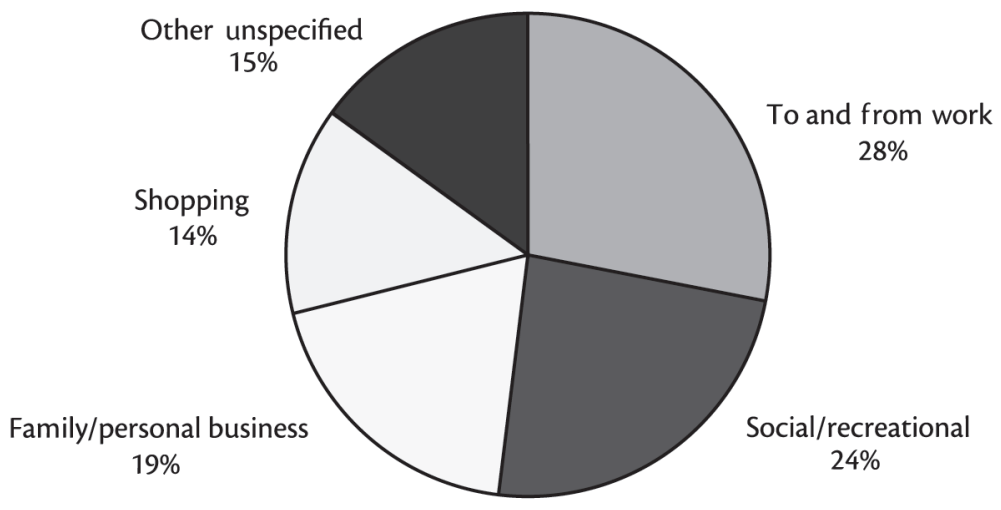

Mean vehicle occupancy for work trips is 1.14 , the lowest occupancy rate for any trip purpose. Moreover, work trips tend to follow fairly well-defined commuting patterns, making them relatively easy to serve with public transportation.

The paper calculates a $\mathrm{CO}_{2}$ emissions inventory for work trips under each of the three scenarios and finds that BRT offers greater potential for GHG reductions than an electric rail system, based on national average electricity generation emissions. Because BRT can be implemented for lower capital costs and in much less time than LRT, BRT appears to be a good strategy for state and local officials looking to achieve near-term $\mathrm{CO}_{2}$ emissions reductions.

As a scenario-based analysis, this paper relies upon assumptions about ridership, mode-shift and other parameters. These assumptions generally were derived from actual operating and performance data, and our approach is consistent with other scenario-based studies examining transit air quality.

It is important to note that localized factors, such as electricity generation mix, geography and culture, will affect the results in particular cities. Similarly, cities can implement complementary policies, like transit-oriented development and congestion pricing, to improve the performance of their transit system.

It also is important to note that our results are mostly due to the relatively high $\mathrm{CO}_{2}$ emissions from electricity generation necessary for rail and to the relatively low $\mathrm{CO}_{2}$ emissions for modern buses. Thus, our assumptions could be changed significantly without changing the underlying conclusion. 
Additional research would be valuable in this area. For example, a BRT system typically operates at a higher average speed than an urban bus system. However, we were unable to find sufficient bus emissions data for vehicles operating at these higher speeds. Thus, we relied on data from the slower Central Business District (CBD) cycle, which most likely overestimates $\mathrm{CO}_{2}$ emissions from BRT.

There is also a need for better data on average trip lengths, load factors for BRT operations, levels of mode-shifting to BRT and other relevant issues. Many transportation data sources, such as the National Transit Database, provide modespecific data for LRT but not for BRT. This makes direct comparisons among the modes more difficult.

Despite the challenges and limitations of this analysis, we believe that it is likely that a BRT system can achieve significantly greater $\mathrm{CO}_{2}$ reductions than LRT in most U.S. cities. Cities interested in new transit infrastructure as a way to reduce GHG emissions ought to look carefully at both BRT and LRT before reaching any conclusions.

\section{Base-Case Scenario}

For our base-case city, which we call "Transtown," we assumed a metropolitan area population of 2 million people. According to the 2001 National Household Travel Survey (NHTS), the average American makes 4.1 trips per day, or roughly 1,500 trips per year (U.S. DOT 2003). Multiplying by our population of 2 million, we assumed that Transtown residents make 3 billion annual trips. ${ }^{2}$

In 2001, work trips constituted 14.8 percent of all trips (US DOT 2003). Multiplying 3 billion annual trips by 14.8 percent results in 444 million annual work trips. Roughly 91.2 percent of commute trips are by personal vehicle and 4.9 percent are by transit (U.S. DOT 2003). Thus, we assumed that 404.928 million work trips are by personal vehicle and 21.756 million work trips are by transit.

The NHTS shows that average commuting trip length for both private vehicle and public transit travel hovered around 12 miles between 1990 and 2001, so we used 12 miles as our assumption for average bus and car trip lengths.

Using our assumption of 404.928 million work trips in personal vehicles, we derived 4.859 billion annual passenger miles in personal vehicles. Using our assumption of 21.756 million annual transit passenger trips, we derived 261.072 million annual passenger miles on transit. 
Table 1. Base Case Annual Commuting Passenger Miles in Transtown

\begin{tabular}{|l|c|c|c|r|}
\hline & $\begin{array}{c}\text { Commuting Trips } \\
\text { Via Mode }\end{array}$ & $\begin{array}{c}\text { Percentage of All } \\
\text { Commuting Trips }\end{array}$ & $\begin{array}{c}\text { Average Trip } \\
\text { Length (miles) }\end{array}$ & $\begin{array}{c}\text { Total Passenger } \\
\text { Miles }\end{array}$ \\
\hline $\begin{array}{l}\text { Personal } \\
\text { Vehicle }\end{array}$ & $404,928,000$ & 91.2 & 12 & $4,859,136,000$ \\
\hline Transit & $21,756,000$ & 4.9 & 12 & $261,072,000$ \\
\hline All Trips & $444,000,000$ & & & $5,120,208,000$ \\
\hline
\end{tabular}

\section{CO2 Emissions per Passenger Mile-Existing Fleet in Base Year}

\section{Personal Cars}

We assumed that the average $\mathrm{CO}_{2}$ emissions for Transtown personal vehicles are 1 pound $\mathrm{CO}_{2}$ per mile. The average U.S. passenger car emits 0.916 pounds $\mathrm{CO}_{2}$ per mile, and the average light truck emits 1.15 pound of $\mathrm{CO}_{2}$ per mile (U.S. EPA 2000). The U.S. vehicle fleet is roughly 60 percent automobiles and 40 percent light trucks (FHWA 2000). Our one pound per mile is the weighted average of the $\mathrm{CO}_{2}$ emissions of the U.S. vehicle fleet and is consistent with other recent studies (Shapiro 2002).

The average vehicle occupancy for work trips is 1.14 (U.S. DOT 2003). We divided one pound $\mathrm{CO}_{2}$ per mile by the average occupancy rate of 1.14 , yielding average $\mathrm{CO}_{2}$ emissions of 0.877 pounds, or 397.89 grams, per passenger mile. We multiplied 397.89 grams per passenger mile by 4.859 billion passenger miles and derived 1.933 million metric tons of $\mathrm{CO}_{2}$ attributable to commute trips in personal vehicles.

\section{Existing Bus Fleet}

We assume that Transtown's current transit demand is met by a fleet of 1999 model year, $40-\mathrm{ft}$ Orion $\mathrm{V}$ buses using Detroit Diesel Series 50 engines, diesel particulate filters and low sulfur diesel. In recent testing on the Central Business District Cycle (CBD), these buses were found to emit 2,942 grams $\mathrm{CO}_{2}$ per vehicle mile (NYS DEC 2005).

Using bus data from the APTA 2005 Public Transportation Factbook, we divided total annual passenger miles by total annual vehicle revenue miles to derive an average occupancy rate on Transtown buses of 10 passengers per mile. ${ }^{3}$ Dividing 2,942 grams $\mathrm{CO}_{2}$ by the average occupancy rate of 10 , we assumed 294.2 grams $\mathrm{CO}_{2}$ emitted per passenger mile on Transtown's existing bus system. We then multiplied 294.2 grams per passenger mile by 261.072 bus passenger miles and 
derived 76,807.38 metric tons of annual $\mathrm{CO}_{2}$ emissions attributable to commuting bus trips.

\section{Table 2. Base Case $\mathrm{CO}_{2}$ Emissions for Commuting in Transtown}

\begin{tabular}{|l|r|r|r|}
\hline & Passenger Miles & CO $_{2} /$ Passenger Mile & $\begin{array}{c}\text { Total Annual CO } \\
\text { Emissions (Metric Tons) }\end{array}$ \\
\hline $\begin{array}{l}\text { Personal } \\
\text { Vehicles }\end{array}$ & $4,859,136,000$ & 397.89 & $1,933,401.62$ \\
\hline Transit Buses & $261,072,000$ & 294.2 & $76,807.38$ \\
\hline Total & $5,120,208,000$ & & $2,010,209.00$ \\
\hline
\end{tabular}

\section{$\mathrm{CO}_{2}$ Emissions per Passenger Mile-Alternative Transit Fleet}

Next, we calculated the $\mathrm{CO}_{2}$ emissions associated with potential alternatives to Transtown's diesel bus system. The options we examined were light rail and low emission 40- and 60- $\mathrm{ft}$ buses operating in BRT service.

\section{Light Rail}

The national average of $\mathrm{CO}_{2}$ emissions per kilowatt-hour ( $\mathrm{kWh}$ ) from electricity generation is 1.341 pounds (U.S. DOE and US EPA 2000). ${ }^{4}$ U.S. light rail systems consume about 510 million kWh of electricity annually to deliver 1.476 billion passenger miles on 63.53 million vehicle revenue miles (APTA 2005).

Dividing passenger miles by vehicle revenue miles yields an average passenger load of 23.23 passengers per mile for light rail. Dividing 510 million kWh by 1.476 billion passenger miles yields an average of $0.345 \mathrm{kWh}$ per passenger mile. Multiplying 0.345 by the average of 1.341 pound $\mathrm{CO}_{2}$ emissions per $\mathrm{kWh}$ yields an average of 0.462 pounds, or 209.56 grams, of $\mathrm{CO}_{2}$ per passenger mile.

\section{Table 3. $\mathrm{CO}_{2}$ Emissions From Light Rail Operation (National Average)}

\begin{tabular}{|l|c|}
\hline $\begin{array}{l}\text { Average Electricity Consumption } \\
\text { (kWh per passenger mile) }\end{array}$ & 0.345 \\
\hline $\begin{array}{l}\text { Average } \mathrm{CO}_{2} \text { Emissions } \\
\text { (grams per passenger mile ) }\end{array}$ & 209.56 \\
\hline
\end{tabular}




\section{Low Emission Buses Operating in BRT Mode}

Bus rapid transit is a system of bus-related improvements including dedicated rights-of-way, priority treatment for vehicles on shared rights-of-way, level boarding, off-vehicle fare collection, and reduced spacing between stops. The result is an integrated system that functions more like a rail system than a typical urban bus system, but at a fraction of the cost of a rail system.

There has been no systematic data reporting on average passenger loading of BRT systems. We assumed a passenger loading of 23.23, equivalent to the average LRT loading because BRT systems often are designed to perform like LRT. There is reason to believe that our assumptions may underestimate BRT passenger loads. For example, the Los Angeles Metropolitan Transportation Authority's Orange Line averages 70 to 80 passengers per $60-\mathrm{ft}$ BRT bus on an average weekday (Drayton email).

Information for $40-\mathrm{ft}$ buses was taken from a 2003 study that examined emission results for diesel, low sulfur diesel, hybrid, and CNG 40-ft buses tested on the CBD cycle. ${ }^{5}$ The best performing bus in these CBD tests was a 1999 New Flyer hybridelectric bus fueled by low sulfur diesel, which emitted 2,088 grams of $\mathrm{CO}_{2}$ per mile. Using the assumed BRT load of 23.23 passengers per revenue mile, we assume 89.91 grams of $\mathrm{CO}_{2}$ per passenger mile. ${ }^{6}$

We also looked at a 40-ft CNG bus with a 2000 DDC Series 50G engine tested on the Urban Dynamometer Driving Schedule (UDDS). This bus achieved average $\mathrm{CO}_{2}$ emissions of $1,534.91$ grams per mile. Dividing by 23.23 , we calculated its emissions to be 66.07 grams $\mathrm{CO}_{2}$ per passenger mile (Ayala 2002). The UDDS has a higher average speed ( $19 \mathrm{mph}$ ) than the CBD driving cycle and thus may be more representative of BRT service.

Finally, we looked at two 60-ft New Flyer buses: a diesel bus equipped with a 2004 Caterpillar C9 engine rated at $330 \mathrm{hp}$ and a diesel particular filter (DPF) and a 60$\mathrm{ft}$ hybrid-electric bus equipped with the identical engine and DPF device. ${ }^{7}$ Both buses were recently subjected to fuel economy tests on the CBD cycle by the National Renewable Energy Laboratory.

We derived $\mathrm{CO}_{2}$ per mile by dividing the emissions associated with burning one gallon of diesel by the vehicles' fuel economy. According to the Energy Information Administration, diesel fuel emits $22.4 \mathrm{lbs}$ of $\mathrm{CO}_{2}$ per gallon burned. The 60 - $\mathrm{ft}$ diesel bus averaged 2.2 miles per gallon. Dividing $22.4 \mathrm{lbs}$ per gallon by 2.2 gives us 10.18 
Ibs, or 4,617 grams, of $\mathrm{CO}_{2}$ per mile. The hybrid-diesel bus averaged $3.3 \mathrm{mpg}$. Using the same calculation, we derived $6.79 \mathrm{lbs}$. (3,080 grams) per mile.

Finally, we divided the $\mathrm{CO}_{2}$ emissions per mile by the average passenger load of 23.23 . All four buses performed better than LRT. The results are presented in Table 4.

\section{Table 4. $\mathrm{CO}_{2}$ Emissions Per Passenger Mile for BRT 40-ft and 60-ft Bus Options}

\begin{tabular}{|l|l|c|c|c|c|}
\hline \multirow{2}{*}{ Bus Size } & Fuel Type & Test Cycle & $\mathbf{C O}_{\mathbf{2}} \mathbf{g} /$ mile & $\begin{array}{c}\text { Passenger } \\
\text { Load }\end{array}$ & $\begin{array}{c}\mathbf{C O}_{2} \text { per } \\
\text { Passenger Mile }\end{array}$ \\
\hline \multirow{2}{*}{$40-\mathrm{ft}$} & Hybrid-Diesel & CBD & 2,088 & 23.23 & 89.91 \\
\cline { 2 - 6 } & CNG & UDDS & 1,535 & 23.23 & 66.07 \\
\hline \multirow{2}{*}{$60-\mathrm{ft}$} & Diesel & CBD & 4,617 & 23.23 & 198.75 \\
\cline { 2 - 6 } & Hybrid-Diesel & CBD & 3,080 & 23.23 & 132.59 \\
\hline
\end{tabular}

\section{Future Transportation Options for Transtown}

The mayor of Transtown recently signed the Mayors Climate Protection Agreement and is committed to meeting the Kyoto $\mathrm{CO}_{2}$ emissions reduction targets in Transtown within five years. To reduce $\mathrm{CO}_{2}$ emissions from the transportation sector, the mayor is considering implementing a new public transit service to encourage commuters to use transit as part of the city's overall transportation GHG emissions reduction strategy.

We assumed that Transtown will add 100,000 residents over the next five years, for a total population of 2,100,000 in 2011. We then analyzed the $\mathrm{CO}_{2}$ emissions that would result from the following scenarios for meeting increased transportation demand:

- Accommodating increased demand with the existing transportation system

- Building an LRT system

- Building a BRT system using low emission buses

Figure 2 compares the $\mathrm{CO}_{2}$ emissions we derived in the previous section for the existing transportation and these new transit options. 
Figure 2. $\mathrm{CO}_{2}$ Emissions Per Passenger Mile For All Transportation Modes

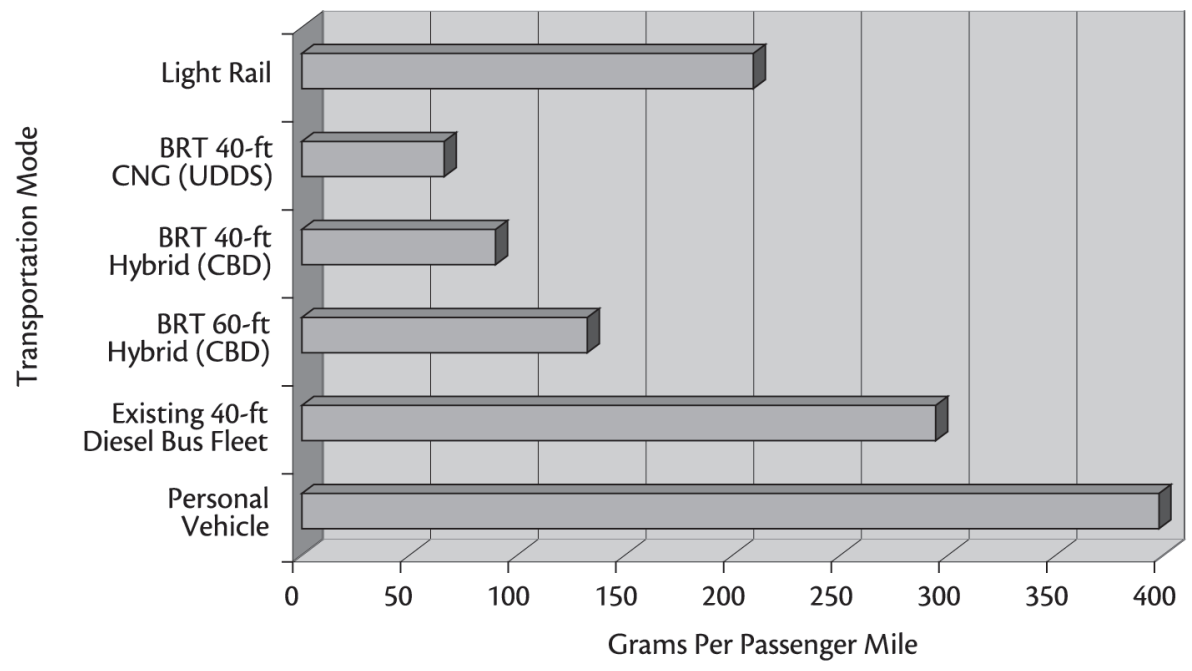

\section{Meet Demand with Existing Travel Options-“No Build" Option}

Using our estimate of 1,500 trips per year, Transtown will have a total annual demand of 3.150 billion personal trips in 2011, an increase of 150 million. Multiplying 3.150 billion trips by 14.8 percent, we calculated 466.2 million annual commute trips in 2011. Multiplying by 91.2 percent, our assumed mode share for personal

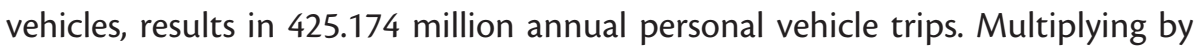
4.9 percent, our assumed mode share for transit, results in 22.843 million annual transit trips.

To calculate passenger miles, we multiplied the number of trips by an average of 12 passenger miles per trip. This results in 5.102 billion annual passenger miles in personal vehicles and 274.125 million annual passenger miles in transit. As shown in Table 5, multiplying by grams per passenger mile results in 2.03 million metric tons of $\mathrm{CO}_{2}$ annually due to commuting by cars, and 80.6 thousand metric tons of $\mathrm{CO}_{2}$ from buses. Adding these together, we derived 2.110 million metric tons of $\mathrm{CO}_{2}$ emissions in 2011 from commuting. 
Table 5. Base Case $\mathrm{CO}_{2}$ Emissions in 2011

\begin{tabular}{|l|c|c|c|c|c|}
\hline $\begin{array}{l}\text { Trip } \\
\text { Mode }\end{array}$ & Annual Trips & $\begin{array}{c}\text { Average Trip } \\
\text { Length } \\
\text { (miles) }\end{array}$ & $\begin{array}{c}\text { Total Passenger } \\
\text { Miles }\end{array}$ & $\begin{array}{c}\mathrm{CO}_{2} \text { Per } \\
\text { Passenger } \\
\text { Mile (grams) }\end{array}$ & $\begin{array}{c}\text { Total } \mathrm{CO}_{2} \\
\text { Emissions } \\
\text { (metric tons) }\end{array}$ \\
\hline $\begin{array}{l}\text { Personal } \\
\text { Vehicles }\end{array}$ & $425,174,400$ & 12 & $5,102,000,000$ & 397.89 & $2,030,071.70$ \\
\hline $\begin{array}{l}\text { Transit } \\
\text { Buses }\end{array}$ & $22,843,800$ & 12 & $274,125,000$ & 294.20 & $80,647.75$ \\
\hline Total & & & & & $\mathbf{2 , 1 1 0 , 7 1 9 . 4 5}$ \\
\hline
\end{tabular}

\section{Implementing a Light Rail System}

We next calculated the expected $\mathrm{CO}_{2}$ emissions of a new light rail system. We assumed that 10 percent of the 2011 bus trips would switch to light rail. This is consistent with recent light rail projects, where bus ridership typically declines immediately after light rail opens (Polzin 2003). It also is consistent with the practice of using buses to feed LRT service. Thus, of the 22.843 million bus trips in our 2011 scenario, 2.284 million will transfer to light rail, leaving 20.559 million annual trips on the bus system.

Next, we assumed that half of the 2.284 million trips that move to LRT would switch their entire 12-mile bus trip to LRT. The other half would transfer to a bus either at the beginning of the trip or at the end of the trip. We refer to trips that are part of an intermodal transfer as "split" trips.

For split trips, we assumed 8 miles would be on LRT and 4 miles would be on a bus, maintaining a total commute trip of 12 miles. Thus, 1.142 million trips have their entire 12 mile trip on LRT, while 1.142 million trips have 8 miles of their trip on LRT and the other 4 miles on the existing bus system.

Finally, we assumed that the light rail would attract 10,000 average weekday new riders; this is consistent with light rail projects listed in FTA's Annual New Starts report. We further assumed that all new riders would be attracted from cars and all of whom would make two commuting trips per weekday. We multiplied 250 weekdays per year by 20,000 trips (10,000 new riders making 2 trips per day) and derived 5 million additional light rail trips.

Like the bus trips, we assumed that half of the car riders would completely displace their car trip by light rail; the other half would commute by car to a light rail station. We assumed that this car trip would average 4 miles, with 8 miles on the LRT, maintaining an overall 12-mile commute trip average. Thus, 2.5 million car 
passengers will leave their car at home and take LRT, and 2.5 million will drive 4 miles and ride LRT for 8 miles.

Finally, as shown in Table 6, we multiplied annual trips by the average trip length to derive annual passenger miles. We then multiplied passenger miles by our modal emission assumptions, resulting in a subtotal of annual emissions by mode. Adding these together, we derived the total emissions for the LRT scenario. We then compared this total with the total emissions for our no-build option to show the amount reduced by the LRT scenario. We also multiplied the reduction by 20 years, showing the total amount reduced over that timeframe, assuming no additional growth or changes in the system.

\section{Table 6. Total Commute Trip $\mathrm{CO}_{2}$ Emissions}

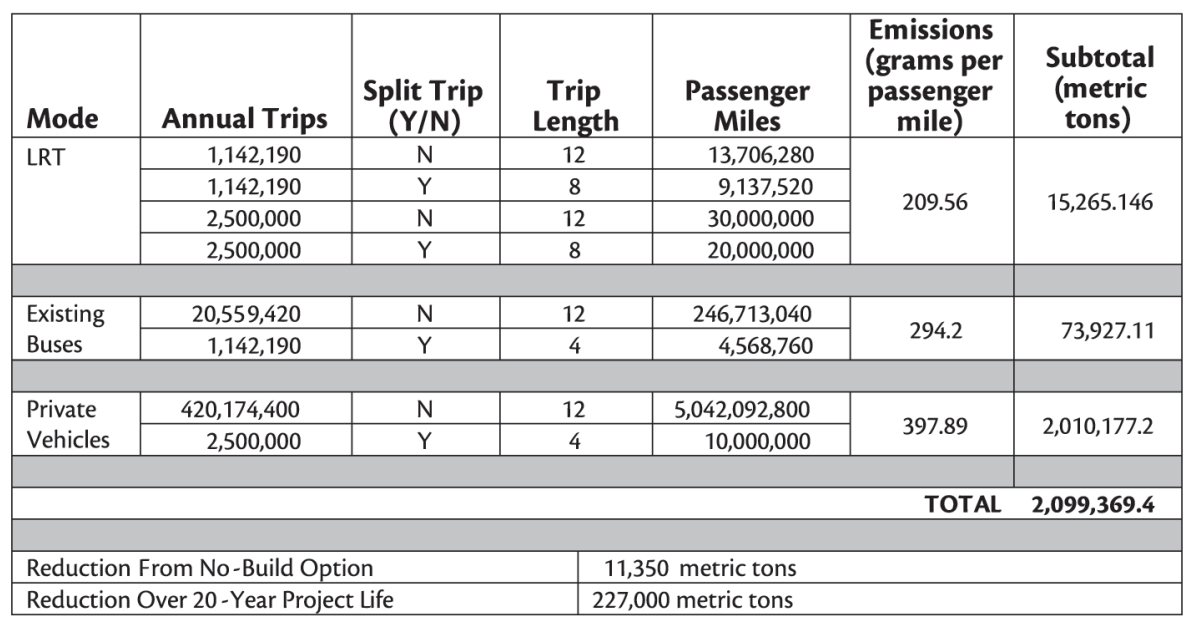

\section{BRT with Low Emission 40-ft or 60-ft Buses}

For the BRT scenario, we repeated the steps used for the LRT analysis and made one additional assumption. LRT systems typically cost between $\$ 40$ and $\$ 60$ million per mile, whereas most BRT systems have been well under $\$ 20$ million per mile. Thus, we assumed that within a given budget, the mayor could build twice as much BRT infrastructure as LRT. We also assumed that this additional infrastructure would attract 50 percent more bus passengers and new riders than the light rail option. 
Like the LRT scenario, we started with trips attracted from the bus system. We assumed that 15 percent of the 2011 bus trips would switch to BRT. This is derived by taking the 10 percent switch assumed for light rail and adjusting it by the additional infrastructure built using BRT technology. We multiplied 22.843 million annual transit trips from our no-build scenario by 15 percent, resulting in 3.426 million annual bus trips switching to BRT and 19.417 million annual bus trips remaining on the bus system.

Next, we assumed that half of the 3.426 million trips that move to BRT would switch their entire 12-mile bus trip to BRT. The other half would be split trips, transferring to a bus either at the beginning of the trip or at the end of the trip. Like the light rail option, we assumed 8 miles would be on the BRT and 4 miles would be on a bus, maintaining a total transit commute of 12 miles. Thus, 1.713 million trips have their entire 12 mile trip on BRT, while 1.713 million trips have 8 miles of their trip on BRT and the other 4 on the existing bus system.

Next, we assumed that the BRT would attract 15,000 average weekday new riders; as with the bus mode shift, this number is derived by adjusting the 10,000 new riders assumed for light rail and adding 50 percent more. Again, as with the light rail, all new riders would be attracted from cars, and all would make two transit trips per weekday as commuters. We multiplied 250 weekdays per year by 30,000 trips (15,000 new riders making 2 trips per day) and derived 7.5 million additional transit commute trips.

Our assumption that BRT will increase transit ridership is consistent with published case studies. A 2005 FTA analysis reported ridership increases of 42 and 27 percent, respectively, along the Los Angeles Wilshire/Whittier Boulevard and the Ventura corridor after BRT was implemented. Other BRT systems featured in this analysis reported ridership increases ranging from 21 to 84 percent (FTA 2005).

Finally, we assumed that half of the car riders would completely displace their car trip by BRT. The other half would be split trips, commuting 4 miles to a BRT station and 8 miles on the BRT, maintaining our average of 12 miles. Thus, 3.75 million car passengers will leave their car at home and take BRT, and 3.75 million will drive 4 miles and ride BRT for 8 miles.

To determine $\mathrm{CO}_{2}$ emissions, we calculated emissions using three types of buses for our BRT system: $40-\mathrm{ft}$ CNG buses on a UDDS driving cycle achieving average emissions of 66.07 grams per passenger mile; $40-\mathrm{ft}$ diesel hybrids on a CBD driving 
cycle achieving 89.91 grams per passenger mile; and 60-ft diesel hybrids achieving 132.54 grams of $\mathrm{CO}_{2}$ per passenger mile on a CBD driving cycle.

Tables 7, 8, and 9 present the results for each of the different bus types.

Table 7. Total Commute Trip $\mathrm{CO}_{2}$ Emissions, 40-ft CNG

\begin{tabular}{|c|c|c|c|c|c|c|}
\hline Mode & Annual Trips & $\begin{array}{c}\text { Split Trip } \\
(\mathrm{Y} / \mathrm{N})\end{array}$ & $\begin{array}{c}\text { Trip } \\
\text { Length }\end{array}$ & $\begin{array}{l}\text { Passenger } \\
\text { Miles }\end{array}$ & $\begin{array}{c}\text { Emissions } \\
\text { (grams per } \\
\text { passenger } \\
\text { mile) }\end{array}$ & $\begin{array}{c}\text { Subtotal } \\
\text { (metric } \\
\text { tons) }\end{array}$ \\
\hline \multirow[t]{4}{*}{ BRT } & $1,713,285$ & $\mathrm{~N}$ & 12 & $20,559,420$ & \multirow{4}{*}{66.07} & \multirow{4}{*}{$7,219.18$} \\
\hline & $1,713,285$ & $\mathrm{Y}$ & 8 & $13,706,280$ & & \\
\hline & $3,750,000$ & $\mathrm{~N}$ & 12 & $45,000,000$ & & \\
\hline & $3,750,000$ & $\mathrm{Y}$ & 8 & $30,000,000$ & & \\
\hline \multirow{2}{*}{$\begin{array}{l}\text { Existing } \\
\text { Buses }\end{array}$} & $19,417,230$ & $\mathrm{~N}$ & 12 & $233,006,760$ & \multirow[b]{2}{*}{294.2} & \multirow[b]{2}{*}{$70,566.78$} \\
\hline & $1,713,285$ & $Y$ & 4 & $6,853,140$ & & \\
\hline \multirow{2}{*}{$\begin{array}{l}\text { Private } \\
\text { Vehicles }\end{array}$} & $417,674,000$ & $\mathrm{~N}$ & 12 & $5,012,088,000$ & \multirow[b]{2}{*}{397.89} & \multirow{2}{*}{$2,000,227.9$} \\
\hline & $3,750,000$ & $\mathrm{Y}$ & 4 & $15,000,000$ & & \\
\hline \multicolumn{6}{|r|}{ TOTAL } & $2,078,013.7$ \\
\hline \multicolumn{4}{|c|}{ Reduction From No-Build Option } & \multicolumn{2}{|c|}{$32,705.7$ metric tons } & \\
\hline \multicolumn{4}{|c|}{ Reduction Over 20 -Year Project Life } & \multicolumn{2}{|c|}{$654,114.0$ metric tons } & \\
\hline
\end{tabular}

\section{Table 8. Total Commute Trip $\mathrm{CO}_{2}$ Emissions, 40-ft Diesel Hybrid}

\begin{tabular}{|c|c|c|c|c|c|c|}
\hline Mode & Annual Trips & $\begin{array}{c}\text { Split Trip } \\
(\mathrm{Y} / \mathrm{N})\end{array}$ & $\begin{array}{c}\text { Trip } \\
\text { Length }\end{array}$ & $\begin{array}{c}\text { Passenger } \\
\text { Miles }\end{array}$ & $\begin{array}{c}\text { Emissions } \\
\text { (grams per } \\
\text { passenger } \\
\text { mile) }\end{array}$ & $\begin{array}{c}\text { Subtotal } \\
\text { (metric } \\
\text { tons) }\end{array}$ \\
\hline \multirow{4}{*}{ BRT } & $1,713,285$ & $\mathrm{~N}$ & 12 & $20,559,420$ & \multirow{4}{*}{89.91} & \multirow{4}{*}{$9,824.08$} \\
\hline & $1,713,285$ & $\mathrm{Y}$ & 8 & $13,706,280$ & & \\
\hline & $3,750,000$ & $\mathrm{~N}$ & 12 & $45,000,000$ & & \\
\hline & $3,750,000$ & $\mathrm{Y}$ & 8 & $30,000,000$ & & \\
\hline & & & & & & \\
\hline \multirow{2}{*}{$\begin{array}{l}\text { Existing } \\
\text { Buses }\end{array}$} & $19,417,230$ & $\mathrm{~N}$ & 12 & $233,006,760$ & \multirow{2}{*}{294.2} & \multirow{2}{*}{$70,566.78$} \\
\hline & $1,713,285$ & $\mathrm{Y}$ & 4 & $6,853,140$ & & \\
\hline \multirow{2}{*}{$\begin{array}{l}\text { Private } \\
\text { Vehicles }\end{array}$} & $417,674,000$ & $\mathrm{~N}$ & 12 & $5,012,088,000$ & \multirow{2}{*}{397.89} & \multirow{2}{*}{$2,000,227.9$} \\
\hline & $3,750,000$ & $Y$ & 4 & $15,000,000$ & & \\
\hline \multirow{2}{*}{\multicolumn{4}{|c|}{ Reduction From No-Build Option }} & & TOTAL & $2,080,618.6$ \\
\hline & & & & \multicolumn{2}{|c|}{$30,100.8$ metric tons } & \\
\hline \multicolumn{4}{|c|}{ Reduction Over 20 -Year Project Life } & $602,016.0$ metric $t$ & & \\
\hline
\end{tabular}


Table 9. Total Commute Trip $\mathrm{CO}_{2}$ Emissions, 60-ft Diesel Hybrid

\begin{tabular}{|c|c|c|c|c|c|c|}
\hline Mode & Annual Trips & $\begin{array}{l}\text { Split Trip } \\
(\mathrm{Y} / \mathrm{N})\end{array}$ & $\begin{array}{c}\text { Trip } \\
\text { Length }\end{array}$ & $\begin{array}{l}\text { Passenger } \\
\text { Miles }\end{array}$ & $\begin{array}{c}\text { Emissions } \\
\text { (grams per } \\
\text { passenger } \\
\text { mile) }\end{array}$ & $\begin{array}{l}\text { Subtotal } \\
\text { (Metric } \\
\text { Tons) }\end{array}$ \\
\hline \multirow{4}{*}{ BRT } & $1,713,285$ & $\mathrm{~N}$ & 12 & $20,559,420$ & \multirow{4}{*}{132.54} & \multirow{4}{*}{$14,482.07$} \\
\hline & $1,713,285$ & $Y$ & 8 & $13,706,280$ & & \\
\hline & $3,750,000$ & $\mathrm{~N}$ & 12 & $45,000,000$ & & \\
\hline & $3,750,000$ & $\mathrm{Y}$ & 8 & $30,000,000$ & & \\
\hline \multirow{2}{*}{$\begin{array}{l}\text { Existing } \\
\text { Buses }\end{array}$} & 19417230 & $N$ & 12 & 233006760 & \multirow{2}{*}{294.2} & \multirow{2}{*}{$70,566.78$} \\
\hline & $1,713,285$ & Y & 4 & $6,853,140$ & & \\
\hline & & & & & & \\
\hline \multirow{2}{*}{$\begin{array}{l}\text { Private } \\
\text { Vehicles }\end{array}$} & $417,674,000$ & $\mathrm{~N}$ & 12 & $5,012,088,000$ & \multirow{2}{*}{397.89} & \multirow{2}{*}{$2,000,227.9$} \\
\hline & $3,750,000$ & $\bar{Y}$ & 4 & $15,000,000$ & & \\
\hline \multicolumn{6}{|r|}{ TOTAL } & $2,085,276.7$ \\
\hline \multicolumn{4}{|c|}{ Reduction From No -Build Option } & \multicolumn{2}{|c|}{$25,442.7$ metric tons } & \\
\hline \multicolumn{4}{|c|}{ Reduction Over 20 - Year Project Life } & \multicolumn{2}{|c|}{$508,854.0$ metric tons } & \\
\hline
\end{tabular}

All three BRT options provide significant reductions over the no-build option. As shown in Figure 3, all three also significantly outperform the LRT option, with the $40-\mathrm{ft}$ CNG buses exceeding the LRT reductions by nearly 300 percent.

\section{Figure 3. $\mathrm{CO}_{2}$ Emissions "Saved" Over 20-Year Project Life}

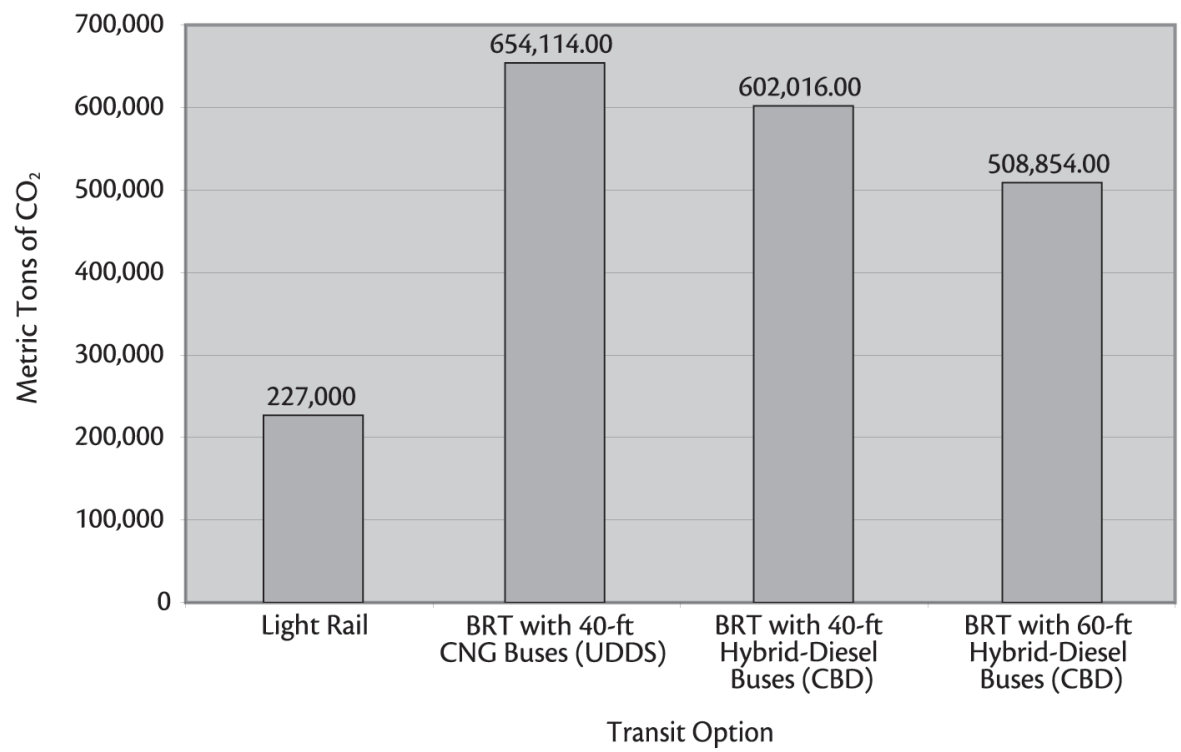




\section{Conclusion}

BRT can provide significantly greater $\mathrm{CO}_{2}$ reductions than LRT for most U.S. cities. The main reason appears to be the generation mix of electricity used to power LRT. Electricity generated from fossil fuels produces a large amount of $\mathrm{CO}_{2}$, and the trend in this country is toward greater use of fossil fuels in electricity generation.

A secondary reason is that BRT costs significantly less to build than LRT, and thus more can be deployed for a given budget. However, even without this additional benefit, the per passenger mile $\mathrm{CO}_{2}$ emissions for a BRT system are likely to be significantly lower than those of an LRT system almost anywhere in the country.

The most significant potential appears to be if a number of cities, such as the signatories to the Mayors Climate Protection Agreement, each agree to use BRT as a $\mathrm{CO}_{2}$ reduction strategy. For example, if 20 cities each achieve results similar to what we found with the $40-\mathrm{ft} \mathrm{CNG}$ vehicles, they could achieve total reductions over 20 years in excess of 13 million metric tons. If these cities build additional corridors and make other changes over the 20 years, such as better integration of transit and land use, the reductions could be much higher still.

This line of inquiry needs further study to develop a more comprehensive methodology that cities and states could use to estimate expected $\mathrm{CO}_{2}$ reductions from a BRT system. For example, further study could utilize bus emissions data from higher-speed test cycles that more accurately reflect BRT operations. Further study could also refine estimated passenger loads for BRT buses; particularly valuable would be a comparison between $40-\mathrm{ft}$ and $60-\mathrm{ft}$ bus loads. We believe that it would be valuable to calculate potential $\mathrm{CO}_{2}$ reductions from deploying fuel cell buses, which may be a commercially viable option in five years. It would also be valuable to better understand the potential mode shift that could be expected if a BRT system were implemented. Nevertheless, this initial study shows that BRT is a promising transit option for cities looking to reduce their transportation-related GHG emissions, especially if it is part of a larger strategy to encourage mode-shifting.

\section{Endnotes}

${ }^{1}$ This study does not analyze criteria pollutant emissions. While these are important, our focus is on the comparative viability of BRT and LRT as near-term GHG emissions reduction strategies. 
2 A "trip" refers to travel completed by an individual, regardless of the mode and vehicle occupancy level, and not necessarily a single vehicle trip, which may include multiple passengers.

${ }^{3}$ The 2002 APTA report on public transit emissions by Robert Shapiro et al. used all vehicle miles, not just revenue miles, to derive an average passenger load of 9 in 1998. However, we felt it would be more accurate to include only miles devoted to the passenger trip. APTA data show wide variations in average occupancy rates among urban areas in the U.S., from 4.9 in Albuquerque to 16.5 for Honolulu, so individual cities may need to take this into consideration in making $\mathrm{CO}_{2}$ projections.

${ }^{4}$ In some regions, like the West Coast, the average is much lower ( 0.435 pounds), while in other regions, like the upper Midwest, the average is much higher (1.746 pounds).

${ }^{5}$ We used the emissions and fuel economy results from the CBD cycle because it is the standard for transit bus testing. The average speed for this cycle is $12.6 \mathrm{mph}$. A BRT system would likely operate at higher speeds; thus, this study tends to underestimate the $\mathrm{CO}_{2}$ reductions from BRT implementation.

${ }^{6}$ We used the average passenger load for light rail because BRT service generally is designed to emulate light rail service. Moreover, some bus systems, like Honolulu, already have average passenger loadings approaching the average loading for some light rail systems. Thus, it is reasonable to assume that a BRT system that operates like a light rail system could achieve similar passenger loadings to light rail.

${ }^{7}$ We could not find data for a comparable $60-\mathrm{ft}$ CNG bus.

\section{References}

American Public Transportation Association. 2005. 2005 Public Transportation Fact Book. http://www.apta.com/research/stats/factbook/.

American Public Transportation Association. 2003. Public transportation ridership statistics. http://www.apta.com/research/stats/ridershp/trlength.cfm.

Ayala, Alberto, Norman Kado, Robert Okamoto, Britt Holmen, Paul Kuzmicky, Reiko Kobayashi, Keith Stiglitz. 2002. Diesel and CNG heavy-duty bus emissions over multiple driving schedules: Regulated pollutants and project overview. Society of Automotive Engineers. 
City of Seattle, Office of the Mayor. http://www.cityofseattle.net/mayor/climate/ (accessed April 2006).

Email from John Drayton, LA MTA Vehicle Technology Manager, April 7, 2006

Energy Information Administration. 2005. Fuel and energy source code and emission coefficients. http://www.eia.doe.gov/oiaf/1605/factors.html (accessed February 2006).

Energy Information Administration. 2005. Emissions of greenhouse gases in the United States 2004. ftp://ftp.eia.doe.gov/pub/oiaf/1605/cdrom/pdf/ ggrpt/057304.pdf.

Federal Highway Administration, U.S. Department of Transportation. Our nation's highways - 2000; Selected facts and figures. http://www.fhwa.dot.gov/ohim/ onh00/onh2p3.htm.

New York State Department of Environmental Conservation et al. 2005. Interim report: Emission results from clean diesel demonstration program with CRT particulate filter at New York City Transit. http://www.epa.gov/otaq/retrofit/ documents/ny_crt_presentation.pdf.

Pew Center on Global Climate Change. 2006. Learning from state action on climate change. February 2006 Update. http://www.pewclimate.org/docUploads/PewStatesBriefFeb2006\%2Epdf.

Pew Center on Global Climate Change website FAQ, http://www.pewclimate.org/ global-warming-basics/faq_s/faqs_policy.cfm (accessed April 2006).

Polzin, Steve, and Oliver Page. 2003. Ridership trends of new start rail projects. Florida: National Center for Transit Research, Center for Urban Transportation Research, National BRT Institute, University of South Florida.

Shapiro, Robert, Kevin A. Hassett and Frank S. Arnold. 2002. Conserving energy and preserving the environment. Washington, D.C.: American Public Transportation Association.

U.S. Department of Energy and U.S. Environmental Protection Agency. 2000. Carbon dioxide emissions from the generation of electric power in the United States. http://www.eia.doe.gov/cneaf/electricity/page/CO2_report/ CO2emiss.pdf. 
U.S. Department of Transportation. 2003. Highlights of the National Household Travel Survey. http://www.bts.gov/publications/highlights_of_the_2001_ national_household_travel_survey/.

U.S. Department of Transportation and Federal Highway Administration Office of Planning. 2003. Journey to work trends in the United States and its major metropolitan areas 1960 - 2000. http://www.fhwa.dot.gov/ctpp/jtw/jtw4.htm.

U.S. Environmental Protection Agency. 2005. Inventory of U.S. greenhouse gas emissions and sinks: 1990-2003. http://yosemite.epa.gov/oar/globalwarming. nsf/content/ResourceCenterPublicationsGHGEmissionsUSEmissionsInventory2005.html.

U.S. Environmental Protection Agency. 2000. Emission facts: Average annual emissions and fuel consumption for passenger cars and light trucks. http://www.epa. gov/otaq/consumer/f00013.pdf.

U.S. Environmental Protection Agency. website http://yosemite.epa.gov/oar/globalwarming.nsf/content/climateuncertainties.html (accessed April 2006).

U.S. Federal Transit Administration. 2005. Bus Rapid Transit Ridership Analysis, FTA-CA-26-7068-2004.1.

Vincent, William, and Brian Walsh. 2003. The electric rail dilemma: Clean transportation from dirty electricity? Washington, D.C.: Breakthrough Technologies Institute.

Walkowicz, Kevin. 2006. National Renewable Energy Laboratory. Performance testing and evaluation of the GM/Allison Hybrid System in the King County Metro Transit Fleet - Seattle, WA. Presentation to SAE Hybrid Vehicle Technologies Symposium.

Wright, Lloyd, and Lewis Fulton. 2005. Climate change mitigation and transport in developing nations. Transport Reviews. 25(6): 691-717.

\section{About the Authors}

WILliam VINCENT (Vincent@fuelcells.org) is a former official with the U. S. Department of Transportation where, among other things, he was responsible for developing policy and communications strategies for several safety programs and for reauthorizing various provisions of the original ISTEA bill. He currently serves as General Counsel for the Breakthrough Technologies Institute, a Washington, DC- 
based non-profit that promotes advanced energy and environmental technologies. He is a frequent presenter on bus rapid transit as well as fuel cell technology in local, national, and international forums.

Lisa Callaghan JerRam (lisa@fuelcells.org) is Technology Director for Breakthrough Technologies Institute (BTI). She works to promote and provide independent analysis of clean transportation technologies such as BRT, fuel cells and hybrids. Before joining BTI, she worked at the Northeast Advanced Vehicle Consortium in Boston, where she co-authored reports on fuel cells and clean buses, including the August 2005 Analysis of Electric Drive Technologies for Transit Applications published by the Federal Transit Administration. 
Journal of Public Transportation, 2006 BRT Special Edition 


\title{
Calibration of Vissim for Bus Rapid Transit Systems in Beijing Using GPS Data
}

\author{
Liu Yu, Beijing Jiaotong University \\ Lei Yu, Texas Southern University and Beijing Jiaotong University \\ Xumei Chen, Beijing Jiaotong University \\ Tao Wan, Beijing Jiaotong University \\ Jifu Guo, Beijing Transportation Research Center
}

\begin{abstract}
Bus Rapid Transit systems have grown in popularity in recent years. With the rapid development of computer technologies, using microscopic simulation models to study various strategies on planning, implementation and operation of BRT systems has become a hot research area in the field of public transportation. To make the simulation models accurately replicate field traffic conditions, model calibration is crucial. This paper presents an approach for calibrating the microscopic traffic simulation model VISSIM using GPS data for application to Beijing BRT systems. The Sum of Squared Error (SSE) of the collected versus simulated vehicle speeds at the cross-sections along the test route is specified as the evaluation index. A Genetic Algorithm is adopted as the optimization tool to minimize the SSE. Taking the Beijing North-South Central Axis BRT Corridor as a case study, it shows that the proposed approach is a practical and effective method for the model calibration.
\end{abstract}




\section{Introduction}

Bus Rapid Transit (BRT) systems have grown in popularity in recent years. With the rapid development of computer technologies, using microscopic simulation models to study various strategies on planning, implementation and operation of BRT systems has become a hot research area in the field of public transportation, particularly in cases where field experiments are difficult or expensive to conduct.

There are plenty of available microscopic simulation models used worldwide, such as VISSIM, CORSIM, PARAMICS, etc. In such models, there are a number of parameters describing the traffic flow characteristics, driving behavior, and traffic system operations, which have significant effects on simulation results. Although these models provide a set of default values for each parameter and users can conduct a simulation without calibrating them, the default values may not always be representative of the traffic situation under study. For example, the driving behavior of BRT vehicles on the exclusive lanes may be different from those on urban streets or freeways because BRT has some unique traffic characteristics (e.g., dispatching according to schedule, stopping at bus stops for serving passengers, etc.). Even BRT systems in different countries or different cities may have different characteristics. For a simulation study of BRT systems, adequate calibration based on observed traffic conditions can result in accurate and reliable simulation results, which can help transit operators make more appropriate decisions for BRT planning and implementation. So, when using a simulation model for different geographic and traffic conditions, the most important and difficult step is the calibration and validation of the model. The calibration is the process by which the values of a simulation model input parameters are refined and adjusted so that the model accurately replicates field-measured and observed traffic conditions.

The aim of this paper is to propose an approach for the automatic calibration of the driving behavior parameters of VISSIM using GPS data for application to Beijing BRT systems. A Genetic Algorithm (GA) is used for finding the best combination of VISSIM driving behavior parameters, and a particular computer simulation program named AUTOSIM is designed to run the VISSIM simulation automatically and consecutively. The validity of the proposed approach was demonstrated via a case study for the Beijing North-South Central Axis BRT Corridor. The results show that it is a practical and efficient approach for the calibration of VISSIM. 


\section{Review of Calibration Methodologies}

The problem of model calibration is very complex because of the absence of a clear analytical formulation for model users to follow. In recent years, more and more transportation researchers have realized the importance of model calibration and made great efforts to develop various methodologies to calibrate traffic simulation models.

In earlier studies, manual changes were used for calibrating model parameters (Daigle et al. 1998), which was found not efficient and practical. Fellendorf and Vortisch (2001) calibrated the car following behavior of VISSIM with measurement on the level of single vehicles, i.e., data about headways, perception thresholds, and driving characteristics. However, it is difficult for model users to collect some of such data in the field. Merritt (2003) proposed a methodology for the calibration and validation of CORSIM using empirical data. He found that extensive field data need to be collected to improve accuracy of the model calibration.

With the recent applications of ITS technologies and computational resources, there are more opportunities to calibrate simulation models based on optimization theories and algorithms. Ben-Akiva et al. (2004) presented a framework for the calibration of microscopic traffic simulation models using aggregate data. They adopted a systematic search approach based on Box's Complex algorithm for calibration, which did not require calculations of derivatives of the objective function. Nevertheless, their study found that efficient algorithms are still required to perform the calibration step. Some other algorithms, such as sequential simplex algorithm (Kim 2003) and simulated annealing algorithm (Wieland 2004), also have been studied by several researches.

In recent years, microscopic traffic simulation models have been widely used as an important tool for the analysis and design of transportation systems in China. However, many users conduct simulations simply with the default parameters provided by the model without calibrating them. The study on the calibration of traffic simulation models in China is also scarce. Sun and Yang (2004) proposed a procedure for microscopic simulation model calibration in China. They designed the experiment by using Latin Square algorithm and calibrated four of the driving behavior parameters of VISSIM, including waiting time before diffusion, minimum headway, observed vehicles, and average standstill distance. However, it takes much time to finish all the simulation experiments and these four parameters cannot represent the whole set of driving behavior parameters of VISSIM. 


\section{Proposed Calibration Approach}

\section{Identification of Calibration Parameters in VISSIM}

VISSIM is a microscopic, time-step and behavior-based simulation model developed to model urban traffic and public transit operations. It provides significant enhancements in terms of driver behavior, multi-modal transit operations, interface with planning/forecasting models, and 3-D simulation. VISSIM contains a psycho-physical car-following model for longitudinal vehicle movement and a rule-based algorithm for lateral movements. Ten calibration parameters are selected in VISSIM, including:

- Waiting Time before Diffusion - It defines the maximum amount of time a vehicle can wait at the emergency stop position waiting for a gap to change lanes in order to stay on its route. When this time is reached the vehicle is taken out of the network (diffusion) and a warning message will be written to the error file denoting the time and location of the removal.

- Minimum Headway (front/rear)-defines the minimum distance to the vehicle in front that must be available for a lane change in standstill condition.

- Maximum Deceleration - the fastest a vehicle can slow down or stop.

- -1 per Distance-used to reduce the maximum deceleration with increasing distance to the emergency stop position.

- Accepted Deceleration - the value of it is smaller than maximum deceleration but bigger than minimum deceleration, and the vehicle can slow down safely without any dangerous with accepted deceleration.

- Maximum Look Ahead Distance - the maximum distance that a vehicle can see forward in order to react to other vehicles either in front or to the side of it (within the same link). This value relates to human's physical observation ability.

- Average Standstill Distance-defines the average desired distance between stopped cars and also between cars and stop lines (signal heads, priority rules, etc.)

- Additive Part of Desired Safety Distance-this parameter and the next one (i.e. Multiple Part of Desired Safety Distance) contained with the car following model determine the saturation flow rate for VISSIM. The saturation flow rate defines the number of vehicles that can free flow through a VISSIM model during one hour. 
- Multiple Part of Desired Safety Distance-described above.

- Distance of Standing at $50 \mathrm{~km} / \mathrm{h}$ - the safety distance between two parallel cars at both the condition of stop and moving.

As the parameters mentioned above directly affect the vehicle interaction and thus can cause substantial differences in simulation results, calibration of these parameters become very important. To this end, a scientific approach is needed to calibrate these parameters.

\section{Selection of an Optimization Algorithm}

For calibration of a traffic simulation model, the difficulty is to select the best combination of the parameters being calibrated. However, all of these parameters need to be calibrated simultaneously, and each may have a different value range, which make the calibration process very complicated and time consuming. So, to identify the best parameter set for the model, an optimization algorithm is required.

A Genetic Algorithm (GA) is a search technique used in computer science to find approximate solutions to optimization and search problems. It is a particular class of evolutionary algorithms that use techniques inspired by evolutionary biology, such as inheritance, mutation, natural selection, and recombination (or crossover). It models each possible parameter set as a separate chromosome, and each chromosome is evaluated by a fitness function that represents how well it fits a given problem (Kim 2001). GA is considered robust because it performs a search from multiple points instead of starting the search at a single point. So, using the GA approach can considerably reduce the number of search steps needed and the amount of time required to complete the search when the search space is large and complex.

\section{Index of Simulation Accuracy}

To evaluate the quality of the simulation in the calibration, an evaluation index needs to be defined. There are various indexes that can be used, such as traffic volumes, average travel time, average travel speed, queue lengths, etc. This paper uses the Sum of Squared Error (SSE) between the vehicle speeds collected and those simulated at pre-defined cross-sections at a 20-meter interval along the test route, which is calculated by the following equation:

$$
S S E=\sum_{i=1}^{n}\left(v_{i}^{c}-v_{i}^{S}\right)^{2}
$$


where:

$i$ cross-section number at a 20-meter interval along the route where the speed is collected

$n$ number of cross-sections

$v_{i}^{c}$ vehicle speed collected at cross-section $i$ by GPS, and

$v_{i}^{s}$ vehicle speed simulated at cross-section $i$ by VISSIM

The speeds of vehicles in the simulation network are a good reflection of driving behavior parameters, provided the traffic volumes are known. Further, the instantaneous speed data can easily be collected by using GPS. Therefore, using the speed to evaluate the accuracy of model calibrated is not only appropriate but also practical.

For VISSIM, SSE can be considered as a function of 10 driving behavior parameters (Yu et al. 2005):

$$
S S E=f\left(x_{1}, x_{2}, x_{3}, x_{4}, x_{5}, x_{6}, x_{7}, x_{8}, x_{9}, x_{10}\right)
$$

where $x_{i}$ represents the value of the ith calibrated parameter, and $f$ is a function that is difficult to express in an analytical form. It cannot be solved through an analytical approach either. This paper establishes a simulation procedure to indirectly express the relationship between SSE and the 10 parameters.

\section{Calibration Approach Using GA}

The objective of the calibration process is to minimize the SSE, in which the GA is used as the optimization tool. The complete optimization process, which combines GA and VISSIM to find the optimal values for the 10 driving behavior parameters, consists of the following steps:

\section{Step 1. Define the Agent to Represent the Parameters}

For GA, the terms agent and gene are used. The term gene is represented by a binary digit 0 or 1 . One agent is defined as a group of genes used to represent a value of each parameter. Furthermore, one generation is defined as the specified numbers of agents. The population size is defined as the number of agents included in one generation. 


\section{Step 2. Determine the Number of Genes for Each Parameter}

For each parameter, the number of genes needed vary according to the domain of the parameter and the increment of the parameter value. The following equation is used to determine the number of genes $n_{i}$ needed for each parameter:

$$
\begin{gathered}
\max \left(x_{i}\right)-\min \left(x_{i}\right)=\alpha_{i}\left(2^{n_{i}}-1\right) \\
i=1,2,3, \ldots, 10
\end{gathered}
$$

where:

$$
\begin{array}{ll}
x_{i} & \text { the value of } i \text { th calibrated parameter } \\
\max \left(x_{i}\right) & \text { the maximum value of } x_{i} \\
\min \left(x_{i}\right) & \text { the minimum value of } x_{i} \\
\alpha_{i} & \text { the increment value of } x_{i} \text {, and } \\
n_{i} & \text { the number of genes of the agent to represent } x_{i}
\end{array}
$$

In Equation (3), $\max \left(x_{i}\right)$ and $\min \left(x_{i}\right)$ should first be identified. Then an initial value is assigned to $\alpha_{i}$ based on the number of increments desired in the search process for this parameter. Finally, $n_{i}$ is determined. After $n_{i}$ is determined, it can be substituted back into Equation (3) to calculate the final precise value of $\alpha_{i}$. The results of the calculation for all the 10 driving behavior parameters are illustrated in Table 1. The values of $\max \left(x_{i}\right)$ and $\min \left(x_{i}\right)$ are given by VISSIM.

\section{Table 1. Number of Genes and Increment of Each Parameter}

\begin{tabular}{|l|c|c|c|c|}
\hline \multicolumn{1}{|c|}{ Parameter $\boldsymbol{i}$} & $\begin{array}{c}\text { Max } \\
\left(\boldsymbol{x}_{i}\right)\end{array}$ & $\begin{array}{c}\text { Min } \\
\left(\boldsymbol{x}_{\boldsymbol{i}}\right)\end{array}$ & $\begin{array}{c}\text { \# of } \\
\text { genes } \\
\left(n_{i}\right)\end{array}$ & $\begin{array}{c}\text { Increme } \\
\boldsymbol{n t}\left(\alpha_{i}\right)\end{array}$ \\
\hline 1. Waiting time before diffusion (second) & 90 & 30 & 5 & 1.9 \\
\hline 2. Minimum headway (meter) & 1 & 0.1 & 4 & 0.06 \\
\hline 3. Maximum deceleration $\left(\mathrm{m} / \mathrm{s}^{2}\right)$ & -2 & -6 & 3 & 0.6 \\
\hline 4. -1 $\mathrm{m} / \mathrm{s}^{2}$ per distance (meter) & 150 & 50 & 5 & 1.9 \\
\hline 5. Accepted deceleration $\left(\mathrm{m} / \mathrm{s}^{2}\right)$ & -0.2 & -3 & 4 & 0.2 \\
\hline 6. Maximum look ahead distance (meter) & 300 & 200 & 4 & 6.7 \\
\hline 7. Average standstill distance (meter) & 5 & 0.2 & 3 & 0.7 \\
\hline $\begin{array}{l}\text { 8. Additive part of desired safety distance } \\
\text { (meter) }\end{array}$ & 5 & 0.2 & 3 & 0.7 \\
\hline $\begin{array}{l}\text { 9. Multiple part of desired safety distance } \\
\text { (meter) }\end{array}$ & 6 & 1 & 4 & 0.34 \\
\hline $\begin{array}{l}\text { 10. Distance of standing and at } 50 \mathrm{~km} / \mathrm{h} \\
\text { (meter) }\end{array}$ & 2 & 0.5 & 4 & 0.1 \\
\hline
\end{tabular}




\section{Step 3. Build Agent and Create Initial Generation}

Table 1 shows that a total of 39 genes are needed to represent these 10 parameters. The population size, which is the number of agents in one generation, is defined as, but not limited to 16 in this paper (the number is randomly chosen, but as a sample, it should be a relatively large number so that the better individual could be found in a very short time). In the initial generation, each gene of the agent is assigned 0 or 1 randomly.

\section{Step 4. Decode Each Agent to Parameter Value}

Equations (4) and (5) are used to decode the agent $A$ to the actual parameter value $x_{i}$.

$$
\begin{aligned}
x_{i} & =\alpha_{i} * A * B+\beta \\
A & =\left(a_{1}, a_{2}, a_{3}, \ldots, a_{n_{i}}\right) \\
B & =\left(\begin{array}{c}
2^{n_{i}-1} \\
\cdot \\
\cdot \\
2 \\
1
\end{array}\right) \\
i & =1,2,3, \ldots, 10
\end{aligned}
$$

where:

$$
\begin{array}{ll}
x_{i} & \text { the value of ith calibrated parameter, } \\
\alpha_{i} & \text { the increment value of } x_{i^{\prime}} \\
n_{i} & \text { the number of genes of the agent to represent } x_{i^{\prime}} \\
\beta_{i} & \min \left(x_{i}\right), \text { listed in Table } 1, \\
A & \text { vector to represent agent, } \\
B & \text { coefficient vector, and } \\
\alpha_{1}, \alpha_{2}, \alpha_{3}, \ldots, \alpha_{n_{i}} & 0 \text { or } 1
\end{array}
$$




\section{Step 5. AUTOSIM}

Fitness is used to evaluate the quality of the agent. The higher the fitness, the better the agent. In other words, the set of 10 driving behavior parameters is better if the fitness resulted from the simulation is higher. In the proposed approach, SSE is used as the fitness function, where the fitness is the highest when SSE is the minimum. As mentioned earlier, $f$ is a function that cannot be expressed in an analytical form. As such, a simulation procedure named AUTOSIM is designed to express the relationship between SSE and the 10 parameters. This procedure automatically runs VISSIM with different values of the input parameters and generates the outputs of SSE. The flowchart of the AUTOSIM procedure, programmed with Visual Basic 6.0, is shown in Figure 1.

\section{Figure 1. The Flowchart of AUTOSIM}

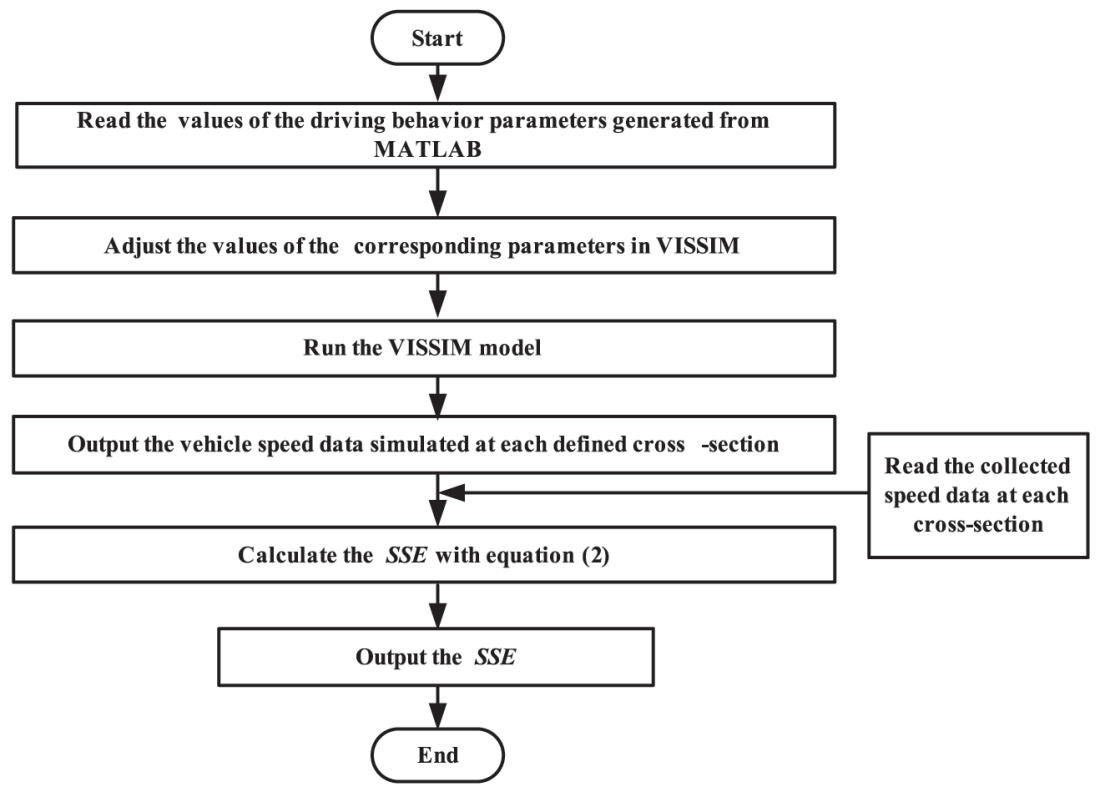

\section{Step 6. Evaluate the Fitness of Agents and Select the Best Agent}

With the AUTOSIM, the evaluation of each agent in one generation can be performed. Before the AUTOSIM is entered, Equations (4) and (5) are used to decode 
the agent to derive the values of the parameters. After all agents in the current generation have gone through the AUTOSIM, the fitness of agents is evaluated based on SSE, and then the best agent is selected. If the SSE of the best agent in the current generation does not satisfy a pre-defined criterion, the following step is taken to create the next generation of agents. Otherwise, the process stops, and the optimal parameter values are derived.

\section{Step 7. Select, Crossover and Mutate Agent}

In GA, select, crossover and mutate are three chief operators needed in creating the next generation of agents. Selection is based on the probability, and the agents with higher fitness values will most likely be selected. To crossover, two agents interchange part of their genes to create two new agents. One agent is mutated to create a new agent by changing one of its genes from 1 to 0 or from 0 to 1 .

\section{Step 8. Create a New Generation}

The search for the optimum values is an iterative process. After the operators of selection, crossover and mutation are carried out to the agents of the former generation, more agents will be produced to form a new generation while keeping the same population size.

\section{Step 9. Implementation of the approach}

The MATLAB platform is used for programming to implement the GA-based approach. The Genetic Algorithm Toolbox developed by University of Sheffield also is used. This toolbox provides functions to implement the operators of selection, crossover and mutation. The final program integrates the MATLAB, GA toolbox, Visual Basic, and VISSIM.

\section{Case Study for Beijing BRT Systems}

Beijing is the capital and most congested city in China, with the number of registered motor vehicles exceeding 2 million (including 1.28 million cars). Traffic speed on some urban roads averaged $12 \mathrm{~km} / \mathrm{h}$ in 2003, compared to $20 \mathrm{~km} / \mathrm{h}$ in 1996 , and $45 \mathrm{~km} / \mathrm{h}$ in 1994. More than 40 percent of residents spent more than one hour getting to work, and 87 percent of road sections are constantly congested. Therefore, traffic congestion will be a major challenge for Beijing for the 2008 summer Olympic Games. Developing BRT is, of course, one of the feasible solutions for Beijing. 
With technical support from the Beijing Energy Foundation, the Beijing NorthSouth Central Axis BRT Corridor was launched in December 2004 as a test BRT corridor, which was the first closed BRT system (stations requiring fare collection before boarding) in China and only the second outside Latin America. The Beijing North-South Central Axis BRT Corridor is 15.8 kilometers long and passes the Qianmen commercial area and four ring roads. This BRT Corridor was completed in two phases. Phase I opened for operation on December 25, 2004, and starts at Qianmen toward Muxiyuan, with 5 stops, and is 5 kilometers long. Phase ll opened on December 30, 2005, and goes from Muxiyuan to Demaozhuang, with 11 stops, and is 11 kilometers long.

\section{Test Site}

The test site in this paper is the Phase I of the Beijing North-South Central Axis BRT Corridor, which is $5 \mathrm{~km}$ long, with $2.5 \mathrm{~km}$ exclusive bus lanes and $2.5 \mathrm{~km}$ mixed use roadway, including eight intersections. The exclusive bus lanes are separated from cars at the center of the road, and the bus stops are $5 \mathrm{~m}$ wide and 40-60 m long. The BRT buses operating on the exclusive lanes are 18 meters long, air-conditioned, with left-open doors, low floors and a capacity of 200 passengers. The BRT buses run from 5:00 am to 10:30 pm, with a headway of 2-3 minutes at peak hour and 4-5 minutes at off-peak hour. The layout of the test site is shown in Figure 2.

\section{Figure 2. Layout of the Test Site}

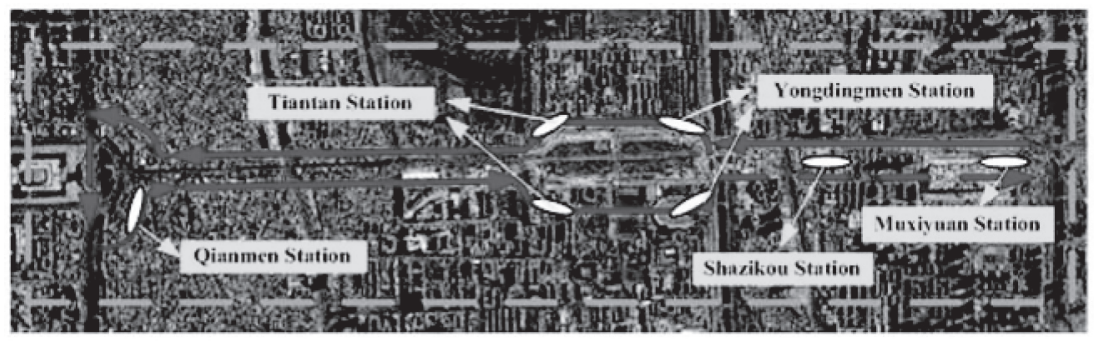

\section{Data Collection}

For the purpose of calibration, traffic and GPS data need to be collected. Traffic data include the traffic volumes entering into the network, the turning ratio at each intersection, the signal timing of the signalized intersections, the schedule 
of the BRT operation, and the BRT dwelling time at each bus stop. GPS data are instantaneous speed of vehicles collected by using GPS equipped on the test BRT vehicle or car. The vehicle equipped with GPS is driven along the test route in a similar way to the floating car method. In this study, both the speeds of BRT vehicle and car were collected. Ten repeated cycle runs of the test were conducted along the same route.

Six sections for BRT and two sections for car were defined to conduct the data collection, as shown in Figure 3 and Figure 4.

\section{Figure 3. Six Sections for BRT along the North-South Central Axis BRT Corridor}

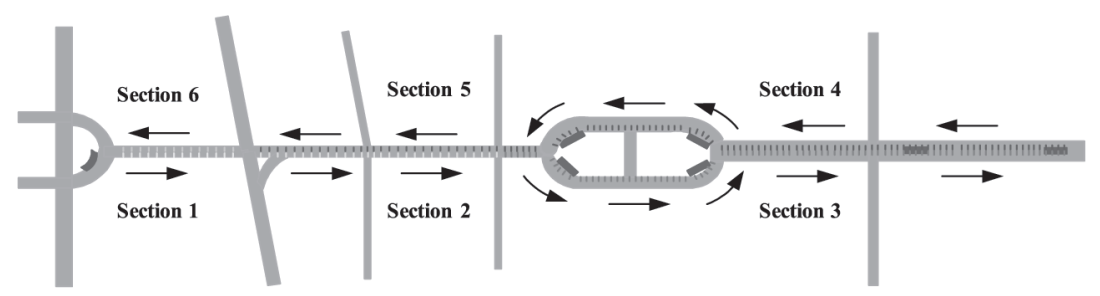

\section{Figure 4. Two Sections for Car around the North-South Central Axis Road}

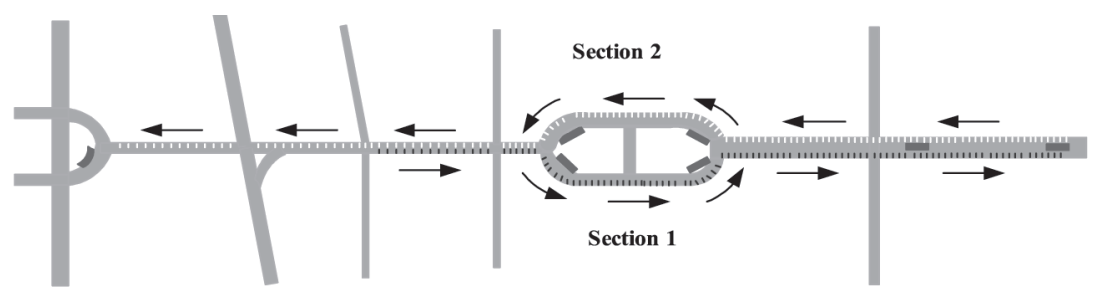

Table 2 describes the sections defined.

To calculate the SSE of each section, the simulated speeds of vehicles should be output by setting up detectors along the test route in VISSIM. 
Table 2. Description of the Sections Defined

\begin{tabular}{|c|c|c|c|}
\hline $\begin{array}{c}\text { Vehicle } \\
\text { Type }\end{array}$ & $\begin{array}{c}\text { Section } \\
\text { Number }\end{array}$ & Length $(\boldsymbol{m})$ & Route Direction \\
\hline \multirow{4}{*}{ BRT } & 1 & 820 & Qianmen to Zhushikou \\
\cline { 2 - 4 } & 2 & 1150 & Zhushikou to Tiantan West Gate \\
\cline { 2 - 4 } & 3 & 2360 & Tiantan West Gate to Muxiyuan \\
\cline { 2 - 4 } & 4 & 2360 & Muxiyuan to Tiantan West Gate \\
\cline { 2 - 4 } & 5 & 1150 & Tiantan West Gate to Zhushikou \\
\hline \multirow{4}{*}{ Car } & 6 & 820 & Zhushikou to Qianmen \\
\cline { 2 - 4 } & I & 2980 & Tianqiao to Muxiyuan \\
\hline
\end{tabular}

\section{Model Calibration and Results}

Because of the difference between BRT and general traffic in operation, the values of driving behavior parameters of BRT vehicles may be different from those on urban streets or freeways. Therefore, both the driving behavior parameters of $B R T$ vehicles and cars should be calibrated. To carry out the calibration process, the MATLAB platform is used for programming to implement the calibration approach and the Genetic Algorithm Toolbox in MATLAB is used for performing the GA operation. In this MATLAB platform, the AUTOSIM program mentioned earlier can be called to run the VISSIM model automatically.

In this case study, a criterion is specified on when the program should stop. The stopping criterion is specified as when either 10 consecutive generations have the same SSE, or the difference between SSEs from two consecutive runs is less than or equal to 1 percent (not including two consecutive generations with the same SSE). Table 3 illustrates the results from the calibration, in which the criterion is met after the program runs for 28 generations for BRT and 25 generations for Cars.

Tables 4 and 5 show part of the results of SSE from the program for BRT and cars. 
Table 3. The Values of Default and Optimal Parameters

\begin{tabular}{|c|c|c|c|}
\hline \multirow{2}{*}{ Driving Behavior Parameter } & \multirow{2}{*}{$\begin{array}{c}\text { Default } \\
\text { Value }\end{array}$} & \multicolumn{2}{|c|}{ Optimal Value } \\
\hline & & $B R T$ & Car \\
\hline Waiting time before diffusion $(s)$ & 60.00 & 43.30 & 64.20 \\
\hline Minimum headway $(m)$ & 0.50 & 0.22 & 1.00 \\
\hline Maximum deceleration $\left(\mathrm{m} / \mathrm{s}^{2}\right)$ & -4.00 & -4.40 & -4.40 \\
\hline$-1 m / s^{2}$ per distance $(m)$ & 100.00 & 133.20 & 78.80 \\
\hline Accepted deceleration $\left(\mathrm{m} / \mathrm{s}^{2}\right)$ & -1.00 & -0.10 & -0.30 \\
\hline Maximum look ahead distance $(m)$ & 250.00 & 300.0 & 273.70 \\
\hline Average standstill distance $(m)$ & 2.00 & 1.60 & 1.60 \\
\hline $\begin{array}{l}\text { Additive part of desired safety distance } \\
(m)\end{array}$ & 2.00 & 1.60 & 4.40 \\
\hline $\begin{array}{l}\text { Multiple part of desired safety distance } \\
(m)\end{array}$ & 3.00 & 2.70 & 3.72 \\
\hline $\begin{array}{l}\text { Distance of standing and at } 50 \mathrm{~km} / \mathrm{h} \\
(m)\end{array}$ & 1.00 & 2.00 & 1.90 \\
\hline
\end{tabular}

Table 4. Simulation Results of SSE from 28 Iterations for BRT

\begin{tabular}{|c|c|c|c|}
\hline Generation\# & $\begin{array}{c}\text { SSE of the Best } \\
\text { Agent }\end{array}$ & $\begin{array}{c}\text { Difference of SSEs } \\
\text { with the Previous } \\
\text { Generation }\end{array}$ & \% Difference \\
\hline 0 & 3253 & & \\
\hline 5 & 3158 & 352 & 10.04 \\
\hline 10 & 2448 & 178 & 6.79 \\
\hline 15 & 1885 & 48 & 2.46 \\
\hline 20 & 1857 & 28 & 1.47 \\
\hline 28 & 1513 & 14 & 0.91 \\
\hline
\end{tabular}

Table 5. Simulation Results of SSE from 25 Iterations for Cars

\begin{tabular}{|c|c|c|c|}
\hline Generation\# & $\begin{array}{c}\text { SSE of the Best } \\
\text { Agent }\end{array}$ & $\begin{array}{c}\text { Difference of SSEs } \\
\text { with the Previous } \\
\text { Generation }\end{array}$ & \% Difference \\
\hline 0 & 1929 & & \\
\hline 5 & 2176 & 0 & 0.00 \\
\hline 10 & 1470 & 32 & 2.13 \\
\hline 15 & 1139 & 22 & 1.88 \\
\hline 20 & 1005 & 17 & 1.64 \\
\hline 25 & 852 & 8 & 0.98 \\
\hline
\end{tabular}


In Tables 4 and 5, generation number 0 means the default parameter values. For the first generation, the agents are created at random, so the SSE of the best agent in this generation is greater than the default SSE. However, in the following generations, the SSE of the latter generation is smaller than (or equal to) the former. Take BRT as an example. After the computer program runs for 5,10 and 28 generations, its values are reduced to 3158,2448 and 1513 , respectively. Thus, the SSE has decreased almost 53.5 percent when the parameters are changed from the default values to the optimal ones. To the planning of BRT projects in practical terms, this value means potential benefits, such as operating cost savings, improved service planning and level of service, because BRT operators can make better decisions according to the simulation results provided by the model calibrated, which accurately replicates the observed traffic conditions.

To visualize the results, the speeds simulated using the default parameter values, collected by using GPS system and optimized after the calibration, are compared. Figure 5 shows an example of the speed profile for BRT, and Figure 6 is an example of the speed profile for cars.

For comparison purposes, the errors between the simulated speeds and the collected speeds at cross-sections are computed. For BRT, with the default parameter values, the percentage of relative errors greater than 20 percent of the total sample is 80.3 percent, compared with only 19.7 percent when the optimal parameter values are used. Furthermore, the overall Standard Deviation with default values is 19.32 , and only 5.55 with optimal values. The results show that the accuracy of the model after calibration is improved considerably.

\section{Model Validation}

To determine that the model calibrated accurately represents the real system, the Tianqiao Intersection is used to do the model validation. The measured volumes of the South Approaches of this intersection, the simulated volumes using the default parameters, and the simulated volumes using the calibrated parameters are compared (shown in Figure 7). From this figure, it is found that the model calibrated matches the field observations within a small error range, in which the maximum relative error is only 2.5 percent. However, the maximum error of the model with default parameters can reach to 27.4 percent. 
Figure 5. Comparison of BRT Vehicle Speed Profile for Section 1

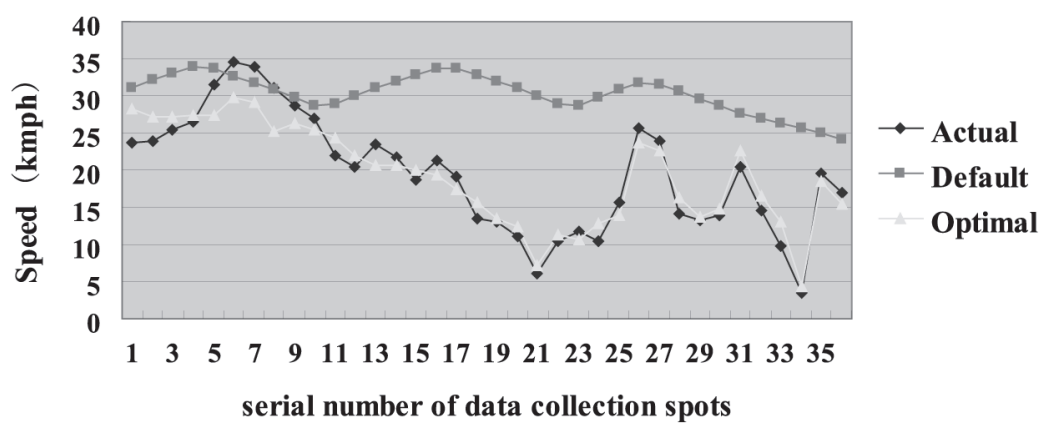

Figure 6. Comparison of Car Speed Profile for Section II

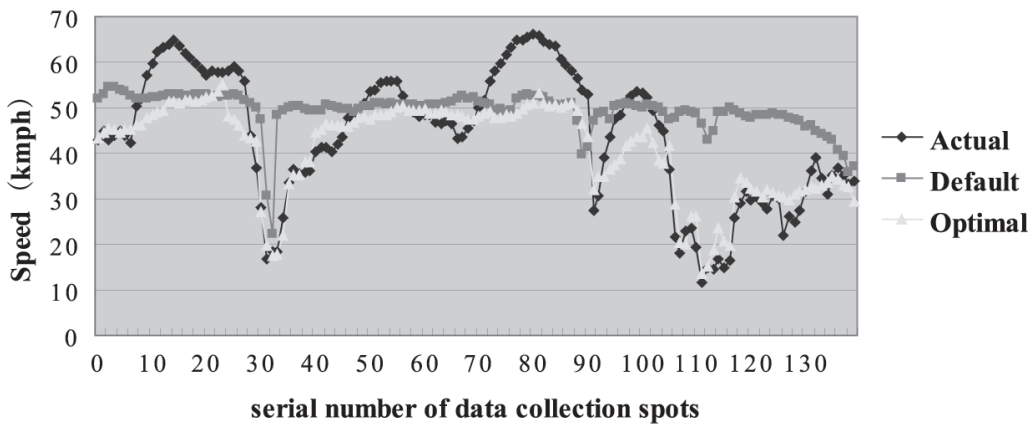

Figure 7. Comparison of Volumes with Default versus Optimal values

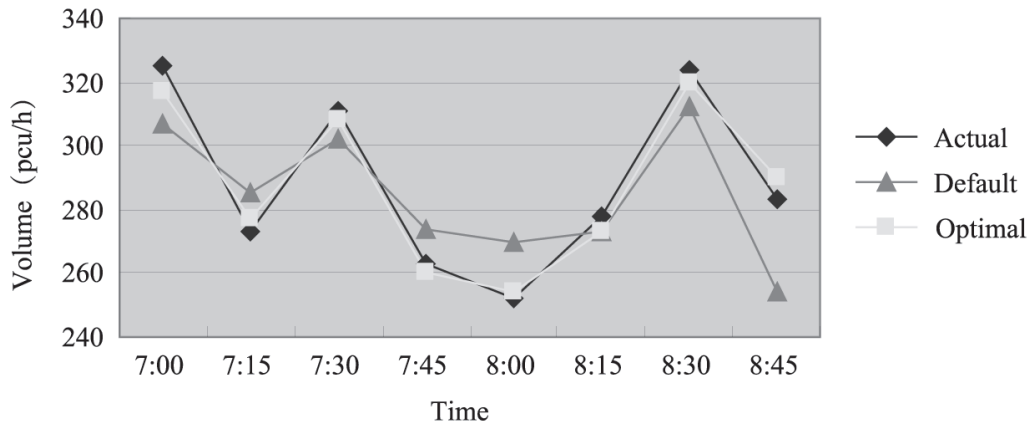




\section{Conclusions and Recommendations}

This paper presented an approach for calibrating the microscopic simulation model VISSIM for Beijing BRT systems using GPS data. The SSE of the collected versus simulated vehicle speeds at the cross-sections was defined as the evaluation index. The objective of the calibration is to search for the best combination of the parameters that minimize the SSE, and a Genetic Algorithm is adopted as an optimization tool to implement the search process. For the efficiency improvement of calibration, a computer program is developed to integrate the MATLAB, Visual Basic, and VISSIM. The validity of the proposed approach was demonstrated via a case study for the Beijing North-South Central Axis BRT Corridor. Both the field instantaneous speeds of BRT vehicle and cars along the test route were collected by using GPS for calibration. The case study shows that the proposed approach is a practical and effective method for calibrating the VISSIM model.

Since this study used only one Measure of Effectiveness (MOE), i.e., SSE, for model calibration, the performance of other MOEs is uncertain. Further research is recommended to include more MOEs (e.g., delay or queue) in the calibration process. Furthermore, with an increased trend of simulation application for study on BRT systems, other types of BRT (e.g., all arterial or all exclusive right-of-way) should be considered to verify the performance of the proposed approach. Doing so will provide more insight on the feasibility of the proposed approach.

\section{Acknowledgements}

This paper was prepared based on a project (Y0604002040691) funded by Beijing Municipal Science \& Technology Commission titled "BRT Planning, Operational and Organizational Coordination Techniques," the projects of "Talent Building" Foundation of Beijing Jiaotong University (YSJ04001), and National Natural Science Foundation of China (50208002).

\section{References}

Ben-Akiva, M.E., D. Darda, M. Jha, H.N. Koutsopoulos, and T. Toledo. 2004. Calibration of microscopic traffic simulation models with aggregate data. Proceedings of the 83rd Transportation Research Board Annual Meeting, Washington, DC. 
Daigle, G., M. Thomas, and M. Vasudevan. 1998. Field applications of CORSIM: I-40 freeway design evaluation, Oklahoma city, OK. Proceedings of the 1998 Winter Simulation Conference:1161-1167.

Fellendorf, M., and P.Vortisch. 2001. Validation of the microscopic traffic flow model VISSIM in different real-world situations. Paper presented at the 81st Transportation Research Board Annual Meeting, Washington, DC.

Kim, K., and L.R. Rilett. 2003. Simplex based calibration of traffic micro-simulation models using ITS data. Presented at 82nd Annual Meeting of the Transportation Research Board, Washington, DC.

Kim, K., and L.R. Rilett. 2001. Genetic-algorithm-based approach for calibrating microscopic simulation models. 2001 IEEE Intelligent Transportation Systems Conference Proceedings: 298-704.

Merritt, E. 2003. Calibration and validation of CORSIM for Swedish road traffic conditions. In Preprints of the 83rd Transportation Research Board Annual Meeting, Washington, DC.

Sun,J., and X. Yang, 2004. Study on calibration of microscopic traffic simulation models-Taking VISSIM as an example. COMPUTER AND COMMUNICATIONS, 3(22): \#3-6.

Wieland, F., and T.C. Holden. 2004. Model calibration by simulaiton optimization. The MITRE Corporation.

Yu, L., X. Li, and W. Zhuo. 2005. GA-Based calibration of VISSIM for Intercontinental Airport of Houston (IAH) network using GPS data. 84th Transportation Research Board Annual Meeting CD-ROM, Washington, DC.

\section{About the Authors}

LIU YU (yuliu1991@163.com) is a Ph.D. candidate at School of Traffic and Transportation, Beijing Jiaotong University in Beijing, China. Her research interests involve Bus Rapid Transit development, transportation simulation, and Intelligent Transportation Systems.

LEI Yu (yu_lx@tsu.edu) is Professor and Chairman of Department of Transportation Studies, Texas Southern University. He is also Changjiang Scholar of Beijing Jiaotong University and has managed 50 research projects and has published over 100 scientific papers. 
XUmei Chen (chenxumei@jtys.bjtu.edu.cn) is an associate professor of School of Traffic and Transportation, Beijing Jiaotong University in Beijing, China. Her research interests involve ITS technologies, network planning of urban rail transit, and industry policy of transportation.

TAO WAN (seaowner800@163.com) is a graduate research assistant at School of Traffic and Transportation, Beijing Jiaotong University in Beijing, China. His research interests involve vehicle exhaust emission testing, Bus Rapid Transit development, and transportation modelling.

Jıfu Guo (guojf@bjtrc.org.cn) is the Deputy Director of Beijing Transportation Research Centre (BTRC). His main research areas traffic forecasting, metro/highway planning, traffic impact analysis, and traffic environment analysis. 